\title{
Development of new radio-labeled tracers for imaging and quantification of brown adipose tissue
}

Citation for published version (APA):

Paulus, A. (2019). Development of new radio-labeled tracers for imaging and quantification of brown adipose tissue. [Doctoral Thesis, Maastricht University]. Druckerei Mainz. https://doi.org/10.26481/dis.20190424ap

Document status and date:

Published: 01/01/2019

DOI:

10.26481/dis.20190424ap

Document Version:

Publisher's PDF, also known as Version of record

\section{Please check the document version of this publication:}

- A submitted manuscript is the version of the article upon submission and before peer-review. There can be important differences between the submitted version and the official published version of record.

People interested in the research are advised to contact the author for the final version of the publication, or visit the DOI to the publisher's website.

- The final author version and the galley proof are versions of the publication after peer review.

- The final published version features the final layout of the paper including the volume, issue and page numbers.

Link to publication

\footnotetext{
General rights rights.

- You may freely distribute the URL identifying the publication in the public portal. please follow below link for the End User Agreement:

www.umlib.nl/taverne-license

Take down policy

If you believe that this document breaches copyright please contact us at:

repository@maastrichtuniversity.nl

providing details and we will investigate your claim.
}

Copyright and moral rights for the publications made accessible in the public portal are retained by the authors and/or other copyright owners and it is a condition of accessing publications that users recognise and abide by the legal requirements associated with these

- Users may download and print one copy of any publication from the public portal for the purpose of private study or research.

- You may not further distribute the material or use it for any profit-making activity or commercial gain

If the publication is distributed under the terms of Article $25 \mathrm{fa}$ of the Dutch Copyright Act, indicated by the "Taverne" license above, 
Development of new radio-labeled tracers for imaging and quantification of brown adipose tissue

\author{
Andreas Paulus
}


(C) Andreas Paulus, Maastricht 2019

All rights reserved. No part of this publication may be reproduced, stored in a retrieval system or transmitted, in any form or by any means, electronic, mechanical, photocopying, recording or otherwise, without permission in writing from the publisher.

Cover \& Layout: Andreas Paulus \& Druckerei Mainz

Printed by: Druckerei Mainz

Published by: Druckerei Mainz

ISBN:

The studies presented in this thesis were performed within NUTRIM School for Nutrition and Translational Research in Metabolism. 


\title{
Development of new radio-labeled tracers for imaging and quantification of brown adipose tissue
}

\author{
DISSERTATION \\ to obtain the degree of Doctor at the Maastricht University, \\ on the authority of the Rector Magnificus, \\ Prof. Dr. Rianne Letschert \\ in accordance with the decision of the Board of Deans, \\ to be defended in public on Wednesday 24.04.2019, at 12:00 o'clock \\ by Andreas Paulus \\ born on October $27^{\text {th }} 1988$ in Düren
}


Supervisors:

Prof. Dr. Felix M. Mottaghy

Prof. Dr. Wouter D. van Marken Lichtenbelt

\section{Co-supervisor}

Dr. Matthias Bauwens

\section{Assessment Committee}

Prof. Dr. Patrick Schrauwen

Prof. Dr. Bernd Neumaier

Prof. Dr. Christophe van de Wiele

Dr. Ingrid Dijkgraaf 


\section{Table of Content}

$\begin{array}{ll}\text { Abbreviations } & 6\end{array}$

$\begin{array}{lll}\text { Chapter } 1 & \text { Introduction }\end{array}$

Chapter $2 \quad$ Brown adipose tissue and lipid metabolism imaging 27

Chapter $3 \quad$ Characterization of BAT activity in rats using invasive 55 and non-invasive techniques

Chapter $4 \quad$ Synthesis, radiosynthesis and in vitro evaluation of $\left[{ }^{18} \mathrm{~F}\right]$ Bodipy-C16/triglyceride as a dual modal imaging agent for brown adipose tissue

Chapter $5 \quad\left[{ }^{18} \mathrm{~F}\right] \mathrm{BODIPY}$-triglyceride-containing chylomicron-like particles as an imaging agent for brown adipose tissue in vivo

Chapter $6 \quad$ Triglyceride-rich lipoprotein derived fatty acid uptake by brown adipose tissue in control and diabetic mice at room temperature, acute cold exposure and cold acclimation 


\section{Abbreviations}

Chronological appearance in the thesis:

BAT

WAT

UCP1

TG

FA

CD36

FATP

PET

$\left[{ }^{18} \mathrm{~F}\right] \mathrm{FDG}$

LCFA

TRL

LPL

SPECT

MRI

CT

ACSL

CoA

PTHrP

$\left[{ }^{18} \mathrm{~F}\right] \mathrm{FTHA}$

$\left[{ }^{11} \mathrm{C}\right]$ palmitate

$\left[{ }^{123}\right.$ I]BMIPP

BODIPY- $\mathrm{C}_{16}$

$\left[{ }^{123} \mathrm{I}\right] \mathrm{IHXA}$
Brown Adipose Tissue

White Adipose Tissue

Uncoupling Protein 1

Triglyceride

Fatty Acid

Cluster of Differentiation 36

Fatty Acid Transport Proteins

Positron Emission Tomography

$\left[{ }^{18}\right.$ F]Fluoro-2-deoxy-2-D-glucose

Long Chain Fatty Acid

Triglyceride Rich Lipoprotein

Lipoprotein Lipase

Single Photon Emission Computed Tomography

Magnetic Resonance Imaging

Computed Tomography

Fatty acyl-CoA Synthetase

Coenzyme A

Parathyroid Hormone-related Protein

14(R,S)-[ $\left.{ }^{18} \mathrm{~F}\right]$ fluoro-6-thia-heptadecanoic acid

$\left[{ }^{11} \mathrm{C}\right]$ hexadecanoic acid

15-(4-[123]]iodophenyl)-3-methyl-pentadecanoic acid

4,4-Difluoro-5,7-Dimethyl-4-Bora-3a,4a-Diaza-sIndacene-3-Hexadecanoic acid

$\left[{ }^{123} \mid\right]$ iodohexadecanoic acid 
$\left[{ }^{123} \mid\right]$ IHDA

$\left[{ }^{123} \mid\right]$ IPPA

BODIPY

QD

iBAT

ADIFAB

$\left[{ }^{99 m} \mathrm{Tc}\right] \mathrm{TcM} \mathrm{MBI}$

$\left[{ }^{123}\right.$ I]MIBG

$\left[{ }^{123} \mid\right] I P A$

MRS

TR-1

MIBI

VOI

SUV

FLASH

iAT

cBAT

ipWAT

BDP-FA

BDP-TG

ESI-Q

Ppm

RCY

NE

SO

r.t.

p $\left[{ }^{123} \mid\right]$ iodoheptadecanoic acid

$15-\left(p-\left[{ }^{123} l\right]\right.$ iodophenyl)-pentadecanoic acid

Boron-dipyrromethene

Quantum Dots

interscapular Brown Adipose Tissue

Acrylodan labelled rat intestinal fatty acid binding

protein

[ $\left.{ }^{99 m} \mathrm{Tc}\right]$ Tc-2-methoxy-isobutyl-isonitrile

meta-[ $\left.{ }^{123} \mid\right]$ iodobenzylguanidine

$\left[{ }^{123} \mid\right]$ iodophenylalanine

Magnetic Resonance Spectroscopy

Temperature Regime 1

Sestamibi

Volume of Interest

Standardized Uptake Value

Fast Low Angle SHot

interscapular Adipose Tissue

cervical Brown Adipose Tissue

intraperitoneal White Adipose Tissue

Bodipy- $\mathrm{C}_{16}$

Bodipy-triglyceride

Electrospray Ionization Quadrupole

parts per million

Radiochemical Yield

Norepinephrine

Sulfosuccinimidyl-oleat

room temperature

probability leve 
Chapter 1:

Introduction 


\section{Brown Adipose Tissue (BAT) in mammals}

BAT is uniquely found in mammals and enables them to produce heat to maintain their body temperature below their thermoneutral zone ${ }^{1}$. In contrast to typical white adipose tissue (WAT), BAT consists of multiple cellular lipid droplets for storage purposes which facilitates the opportunity of fast lipolysis due to its enhanced lipid surface ${ }^{2}$. BAT is also distinguished by its high number of mitochondria where its brown color originates from. Its high degree of vascularisation provides heat transport throughout the whole body in times of thermogenesis ${ }^{3}$.

BATs thermogenic potential results from the BAT specific uncoupling protein 1 (UCP1) ${ }^{4-7}$. During activation high amounts of internal triglycerides (TGs) are lipolysed and transported towards the mitochondria where usually $\beta$-oxidation leads to ATP synthesis. UCP1 uncouples this process by permeabilizing the inner mitochondrial membrane for protons whereby heat is produced ${ }^{1,8}$.

The ability to "burn" fatty acids (FAs) instead of storing energy makes BAT an interesting target in understanding the development of obesity and potentially fighting its related metabolic syndromes.

\section{FA metabolism}

Obesity is considered as a worldwide epidemic which will become even more severe in the near future. Already in 20161.9 billion adults were overweight from which 650 million were obese. Obesity results from a positive energy balance and is correlated to other diseases such as diabetes type- $\|^{9,10}$, atherosclerosis ${ }^{11}$ and cancer ${ }^{12}$, together referred to as metabolic syndrome.

FAs are the major source of energy and either derived from food intake or lipogenesis that includes glycolysis and the citric acid cycle ${ }^{13}$. In animals predominantly FAs with even numbers can be found and FAs are grouped by their chain length, short chain (2-6 carbon atoms), medium chain (8-12 carbon atoms), long chain (14-18 carbon atoms) and very long chain (20-26 carbon atoms). The main type of circulating FAs are long-chain and very long- 
chain with varying degrees of saturation. FAs are stored as TGs in adipocytes and set free in times of starvation or fasting ${ }^{14}$.

Most types of tissue can switch between glucose and FA metabolism. A major tissue for energy expenditure is muscle because of its relative large size ${ }^{15,16}$. Other tissues such as heart also show this ability but because of its relative small size the heart can only increase its contribution to whole body energy expenditure to $5-10 \%{ }^{17}$. Significant amounts of glucose are cleared by the liver after a meal but also FAs are taken up, oxidised and incorporated as TGs into lipoproteins to transport them into other tissues for storage purposes ${ }^{18,19}$.

Uptake of FAs into cells was long thought to be the result of simple diffusion. Recently it was found that FA uptake is dependent on specific transport proteins such as cluster of differentiation 36 (CD36) or fatty acid transport proteins (FATP) ${ }^{20}$. Once in the cell FAs can be stored in lipid droplets or used in the mitochondria. The main pathway for FA degradation is mitochondrial $\beta$-oxidation ${ }^{21}$ by which ATP is produced. It is important to mention that by a complete oxidation of one FA molecule e.g. palmitate more molecules ATP are produced than by an oxidation of one glucose molecule (105 vs. 31$)^{22}$.

Even though a high number of guidelines by national and international authorities has been published on healthy diets and physical activity, to fight against obesity and related metabolic syndromes, studies could show that patients only adhered short times and a recidivism to old behaviour patterns was the common case ${ }^{23-26}$

Therefore BAT with its ability to uncouple its ATP production is an interesting target to increase overall body energy expenditure and to reduce weight of obese subjects.

\section{Brown adipose tissue (BAT)}

BAT research evolved within the last 20-40 years, revived in 2009 and is now an important topic in the field of endocrine research. Active BAT in adult humans was found using retrospective positron emission tomography (PET) studies with $\left[{ }^{18} \mathrm{~F}\right]$ Fluoro-2-deoxy-2-Dglucose $\left(\left[{ }^{18} \mathrm{~F}\right] \mathrm{FDG}\right){ }^{27-29}$. As already mentioned BAT has the unique ability to uncouple its 
ATP production in its mitochondria by the BAT specific protein UCP1 and to produce heat during this process ${ }^{4-7}$.

In the absence of heat production protons which are transported against the concentration gradient cause a voltage difference across the inner mitochondrial membrane. Protons which reenter the matrix by ATPase release their energy, which is necessary for ATP synthesis. During BAT activation protons enter the matrix by UCP1 ${ }^{30}$ and energy is released as heat ${ }^{1,8}$. This process is responsible for nonshivering thermogenesis ${ }^{1,31}$.

It was shown that long chain fatty acids (LCFA) (> 12 carbon atoms ${ }^{32}$ ) are of immense importance for the uncoupling process as they work as a carrier for protons through UCP ${ }^{33}$. Purine nucleotides like ATP inhibit UCP1 from the cytosolic side ${ }^{8,34-36}$. LCFA can overcome the blocking of UCP1 and support the activation of the uncoupling process ${ }^{1,33,37}$.

BAT is activated by cold exposure of the subject ${ }^{38-40}$. Thermoreceptors in the skin are stimulated by cold, those stimuli are transmitted by the somatic nervous system and neurons are activated in the ventromedial nucleus of the hypothalamus resulting in release of norepiephrine by the postsynaptic nerve endings, triggering BAT activation 1,41. Norepinephrine binding to $\beta 3$-adrenoeceptors on BAT activates cyclic adenosine monophosphate, which in the next step stimulates protein kinase. Hormone sensitive lipase is activated resulting in TG lipolysis and FAs are released which are necessary for UCP1 activation ${ }^{1,42,43}$. By norepinephrine activation TGs stored in intracellular lipid droplets are lipolyzed to single FAs and metabolized in the mitochondria. Lipid droplets can then be potentially replenished in three different manners: glucose uptake with following de novo lipogenesis, free FA uptake facilitated by albumin binding, and uptake of triglyceride-rich lipoprotein (TRL)-derived FAs from the plasma with subsequent esterification to TGs ${ }^{1,44-46}$. TRL-derived FAs were identified as the main supply of TGs in BAT ${ }^{44}$ and FA internalization was shown to be dependent on the presence of lipoprotein lipase (LPL) ${ }^{47,48}$, cluster of CD36 ${ }^{49}$ and FATP ${ }^{50}$ which need to be located at the outer cellular membrane.

Increased $\left[{ }^{18} \mathrm{~F}\right] \mathrm{FDG}$ uptake as a measure for glucose consumption in BAT was recently observed in obese cold acclimated humans concluding that significant amounts of BAT can 
be recruited during repeated cold exposure ${ }^{51}$. Glucose is mainly taken up by protein transporters of the GLUT family, mainly the fat muscle specific isoform GLUT4 ${ }^{52,53}$. Glucose is processed in different pathways e.g. in the citric acid cycle ${ }^{54}$ or it is conversed to FAs ${ }^{55,56}$. The main metabolized substance class in BAT is FAs. Therefore BAT activity can be largely underestimated by $\left[{ }^{18} \mathrm{~F}\right] \mathrm{FDG}$ scans, which is till now the most often used technique to quantify BAT activity and volume. The aim of this work was to develop a lipid based tracer to gain more information and to quantify FA metabolism in BAT because till now it is not known to what extend activated BAT contributes to energy consumption in obese.

\section{PET and single photon emission computed tomography (SPECT)}

The era of tracer based non-invasive imaging was a huge progress for the society of nuclear medicine. Two prominent examples, which are frequently used to visualize processes in vivo, are PET and SPECT. Both rely on the same idea of radioactive material which is injected into a living organism and its distribution in the body can be followed up at later time stages. In PET $\beta^{+}$-emitting radionuclides are used where the following pair of annihilation radiation can be measured in coincidence by a detector ring. By this technique a high amount of unspecific signals can be filtered out which makes it possible to precisely localise the point of the annihilation and has a positive effect on resolution and sensitivity. In SPECT Y-emitting radionuclides are used. Here a collimator is necessary to gain information about the direction of the emitted $y$-ray. Because of this filter only a minor amount of the emission reaches the camera which makes SPECT less efficient in comparison to PET. A more recent approach is the combination of PET or SPECT with other imaging modalities such as computer tomography or magnetic resonance imaging. Next to the tracer distribution also information about morphological structures are obtained which help to better localize the side of the tracer accumulation. 


\section{Tracers and Isotopes}

As described in the previous section PET and SPECT imaging offer the opportunity to gain information about the biodistribution of a radioactive drug by non-invasive imaging. This can help to identify for example disease patterns, cancer, injuries or metabolic activity. The design of the radioactive drug or also called tracer is of immense importance and varies for different tasks. In all cases a carrier molecule, which should target the region of interest is modified by a radionuclide. Sometimes the addition of the radionuclide is not trivial and can only be achieved by precursor molecules or chelators. Usually the radiolabeled drug is applied in amounts which have no pharmacological effect. This is the reason why they are also called tracer or radio-tracer.

\section{PET radionuclides and tracer}

Various PET suitable radionuclides exist and most of them have a half life comparable to the biological half life of the radiotracer. In Tab. 1 the most common radionuclides are listed. The primary mode of decay should be positron emission. Although many different radionuclides could be used in theory, carbon-11 and fluorine-18 are the most prominent ones. All organic compounds in nature consist of carbon atoms. Therefore an exchange of stable carbon-12 by carbon-11 has no effect on the pharmacological properties of a compound. Fluorine usually cannot be found in biomolecules but, its size is similar to the size of the hydroxyl group which implies only a minor change in steric properties. Fluorine is the atom with the highest electronegativity. Therefore introduction of fluorine can cause a change in electronic properties which might have an advantageous effect on the binding affinity ${ }^{57}$. Its relative long half life compared to e.g. carbon-11 and the lowest decay energy of all PET radionuclides makes fluorine-18 the radionuclide with the best nuclear properties. 


\begin{tabular}{cccc}
\hline Radionuclide & Half Life & Decay Mode & $\begin{array}{c}\text { Max. Decay Energie } \\
{[\mathrm{MeV}]}\end{array}$ \\
\hline${ }^{11} \mathbf{C}$ & $20.3 \mathrm{~min}$ & $\beta^{+}$ & 0.97 \\
${ }^{13} \mathrm{~N}$ & $10 \mathrm{~min}$ & $\beta^{+}$ & 1.20 \\
${ }^{15} \mathrm{O}$ & $2 \mathrm{~min}$ & $\beta^{+}$ & 0.64 \\
${ }^{18} \mathrm{~F}$ & $110 \mathrm{~min}$ & $\beta^{+}$ & 0.66 \\
${ }^{64} \mathrm{Cu}$ & $12.7 \mathrm{~h}$ & $\beta^{+} /$electron capture & 1.90 \\
${ }^{68} \mathrm{Ga}$ & $67.6 \mathrm{~min}$ & $\beta^{+} /$electron capture & 4.00 \\
${ }^{16} \mathrm{Br}$ & $16.2 \mathrm{~h}$ & $\beta^{+} /$electron capture & 2.14 \\
\hline
\end{tabular}

For diagnostics, the most often used tracer is $\left[{ }^{18} \mathrm{~F}\right] \mathrm{FDG}$. This glucose analog was developed in the 1970's ${ }^{58}$ and its synthesis was improved further a decade later ${ }^{59}$. Its field of application reaches from oncologic questions to neurology. Because of its broad application, $\left[{ }^{18} \mathrm{~F}\right] \mathrm{FDG}$ can have some limitations such as high uptake in brain, bladder and in inflamed tissue. Therefore more dedicated tracer have been developed e.g. [ $\left.{ }^{68} \mathrm{Ga}\right] \mathrm{GaPSMA}{ }^{60}$, $\left[{ }^{18} \mathrm{~F}\right] \mathrm{FLT}{ }^{61}$ or $\left[{ }^{11} \mathrm{C}\right] \mathrm{PK} 11195{ }^{62}$. This selection of tracers is only a small list and should represent important fields of PET imaging. It does not reflect the enormous number of tracers which are available today.

\section{SPECT radionuclides and tracer}

In SPECT imaging radionuclides which directly emit $\mathrm{y}$-rays are used. In Tab. 2 the most important nuclides used in SPECT are listed. It is to mention that SPECT isotopes have in general a longer half life than PET isotopes. Therefore longer and excessive radiosynthesis can be conducted and longer processes in vivo can be visualized. The longer half life offers also the possibility to transport the radiopharmaceuticals to other institutions, adding an important commercial aspect to imaging with SPECT isotopes. The most important radionuclide is technetium- $99 \mathrm{~m}$. Different to the other isotopes it does not need to be produced in a cyclotron because it is produced during the decay of its mother nuclide 
molybdenum-99. This generator approach led to the label "workhouse of nuclear medicine" for technetium-99m.

Table 2: SPECT radionuclides

\begin{tabular}{cccc}
\hline Radionuclide & Half Life & Decay Mode & $\begin{array}{c}\text { Principal Photon emission } \\
\text { energy [MeV] }\end{array}$ \\
\hline${ }^{123} \mathrm{I}$ & $13.2 \mathrm{~h}$ & Electron capture & 0.16 \\
${ }^{99 \mathrm{~m}} \mathrm{Tc}$ & $6 \mathrm{~h}$ & Isomeric transition & 0.14 \\
${ }^{1{ }^{1} \mathrm{In}}$ & $67.9 \mathrm{~h}$ & Electron capture & $0.17 / 0.25$ \\
${ }^{6 /} \mathrm{Ga}$ & $78.3 \mathrm{~h}$ & Electron capture & $0.09 / 0.19 / 0.30$ \\
${ }^{201} \mathrm{TI}$ & $73.1 \mathrm{~h}$ & Electron capture & 0.17 \\
\hline
\end{tabular}

To label a biomarker with technetium-99m a chelating agent is necessary. Technetium-99m chemistry relies on complex chemistry to design a precursor molecule which has the ability to allow labelling with technetium-99m but also retain its binding affinity in vivo. The use of bulky chelating agents limits the application of technetium-99m-labeled compounds e.g. in neuroscience because the blood brain barrier could preclude target binding.

Another important SPECT radionuclide is iodine-123. Similar to fluorine-18, iodine forms covalent bonds with carbon atoms, making it easy to incorporate it into small molecules. $\mathrm{A}$ disadvantage compared to incorporation of fluorine-18 into a molecule is that iodine has a larger van der Waal's radius and therefore higher steric alteration can be expected, especially for smaller molecules. The fact that iodine has several isotopes that can be used in nuclear medicine ( $\beta$ and $\gamma$ emitters) offers the advantage to use iodine labeled compounds for imaging and therapy with the same molecule. An important agent for this purpose is MIBG where $\left[{ }^{123}\right]$ MIBG is used to visualize neuroendocrine tumors and patients with MIBG positive areas obtain a therapy with $\left[{ }^{131} \mathrm{I}\right] \mathrm{MIBG}{ }^{63}$. Other important SPECT tracers are $\left[{ }^{123}\right.$ I]FP-CIT ${ }^{64}$ a tracer to target the dopamine transporter in the brain or [ $\left.{ }^{99 m} \mathrm{Tc}\right] \mathrm{TcMAG} 3$ which is used for renography ${ }^{65}$. 


\section{Tracers for BAT imaging}

\section{PET suitable tracer}

As already mentioned $\left[{ }^{18} \mathrm{~F}\right] \mathrm{FDG}$ is the most frequently used tracer so far which might be a result of a high number of retrospective studies as well as its availability. It was found in dedicated experiments that age, obesity and various pathological conditions have a negative effect on detectable BAT volume ${ }^{38,66-69}$. Uptake of $\left[{ }^{18} \mathrm{~F}\right] \mathrm{FDG}$ is also influenced by outdoor temperatures, fasting, and different medications e.g. $\beta$-blockers ${ }^{28,43,70}$. Apart from quantification of BAT $\left[{ }^{18} \mathrm{~F}\right] \mathrm{FDG}$ is also used to explore BATs role in glucose metabolism. Lower amounts of active BAT were found in hyperglycaemic and diabetic patients ${ }^{71,72}$.

Different fatty acid based tracers such as $\left[{ }^{18} \mathrm{~F}\right] \mathrm{FTHA}{ }^{73},\left[{ }^{11} \mathrm{C}\right]$ palmitate ${ }^{74}$ and others ${ }^{75-77}$ have been developed. Most of them have been used for myocardial imaging, before their suitability to visualize BAT was considered to be useful. A more detailed discussion about lipid based tracers can be found in chapter 2.

$\left[{ }^{11} \mathrm{C}\right]$ acetate is able to quantify FA synthase activity by visualizing BATs oxidative metabolism ${ }^{73}$. In studies with healthy test subjects exposed to cold a significant $\left[{ }^{11} \mathrm{C}\right]$ acetate increase in uptake was observed ${ }^{78}$. In addition oxygen-15 tracers are also used to determine BATs oxidative capacity.

Studies with $\left[{ }^{15} \mathrm{O}\right] \mathrm{O}_{2}$ showed an increased metabolic BAT activity in cold exposed subjects ${ }^{79}$. $\left[{ }^{15} \mathrm{O}\right] \mathrm{H}_{2} \mathrm{O}$ as a perfusion tracer, was able to show an increase in perfusion due to cold ${ }^{80}$. Obesity attenuates this effect ${ }^{81}$.

$\left[{ }^{11} \mathrm{C}\right] \mathrm{MRB}$ as a highly selective ligand for the norepinephrine transporter was found to accumulate in BAT. This elevated uptake values could be already reached at room temperature while cold exposure only slightly increased $\left[{ }^{11} \mathrm{C}\right] \mathrm{MRB}$ uptake ${ }^{82}$.

In a retrospective study with patients scanned for pheochromocytoma by $\left[{ }^{18} \mathrm{~F}\right] \mathrm{F}-\mathrm{DA}$, a dopamine analog, it was found that BAT could be visualized in $18 \%$ of the patients ${ }^{69}$. A similar occurrence was achieved by $\left[{ }^{18} \mathrm{~F}\right] \mathrm{FDG}$ scans. However it is to mention that those 
patients might have a larger BAT tissue mass or activation because of increased levels of catecholamines excreted from their tumor.

Apart from the here presented tracer with a clinical application, a high number of promising pre-clinical tracer exist. Prominent examples are radiolabeled triphenylphosphonium based tracer targeting the voltage difference of the inner mitochondrial membrane ${ }^{83,84}$.

\section{SPECT suitable tracer}

$\left[{ }^{123}\right.$ I]MIBG is an FDA approved tracer for pheochromocytoma, neuroblastoma and cardiac imaging. Its biodistribution is known to be dependent on catecholamine production ${ }^{85}$. In retrospective studies a prevalence of finding fat depots which are linked to BAT was $18 \%{ }^{69}$ and in preclinical studies BAT uptake was increased by 3 fold due to cold exposure ${ }^{86}$. In dedicated clinical studies in healthy adults $\left[{ }^{18} \mathrm{~F}\right] \mathrm{FDG}$ uptake correlated with $\left[{ }^{123} \mathrm{I}\right] \mathrm{MIBG}$ in BAT $^{87}$

$\left.{ }^{99 \mathrm{~m}} \mathrm{Tc}\right] \mathrm{TcMIBI}$ is taken up in tissue with an increased blood flow and high mitochondrial density due to its lipophilic and cationic properties. An increased [ ${ }^{99 m} \mathrm{Tc}$ ]TcMIBI uptake in BAT vs. WAT was reported in a preclinical study where uptake in BAT was increased by adrenergic stimulation. In retrospective human studies BAT was detectable ${ }^{88,89}$ and BATs presence in $\left[{ }^{99 m} \mathrm{Tc}\right]$ TcMIBI positive samples was confirmed by immunohistochemistry ${ }^{88}$. $\left[{ }^{123}\right.$ I]BMIPP ${ }^{90,91}$ is another FA based tracer which was initially developed for myocardial imaging. Similar to $\left[{ }^{18} \mathrm{~F}\right] \mathrm{FTHA}$ it is now used to study BAT uptake of FAs.

Another lipophilic tracer which originally was developed for cardiac imaging is $\left.{ }^{99 \mathrm{~m}} \mathrm{Tc}\right] \mathrm{TcTetrofosmin}$. Due to its lipophilic properties it is enriched in tissue with high amounts of mitochondria. In a retrospective study it was found that its prevalence to detect BAT depots in humans was $17 \%{ }^{92}$ making it a suitable tracer to explore BATs mitochondrial function. 


\section{Other BAT detection techniques}

Apart from the presented nuclear tracer there are other techniques suitable to visualize BAT and its metabolism. The possibilities to image BAT are here presented very briefly. More detailed information are given in chapter 2.

A high number of preclinical work is performed with fluorescent in vitro uptake experiments ${ }^{93-}$ 97. The chance of analyzing BAT uptake on a sub-cellular scale, working without patients or animals and without exposure to radioactivity makes this method suitable for a high throughput of experiments.

Next to imaging with radioactive tracers or fluorescent imaging there is also the possibility to image BAT with labelled particles. This particle visualization can consist of fluorescent labeled particles ${ }^{45}$, radioactive labeled particles ${ }^{46,98}$ or MR functional particles ${ }^{45}$. Incorporation of the tracer in particles might have beneficial effects on the biodistribution of the tracer itself. E.g. a bare FA based tracer relies on several uptake mechanism before it can be transported via the bloodstream and might therefore not reflect the real processes in vivo. For more detailed information see chapter 2.

Other methods to determine BATs volume are Magnetic Resonance Imaging (MRI) and Computed Tomography (CT). MRI is able to determine the water/lipid content in BAT by detecting a radio-frequency of excited protons in a magnetic field. This frequency is dependent on the chemical surrounding of the excited protons and is therefore tissue specific. By comparing it to previous records it is possible to gain information about BATs activation state and lipid consumption ${ }^{99,100}$. In comparison to PET, MRI has the advantage that it can detect following properties of BAT: temporal and quantitative measurements of tissue fat content, changes in blood flow, volume, and oxygenation of active BAT ${ }^{100}$. Additionally MR Spectroscopy is able to detect the relative abundance of chemicals within a single localized region and therefore helps to quantify changes in BATs lipid composition due to stimulation. CT on its own is almost not able to detect BAT. As BAT and its surrounding tissue do not differ too much in its Hounsfield units a standalone CT cannot distinguish between e.g. BAT and WAT next to each other. Also the interpretation of Hounsfield units is 
biased ${ }^{101-104}$. Anyway, CT and MRI are useful additions to the common used ways to visualize BAT by adding morpohological information to the image.

\section{Aim of this dissertation}

Multiple imaging and quantification approaches for BAT are available. The most often used technique is PET/CT with $\left[{ }^{18} \mathrm{~F}\right] \mathrm{FDG}$. Its broad field of application as well as its use in clinical routine makes this tracer very popular, also in the field of BAT imaging. Nevertheless $\left[{ }^{18} \mathrm{~F}\right] \mathrm{FDG}$ has a huge disadvantage: it is a glucose based tracer. Although $\left[{ }^{18} \mathrm{~F}\right] \mathrm{FDG}$ was able to visualize BAT and to show increased metabolic activity in cold exposed animals and humans, lipids in the form of FAs are the main metabolized substance class. Therefore it is impossible to calculate BAT's total metabolic activity.

At first FA based tracers, such as $\left[{ }^{18} \mathrm{~F}\right] \mathrm{FTHA}$ or $\left[{ }^{123} \mathrm{I}\right.$ BMIPP, were used to quantify BATs its demand of FAs. However, this method does not completely reflect the situation in vivo where FAs are transported as TGs incorporated in TRLs towards BAT.

Therefore the aim of this dissertation was to synthesize a radiolabeled TG and to incorporate it into a TRL which than can be applied in vivo. To our understanding this would come closest to the in vivo situation and will probably help to understand BATs role in whole body energy expenditure. Additionally such a tracer would also be useful for other applications (e.g. fatty liver disease, obesity and fatty acid metabolism in general). 


\section{References}

1 Cannon, B. \& Nedergaard, J. Brown adipose tissue: function and physiological significance. Physiol Rev 84, 277-359, doi:10.1152/physrev.00015.2003 (2004).

2 Keipert, S. \& Jastroch, M. Brite/beige fat and UCP1 - is it thermogenesis? Biochim Biophys Acta 1837, 1075-1082, doi:10.1016/j.bbabio.2014.02.008 (2014).

3 Reddy, N. L., Tan, B. K., Barber, T. M. \& Randeva, H. S. Brown adipose tissue: endocrine determinants of function and therapeutic manipulation as a novel treatment strategy for obesity. BMC obesity 1, 13, doi:10.1186/s40608-014-0013-5 (2014).

Aquila, H., Link, T. A. \& Klingenberg, M. The uncoupling protein from brown fat mitochondria is related to the mitochondrial ADP/ATP carrier. Analysis of sequence homologies and of folding of the protein in the membrane. EMBO J 4, 2369-2376 (1985).

Bouillaud, F., Weissenbach, J. \& Ricquier, D. Complete cDNA-derived amino acid sequence of rat brown fat uncoupling protein. J Biol Chem 261, 1487-1490 (1986).

Heaton, G. M., Wagenvoord, R. J., Kemp, A. \& Nicholls, D. G. Brown-adipose-tissue mitochondria: photoaffinity labelling of the regulatory site of energy dissipation. Eur $J$ Biochem 82, 515-521 (1978).

Ridley, R. G., Patel, H. V., Gerber, G. E., Morton, R. C. \& Freeman, K. B. Complete nucleotide and derived amino acid sequence of cDNA encoding the mitochondrial uncoupling protein of rat brown adipose tissue: lack of a mitochondrial targeting presequence. Nucleic Acids Res 14, 4025-4035 (1986).

8 Nicholls, D. G. \& Locke, R. M. Thermogenic mechanisms in brown fat. Physiol Rev 64, 1-64 (1984).

9 Svacina, S. Treatment of obese diabetics. Advances in experimental medicine and biology 771, 459-464 (2012).

10 Schwartz, S., Fabricatore, A. N. \& Diamond, A. Weight reduction in diabetes. Advances in experimental medicine and biology 771, 438-458 (2012).

11 Kortelainen, M. L. Association between cardiac pathology and fat tissue distribution in an autopsy series of men without premortem evidence of cardiovascular disease. International journal of obesity and related metabolic disorders : journal of the International Association for the Study of Obesity 20, 245-252 (1996).

Gallagher, E. J. \& LeRoith, D. Obesity and Diabetes: The Increased Risk of Cancer and CancerRelated Mortality. Physiol Rev 95, 727-748, doi:10.1152/physrev.00030.2014 (2015).

Wakil, S. J. Fatty acid synthase, a proficient multifunctional enzyme. Biochemistry 28, 45234530 (1989).

14 Kruger, M. C., Coetzee, M., Haag, M. \& Weiler, H. Long-chain polyunsaturated fatty acids: selected mechanisms of action on bone. Progress in lipid research 49, 438-449, doi:10.1016/j.plipres.2010.06.002 (2010).

15 James, D. E., Jenkins, A. B. \& Kraegen, E. W. Heterogeneity of insulin action in individual muscles in vivo: euglycemic clamp studies in rats. Am J Physiol 248, E567-574, doi:10.1152/ajpendo.1985.248.5.E567 (1985).

16 Furler, S. M. et al. Local factors modulate tissue-specific NEFA utilization: assessment in rats using 3H-(R)-2-bromopalmitate. Diabetes 49, 1427-1433 (2000).

17 Rolfe, D. F. \& Brown, G. C. Cellular energy utilization and molecular origin of standard metabolic rate in mammals. Physiol Rev 77, 731-758, doi:10.1152/physrev.1997.77.3.731 (1997).

18 Postic, C., Dentin, R. \& Girard, J. Role of the liver in the control of carbohydrate and lipid homeostasis. Diabetes \& metabolism 30, 398-408 (2004).

19 Moore, M. C., Coate, K. C., Winnick, J. J., An, Z. \& Cherrington, A. D. Regulation of hepatic glucose uptake and storage in vivo. Advances in nutrition (Bethesda, Md.) 3, 286-294, doi:10.3945/an.112.002089 (2012). 
Glatz, J. F., Luiken, J. J. \& Bonen, A. Membrane fatty acid transporters as regulators of lipid metabolism: implications for metabolic disease. Physiol Rev 90, 367-417, doi:10.1152/physrev.00003.2009 (2010).

21 Knoop, F. Der Abbau aromatischer Fettssäuren im Tierkörper. Beitr. Z. Chem. Phys. U. Pathol. 6, 150-162 (1904).

22 Lopaschuk, G. D., Ussher, J. R., Folmes, C. D., Jaswal, J. S. \& Stanley, W. C. Myocardial fatty acid metabolism in health and disease. Physiol Rev 90, 207-258, doi:10.1152/physrev.00015.2009 (2010).

23 Wing, R. R. \& Phelan, S. Long-term weight loss maintenance. The American journal of clinical nutrition 82, 222s-225s, doi:10.1093/ajcn/82.1.222S (2005).

24 Bensimhon, D. R., Kraus, W. E. \& Donahue, M. P. Obesity and physical activity: a review. American heart journal 151, 598-603, doi:10.1016/j.ahj.2005.03.005 (2006).

25 Dunstan, D. W. et al. Home-based resistance training is not sufficient to maintain improved glycemic control following supervised training in older individuals with type 2 diabetes. Diabetes care 28, 3-9 (2005).

26 King, D. E., Mainous, A. G., 3rd, Carnemolla, M. \& Everett, C. J. Adherence to healthy lifestyle habits in US adults, 1988-2006. The American journal of medicine 122, 528-534, doi:10.1016/j.amjmed.2008.11.013 (2009).

27 Lee, P., Greenfield, J. R., Ho, K. K. \& Fulham, M. J. A critical appraisal of the prevalence and metabolic significance of brown adipose tissue in adult humans. Am J Physiol Endocrinol Metab 299, E601-606, doi:ajpendo.00298.2010 [pii] 10.1152/ajpendo.00298.2010 (2010).

Cohade, C., Mourtzikos, K. A. \& Wahl, R. L. "USA-Fat": prevalence is related to ambient outdoor temperature-evaluation with 18F-FDG PET/CT. Journal of nuclear medicine : official publication, Society of Nuclear Medicine 44, 1267-1270 (2003).

29 Hany, T. F. et al. Brown adipose tissue: a factor to consider in symmetrical tracer uptake in the neck and upper chest region. Eur J Nucl Med Mol Imaging 29, 1393-1398, doi:10.1007/s00259-002-0902-6 (2002).

30 Matthias, A. et al. Thermogenic responses in brown fat cells are fully UCP1-dependent. UCP2 or UCP3 do not substitute for UCP1 in adrenergically or fatty scid-induced thermogenesis. $J$ Biol Chem 275, 25073-25081, doi:10.1074/jbc.M000547200 (2000).

31 Enerbäck, S. et al. Mice lacking mitochondrial uncoupling protein are cold-sensitive but not obese. Nature 387, 90-94, doi:10.1038/387090a0 (1997).

32 Beermann, C. et al. Short term effects of dietary medium-chain fatty acids and n-3 long-chain polyunsaturated fatty acids on the fat metabolism of healthy volunteers. Lipids Health Dis $\mathbf{2}$, 10, doi:10.1186/1476-511x-2-10 (2003).

33 Fedorenko, A., Lishko, P. V. \& Kirichok, Y. Mechanism of fatty-acid-dependent UCP1 uncoupling in brown fat mitochondria. Cell 151, 400-413, doi:10.1016/j.cell.2012.09.010 (2012).

34 Klingenberg, M. Wanderings in bioenergetics and biomembranes. Biochim Biophys Acta 1797, 579-594, doi:10.1016/j.bbabio.2010.02.012 (2010).

35 Nicholls, D. G. The physiological regulation of uncoupling proteins. Biochim Biophys Acta 1757, 459-466, doi:10.1016/j.bbabio.2006.02.005 (2006).

36 Shabalina, I. G., Jacobsson, A., Cannon, B. \& Nedergaard, J. Native UCP1 displays simple competitive kinetics between the regulators purine nucleotides and fatty acids. J Biol Chem 279, 38236-38248, doi:10.1074/jbc.M402375200 (2004).

37 Rial, E. \& González-Barroso, M. M. Physiological regulation of the transport activity in the uncoupling proteins UCP1 and UCP2. Biochim Biophys Acta 1504, 70-81 (2001).

38 van Marken Lichtenbelt, W. D. et al. Cold-activated brown adipose tissue in healthy men. $N$ Engl J Med 360, 1500-1508, doi:10.1056/NEJMoa0808718 (2009).

39 Virtanen, K. A. et al. Functional brown adipose tissue in healthy adults. N Engl J Med 360, 1518-1525, doi:10.1056/NEJMoa0808949 (2009). 
Saito, M. et al. High incidence of metabolically active brown adipose tissue in healthy adult humans: effects of cold exposure and adiposity. Diabetes 58, 1526-1531, doi:10.2337/db090530 (2009).

41 Lowell, B. B. \& Spiegelman, B. M. Towards a molecular understanding of adaptive thermogenesis. Nature 404, 652-660, doi:10.1038/35007527 (2000).

42 Bachman, E. S. et al. betaAR signaling required for diet-induced thermogenesis and obesity resistance. Science 297, 843-845, doi:10.1126/science.1073160 (2002).

43 Cypess, A. M. et al. Activation of human brown adipose tissue by a $\beta 3$-adrenergic receptor agonist. Cell Metab 21, 33-38, doi:10.1016/j.cmet.2014.12.009 (2015).

44 Festuccia, W. T., Blanchard, P. G. \& Deshaies, Y. Control of Brown Adipose Tissue Glucose and Lipid Metabolism by PPARgamma. Frontiers in endocrinology 2, 84, doi:10.3389/fendo.2011.00084 (2011).

45 Bartelt, A. et al. Brown adipose tissue activity controls triglyceride clearance. Nat Med 17, 200-205, doi:10.1038/nm.2297 (2011).

46 Khedoe, P. P. S. J. et al. Brown adipose tissue takes up plasma triglycerides mostly after lipolysis. J Lipid Res 56, 51-59, doi:10.1194/jlr.M052746 (2015).

47 Doege, H. \& Stahl, A. Protein-mediated fatty acid uptake: novel insights from in vivo models. Physiology (Bethesda) 21, 259-268, doi:10.1152/physiol.00014.2006 (2006).

48 Labbé, S. M. et al. In vivo measurement of energy substrate contribution to cold-induced brown adipose tissue thermogenesis. FASEB J 29, 2046-2058, doi:10.1096/fj.14-266247 (2015).

49 Coburn, C. T., Hajri, T., Ibrahimi, A. \& Abumrad, N. A. Role of CD36 in membrane transport and utilization of long-chain fatty acids by different tissues. J Mol Neurosci 16, 117-121; discussion 151-117, doi:10.1385/jmn:16:2-3:117 (2001).

50 Stahl, A. A current review of fatty acid transport proteins (SLC27). Pflugers Arch 447, 722727, doi:10.1007/s00424-003-1106-z (2004).

51 Hanssen, M. J. et al. Short-term cold acclimation recruits brown adipose tissue in obese humans. Diabetes, doi:10.2337/db15-1372 (2016).

52 Le Marchand-Brustel, Y. et al. Glucose transporter in insulin sensitive tissues of lean and obese mice. Effect of the thermogenic agent BRL 26830A. Endocrinology 127, 2687-2695, doi:10.1210/endo-127-6-2687 (1990).

53 Santalucía, T. et al. Developmental regulation of GLUT-1 (erythroid/Hep G2) and GLUT-4 (muscle/fat) glucose transporter expression in rat heart, skeletal muscle, and brown adipose tissue. Endocrinology 130, 837-846, doi:10.1210/endo.130.2.1370797 (1992).

54 Cannon, B. \& Nedergaard, J. Cultures of adipose precursor cells from brown adipose tissue and of clonal brown-adipocyte-like cell lines. Methods Mol Biol 155, 213-224, doi:10.1385/159259-231-7:213 (2001).

55 Buckley, M. G. \& Rath, E. A. Regulation of fatty acid synthesis and malonyl-CoA content in mouse brown adipose tissue in response to cold-exposure, starvation or re-feeding. Biochem J 243, 437-442 (1987).

56 Darnley, A. C., Carpenter, C. A. \& Saggerson, E. D. Changes in activities of some enzymes of glycerolipid synthesis in brown adipose tissue of cold-acclimated rats. Biochem J 253, 351355 (1988).

57 Zhang, W., Koehler, K. F., Harris, B., Skolnick, P. \& Cook, J. M. Synthesis of benzo-fused benzodiazepines employed as probes of the agonist pharmacophore of benzodiazepine receptors. Journal of medicinal chemistry 37, 745-757 (1994).

58 Ido,T. et al. Labeled 2-deoxy-D-glucose analogs. 18F-labeled 2-deoxy-2-fluoro-D-glucose, 2-deoxy-2-fluoro-D-mannose and 14C-2-deoxy-2-fluoro-D-glucose. Journal of Labelled Compounds and Radiopharmaceuticals 14, 175-183, doi:doi:10.1002/jlcr.2580140204 (1978).

59 Hamacher, K., Coenen, H. H. \& Stocklin, G. Efficient stereospecific synthesis of no-carrieradded 2-[18F]-fluoro-2-deoxy-D-glucose using aminopolyether supported nucleophilic substitution. J Nucl Med 27, 235-238 (1986). 
Kozikowski, A. P. et al. Design of remarkably simple, yet potent urea-based inhibitors of glutamate carboxypeptidase II (NAALADase). Journal of medicinal chemistry 44, 298-301 (2001).

Shields, A. F. et al. Imaging proliferation in vivo with [F-18]FLT and positron emission tomography. Nat Med 4, 1334-1336, doi:10.1038/3337 (1998).

$\mathrm{R}$, C. et al. Synthesis of $\mathrm{N}-(11 \mathrm{C})$ methyl, $\mathrm{N}$-(methyl-1 propyl), (chloro-2 phenyl)-1 isoquinoleine carboxamide-3 (PK 11195): A new ligand for peripheral benzodiazepine receptors. Journal of Labelled Compounds and Radiopharmaceuticals 21, 985-991, doi:doi:10.1002/jlcr.2580211012 (1984).

Bomanji, J. B. et al. Treatment of neuroendocrine tumours in adults with 131I-MIBG therapy. Clinical oncology (Royal College of Radiologists (Great Britain)) 15, 193-198 (2003).

O'Brien, J. T. et al. Dopamine transporter loss visualized with FP-CIT SPECT in the differential diagnosis of dementia with Lewy bodies. Archives of neurology 61, 919-925, doi:10.1001/archneur.61.6.919 (2004).

Fritzberg, A. R., Kasina, S., Eshima, D. \& Johnson, D. L. Synthesis and biological evaluation of technetium-99m MAG3 as a hippuran replacement. J Nucl Med 27, 111-116 (1986).

Yoneshiro, T. et al. Age-related decrease in cold-activated brown adipose tissue and accumulation of body fat in healthy humans. Obesity (Silver Spring, Md.) 19, 1755-1760, doi:10.1038/oby.2011.125 (2011).

Pfannenberg, C. et al. Impact of age on the relationships of brown adipose tissue with sex and adiposity in humans. Diabetes 59, 1789-1793, doi:10.2337/db10-0004 (2010).

Cypess, A. M. et al. Identification and importance of brown adipose tissue in adult humans. $N$ Engl J Med 360, 1509-1517, doi:10.1056/NEJMoa0810780 (2009).

Hadi, M., Chen, C. C., Whatley, M., Pacak, K. \& Carrasquillo, J. A. Brown fat imaging with (18)F-6-fluorodopamine PET/CT, (18)F-FDG PET/CT, and (123)I-MIBG SPECT: a study of patients being evaluated for pheochromocytoma. I Nucl Med 48, 1077-1083, doi:10.2967/jnumed.106.035915 (2007).

Vosselman, M. J. et al. Brown adipose tissue activity after a high-calorie meal in humans. The American journal of clinical nutrition 98, 57-64, doi:10.3945/ajcn.113.059022 (2013).

Jacene, H. A., Cohade, C. C., Zhang, Z. \& Wahl, R. L. The relationship between patients' serum glucose levels and metabolically active brown adipose tissue detected by PET/CT. Molecular imaging and biology : MIB : the official publication of the Academy of Molecular Imaging 13, 1278-1283, doi:10.1007/s11307-010-0379-9 (2011).

72 Matsushita, M. et al. Impact of brown adipose tissue on body fatness and glucose metabolism in healthy humans. International journal of obesity (2005) 38, 812-817, doi:10.1038/ijo.2013.206 (2014).

73 Ouellet, V. et al. Brown adipose tissue oxidative metabolism contributes to energy expenditure during acute cold exposure in humans. J Clin Invest 122, 545-552, doi:10.1172/jci60433 (2012).

74 Bucci, M. et al. Enhanced fatty acid uptake in visceral adipose tissue is not reversed by weight loss in obese individuals with the metabolic syndrome. Diabetologia 58, 158-164, doi:10.1007/s00125-014-3402-x (2015).

75 Poe, N. D., Robinson, G. D., Jr., Graham, L. S. \& MacDonald, N. S. Experimental basis of myocardial imaging with 123l-labeled hexadecenoic acid. Journal of nuclear medicine : official publication, Society of Nuclear Medicine 17, 1077-1082 (1976).

76 Poe, N. D. et al. Myocardial imaging with 1231-hexadecenoic acid. Radiology 124, 419-424, doi:10.1148/124.2.419 (1977).

77 Corbett, J. R. Fatty acids for myocardial imaging. Semin Nucl Med 29, 237-258 (1999).

78 Blondin, D. P. et al. Increased brown adipose tissue oxidative capacity in cold-acclimated humans. The Journal of clinical endocrinology and metabolism 99, E438-446, doi:10.1210/jc.2013-3901 (2014). 
79 Muzik, O. et al. 150 PET measurement of blood flow and oxygen consumption in coldactivated human brown fat. J Nucl Med 54, 523-531, doi:jnumed.112.111336 [pii] 10.2967/jnumed.112.111336 [doi] (2013).

80 Orava, J. et al. Different metabolic responses of human brown adipose tissue to activation by cold and insulin. Cell Metab 14, 272-279, doi:10.1016/j.cmet.2011.06.012 (2011).

81 Orava, J. et al. Blunted metabolic responses to cold and insulin stimulation in brown adipose tissue of obese humans. Obesity (Silver Spring, Md.) 21, 2279-2287, doi:10.1002/oby.20456 (2013).

82 Lin, S. F. et al. Ex vivo and in vivo evaluation of the norepinephrine transporter ligand [11C]MRB for brown adipose tissue imaging. Nuclear medicine and biology 39, 1081-1086, doi:10.1016/j.nucmedbio.2012.04.005 (2012).

83 Madar, I., Isoda, T., Finley, P., Angle, J. \& Wahl, R. 18F-fluorobenzyl triphenyl phosphonium: a noninvasive sensor of brown adipose tissue thermogenesis. Journal of nuclear medicine : official publication, Society of Nuclear Medicine 52, 808-814, doi:10.2967/jnumed.110.084657 (2011).

84 Madar, I. et al. Brown Adipose Tissue Response Dynamics: In Vivo Insights with the Voltage Sensor 18F-Fluorobenzyl Triphenyl Phosphonium. PloS one 10, e0129627, doi:10.1371/journal.pone.0129627 (2015).

85 Fukuchi, K. et al. Radionuclide imaging metabolic activity of brown adipose tissue in a patient with pheochromocytoma. Experimental and clinical endocrinology \& diabetes : official journal, German Society of Endocrinology [and] German Diabetes Association 112, 601-603, doi:10.1055/s-2004-830407 (2004).

86 Baba, S., Engles, J. M., Huso, D. L., Ishimori, T. \& Wahl, R. L. Comparison of uptake of multiple clinical radiotracers into brown adipose tissue under cold-stimulated and nonstimulated conditions. J Nucl Med 48, 1715-1723, doi:jnumed.107.041715 [pii] 10.2967/jnumed.107.041715 [doi] (2007).

87 Admiraal, W. M. et al. Combining 123I-metaiodobenzylguanidine SPECT/CT and 18F-FDG $\mathrm{PET} / \mathrm{CT}$ for the assessment of brown adipose tissue activity in humans during cold exposure. $J$ Nucl Med 54, 208-212, doi:jnumed.112.111849 [pii] 10.2967/jnumed.112.111849 [doi] (2013).

88 Cypess, A. M. et al. Quantification of human and rodent brown adipose tissue function using 99mTc-methoxyisobutylisonitrile SPECT/CT and 18F-FDG PET/CT. J Nucl Med 54, 1896-1901, doi:10.2967/jnumed.113.121012 (2013).

89 Goetze, S., Lavely, W. C., Ziessman, H. A. \& Wahl, R. L. Visualization of brown adipose tissue with 99mTc-methoxyisobutylisonitrile on SPECT/CT. I NuCl Med 49, 752-756, doi:jnumed.107.048074 [pii] 10.2967/jnumed.107.048074 [doi] (2008).

90 Syamsunarno, M. R. A. A. et al. Fatty acid binding protein 4 and 5 play a crucial role in thermogenesis under the conditions of fasting and cold stress. PloS one 9, e90825, doi:10.1371/journal.pone.0090825 (2014).

91 Putri, M. et al. CD36 is indispensable for thermogenesis under conditions of fasting and cold stress. Biochem Biophys Res Commun 457, 520-525, doi:10.1016/j.bbrc.2014.12.124 (2015).

92 Fukuchi, K. et al. Visualization of interscapular brown adipose tissue using $(99 \mathrm{~m})$ Tctetrofosmin in pediatric patients. J Nucl Med 44, 1582-1585 (2003).

93 Thumser, A. E. \& Storch, J. Characterization of a BODIPY-labeled fluorescent fatty acid analogue. Binding to fatty acid-binding proteins, intracellular localization, and metabolism. Mol Cell Biochem 299, 67-73, doi:10.1007/s11010-005-9041-2 (2007).

94 Wang, H. et al. Altered lipid droplet dynamics in hepatocytes lacking triacylglycerol hydrolase expression. Mol Biol Cell 21, 1991-2000, doi:10.1091/mbc.E09-05-0364 (2010).

95 Dubikovskaya, E., Chudnovskiy, R., Karateev, G., Park, H. M. \& Stahl, A. Measurement of longchain fatty acid uptake into adipocytes. Methods Enzymol 538, 107-134, doi:10.1016/b978-012-800280-3.00007-4 (2014). 
96 Kasurinen, J. A novel fluorescent fatty acid, 5-methyl-BDY-3-dodecanoic acid, is a potential probe in lipid transport studies by incorporating selectively to lipid classes of BHK cells. Biochem Biophys Res Commun 187, 1594-1601 (1992).

97 Jenkins, D. E. et al. Bioluminescent imaging (BLI) to improve and refine traditional murine models of tumor growth and metastasis. Clin Exp Metastasis 20, 733-744 (2003).

98 Berbee, J. F. et al. Brown fat activation reduces hypercholesterolaemia and protects from atherosclerosis development. Nature communications 6, 6356, doi:10.1038/ncomms7356 (2015).

99 Holstila, M. et al. Measurement of brown adipose tissue mass using a novel dual-echo magnetic resonance imaging approach: a validation study. Metabolism 62, 1189-1198, doi:10.1016/j.metabol.2013.03.002 (2013).

100 van Rooijen, B. D. et al. Imaging cold-activated brown adipose tissue using dynamic T2*weighted magnetic resonance imaging and 2-deoxy-2-[18F]fluoro-D-glucose positron emission tomography. Invest Radiol 48, 708-714, doi:10.1097/RLI.0b013e31829363b8 (2013).

101 Gorter, P. M. et al. Relation of epicardial and pericoronary fat to coronary atherosclerosis and coronary artery calcium in patients undergoing coronary angiography. Am J Cardiol 102, 380-385, doi:10.1016/j.amjcard.2008.04.002 (2008).

102 Gorter, P. M. et al. Quantification of epicardial and peri-coronary fat using cardiac computed tomography; reproducibility and relation with obesity and metabolic syndrome in patients suspected of coronary artery disease. Atherosclerosis 197, 896-903, doi:10.1016/j.atherosclerosis.2007.08.016 (2008).

103 Maurovich-Horvat, P. et al. Influence of pericoronary adipose tissue on local coronary atherosclerosis as assessed by a novel MDCT volumetric method. Atherosclerosis 219, 151157, doi:10.1016/j.atherosclerosis.2011.06.049 (2011).

104 Mahabadi, A. A. et al. Association of pericoronary fat volume with atherosclerotic plaque burden in the underlying coronary artery: a segment analysis. Atherosclerosis 211, 195-199, doi:10.1016/j.atherosclerosis.2010.02.013 (2010). 


\section{Chapter 2: \\ Brown adipose tissue and lipid metabolism imaging}

Andreas Paulus,

Wouter van Marken Lichtenbelt,

Felix M. Mottaghy,

Matthias Bauwens

published as:

Brown adipose tissue and lipid metabolism imaging. Methods 130, (2017) 


\section{Abstract}

Purpose: Brown adipose tissue (BAT) research has evolved from an underestimated to a fast developing field. Its assumed curing properties for the world wide epidemic obesity, and its related diseases, makes this tissue an interesting target for a broad amount of noninvasive molecular BAT tracers. Apart from $\left[{ }^{18} \mathrm{~F}\right] \mathrm{FDG}$ PET/CT there are several methods to detect BAT and measure its metabolism in a more appropriate way. Especially interesting is the measure of lipid turnover, because fatty acids comprise the main fuel for active BAT. This review outlines different imaging modalities suitable for BAT imaging with the overall goal to explain the yet not completely understood mechanism in BAT and its quantitative contribution to whole body lipid and energy metabolism.

Methods: Publications with focus on brown adipose tissue and lipid metabolism imaging are analyzed, different imaging approaches are introduced and promising BAT tracers are presented.

Results: Radiolabelled and fluorescent fatty acids, labelled particles, $\left[{ }^{3} \mathrm{H}\right]$ Triolein and ADIFAB staining can give information about the inflow and therefore about the utilization of fatty acids which represents the activation state in vivo/in vitro. Non-invasive scanning with CT or MRI is a useful addition to those techniques.

Conclusion: Lipid metabolism imaging offers the opportunity to visualize and quantify yet undiscovered aspects of BAT metabolic activities and is key to completely clarify its role in whole body lipid and energy metabolism. 


\section{Introduction}

\section{Background:}

The function and presence of BAT in adults was neglected until two decades ago. Now the investigation of BAT using molecular imaging has matured to one of the most interesting and fast developing research topics in endocrine research. Because obesity - and its related metabolic syndrome - is reaching epidemic proportions in the western world ${ }^{1}$ and may even become a more severe problem in the near future for the worldwide population, more attention is drawn to adipose tissue metabolism. A turning point was the discovery that WAT, apart from storing energy (fat), is able to secret leptin, an important hormone controlling the energy balance ${ }^{2}$. Other substances ${ }^{3}$ (autocrine and endocrine) released by WAT have been found and by that the consideration of the impact of adipose tissue on whole body metabolism rose continuously. In retrospective PET studies with $\left[{ }^{18} \mathrm{~F}\right] \mathrm{FDG}$, it could be shown that besides WAT, another form of adipose tissue exists in adult humans ${ }^{4-6}$. In these studies, symmetrical accumulations of $\left[{ }^{18} \mathrm{~F}\right] \mathrm{FDG}$ appeared in the supraclavicular region, which were originally thought to be attributed to uptake in cervical muscles. Later, scans with PET/CT indicated that these "artifacts" correlate with Hounsfield units of fat ${ }^{6}$. By these $\left[{ }^{18}\right.$ F]FDG studies it could be proven that BAT is functionally present in adults and is metabolically active. BAT, named after its darker color resulting from higher mitochondria expression within the cell and increased blood circulation ${ }^{7}$, was previously thought to be absent in adult humans and only be present in newborns to maintain their body temperature ${ }^{8}$. The results of the PET scans indicate a chance of observing BAT in 5 - $8 \%$ of standard clinical routine PET scans $^{4,9}$ and a total contribution to body mass of $0,05-0,01 \%{ }^{10}$. These findings could be confirmed later by dedicated cold exposure studies where a direct correlation between cold exposure and BAT metabolic activity, measured through $\left[{ }^{18} \mathrm{~F}\right] \mathrm{FDG}$ uptake, was reported ${ }^{11-13}$. Assuming a fixed relative contribution of glucose and fatty acids and that mainly fatty acids and glucose contribute to energy expenditure ${ }^{12,14}$, an increase in metabolic activity of BAT would result in an increase of total body energy expenditure of $2-28 \%{ }^{15}$. Therefore activation 
of BAT with unchanged food uptake, may lead to significant weight loss, offering an additional treatment option to obese patients. Another field of application would be in patients with pheochromocytoma. It was found that cathecholamine secreting tumors activate BAT and lead to an increase in metabolic activity characterized by FA and glucose uptake ${ }^{16-18}$. In these studies BAT activity was inversely correlated to body mass index and in general patients with cancer cachexia are often suffering from body weight loss and depletion of muscular and adipose tissue ${ }^{19}$.

However, in order to actually calculate the metabolic activity of BAT in humans, in addition to $\left[{ }^{18} \mathrm{~F}\right] \mathrm{FDG} \mathrm{PET} / \mathrm{CT}$, other tracers and techniques are needed. Through the upcoming interest in this tissue, several new activation, targeting and imaging strategies have been developed to visualize BAT's functions. $\left[{ }^{18} \mathrm{~F}\right] \mathrm{FDG}$ has set the stage; several attributions of BAT have been defined. Non-invasive visualization of lipid metabolism could give more insight since lipid turnover is one of the major features of BAT. This review summarizes early as well as the newest inventions of lipid metabolism imaging linked to BAT and describes how visualization of lipid fate and adipose tissue activity has evolved.

\section{Activation of brown adipose tissue and fatty acid metabolism:}

First observations of BAT in humans were performed with $\left[{ }^{18} \mathrm{~F}\right] \mathrm{FDG}{ }^{4-6}$ which visualizes metabolic active tissue in terms of glucose uptake. It was observed that through cold exposure the chance of visualizing BAT increased in animals and lean subjects ${ }^{11-13}$. Besides, it was shown that BAT is activated through binding to $\beta 3$-adrenoeceptor ${ }^{20,21}$. Recently it was observed for the first time that BAT takes up an increased amount of glucose in obese humans after cold acclimation. This led to the conclusion that significant amounts of BAT can be recruited during repeated cold exposure ${ }^{22}$. Glucose is mainly taken up by protein transporters of the GLUT family, mainly the fat muscle specific isoform GLUT4 ${ }^{23,24}$. Glucose is processed in different pathways e.g. in citric acid cycle ${ }^{25}$ or it is conversed to FA 26,27. Nevertheless LCFA are the main "fuel" for BAT. Tracers based on fatty acids, quantify the metabolic activity of BAT in a better way than glucose does. 
Through the norepinephrine activation process FA stored as TG in lipid droplets are consumed in the mitochondria to produce heat and new FA are taken up ${ }^{28,29}$. This identifies FA as the main metabolized substance in BAT and makes them and other compounds targeting lipid metabolism a powerful tool to visualize BAT and its functions within the body. Usually mitochondria oxidize fatty acids and ATP is produced to store the nascent energy but BAT mitochondria contain the BAT specific UCP1 which gives them the ability to uncouple the oxidation process and to produce heat instead of ATP ${ }^{30-33}$. This process is responsible for nonshivering thermogenesis ${ }^{15,34}$. Fedorenko et al. showed that LCFA (> 12 carbon atoms ${ }^{35}$ ) are essential for the uncoupling process as they work as a carrier for $\mathrm{H}^{+}$through the UCP1 and that LCFA are also produced within the inner mitochondria membrane by PLA2 ${ }^{36}$. In BAT cells UCP1 is inhibited by purine nucleotides, mainly ATP. The UCP1 channel is blocked by the nucleotides from the cytosolic side ${ }^{37-40}$. It was shown that LCFA can overcome the blocking of UCP1 and support the activation of the uncoupling process 15,36,41. Activation through LCFA also confirms the observation that lipolysis activates thermogenesis in the same order of magnitude than norepinephrine does ${ }^{42,43}$.

As quoted before, stored TGs in BAT can be utilized for combustion or FA can be taken up after lipolysis by BAT. Uptake of FA from external sources by a brown adipocyte is realized by protein mediated transport ${ }^{44}$, nevertheless the exact mechanism of FA uptake is unclear. FA are transported in TRLs (Triglyceride-rich lipoproteins) by the blood. BAT uptake of FA via internalization of these particles, via direct FA uptake after lipolysis related breakup of TRLs or a combination of both is possible. Khedoe et al. equipped TRLs of different size with $\left[{ }^{3} \mathrm{H}\right]$ oleate and $\left[{ }^{14} \mathrm{C}\right]$ cholesteryl oleate ${ }^{45}$. At room temperature a lipolysis supported uptake could be observed as cholesteryl oleate stays within the particle core due to its hydrophobicity and most taken up activity in BAT resulted from $\left[{ }^{3} \mathrm{H}\right]$ oleate. Left over remnant particles, containing a higher ratio of $\left[{ }^{14} \mathrm{C}\right]$ cholesteryl oleate are cleared by the liver which explains why a much higher carbon-14-activity compared to tritium-activity can be observed in the liver. Also cold exposure or thermoneutrality did not promote internalization of TRLs in 
BAT cells in an important amount but of course changed the amount of FA taken up by BAT 45

In contrast to these experiments is the finding of Bartelt et al. They labelled TRLs with $\left[{ }^{3} \mathrm{H}\right]-$ oleate and hydrophobic $\left[{ }^{59} \mathrm{Fe}\right] \mathrm{SPIO}$ nanocrystals ${ }^{46}$. As a result of lipolysis $\left[{ }^{3} \mathrm{H}\right]$ oleate can enter the cell whereas $\left[{ }^{59} \mathrm{Fe}\right] \mathrm{SPIO}$ nanocrystals stay inside of the TRL's. In cold exposed mice a significant faster clearance of $\left[{ }^{3} \mathrm{H}\right]$ oleate and $\left[{ }^{59} \mathrm{Fe}\right] \mathrm{SPIO}$ and a tenfold higher uptake of both imaging agents in BAT is reported. Through intravital microscopy a rapid attachment to the endothelium, followed by an internalization of the TRLs could be observed ${ }^{46}$. Bartelt et al. explain their observations that through lipolysis products the endothelial barrier function is decreased and TRLs can enter the cell ${ }^{47}$.

The discrepancy between both experiments may be explained by different imaging agents used and therefore different uptake mechanisms are needed to explain the results. Nevertheless, the dominant uptake mechanism (lipolysis assisted uptake of FA or internalization of TRLs) is not determined at the moment and needs to be established by other imaging approaches and experiments.

In terms of lipolysis, LPL is the first of multiple proteins involved in the process of FA uptake into BAT ${ }^{29,48,49}$. Other important proteins related to FA uptake of BAT are fatty acid translocase (FAT/CD36) ${ }^{50}$, fatty acid transport proteins (FATPs) ${ }^{51}$ and fatty acyl-CoA synthetases (ACSL) ${ }^{52}$. The common way of FA uptake is described as in figure 1, according to ${ }^{48}$ 


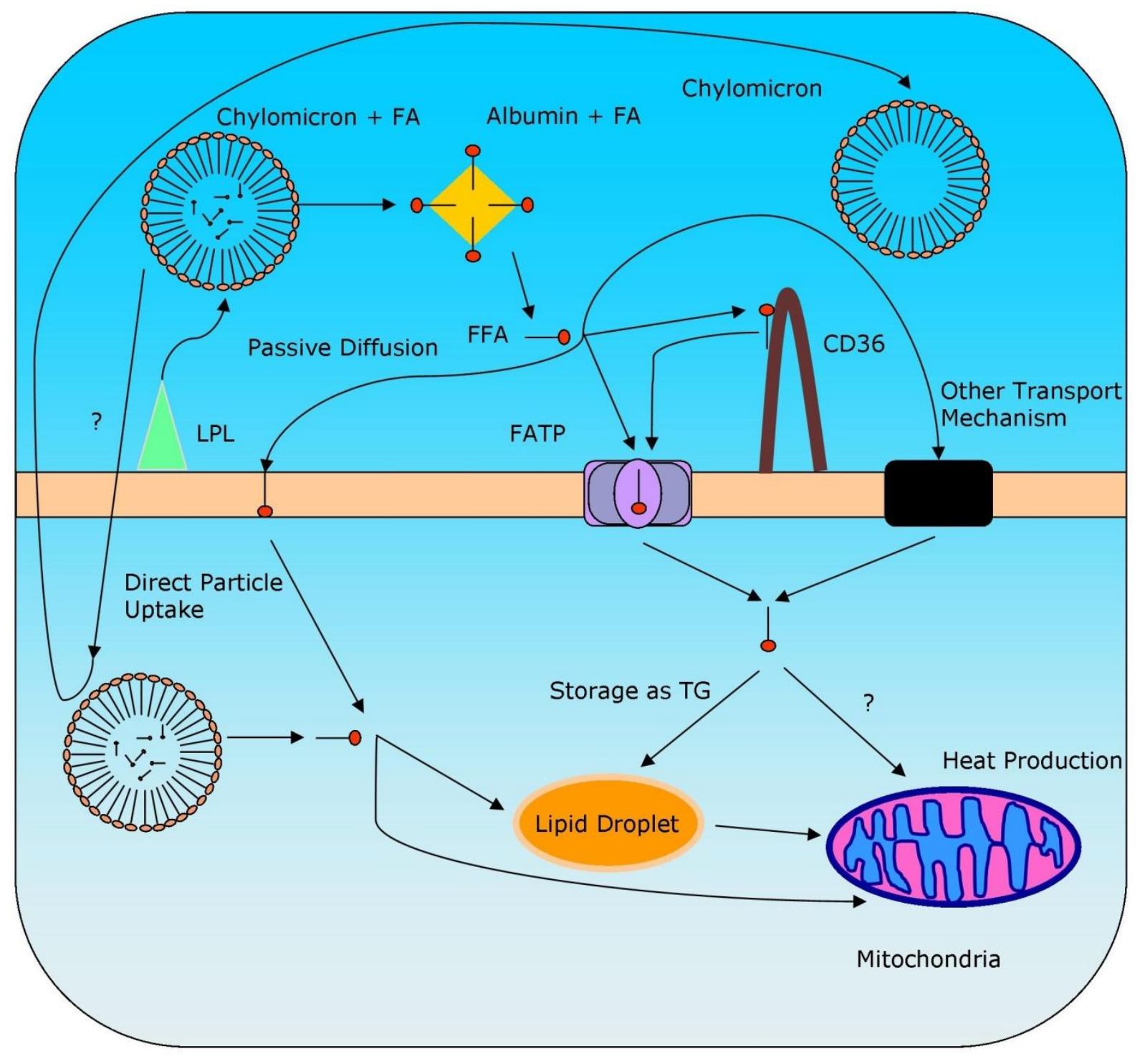

Figure 1: TRLs are hydrolyzed by LPL and FA can bind to albumin. After dissociation from albumin, FA bind to membrane proteins such as CD36 or directly to FATP. A direct diffusion through the membrane is possible but dependent on free FA concentrations and FA already taken up by the cells ${ }^{53}$. FA from CD36 are handed to FATP and are transported through the membrane where they are either processed as FA or activated and coupled to coenzyme A (CoA) by ACSL. Free FA can then be stored in lipid droplets as TG after esterification or directly processed in the mitochondria.

Different studies have identified LPL and CD36 as indispensable factors for FA uptake and a loss of one of these proteins results in an impaired adipose metabolism leading to hypertriglyceridemia, increased glucose uptake and hypothermia during fasting and cold exposure ${ }^{54,55}$. 
LCFA can also be produced through lipogenesis within the cell by fatty acid synthase up to a carbon chain length of 16 carbon atoms ${ }^{29}$. Elongation to very long chain fatty acids is done by very long chain fatty acids enzymes (ELOVL) where ELOVL3 was found to be overexpressed in cold exposed BAT and mice lacking of ELOVL3 where only able to survive cold by shivering thermogenesis ${ }^{56}$. These findings indicate lipogenesis as an essential feature to ensure the TG amount necessary during cold exposure.

Its high amount of mitochondria and multilocular lipid droplets make BAT appear more like muscle than adipose tissue ${ }^{15}$.

\section{White adipose tissue, fat storage and endocrine function}

The main function of WAT is fat storage and fatty acid secretion. When energy intake is higher than consumption, fatty acids are stored in WAT. In times of fasting or cold exposure, WAT is activated to release its fuel (fatty acids) by stimulation of lipolysis through the sympathetic nervous system ${ }^{57}$. Through the 90 's of the last century the interest in WAT changed from a tissue only responsible for energy storage to a tissue that also takes part in body metabolism. Its physiological role has changed through the discovery of the first protein secreted from WAT: leptin ${ }^{2}$. More and more proteins have been discovered that are responsible for different functions in the body ${ }^{3,58,59}$. Leptin e.g. is the critical hormone in energy balance and is produced principally by white fat, giving the tissue an endocrine function. Other proteins are: angiotensinogen, adipsin, acylation-stimulating protein, adiponectin, retinol-binding protein, tumour necrosis factor $\alpha$, interleukin 6 , plasminogen activator inhibitor-1 and tissue factor. These proteins can work as inflammatory cytokines, some influence the lipid metabolism and others are involved in vascular haemostasis ${ }^{60}$.

\section{Beige/brite adipose tissue:}

A special type of adipose tissue is the so called beige (or brite) adipose tissue. Characteristics of the white adipocyte are a large lipid droplet and a small amount of mitochondria. BAT has multiple small lipid droplets, its transcriptional profile is similar to 
skeletal muscle cells ${ }^{61}$ and BAT has a large amount of mitochondria which overexpress UCP1. Beige adipocytes can differentiate in vivo from WAT or WAT precursor cells through activation processes (e.g. $\beta 3$-adrenergic receptor agonists) and then contain multiple lipid droplets and express UCP1 within their mitochondria, which potentially makes them an important player in increasing energy expenditure and fighting against obesity ${ }^{62}$. This clusters of beige cells appear e.g. through prolonged cold exposure in WAT depots close to noradrenergic nerve fibers which trigger the beige adipocyte recruitment ${ }^{63}$. Typically norepinephrine is released from the sympathetic nerves and activates adipocyte (brown and beige) thermogenesis. This process normally induces UCP1 expression through phosphorilation of PPARy coactivator 1alpha and other activators ${ }^{64,65}$. Sidossis et al. investigated the hypermetabolism in patients with burn injuries and found increased circulating levels of epinephrine and norepinephrine as well as elevated expression of UCP1 in the according WAT-areas as a result of adrenergic stress ${ }^{66}$. This proves that epinephrine and norepinephrine are responsible for browning of WAT which makes this tissue able to participate in the process of non-shivering thermogenesis. Alternatively, M2 macrophages are recruited to subcutaneous WAT during cold exposure and secret catecholamines to activate WAT browning ${ }^{67,68}$. Irisin, an exercise-induced myokine, can also induce browning of WAT ${ }^{69,70}$. This paradox finding could be shown in vitro and in vivo ${ }^{69}$ and it has been hypothesized that this mechanism evolved from shivering muscle contraction to support nonshivering thermogenesis by an increase in BAT volume and has thereby a therapeutic potential to treat obesity ${ }^{69,70}$. Another important player in WAT browning is cancer cachexia. Through tumor-derived parathyroid hormone-related protein (PTHrP) WAT browning is promoted and more energy is needed in a Lewis lung cancer model ${ }^{71}$. Deactivation of PTHrP inhibits WAT browning and prohibits energy wastage ${ }^{71}$. Besides of the listed factors for browning there are also environmental factors, endocrine hormones and transcriptional mediators which can cause browning of WAT ${ }^{63}$. Beige adipose tissue cells are only temporarily available for thermogenesis as they develop back to WAT-cells after activation. 
By other studies it could be confirmed that beige adipocytes almost reached UCP1 levels of BAT and that beige fat mitochondria are thermogenically active ${ }^{61}$.

\section{Form of Fatty acids (free fatty acid/ Triglyceride/ LDL-particle)}

The main suppliers of FAs taken up by BAT are TRLs (i.e. chylomicrons or very-low-densitylipoprotein-particles) circulating in the blood ${ }^{72}$. After incorporation into adipocytes, FAs are stored as TGs in lipid droplets. Lately LPL-activity was found to be important for whole body TRL clearance through BAT and WAT ${ }^{46,73}$. Savonen et al. recently found a correlation between LPL distribution and type of tissue where the FA are taken up and identified LPL as a mandatory binding side for LDL particles to be processed (lipolysis with exposure of FA) ${ }^{74}$. 


\section{Fatty acid imaging}

As already mentioned, fatty acids are the main metabolized substance in BAT. For this reason they are used as tracers to visualize adipose tissue and its metabolism.

a)<smiles>CCCC([18F])CCCCCCCSCCCCC(=O)O</smiles>

c)<smiles>CC(CCCCCCCCCCCCc1ccc([125I])cc1)CC(=O)O</smiles>

b)<smiles>CCCCCCCCCCCCCCCC(=O)O</smiles>

d)

Figure 2: common used fatty acids for lipid metabolsim imaging. a) $14(\mathrm{R}, \mathrm{S})-\left[{ }^{18} \mathrm{~F}\right]$ fluoro-6-thia-heptadecanoic acid $\left(\left[{ }^{18} \mathrm{~F}\right] \mathrm{FTHA}\right)$, b) $\left[{ }^{11} \mathrm{C}\right]$ hexadecanoic acid $\left(\left[{ }^{11} \mathrm{C}\right]\right.$ palmitate), c) 15-(4-[23] $]$ iodophenyl)-3-methyl-pentadecanoic acid ([ ${ }^{123}$ ] BBMIPP), d) 4,4-Difluoro-5,7-Dimethyl-4-Bora-3a,4a-Diaza-s-Indacene-3-Hexadecanoic Acid (BODIPY- C $_{16}$ )

\section{$\left[{ }^{18}\right.$ F $]$ FTHA}

FTHA (Fig 2 a)) was developed as a myocardial imaging agent because a high amount of LCFA is processed in the tricarboxylic acid cycle. It can be labelled by fluoride-18 through isotope exchange which makes this compound an easily available PET imaging agent. It is $\beta$ oxidized in the mitochondria and is bound irreversible to mitochondria proteins once the sulphur group is free ${ }^{75}$. Maximal uptake of $\left[{ }^{18} \mathrm{~F}\right] \mathrm{FTHA}$ is similar to $\left[{ }^{11} \mathrm{C}\right]$ palmitate showing that neither the sulphur atom at the sixth position nor the introduction of fluorine-18 has influence on the uptake kinetics ${ }^{76,77}$. 13F3THA analog showed significant lower uptake and faster washout, beta-oxidation is completely blocked by the sulfur atom at the odd position of 13F3THA ${ }^{78,79}$. Radioactivity taken up by BAT was specific to only the even-substituted thia$\left[{ }^{18} \mathrm{~F}\right] \mathrm{FTHA}$ and transport and metabolism steps are hindered for 13F3THA because the carboxyl group and the sulphur are located very close to each other. The fatty acid is internalized through assistance of several binding proteins in the endothelial, interstitial, and 
intracellular spaces ${ }^{76}$. A similar mechanism for BAT as for WAT can be assumed which makes this compound suitable for BAT imaging. In first attempts of imaging BAT with $\left[{ }^{18} \mathrm{~F}\right] \mathrm{FTHA}$ Ouellet ${ }^{80}$ could show increased FA uptake in combination with an elevated $\left[{ }^{11} \mathrm{C}\right]$ acetate uptake, as an oxidative tissue marker and therefore metabolism indicator, in cold exposed humans. Additionally a higher $\left[{ }^{18} \mathrm{~F}\right] \mathrm{FDG}$ uptake was reported indicating a higher energy turnover as a result of a higher metabolic activity during cold exposure ${ }^{80}$. CT gave information about the lipid density, which indicates the amount of intracellular TGs, and a utilization of these stored TG identifies them as the main fuel during cold exposure. These observations are in agreement with findings in other animal models ${ }^{80,81}$.

\section{$\left[{ }^{11} \mathrm{C}\right]$ palmitate}

Another important PET tracer is $\left[{ }^{11} \mathrm{C}\right]$ palmitate (Fig $\left.2 \mathrm{~b}\right)$ ). Its short half life of 20 min. makes an in-house cyclotron mandatory which restricts its use significantly. Apart from that restriction palmitate would be the optimal choice with respect to binding affinity as no big bulky chelatormolecule needs to be coupled for imaging purposes. It behaves like any other natural non-synthesized fatty acid, justifying why it is always compared to modified molecules as a gold standard ${ }^{82} \cdot\left[{ }^{11} \mathrm{C}\right]$ palmitate has been used as a myocardial imaging agent in clinical examinations ${ }^{83-85}$ but as adipose tissue imaging becomes more and more important it is also used as a fat imaging agent in clinical experiments ${ }^{86}$. In comparison to [ ${ }^{123}$ I]BMIPP (see below) and FTHA this FA is fully metabolized and metabolism products including $\left[{ }^{11} \mathrm{C}\right] \mathrm{CO}_{2}$ are secreted by adipocytes which is decreasing the image quality.

\section{$\left[{ }^{123}\right.$ ] BMIPP}

Like $\left[{ }^{18} \mathrm{~F}\right] \mathrm{FTHA},\left[{ }^{123}\right] \mathrm{BMIPP}(\mathrm{Fig} 2 \mathrm{c})$ ) started as a myocardial imaging agent ${ }^{87}$. It is labelled with iodine-123 through an isotopic exchange reaction to produce a SPECT-imaging agent. Commercial availability of BMIPP (up to 2012) and iodine-123 as well as the easy to perform exchange reaction ${ }^{88}$ made this compound favourable for adipose tissue imaging. A dependence on the isomeric confirmation was shown by Lin et al. ${ }^{87}$ and the $\left[{ }^{123} \mathrm{I}\right]-3(\mathrm{R})$ - 
BMIPP version showed uptake suitable for clinical trials. This implies that internalization is not hindered by the bulky benzol ring at the end of the FA. In comparison with palmitic acid under fasting conditions, $\left[{ }^{123}\right.$ I]BMIPP had lower uptake into hepatocytes but similar characteristic changes were observed over time ${ }^{82}$. So far $\left[{ }^{123}\right.$ I]BMIPP has only been used by one group to image BAT and its protein contribution in FA uptake ${ }^{54,89}$.

\section{Other radiolabelled fatty acids}

As already mentioned, radiolabelled fatty acids have been often used as myocardial imaging agents in the past. The already described fatty acids have been shown good characteristics in terms of stability, binding affinity, pharmacokinetics etc. but there have been others developed which will be mentioned in the following paragraph.

$\left[{ }^{123} \mid\right]$ iodohexadecanoic acid $\left(\left[{ }^{123} \mathrm{I}\right] \mathrm{HXX}\right)$ and $\left[{ }^{123} \mid\right]$ iodoheptadecanoic acid $\left(\left[{ }^{123} \mathrm{I}\right] \mathrm{HHDA}\right)$ have been developed as myocardial perfusion agents ${ }^{90,91}$. Clearance kinetics for both agents were compared with $\left[{ }^{11} \mathrm{C}\right]$ palimtate and a similar clearance was found for the fast clearance components. The slow clearance components differed in that way that the half time for IHXA and IHDA was only approximately one fourth of that of $\left[{ }^{11} \mathrm{C}\right]$ palimtate ${ }^{90,92}$. These two components represent $\beta$-oxidation and fatty acid storage in lipid pools. This fast elimination half time makes this compound unsuitable for SPECT as decreased image quality can be expected. In addition a deiodination process could be observed which requires special corrections to differentiate between myocardial and blood pool activity ${ }^{93}$.

15-(p-[ $\left.{ }^{123} \mid\right]$ iodophenyl)-pentadecanoic acid ([ ${ }^{123}$ I]IPPA) showed a faster myocardial clearance compared to $\left[{ }^{123}\right.$ I]BMIPP making it unfavorable for SPECT as this results in image distortions and loss of quantitative image accuracy ${ }^{93}$. This problem is caused mainly because straight chain fatty acids are faster metabolized and cleared via $\beta$-oxidation. The methy-group at the $\beta$-position of BMIPP slows down the oxidation process and improves clearance and image accuracy in that way ${ }^{94}$. 


\section{Boron-dipyrromethene (Bodipy)}

A different imaging approach is fluorescent imaging with Bodipy. Because of its hydrophobic properties, Bodipy dyes can be used for staining of lipids, membranes and other lipophilic substance classes. High fluorescence quantum yields can be achieved due to its wide spread $\pi$-electron system. Fluorescence of this molecule is achieved through excitation at $503 \mathrm{~nm}$ and emission at $512 \mathrm{~nm}$. The extension of the crude dye determines its field of usage for imaging purposes. There are many approaches from tumor imaging to adipose tissue detection with a fatty acid modified Bodipy. It has been proven that Bodipy C-16 (Fig 2 d)) binds specifically to fatty acid binding proteins ${ }^{95}$ with a similar affinity as oleic acid, is incorporated into lipid droplets in hepatocytes ${ }^{96}$, can be quantified by fluorescent cell scanners or plate readers ${ }^{97}$ and can be followed downstream in metabolic processes after uptake ${ }^{98}$. In a first try we were able to visualize WAT and BAT with Bodipy-C16 specifically in vitro with a $2 \mu \mathrm{M}$ Bodipy C-16 solution (unpublished results), like already reported for hepatocytes ${ }^{96}$. Uptake could be identified as specific uptake as the lipid droplets were filled by Bodipy C-16 and no uptake in the cell nucleus can be observed. Incorporation of the fatty acid works as already described through protein mediation and the Bodipy dye does not hinder the uptake qualitatively. As penetration depth of excitation and emitted light cannot overcome the tissue barrier for BAT imaging, fluorescence imaging is restricted to in vitro applications in this approach. With its high spatial resolution it is a powerful tool to image on a cellular level ${ }^{95,97}$.

\section{Luciferin}

By imaging adipose tissue with bioluminescence, problems of PET and SPECT imaging, like short half life and un-physiological uptake can be overcome ${ }^{99}$. To a non-esterified fatty acid probe a luciferine derivative is coupled via a disulfide linker. This disulfide bridge is stable outside of the cells ${ }^{100}$ and through reduction by glutathione within the cell a thiol is produced which undergoes cyclization to release free luciferine ${ }^{101}$. Free luciferine is than converted to oxyluciferine and a photon of light by luciferase ${ }^{102}$. Henkin et al. investigated the imaging 
abilities of this compound and reported specific uptake as it could be blocked by oleate in vitro. Additionally luciferine uptake from micelles containing FA-luciferine could be observed and BAT specific uptake in vivo could be proven as uptake could be increased through BAT stimulation ${ }^{101}$. 


\section{Particle Imaging}

To image lipid metabolism there are also other pathways available apart from imaging FA. Some interesting approaches with indirect measures for FA uptake have been reported and will be described in this section

\section{Fluorescence labelled nanocrystals}

FA are mostly transported in TRLs through the body. At the moment there are two assumptions about the delivery of FA through TRLs. FA can be taken up by adipocytes after TRLs are lipolyzed outside of the cell ${ }^{45}$ or TRLs are internalized before they are lipolyzed ${ }^{46}$. To investigate this process Bartelt et al. labelled TRLs with hydrophobic fluorescent nanocrystals (QD-TRL) ${ }^{46}$. Quantum dots (QD) have a broad excitation and a narrow emission range and are therefore best suited for fluorescence imaging ${ }^{103}$. With QD-TRLs an internalization of lipoproteins due to an increase in permeability of the endothelial barrier function could be observed ${ }^{46}$. Other applications of this imaging agent can be thought of for quantitative and qualitative lipoprotein incorporation.

\section{Functional MRI}

Similar to QD-TRLs, Bartelt et al. labelled lipoproteins with hydrophobic superparamagnetic $\left[{ }^{59} \mathrm{Fe}\right]$ oxide. The intention is the same as for QD-TGLs. The hydrophobic iron nanocrystals stay inside of the lipoprotein and indicate if the particle is incorporated or not. In addition the particle is filled with $\left[{ }^{3} \mathrm{H}\right]$ oleate to control whether FA are taken up. Bartelt et al. observed a faster clearance for the FA as well as for the nanocrystals after cold exposure indicating a contribution of BAT. Total oleate and Fe-oxide concentrations in cold activated mice of BAT and liver were comparable and omitting cold exposure lead to a decrease in BAT uptake for both. These results and the fact that $\left[{ }^{59} \mathrm{Fe}\right]$ oxide concentrations were still increased one week after injection indicate an internalization of the whole lipoprotein particle ${ }^{46}$. 
In contrast to these observations, the study of Khedoe et al. is indicating an extracellular lipolysis followed by protein mediated uptake of FA ${ }^{45}$. 


\section{Other imaging techniques}

\section{MRI}

With the possibility to image with a very high resolution and no radiation dose for the patient, $\mathrm{MRI}$ is an important player in adipose tissue imaging. By measuring the lipid content in interscapular BAT (BAT), Grimpo et al. investigated the response to cold exposure and noradrenaline stimulation for wild type and UCP1 knock-out mice. Lipid content was the same for both groups under all temperature conditions with less FA stored in lipid droplets after cold exposure. A faster noradrenaline response could be observed in wild type mice ${ }^{104}$. Additionally in the study of Holstila et al. MRI was identified as a more adequate method to identify and quantify BAT, independently of its activation state, compared to PET/CT with $\left[{ }^{18} \mathrm{~F}\right]$ FDG. BAT masses calculated with PET/CT were significant smaller than the masses obtained through dissection. MRI provided more accurate information even if a small overestimation has been observed. Advantageous is the independence of the activation state as this method is measuring the water/lipid content and compares it with previous records. For the same reason no cold exposure is necessary to activate BAT. A successful human pilot study was performed too by this group ${ }^{105}$. Additionally first studies have been done in adult humans with $\left[{ }^{18} \mathrm{~F}\right]$ FDG-PET/CT as a reference standard by van Rooijen et al. ${ }^{106}$. In comparison to the mentioned studies in animal models ${ }^{107-110}$, they could not discern active BAT on the basis of tissue fat content. Dynamic BAT activation could be identified by $\mathrm{T} 2^{*}$ weighted MRI during cold stimulation. Eventhough PET provides images of active BAT with a higher contrast, $\mathrm{MRI}$ is capable in gaining additional information such as: temporal and quantitative measurements of tissue fat content, changes in blood flow, volume, and oxygenation of active BAT ${ }^{106}$.

\section{CT}

A standalone computed tomography to identify BAT seems in terms of a lower radiation dose compared to PET/CT a good choice but without PET it is almost impossible to identify BAT 
by the difference in Hounsfield units and gets even more complicated when WAT is located next to it. So most of the recent studies are PET/CT related and some indicate PET/CT with $\left[{ }^{18} \mathrm{~F}\right] \mathrm{FDG}$ not as the optimal choice ${ }^{111}$. Another problem is the difference in interpreting the Hounsfield units as adipocytes. Gortel et al. used a threshold of -200 to -30 , MaurovicHorvat et al. used a threshold from -149 to -30 and Mahabadi et al a threshold of -195 to -45 112-115. By having this differences an under or overestimation is easily possible and does not really describe the amount of BAT. Because of the listed reasons a CT on its own is not capable in identifying BAT and also a PET/CT with $\left[{ }^{18} \mathrm{~F}\right] \mathrm{FDG}$ is not the best choice anymore. There are several better compounds which target BAT without activation and also MRI seems to have more advantages and a more accurate way to identify adipocytes. 


\section{Ex vivo methods}

\section{$\left[{ }^{3} \mathrm{H}\right]$ Triolein}

Tritium does not have the optimal properties for non-invasive imaging. Its really soft radiation makes it impossible to detect it from outside of the body because the emitted electrons are stopped after a few micrometers in tissue. Its field of application is supported by its favourable biodistribution and plasma extraction. By that method the uptake at certain time points can be tested by the fraction of Triolein still present in the blood ${ }^{46,77}$. An impact of cold exposure or BAT activation through noradrenaline can be observed but not a clear quantification of adipocyte uptake can be achieved as lipids can be taken up by other tissues or cleared from the blood.

$\left[{ }^{3} \mathrm{H}\right]$ triolein is also used in autoradiography studies. Stein et al. investigated metabolism steps of starved rat fat cells and found that after exposure with $\left[{ }^{3} \mathrm{H}\right]$ triolein containing blood, $9-17 \%$ of the esterified fatty acids were in the form of diglycerides, less than $1 \%$ were monoglycerides and the rest were TG. They assumed therefore the esterification of diglycerides to TG as the rate limiting step in the TG synthesis in adipose tissue. Four fifth of the signals observed were found within the lipid droplets of the cell identifying them as the primary destination for newly taken up FA ${ }^{116}$.

\section{ADIFAB staining}

ADIFAB is a stain for unbound fatty acids and is only applicable in in vitro work. Acrylodan labelled rat intestinal fatty acid binding protein (ADIFAB) is fluorescent if it is bound to a fatty acid. Kampf et al. ${ }^{117}$ investigated the change in cytosolic unbound FA in response to a change in extracellular unbound FA. They discovered an influx concentration dependence of membrane carrier proteins which could be saturated and a strong influence of translocation for the fatty acid uptake ratio ${ }^{117}$. Other experiments have been done to examine the fatty acid uptake mechanism in vitro with ADIFAB and identified flip-flop as the rate limiting step for oleate transport through the lipid bilayer membrane ${ }^{118}$. 


\section{Conclusion}

Lipid metabolism imaging has a broad field of application. It is generally accepted in terms of myocardial imaging, hepatic imaging etc. Our focus was to outline its broad function in fields within the whole body and specifically for the use to visualize adipose tissue and its metabolism. Its fast developing field within the niche of adipose tissue imaging draws attention to new imaging approaches and agents and helps to understand more and more this, for a long term, underestimated tissue. We expect radiolabelled fatty acids to be the most promising agents in clinical research to unravel adipose tissue processes in BAT for the next years but also fluorescent imaging, with its ability to image on subcellular level, and MRI should not be underestimated and will contribute to the exploration of adipose tissue and lipid metabolism. 


\section{References}

1 Rippe, J. M., Crossley, S. \& Ringer, R. Obesity as a chronic disease: modern medical and lifestyle management. J Am Diet Assoc 98, S9-15 (1998).

2 Zhang, Y. et al. Positional cloning of the mouse obese gene and its human homologue. Nature 372, 425-432, doi:10.1038/372425a0 (1994).

3 Ahima, R. S. \& Flier, J. S. Adipose tissue as an endocrine organ. Trends Endocrinol Metab 11, 327-332 (2000).

4 Lee, P., Greenfield, J. R., Ho, K. K. \& Fulham, M. J. A critical appraisal of the prevalence and metabolic significance of brown adipose tissue in adult humans. Am J Physiol Endocrinol Metab 299, E601-606, doi:ajpendo.00298.2010 [pii] 10.1152/ajpendo.00298.2010 (2010).

Cohade, C., Mourtzikos, K. A. \& Wahl, R. L. "USA-Fat": prevalence is related to ambient outdoor temperature-evaluation with 18F-FDG PET/CT. J Nucl Med 44, 1267-1270 (2003).

Hany, T. F. et al. Brown adipose tissue: a factor to consider in symmetrical tracer uptake in the neck and upper chest region. Eur J Nucl Med Mol Imaging 29, 1393-1398, doi:10.1007/s00259-002-0902-6 (2002).

Anderson, C. M. et al. Dependence of brown adipose tissue function on CD36-mediated coenzyme Q uptake. Cell Rep 10, 505-515, doi:10.1016/j.celrep.2014.12.048 (2015).

Heaton, J. M. The distribution of brown adipose tissue in the human. J Anat 112, 35-39 (1972).

Cypess, A. M. et al. Identification and importance of brown adipose tissue in adult humans. $N$ Engl J Med 360, 1509-1517, doi:10.1056/NEJMoa0810780 (2009).

10 Enerbäck, S. Human brown adipose tissue. Cell Metab 11, 248-252, doi:10.1016/j.cmet.2010.03.008 (2010).

11 van Marken Lichtenbelt, W. D. et al. Cold-activated brown adipose tissue in healthy men. $N$ Engl J Med 360, 1500-1508, doi:10.1056/NEJMoa0808718 (2009).

Virtanen, K. A. et al. Functional brown adipose tissue in healthy adults. N Engl J Med 360, 1518-1525, doi:10.1056/NEJMoa0808949 (2009).

Saito, M. et al. High incidence of metabolically active brown adipose tissue in healthy adult humans: effects of cold exposure and adiposity. Diabetes 58, 1526-1531, doi:10.2337/db090530 (2009).

van der Lans, A. A. J. J. et al. Cold acclimation recruits human brown fat and increases nonshivering thermogenesis. J Clin Invest 123, 3395-3403, doi:10.1172/jci68993 (2013).

Cannon, B. \& Nedergaard, J. Brown adipose tissue: function and physiological significance. Physiol Rev 84, 277-359, doi:10.1152/physrev.00015.2003 (2004).

Puar, T. et al. Genotype-Dependent Brown Adipose Tissue Activation in Patients With Pheochromocytoma and Paraganglioma. The Journal of Clinical Endocrinology \& Metabolism 101, 224-232, doi:10.1210/jc.2015-3205 (2016). Joshi, P. V. \& Lele, V. R. Unexpected visitor on FDG PET/CT--brown adipose tissue (BAT) in mesentery in a case of retroperitoneal extra-adrenal pheochromocytoma: is the BAT activation secondary to catecholamine-secreting pheochromocytoma? Clinical nuclear medicine 37, e119-120, doi:10.1097/RLU.0b013e31824437e7 (2012).

Wang, Q. et al. Brown adipose tissue in humans is activated by elevated plasma catecholamines levels and is inversely related to central obesity. PLoS One 6, e21006, doi:10.1371/journal.pone.0021006 (2011).

The Lancet. Oncology 12, 489-495, doi:10.1016/s1470-2045(10)70218-7 (2011).

20 Bachman, E. S. et al. betaAR signaling required for diet-induced thermogenesis and obesity resistance. Science 297, 843-845, doi:10.1126/science.1073160 (2002).

21 Cypess, A. M. et al. Activation of human brown adipose tissue by a $\beta 3$-adrenergic receptor agonist. Cell Metab 21, 33-38, doi:10.1016/j.cmet.2014.12.009 (2015). 
Hanssen, M. J. et al. Short-term cold acclimation recruits brown adipose tissue in obese humans. Diabetes, doi:10.2337/db15-1372 (2016).

23 Le Marchand-Brustel, Y. et al. Glucose transporter in insulin sensitive tissues of lean and obese mice. Effect of the thermogenic agent BRL 26830A. Endocrinology 127, 2687-2695, doi:10.1210/endo-127-6-2687 (1990).

24 Santalucía, T. et al. Developmental regulation of GLUT-1 (erythroid/Hep G2) and GLUT-4 (muscle/fat) glucose transporter expression in rat heart, skeletal muscle, and brown adipose tissue. Endocrinology 130, 837-846, doi:10.1210/endo.130.2.1370797 (1992).

Cannon, B. \& Nedergaard, J. Cultures of adipose precursor cells from brown adipose tissue and of clonal brown-adipocyte-like cell lines. Methods Mol Biol 155, 213-224, doi:10.1385/159259-231-7:213 (2001).

26 Buckley, M. G. \& Rath, E. A. Regulation of fatty acid synthesis and malonyl-CoA content in mouse brown adipose tissue in response to cold-exposure, starvation or re-feeding. Biochem J 243, 437-442 (1987).

27 Darnley, A. C., Carpenter, C. A. \& Saggerson, E. D. Changes in activities of some enzymes of glycerolipid synthesis in brown adipose tissue of cold-acclimated rats. Biochem J 253, 351355 (1988).

28 Yu, X. X., Lewin, D. A., Forrest, W. \& Adams, S. H. Cold elicits the simultaneous induction of fatty acid synthesis and beta-oxidation in murine brown adipose tissue: prediction from differential gene expression and confirmation in vivo. FASEB J 16, 155-168, doi:10.1096/fj.010568com (2002).

29 Townsend, K. L. \& Tseng, Y.-H. Brown fat fuel utilization and thermogenesis. Trends Endocrinol Metab 25, 168-177, doi:10.1016/j.tem.2013.12.004 (2014).

30 Aquila, H., Link, T. A. \& Klingenberg, M. The uncoupling protein from brown fat mitochondria is related to the mitochondrial ADP/ATP carrier. Analysis of sequence homologies and of folding of the protein in the membrane. EMBO J 4, 2369-2376 (1985).

31 Bouillaud, F., Weissenbach, J. \& Ricquier, D. Complete cDNA-derived amino acid sequence of rat brown fat uncoupling protein. J Biol Chem 261, 1487-1490 (1986).

32 Heaton, G. M., Wagenvoord, R. J., Kemp, A. \& Nicholls, D. G. Brown-adipose-tissue mitochondria: photoaffinity labelling of the regulatory site of energy dissipation. Eur $J$ Biochem 82, 515-521 (1978).

33 Ridley, R. G., Patel, H. V., Gerber, G. E., Morton, R. C. \& Freeman, K. B. Complete nucleotide and derived amino acid sequence of CDNA encoding the mitochondrial uncoupling protein of rat brown adipose tissue: lack of a mitochondrial targeting presequence. Nucleic Acids Res 14, 4025-4035 (1986).

34 Enerbäck, S. et al. Mice lacking mitochondrial uncoupling protein are cold-sensitive but not obese. Nature 387, 90-94, doi:10.1038/387090a0 (1997).

35 Beermann, C. et al. Short term effects of dietary medium-chain fatty acids and n-3 long-chain polyunsaturated fatty acids on the fat metabolism of healthy volunteers. Lipids Health Dis $\mathbf{2}$, 10, doi:10.1186/1476-511x-2-10 (2003).

36 Fedorenko, A., Lishko, P. V. \& Kirichok, Y. Mechanism of fatty-acid-dependent UCP1 uncoupling in brown fat mitochondria. Cell 151, 400-413, doi:10.1016/j.cell.2012.09.010 (2012).

37 Klingenberg, M. Wanderings in bioenergetics and biomembranes. Biochim Biophys Acta 1797, 579-594, doi:10.1016/j.bbabio.2010.02.012 (2010).

38 Nicholls, D. G. The physiological regulation of uncoupling proteins. Biochim Biophys Acta 1757, 459-466, doi:10.1016/j.bbabio.2006.02.005 (2006).

39 Nicholls, D. G. \& Locke, R. M. Thermogenic mechanisms in brown fat. Physiol Rev 64, 1-64 (1984).

40 Shabalina, I. G., Jacobsson, A., Cannon, B. \& Nedergaard, J. Native UCP1 displays simple competitive kinetics between the regulators purine nucleotides and fatty acids. J Biol Chem 279, 38236-38248, doi:10.1074/jbc.M402375200 (2004). 
Rial, E. \& González-Barroso, M. M. Physiological regulation of the transport activity in the uncoupling proteins UCP1 and UCP2. Biochim Biophys Acta 1504, 70-81 (2001).

42 Prusiner, S. B., Cannon, B. \& Lindberg, O. Oxidative metabolism in cells isolated from brown adipose tissue. 1. Catecholamine and fatty acid stimulation of respiration. Eur J Biochem 6, 15-22 (1968).

Reed, N. \& Fain, J. N. Potassium-dependent stimulation of respiration in brown fat cells by fatty acids and lipolytic agents. J Biol Chem 243, 6077-6083 (1968).

Schaffer, J. E. \& Lodish, H. F. Expression cloning and characterization of a novel adipocyte long chain fatty acid transport protein. Cell 79, 427-436 (1994).

Khedoe, P. P. S. J. et al. Brown adipose tissue takes up plasma triglycerides mostly after lipolysis. J Lipid Res 56, 51-59, doi:10.1194/jlr.M052746 (2015).

Bartelt, A. et al. Brown adipose tissue activity controls triglyceride clearance. Nat Med 17, 200-205, doi:10.1038/nm.2297 (2011).

Eiselein, L., Wilson, D. W., Lamé, M. W. \& Rutledge, J. C. Lipolysis products from triglyceriderich lipoproteins increase endothelial permeability, perturb zonula occludens- 1 and F-actin, and induce apoptosis. Am J Physiol Heart Circ Physiol 292, H2745-2753, doi:10.1152/ajpheart.00686.2006 (2007).

Doege, H. \& Stahl, A. Protein-mediated fatty acid uptake: novel insights from in vivo models. Physiology (Bethesda) 21, 259-268, doi:10.1152/physiol.00014.2006 (2006).

Labbé, S. M. et al. In vivo measurement of energy substrate contribution to cold-induced brown adipose tissue thermogenesis. FASEB J 29, 2046-2058, doi:10.1096/fj.14-266247 (2015).

Coburn, C. T., Hajri, T., Ibrahimi, A. \& Abumrad, N. A. Role of CD36 in membrane transport and utilization of long-chain fatty acids by different tissues. J Mol Neurosci 16, 117-121; discussion 151-117, doi:10.1385/jmn:16:2-3:117 (2001).

Stahl, A. A current review of fatty acid transport proteins (SLC27). Pflugers Arch 447, 722727, doi:10.1007/s00424-003-1106-z (2004).

Chiu, H. C. et al. A novel mouse model of lipotoxic cardiomyopathy. J Clin Invest 107, 813822, doi:10.1172/jci10947 (2001).

Hames, K. C., Vella, A., Kemp, B. J. \& Jensen, M. D. Free fatty acid uptake in humans with CD36 deficiency. Diabetes 63, 3606-3614, doi:10.2337/db14-0369 (2014).

Putri, M. et al. CD36 is indispensable for thermogenesis under conditions of fasting and cold stress. Biochem Biophys Res Commun 457, 520-525, doi:10.1016/j.bbrc.2014.12.124 (2015).

Goldberg, I. J., Eckel, R. H. \& Abumrad, N. A. Regulation of fatty acid uptake into tissues: lipoprotein lipase- and CD36-mediated pathways. J Lipid Res 50 Suppl, S86-90, doi:10.1194/jlr.R800085-JLR200 (2009).

Tvrdik, P. et al. Cig30, a mouse member of a novel membrane protein gene family, is involved in the recruitment of brown adipose tissue. J Biol Chem 272, 31738-31746 (1997).

57 Hales, C. N., Luzio, J. P. \& Siddle, K. Hormonal control of adipose-tissue lipolysis. Biochem Soc Symp, 97-135 (1978).

58 Mohamed-Ali, V., Pinkney, J. H. \& Coppack, S. W. Adipose tissue as an endocrine and paracrine organ. Int J Obes Relat Metab Disord 22, 1145-1158 (1998).

59 Ailhaud, G. Adipose tissue as an endocrine organ. Int J Obes Relat Metab Disord 24 Suppl 2, S1-3 (2000).

60 Trayhurn, P. \& Beattie, J. H. Physiological role of adipose tissue: white adipose tissue as an endocrine and secretory organ. Proc Nutr Soc 60, 329-339 (2001).

61 Timmons, J. A. et al. Myogenic gene expression signature establishes that brown and white adipocytes originate from distinct cell lineages. Proc Natl Acad Sci U S A 104, 4401-4406, doi:10.1073/pnas.0610615104 (2007).

$62 \mathrm{Wu}$, J., Cohen, P. \& Spiegelman, B. M. Adaptive thermogenesis in adipocytes: is beige the new brown? Genes Dev 27, 234-250, doi:10.1101/gad.211649.112 (2013). 
Sidossis, L. \& Kajimura, S. Brown and beige fat in humans: thermogenic adipocytes that control energy and glucose homeostasis. J Clin Invest 125, 478-486, doi:10.1172/jci78362 (2015).

64 Gnad, T. et al. Adenosine activates brown adipose tissue and recruits beige adipocytes via A2A receptors. Nature 516, 395-399, doi:10.1038/nature13816 (2014).

Collins, S. $\beta$-Adrenoceptor Signaling Networks in Adipocytes for Recruiting Stored Fat and Energy Expenditure. Front Endocrinol (Lausanne) 2, 102, doi:10.3389/fendo.2011.00102 (2011).

Sidossis, L. S. et al. Browning of Subcutaneous White Adipose Tissue in Humans after Severe Adrenergic Stress. Cell Metab 22, 219-227, doi:10.1016/j.cmet.2015.06.022 (2015).

Nguyen, K. D. et al. Alternatively activated macrophages produce catecholamines to sustain adaptive thermogenesis. Nature 480, 104-108, doi:10.1038/nature10653 (2011).

Qiu, Y. et al. Eosinophils and type 2 cytokine signaling in macrophages orchestrate development of functional beige fat. Cell 157, 1292-1308, doi:10.1016/j.cell.2014.03.066 (2014).

69 Boström, P. et al. A PGC1- $\alpha$-dependent myokine that drives brown-fat-like development of white fat and thermogenesis. Nature 481, 463-468, doi:10.1038/nature10777 (2012). Lee, P. et al. Irisin and FGF21 are cold-induced endocrine activators of brown fat function in humans. Cell Metab 19, 302-309, doi:10.1016/j.cmet.2013.12.017 (2014).

71 Kir, S. et al. Tumour-derived PTH-related protein triggers adipose tissue browning and cancer cachexia. Nature 513, 100-104, doi:10.1038/nature13528 (2014).

72 Festuccia, W. T., Blanchard, P.-G. \& Deshaies, Y. Control of Brown Adipose Tissue Glucose and Lipid Metabolism by PPARY. Front Endocrinol (Lausanne) 2, 84, doi:10.3389/fendo.2011.00084 (2011).

73 Laplante, M. et al. Tissue-specific postprandial clearance is the major determinant of PPARgamma-induced triglyceride lowering in the rat. Am J Physiol Regul Integr Comp Physiol 296, R57-66, doi:10.1152/ajpregu.90552.2008 (2009).

74 Savonen, R. et al. The tissue distribution of lipoprotein lipase determines where chylomicrons bind. J Lipid Res 56, 588-598, doi:10.1194/jlr.M056028 (2015).

75 Bauwens, M. et al. Molecular imaging of brown adipose tissue in health and disease. Eur J Nucl Med Mol Imaging 41, 776-791, doi:10.1007/s00259-013-2611-8 (2014).

76 DeGrado, T. R., Coenen, H. H. \& Stocklin, G. 14(R,S)-[18F]fluoro-6-thia-heptadecanoic acid (FTHA): evaluation in mouse of a new probe of myocardial utilization of long chain fatty acids. J Nucl Med 32, 1888-1896 (1991).

77 Labbé, S. M. et al. Organ-specific dietary fatty acid uptake in humans using positron emission tomography coupled to computed tomography. Am J Physiol Endocrinol Metab 300, E445453, doi:10.1152/ajpendo.00579.2010 (2011).

78 Hovik, R. et al. Effects of thia-substituted fatty acids on mitochondrial and peroxisomal betaoxidation. Studies in vivo and in vitro. Biochem J 270, 167-173 (1990).

79 Skrede, S., Narce, M., Bergseth, S. \& Bremer, J. The effects of alkylthioacetic acids (3-thia fatty acids) on fatty acid metabolism in isolated hepatocytes. Biochim Biophys Acta 1005, 296-302 (1989).

80 Ouellet, V. et al. Brown adipose tissue oxidative metabolism contributes to energy expenditure during acute cold exposure in humans. J Clin Invest 122, 545-552, doi:10.1172/jci60433 (2012).

81 Baba, S., Jacene, H. A., Engles, J. M., Honda, H. \& Wahl, R. L. CT Hounsfield units of brown adipose tissue increase with activation: preclinical and clinical studies. J Nucl Med 51, 246250, doi:10.2967/jnumed.109.068775 (2010).

82 Yamasaki, K. et al. Radiolabeled BMIPP for imaging hepatic fatty acid metabolism: evaluation of hepatic distribution and metabolism in mice at various metabolic statuses induced by fasting in comparison with palmitic acid. Mol Imaging 14, doi:10.2310/7290.2014.00058 (2015). 
Tamaki, N. et al. Assessment of myocardial fatty acid metabolism with positron emission tomography at rest and during dobutamine infusion in patients with coronary artery disease. Am Heart J 125, 702-710 (1993).

Schelbert, H. R. et al. Effects of substrate availability on myocardial C-11 palmitate kinetics by positron emission tomography in normal subjects and patients with ventricular dysfunction. Am Heart J 111, 1055-1064 (1986).

Schelbert, H. R. Myocardial ischemia and clinical applications of positron emission tomography. Am J Cardiol 64, 46E-53E (1989).

Bucci, M. et al. Enhanced fatty acid uptake in visceral adipose tissue is not reversed by weight loss in obese individuals with the metabolic syndrome. Diabetologia 58, 158-164, doi:10.1007/s00125-014-3402-x (2015).

87 Lin, Q. et al. Effects of configuration on the myocardial uptake of radioiodinated 3(R)-BMIPP and 3(S)-BMIPP in rats. J Nucl Med 38, 1434-1441 (1997).

Mertens, J., Eersels, J. \& Vanryckeghem, W. New high yield $\mathrm{Cu}(\mathrm{I})$ assisted $123 \mathrm{I}$ radioiodination of 15(p-I-phenyl)-9-methyl pentadecanoic acid, a potential myocardial tracer. Eur J Nucl Med 13, 159-160 (1987).

Syamsunarno, M. R. A. A. et al. Fatty acid binding protein 4 and 5 play a crucial role in thermogenesis under the conditions of fasting and cold stress. PLoS One 9, e90825, doi:10.1371/journal.pone.0090825 (2014).

Poe, N. D., Robinson, G. D., Jr., Graham, L. S. \& MacDonald, N. S. Experimental basis of myocardial imaging with 123I-labeled hexadecenoic acid. J Nucl Med 17, 1077-1082 (1976). doi:10.1148/124.2.419 (1977).

Notohamiprodjo, G., Schmid, A., Spohr, G., Vyska, K. \& Feinendegen, L. E. Comparison of 11C-Palmitic Acid (CPA), and 123-I-heptadecanoic acid (IHA) turnover in human heart. Journal of Nuclear Medicine 26, 88 (1985).

93 Corbett, J. R. Fatty acids for myocardial imaging. Semin Nucl Med 29, 237-258 (1999).

94 Livni, E., Elmaleh, D. R., Levy, S., Brownell, G. L. \& Strauss, W. H. Beta-methyl[111C]heptadecanoic acid: a new myocardial metabolic tracer for positron emission tomography. J Nucl Med 23, 169-175 (1982).

Thumser, A. E. \& Storch, J. Characterization of a BODIPY-labeled fluorescent fatty acid analogue. Binding to fatty acid-binding proteins, intracellular localization, and metabolism. Mol Cell Biochem 299, 67-73, doi:10.1007/s11010-005-9041-2 (2007).

expression. Mol Biol Cell 21, 1991-2000, doi:10.1091/mbc.E09-05-0364 (2010).

97 Dubikovskaya, E., Chudnovskiy, R., Karateev, G., Park, H. M. \& Stahl, A. Measurement of longchain fatty acid uptake into adipocytes. Methods Enzymol 538, 107-134, doi:10.1016/b978-012-800280-3.00007-4 (2014).

98 Kasurinen, J. A novel fluorescent fatty acid, 5-methyl-BDY-3-dodecanoic acid, is a potential probe in lipid transport studies by incorporating selectively to lipid classes of BHK cells. Biochem Biophys Res Commun 187, 1594-1601 (1992).

99 DeGrado, T. R. et al. Synthesis and preliminary evaluation of (18)F-labeled 4-thia palmitate as a PET tracer of myocardial fatty acid oxidation. Nucl Med Biol 27, 221-231 (2000).

100 Jones, L. R. et al. Releasable luciferin-transporter conjugates: tools for the real-time analysis of cellular uptake and release. J Am Chem Soc 128, 6526-6527, doi:10.1021/ja0586283 (2006).

101 Henkin, A. H. et al. Real-time noninvasive imaging of fatty acid uptake in vivo. ACS Chem Biol 7, 1884-1891, doi:10.1021/cb300194b (2012).

102 Jenkins, D. E. et al. Bioluminescent imaging (BLI) to improve and refine traditional murine models of tumor growth and metastasis. Clin Exp Metastasis 20, 733-744 (2003). 
103 Bruns, O. T. et al. Real-time magnetic resonance imaging and quantification of lipoprotein metabolism in vivo using nanocrystals. Nat Nanotechnol 4, 193-201, doi:10.1038/nnano.2008.405 (2009).

104 Grimpo, K. et al. Brown adipose tissue dynamics in wild-type and UCP1-knockout mice: in vivo insights with magnetic resonance. J Lipid Res 55, 398-409, doi:10.1194/jlr.M042895 (2014).

105 Holstila, M. et al. Measurement of brown adipose tissue mass using a novel dual-echo magnetic resonance imaging approach: a validation study. Metabolism 62, 1189-1198, doi:10.1016/j.metabol.2013.03.002 (2013).

106 van Rooijen, B. D. et al. Imaging cold-activated brown adipose tissue using dynamic T2*weighted magnetic resonance imaging and 2-deoxy-2-[18F]fluoro-D-glucose positron emission tomography. Invest Radiol 48, 708-714, doi:10.1097/RLI.0b013e31829363b8 (2013).

107 Branca, R. T. \& Warren, W. S. In vivo brown adipose tissue detection and characterization using water-lipid intermolecular zero-quantum coherences. Magn Reson Med 65, 313-319, doi:10.1002/mrm.22622 (2011).

108 Hu, H. H., Smith, D. L., Nayak, K. S., Goran, M. I. \& Nagy, T. R. Identification of brown adipose tissue in mice with fat-water IDEAL-MRI. J Magn Reson Imaging 31, 1195-1202, doi:10.1002/jmri.22162 (2010).

109 Sbarbati, A., Cavallini, I., Marzola, P., Nicolato, E. \& Osculati, F. Contrast-enhanced MRI of brown adipose tissue after pharmacological stimulation. Magn Reson Med 55, 715-718, doi:10.1002/mrm.20851 (2006).

110 Khanna, A. \& Branca, R. T. Detecting brown adipose tissue activity with BOLD MRI in mice. Magn Reson Med 68, 1285-1290, doi:10.1002/mrm.24118 (2012).

111 Flynn, A. et al. Contrast-Enhanced Ultrasound: A Novel Noninvasive, Nonionizing Method for the Detection of Brown Adipose Tissue in Humans. J Am Soc Echocardiogr 28, 1247-1254, doi:10.1016/j.echo.2015.06.014 (2015).

112 Gorter, P. M. et al. Quantification of epicardial and peri-coronary fat using cardiac computed tomography; reproducibility and relation with obesity and metabolic syndrome in patients suspected of coronary artery disease. Atherosclerosis 197, 896-903, doi:10.1016/j.atherosclerosis.2007.08.016 (2008).

113 Maurovich-Horvat, P. et al. Influence of pericoronary adipose tissue on local coronary atherosclerosis as assessed by a novel MDCT volumetric method. Atherosclerosis 219, 151157, doi:10.1016/j.atherosclerosis.2011.06.049 (2011).

114 Mahabadi, A. A. et al. Association of pericoronary fat volume with atherosclerotic plaque burden in the underlying coronary artery: a segment analysis. Atherosclerosis 211, 195-199, doi:10.1016/j.atherosclerosis.2010.02.013 (2010).

115 Gorter, P. M. et al. Relation of epicardial and pericoronary fat to coronary atherosclerosis and coronary artery calcium in patients undergoing coronary angiography. Am J Cardiol 102, 380-385, doi:10.1016/j.amjcard.2008.04.002 (2008).

116 Stein, O., Scow, R. O. \& Stein, Y. FFA-3H uptake by perfused adipose tissue: electron microscopic autoradiographic study. Am J Physiol 219, 510-518 (1970).

117 Kampf, J. P., Parmley, D. \& Kleinfeld, A. M. Free fatty acid transport across adipocytes is mediated by an unknown membrane protein pump. Am J Physiol Endocrinol Metab 293, E1207-1214, doi:10.1152/ajpendo.00259.2007 (2007).

118 Cupp, D., Kampf, J. P. \& Kleinfeld, A. M. Fatty acid-albumin complexes and the determination of the transport of long chain free fatty acids across membranes. Biochemistry 43, 44734481, doi:10.1021/bi036335I (2004). 


\title{
Chapter 3: \\ Characterization of BAT activity in rats using invasive and non-invasive techniques
}

\author{
Andreas Paulus, \\ Petronella A. van Ewijk, \\ Emmani B.M. Nascimento, \\ Marijke De Saint-Hubert, \\ Geert Hendrikx, \\ Andreas Vogg, \\ Ivo Pooters, \\ Melanie Schnijderberg, \\ Joris Vanderlocht, \\ Gerard Bos, \\ Boudewijn Brans, \\ Vera B. Schrauwen-Hinderling, \\ Felix M. Mottaghy, \\ Matthias Bauwens
}

submitted as:

Characterization of BAT activity in rats using invasive and non-invasive techniques. PLoS

One, (2018) 


\section{Abstract}

Brown adipose tissue (BAT) is widely considered as a potential target for combating obesity in humans where active BAT metabolizes glucose and fatty acids as fuel resulting in heat production. Several prospective studies in humans have been set up to further study the presence and metabolic activity of BAT mostly using PET imaging in cold-stimulated conditions with the radiolabeled glucose derivative $\left[{ }^{18} \mathrm{~F}\right] \mathrm{FDG}$. However, radiotracers beyond $\left[{ }^{18} \mathrm{~F}\right] \mathrm{FDG}$ have been proposed to investigate BAT activity, targeting various aspects of BAT metabolism. It remains questionable which tracer is best suited to detect metabolic BAT activity and to what extent the generated results correlate with ex vivo metabolic BAT activity. Methods: Dynamic PET and SPECT imaging, targeting different aspects of BAT activation such as glucose metabolism, fatty acid metabolism, noradrenergic stimulation, blood perfusion and amino acid transport system, was performed immediately after injection of the tracer in rats under different temperatures: room temperature, acute cold $\left(4^{\circ} \mathrm{C}\right.$ for $4 \mathrm{~h}$ ) or acclimated to cold ( $4{ }^{\circ} \mathrm{C}$ for $6 \mathrm{~h}$ per day during 28 days). Furthermore, MRS-derived BAT temperature was measured in control and cold-acclimated rats.

Results: In rats housed at room temperature, only $\left[{ }^{18} \mathrm{~F}\right] \mathrm{FDG}$ visualized BAT. Glucose metabolism, fatty acid metabolism, noradrenergic stimulation and blood perfusion showed a clear tracer-dependent twofold increase in BAT uptake upon cold exposure. Only the tracer for the amino acid transport system did not show BAT specific uptake under any of the experimental conditions. MRS demonstrated that cold-acclimated animals had BAT with a stronger heat-production compared to control animals.

Conclusion: BAT activity following cold exposure in rats was visualized by several tracers, while only $\left[{ }^{18} \mathrm{~F}\right] \mathrm{FDG}$ was also able to show BAT activity under non-stimulated conditions (room temperature). The variances in uptake of the different tracers should be taken into account when developing future clinical applications in humans. 


\section{Introduction}

Brown adipose tissue (BAT) has gained considerable attention over the last decade, as its appearance and function in humans is becoming more elucidated. The main function of BAT is to dissipate energy in the form of heat, a process driven by the mitochondrial uncoupling protein 1 (UCP1), in response to cold exposure ${ }^{1,2}$. BAT is highly vascularized, densely innervated by the sympathetic nervous system and has thermogenic capacity that can significantly influence homeostasis ${ }^{3-5}$.

The presence and/or activity of BAT can be non-invasively visualized in humans using magnetic resonance imaging (MRI), computed tomography (CT), thermography and molecular imaging ${ }^{6-9}$. Thermography is a relatively cheap technique, able to quantify elevations in skin temperature resulting from increased BAT activity ${ }^{9,10}$. Since skin temperature is only indirectly correlated to BAT abundance $\left(R^{2}<0.3\right)^{10}$, this technique is not optimally suited for directly monitoring BAT activity. MRI and CT are capable of visualizing soft tissue with a high spatial resolution but struggle to distinguish between white adipose tissue (WAT) and BAT. These techniques quantify the decrease in fat content during cold exposure as a reflection of BAT activation. Molecular imaging, using either positron emission tomography (PET) or single photon emission computed tomography (SPECT) is performed with different radiopharmaceuticals. In this study we employed $2-\left[{ }^{18} \mathrm{~F}\right]$ fluorodeoxyglucose $\left(\left[{ }^{18} \mathrm{~F}\right] \mathrm{FDG}\right), \quad$ 14- $\left[{ }^{18} \mathrm{~F}\right]$ fluoro-6-thia-heptadecanoic acid $\left(\left[{ }^{18} \mathrm{~F}\right] \mathrm{FTHA}\right), \quad\left[{ }^{99 \mathrm{~m}} \mathrm{Tc}\right] \mathrm{Tc}-2-\mathrm{methoxy}-$ isobutyl-isonitrile ([ $\left.\left.{ }^{99 \mathrm{~m}} \mathrm{Tc}\right] \mathrm{TcMIBI}\right)$ and $\left[{ }^{123} \mathrm{I}\right]$-metaiodobenzylguanidine $\left(\left[{ }^{123} \mathrm{I}\right] \mathrm{MIBG}\right)$. These radiopharmaceuticals are able to visualize and quantify BAT activity in humans ${ }^{11-16}$. $\left[{ }^{18} \mathrm{~F}\right] \mathrm{FDG}$ mainly visualizes glucose transport and is the most frequently used tracer to image BAT due to its high availability. However fatty acids are the main metabolized substance class in BAT ${ }^{17,18}$ and therefore $\left[{ }^{18} \mathrm{~F}\right] \mathrm{FDG}$ might largely underestimate BAT activity. In addition $\left[{ }^{18}\right.$ F]FDG BAT uptake is verifiably reduced in diabetic patients ${ }^{19}$ due to their insulin resistance. $\left[{ }^{18} \mathrm{~F}\right] \mathrm{FTHA}$ visualizes uptake of free fatty acids (probably mainly via CD36 ${ }^{20}$ ). Fatty acids are the main metabolized substance class in BAT and might therefore be a good 
measure for BAT activation state. $\left[{ }^{123}\right.$ I]MIBG visualizes the density of sympathetic nerve endings. Norepinephrine, which is released by the sympathetic nervous system is a known activator for BAT ${ }^{21,22}$ and therefore imaging with ${ }^{123}$ I]MIBG is a good indication of the susceptibility of BAT to be activated. [ $\left.{ }^{99 m} \mathrm{Tc}\right]$ TcMIBI visualizes perfusion of tissue by binding to mitochondria rich cells. BAT cells have a high number of mitochondria and in previous studies it was shown that $\left[{ }^{99 m} \mathrm{Tc}\right]$ TcMIBI is able to visualize BAT under basal conditions ${ }^{11,12}$. In acute cold conditions uptake was only slightly pronounced and it was speculated that $\left[{ }^{99 m} \mathrm{Tc}\right] \mathrm{TcMIBI}$ only shows increased uptake after cold acclimation. Additionally $\left[{ }^{123} \mid\right] \mid-$ Phenylalanine ([ $\left.\left.{ }^{123} \mathrm{I}\right] \mathrm{IPA}\right)$ (targeting LAT1-4 amino acid transport system density) was used. $\left[{ }^{123}\right.$ I]PA has never been reported to visualize BAT clinically or preclinically, but as it correlates to a key amino acid transport system we feel it is important to include it in our study.

PET and SPECT images indicating presumed regions of BAT can also be selectively identified on CT and MRI images, and MRNA and protein analysis from tissue samples from these regions confirmed BAT-characteristics ${ }^{23,24}$. It has also been shown that $\left[{ }^{18} \mathrm{~F}\right] \mathrm{FDG}$ uptake on PET images correlates positively to cold outside temperatures and negatively to a subjects BMI, in correspondence with predictions from in vitro work ${ }^{25}$. However, ex vivo and in vitro data can vary greatly within a specific tissue or type of cell culture ${ }^{26}$, and it remains an open question just to what extent intra-tissue measurements from each of these techniques truly represents its metabolic activity.

The most straightforward method to activate BAT in vivo is exposure to acute cold but also cold acclimation further stimulates $\left[{ }^{18}\right.$ F]FDG PET uptake in humans ${ }^{6,27,28}$. However no other radiopharmaceuticals have been used in a clinical setting to evaluate the effect of cold acclimation, although Baba et al. compared a number of tracers ( $\left[{ }^{201} \mathrm{Tl}\right]$ thaliumchloride, $\left.\left[{ }^{123}\right]\right] M I B G,\left(\left[{ }^{99 m} \mathrm{Tc}\right] \mathrm{TcMIBI},\left[{ }^{18} \mathrm{~F}\right]-\right.$ or $\left[{ }^{3} \mathrm{H}\right] \mathrm{FDG},\left[{ }^{3} \mathrm{H}\right]-$--methionine, and $\left[{ }^{3} \mathrm{H}\right]$ thymidine $)$ to assess BAT uptake in rodents after acute cold exposure ${ }^{11}$.

Therefore 3 questions remain: 1) which aspects of BAT metabolism can best be used to investigate BAT activity upon acute cold exposure and cold acclimation? 2) which 
radiopharmaceutical is most suitable to evaluate this aspects? 3) to what extent does data acquired using radiopharmaceuticals correlate with ex vivo findings and data acquired by other modalities such as MR Spectroscopy (MRS)?

In our study, we primarily investigated to what extent different radiopharmaceuticals are suitable to quantify response of BAT to acute cold and cold acclimation in rats. For this reason, we used a rat model which was acutely exposed to cold or acclimated to cold. We compared tracers that were previously described to visualize BAT in clinical setting, namely $\left[{ }^{18} \mathrm{~F}\right] \mathrm{FDG},\left[{ }^{18} \mathrm{~F}\right] \mathrm{FTHA},\left[{ }^{123} \mathrm{I}\right] \mathrm{MIBG},\left[{ }^{99 \mathrm{~m}} \mathrm{Tc}\right] \mathrm{TcMIBI}$ and $\left(\left[{ }^{123} \mathrm{I}\right] \mathrm{IPA}\right)$. Furthermore, using MRS, we visualized and quantified BAT in rat following acute cold or cold acclimation by means of gradient-echo sequence (FLASH - Fast Low Angle SHot). 


\section{Materials \& Methods}

\section{Animal model}

All animal studies were approved by the local animal ethical committee of the Maastricht University; with the internal permit number: DEC 2012-001. Male 12-week old Wistar rats were acquired from Harlan and housed under controlled temperatures of $22^{\circ} \mathrm{C} \pm 1^{\circ} \mathrm{C}$ and 55-75\% air humidity, in a $12 \mathrm{~h}$ light-dark cycle with water and food chow ad libitum. 36 animals were, after an initial week of normal housing, placed at $4{ }^{\circ} \mathrm{C}$ for $6 \mathrm{~h}$ per day $(9 \mathrm{am}-3$ pm) (food/drink ad libitum) during 28 days, see also figure 1. At day -2 animals were scanned with one of the listed radiotracer to determine the control (room temperature) condition. To measure the acute cold conditions animals were scanned at day 0 after $4 \mathrm{~h}$ cold exposure and cold acclimated conditions were obtained after 28 days of cold exposure for $6 \mathrm{~h} /$ day. At day 30 cold exposed animals were injected in the cold with the PET/SPECT tracer and were further exposed to cold for 30 min before they were scanned to see if cold exposure during injection has an effect. 8 animals served as controls and were maintained at room temperature throughout the experiment. The physiological impact of the experiment was assessed by comparing food uptake, weight gain and discomfort in cold-acclimated and room temperature groups of animals. In addition, supraclavicular BAT was dissected and weighed in sacrificed animals. 


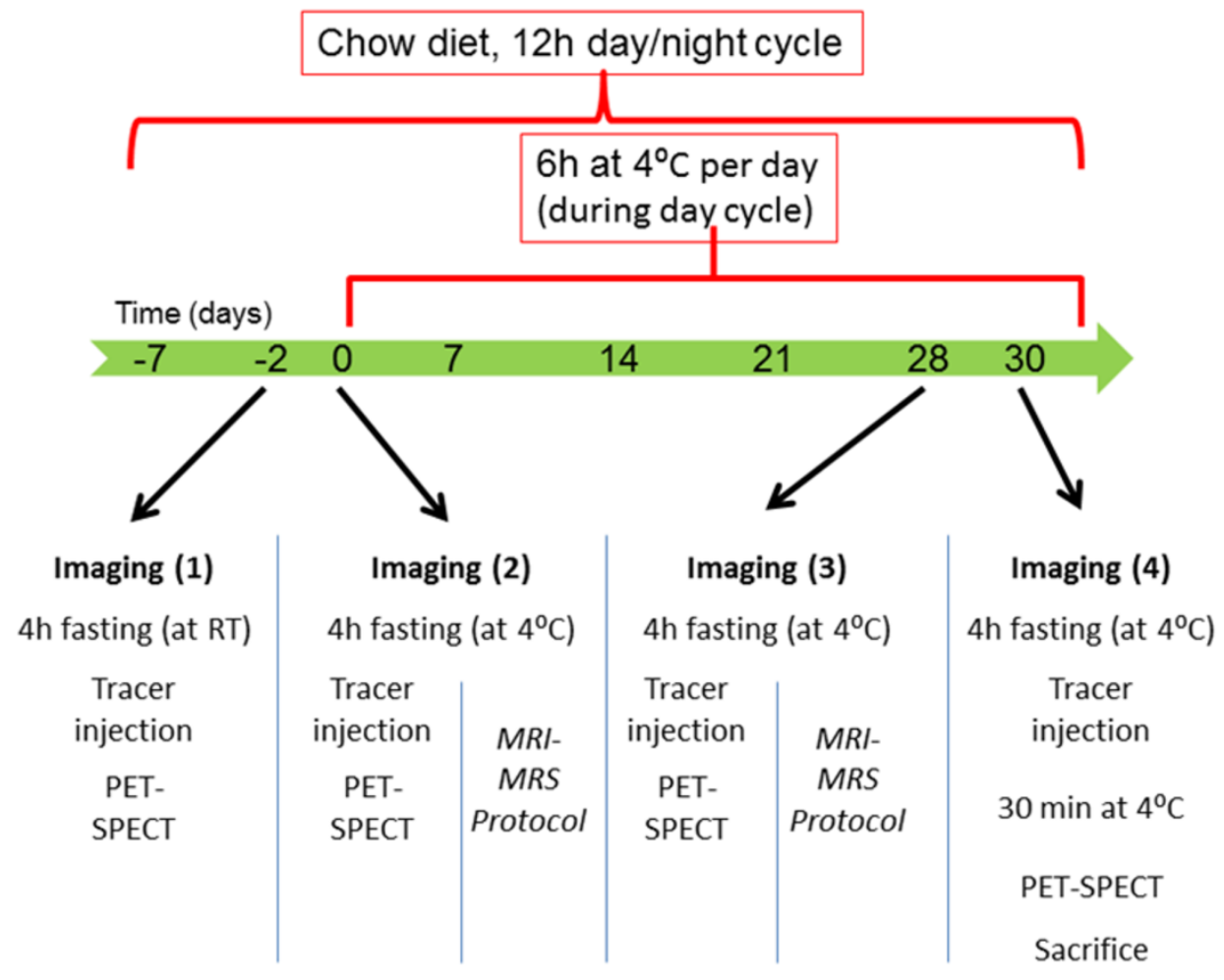

Fig 1: Study design. Imaging with each tracer was performed sequentially in baseline conditions (day 2, temperature regime 1 (TR-1)), after acute cold exposure (day 0, TR-2), after cold acclimation (day 28, TR-3) and after tracer distribution in the cold (day 30, TR-4).

\section{Tracers: radiosynthesis and formulation}

$\left[{ }^{18} \mathrm{~F}\right] \mathrm{FDG}$ was purchased from GE Healthcare. Sestamibi (MIBI) was labeled with technetium$99 \mathrm{~m}$ according to manufacturer guidelines (Mallincrodt Medical). Non-carrier added $\left.\left[{ }^{123}\right]\right] M I B G$ was prepared as suggested by the manufacturer of the precursor ${ }^{29}$. In short, synthesis was achieved by reacting iodine-123 with a polystyrene resin of dibutylstannyl benzylguanidine (Molecular Insight) in an oxidizing solution, transferring the $\left.\left[{ }^{123}\right]\right] M I B G$ over a cation exchange filter, rinsing with saline solution and finally collecting the non-carrier-added tracer by a phosphoric acid/ascorbic acid solution. After neutralization with $\mathrm{NaOH}$ a final volume of about $2 \mathrm{ml}$ is reached and the solution is ready for injection. The synthesis of $\left(\left[{ }^{123}\right]\right]$ IPA) was adapted from earlier publications ${ }^{30,31}$. Non-carrier added $\left[{ }^{18} \mathrm{~F}\right] \mathrm{FTHA}$ was 
prepared according to an adapted procedure from ${ }^{32}$, starting from benzyl-14-(R,S)-tosyloxy6-thiaheptadecanoate $(A B X)$ as a precursor. The final purified compound was formulated using a $0.1 \%$ rat serum albumin solution to ensure solubility. All tracers showed a radiochemical purity of at least $98 \%$.

\section{Imaging - general and anesthesia}

PET, SPECT and MRI was performed according to the timeline represented in figure 1 . The animals were divided into subgroups, with group $A, B, C, D$ and $E$ ( $n=4$ or more per group) being scanned with respectively $\left[{ }^{18} \mathrm{~F}\right] \mathrm{FDG},\left[{ }^{18} \mathrm{~F}\right] \mathrm{FTHA},\left[{ }^{123} \mathrm{I}\right] \mathrm{MIBG},\left[{ }^{99 \mathrm{~m}} \mathrm{Tc}\right] \mathrm{TcMIBI}$ and $\left[{ }^{123} \mathrm{I}\right] \mathrm{IPA}$ and group F was used for MRI $(n=8)$. Imaging started at $1 \mathrm{pm}$. Prior to any scan or animal sacrifice, animals were fasted for 4 hours at either room temperature (baseline control conditions) or at $4{ }^{\circ} \mathrm{C}$ (exposure to cold). PET/SPECT imaging was performed under pentobarbital anesthesia $(0.1 \mathrm{ml}$ of a $60 \mathrm{mg} / \mathrm{ml}$ solution per $100 \mathrm{~g}$ body weight, i.p.), as this

sedative was reported to show the least side effects on BAT activity ${ }^{33}$. MRI/MRS imaging, due to its study duration (2.5-3 h per animal) and difficulty to access the animal, did not allow pentobarbital, so isoflurane was used $\mathrm{O}_{2}$ as carrier, 3\% for initial sedation, $1.8 \%$ for maintenance).

\section{Imaging (PET, SPECT) and biodistribution}

Animals were sedated and subsequently injected in a tail vein under the camera $(\mu \mathrm{PET}$ Focus 120 , Siemens, with a $1.4 \mathrm{~mm}$ spatial resolution or U-SPECT, MiLabs, with a $0.6 \mathrm{~mm}$ resolution) with 20-50 MBq $\left[{ }^{18} \mathrm{~F}\right] \mathrm{FDG}$ (group A), 20-50 MBq $\left[{ }^{18} \mathrm{~F}\right] \mathrm{FTHA}$ (group B), $100 \mathrm{MBq}$ $\left[{ }^{123}\right.$ I]MIBG (group C), $100 \mathrm{MBq}\left[{ }^{99 m} \mathrm{Tc}\right] \mathrm{TcMIBI}$ (group D) or $100 \mathrm{MBq}\left[{ }^{123} \mathrm{I}\right] \mathrm{PA}$ (group E). The imaging room was conditioned to room temperature $\left(21^{\circ} \mathrm{C}\right)$.

On day -2, 0 and 28 dynamic imaging of the rat upper torso was performed immediately after injection for 25 minutes $(8 \times 15 \mathrm{sec}, 6 \times 30 \mathrm{sec}, 5 \times 60 \mathrm{sec}, 3 \times 300 \mathrm{sec}$ for PET, and 15x $3 \mathrm{~min}$ for SPECT), while on day 30 a static image was acquired at 30-55 minutes after injection. On day -2 , the rats were placed on a heating pad, while this pad was omitted on day 0,28 and 
30. Body core temperature was monitored using a rectal probe during imaging. At day 30, immediately after imaging, animals were sacrificed and relevant organs/tissues dissected, weighed and counted (automated $\mathrm{Nal}(\mathrm{TI})$ gamma counter (Wallac Wizard).

\section{Image analysis (PET/SPECT)}

After smoothing to $3 \times 3 \times 3 \mathrm{~mm}$ voxel size, image analysis was performed by drawing a volume of interest (VOI) around the interscapular BAT (BAT), part of the myocardium and part of the liver (PMOD 3.0). The VOI around IBAT was drawn around the visible iBAT (on PET or SPECT image), combined with knowledge of anatomical location. Each VOI was then limited by applying a cut-off value of $30 \%$ of the (maximum- minimum) value in the VOI, thereby maintaining only tissue with true uptake. A cut-off value of $30 \%$ was found to be optimal in previous studies (unpublished), and lead to the final metabolically active volume (metabolic volume). For each VOI, the Standardized Uptake Values $\left(\mathrm{SUV}_{\text {mean }}, \mathrm{Bq} / \mathrm{cc}\right.$ in the region of interest, divided by the injected dose per animal weight)), as well as the metabolic volume and the total metabolic activity (SUV mean multiplied by metabolic volume) were calculated. For PET, this SUV $_{\text {mean }}$ value could be calculated directly using the output parameters from the $\mu \mathrm{PET}$. For SPECT, the output parameter ("counts/cc") was converted to Bq/cc using a previously determined phantom-based conversion factor of 635 (Bq per count) for both technetium-99m and iodine-123.

\section{Imaging (MRI/MRS)}

During the MR exam the rats were placed in a cradle, which was positioned in the center of a quadrature volume coil (ø $72 \mathrm{~mm}$, transmit-receive) in a 7 Tesla MR System (Bruker Biospin, Ettlingen, Germany). Rectal temperature was measured using a fiber probe. Whole-body cooling was achieved by placing of the rats on a waterbed which was connected to a heat exchanger. The water was circulated by a pump and cooled from to $45^{\circ} \mathrm{C}$ to $\sim 25^{\circ} \mathrm{C}$, allowing rats to be cooled by three degrees Celsius from their initial rectal temperature. After 
this temperature loss, animals were warmed again using the waterbed until rectal temperature reached at least $36^{\circ} \mathrm{C}$.

In this study we use a gradient-echo sequence with a fat suppression pulse to visualize the position of BAT. The FLASH (Fast Low Angle SHot) sequence makes use of a moderate flip angle of 40 degrees, short TE of $3.9 \mathrm{msec}$ and long TR of $2050 \mathrm{msec}$. When also applying a fat suppression pulse, the tissues containing relatively more fat will appear darker, allowing to precisely locate iBAT. Temperature-dependent chemical shift between $\mathrm{H}_{2} \mathrm{O}$ and the $\mathrm{CH}_{2}$ peak of fat was measured using point resolved spectroscopy (PRESS, TE=14 ms, TR=4500 $\mathrm{ms}, \mathrm{NSA}=64$ ). Spectra were acquired from a $3 \times 2 \times 3 \mathrm{~mm}$ voxel positioned in BAT, every 4 minutes for at least 2.5 hours. Spectra were fitted using an in-house program. The chemical shift of the resonance of $\mathrm{H}_{2} \mathrm{O}$ and of the $\mathrm{CH}_{2}$ resonance of fat were determined and temperature change was quantified by assuming a temperature-dependent frequency shift of $\mathrm{H}_{2} \mathrm{O}$ of $0.01 \mathrm{ppm} /{ }^{\circ} \mathrm{C}$.

\section{Western blot}

All animals (control animals and cold-acclimated animals) were sacrificed at day 30 of the experiment. iBAT and visceral WAT were dissected and snap-frozen in liquid nitrogen. Western blot has been performed as stated previously ${ }^{34}$. In short, adipose tissue samples were incubated with RIPA buffer, frozen and after thawing lysates were passed through a 25G needle. Lysates were seperated using SDS-PAGE prior to electrophoretic transfer onto nitrocellulose membranes. The UCP1 antibody was from Abcam (Cambridge, UK). CD36 and GLUT4 antibodies were purchased from Santa Cruz (Dallas, TX).

\section{Quantitative real-time PCR}

All animals (control animals and cold-acclimated animals) were sacrificed at day 30 of the experiment. iBAT and visceral WAT were dissected stored in RNA-later prior to further mRNA expression analysis. Rat mRNA primer sets were developed and optimized for PPARy, C/EBPa, Sirtuin1, UCP1, UCP2, ADRB3, DIO2, GLUT4, ATGL, LPL and PRDM16 
transcripts. All gene expression data were normalized to beta-actin (see supplemental materials for detailed information on mRNA analysis).

\section{Statistics}

Imaging data from animal groups were compared using ANOVA (with Bonferroni correction) for inter-group comparison, and a paired student's t-test for intra-group comparison. mRNA data and protein data were compared using an unpaired t-test. $\mathrm{P}<0.05$ was considered to be statistically significant. All statistical tests were performed using GraphPad Prism (GraphPad Software). 


\section{Results}

\section{Physiological impact of the study}

Animals exposed to cold showed no signs of severe discomfort. Only during the first 2-3 days of the study the animals showed mild discomfort (shivering when exposed to cold). Animals acclimated to cold tended to gain less weight compared to animals in control conditions $(1.10$ $\pm 0.15 \mathrm{~g} /$ day vs $1.43 \pm 0.12 \mathrm{~g} /$ day, $\mathrm{p}=0.09$ ), however the cold acclimated animals did eat more $(29.4 \pm 1.1 \mathrm{~g} /$ day vs $26.3 \pm 0.9, \mathrm{p}=0.05)$. In addition, upon dissection, total interscapular adipose tissue (iAT) showed a tendency to be larger in cold-acclimated animals $(1.66 \pm 0.13$ $\mathrm{g}$ vs $1.35 \pm 0.08 \mathrm{~g}, \mathrm{p}=0.13$ ). iAT consisted of brownish adipose tissue, covered by a layer of white-pale adipose tissue. IWAT reduced in weight by cold acclimation from $0.65 \pm 0.08$ to $0.50 \pm 0.06(p=0.14)$, while iBAT increased in weight from $0.70 \pm 0.07 \mathrm{~g}$ to $1.16 \pm 0.10 \mathrm{~g}$ $(p=0.01)($ Fig 2).

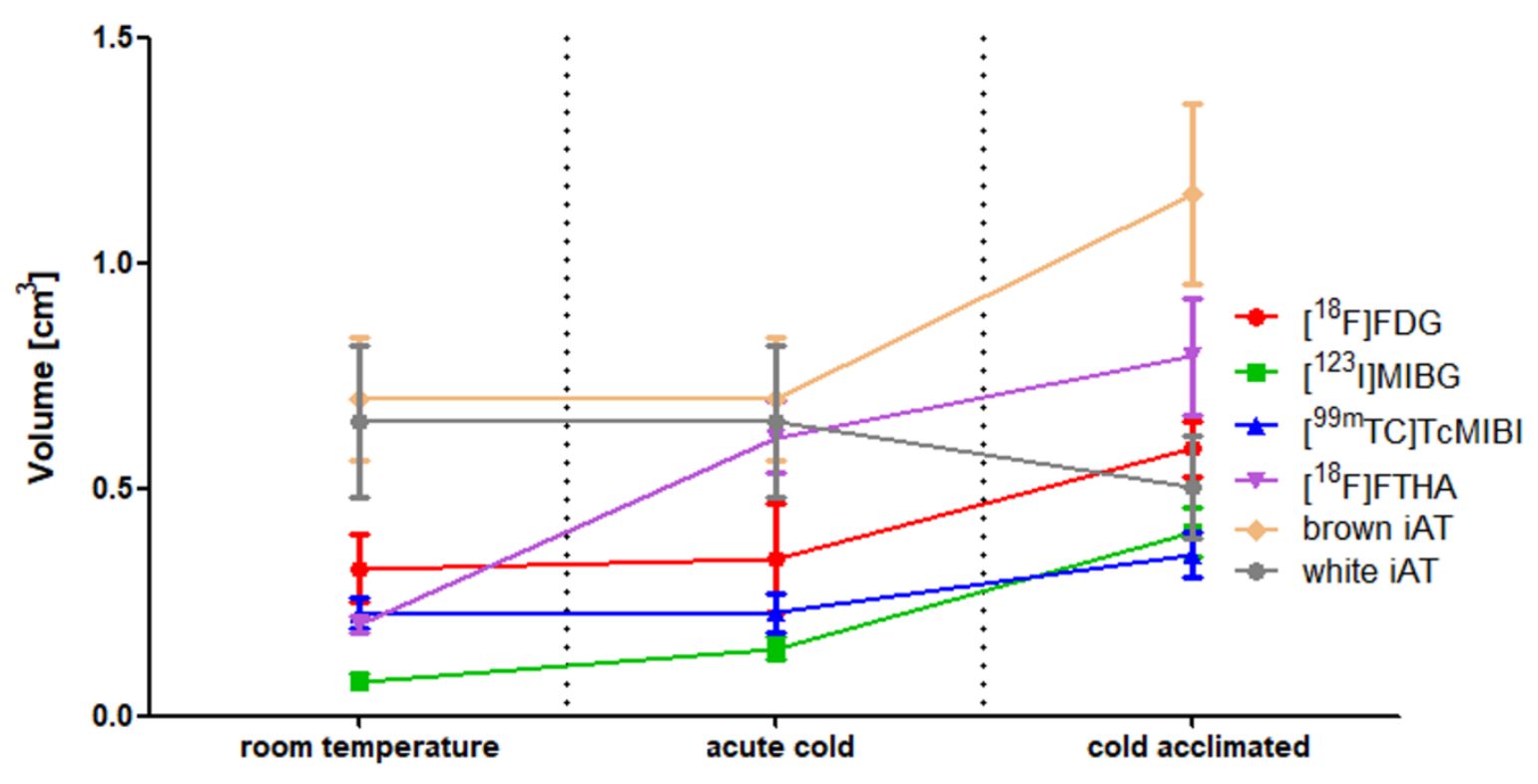

Fig 2: iBAT metabolic volumes of $\left[{ }^{18} \mathrm{~F}\right] \mathrm{FDG},\left[{ }^{18} \mathrm{~F}\right] \mathrm{FTHA},\left[{ }^{123}\right] \mathrm{MIBG}$ and $\left[{ }^{99 \mathrm{~m}} \mathrm{TC}\right] \mathrm{TCMIBI}$, as well as iBAT and iWAT volume determined by dissection, in different temperature conditions. 


\section{PET and SPECT imaging}

In baseline conditions, $\left[{ }^{18} \mathrm{~F}\right] \mathrm{FDG}$ images showed pronounced uptake in heart and brain, and to some extent in iBAT (Fig 3). Upon acute cold exposure, uptake was still increased in the heart and the brain (although less pronounced), but now iBAT and cervical brown adipose tissue (cBAT) were also clearly visible (image not shown). After acclimation, this pattern was very well-defined (Fig 4). For $\left[{ }^{18} \mathrm{~F}\right] \mathrm{FTHA}$, baseline condition images showed a high uptake in the liver and the heart, with only minor uptake in the iBAT. Upon cold exposure, uptake was clear again in the heart and the liver, however, now iBAT was also clearly visible. After acclimation, this pattern was even more pronounced, also showing cBAT (Fig 3 and 4). For $\left[{ }^{123}\right]$ MIBG, a pattern similar as compared to $\left[{ }^{18} \mathrm{~F}\right] \mathrm{FTHA}$ was observed, although uptake in BAT was less prominent (Fig 3 and 4). For [ $\left.{ }^{99 m} \mathrm{Tc}\right]$ TcMIBI, baseline condition images showed again a high uptake in the liver and the heart, with only minor uptake in iBAT. Upon cold exposure or cold acclimation, uptake in iBAT increased mildly (Fig 3 and 4). Finally, $\left[{ }^{123}\right.$ I]IPA showed no specific uptake anywhere in the upper torso in any condition (Fig 3 and 4). 


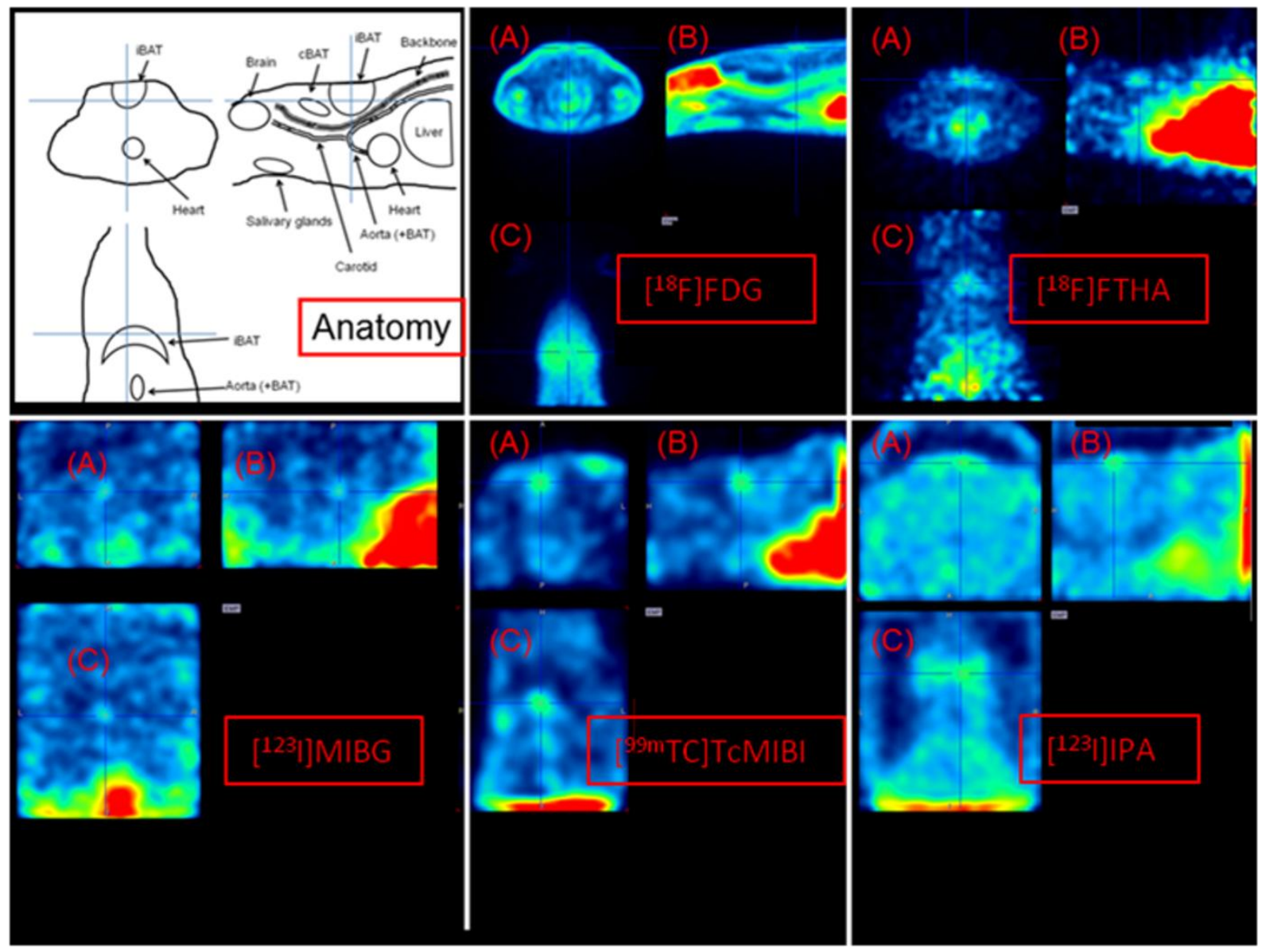

Fig 3: Transverse (A), sagittal (B) and coronal (C) slices of images from a room-temperature housed rat, centered on iBAT, depicting the anatomy, $\left[{ }^{18} \mathrm{~F}\right]-\mathrm{FDG}$ distribution, $\left[{ }^{18} \mathrm{~F}\right]-\mathrm{FTHA}$ distribution, $\left.\left[{ }^{123}\right]\right]-\mathrm{MIBG}$ distribution, $\left[{ }^{99 \mathrm{~m}} \mathrm{Tc}\right]-\mathrm{MIBI}$ and $\left[{ }^{123} \mathrm{I}\right]-\mathrm{IPA}$ distribution. Uptake in BAT is low for all tracers. 


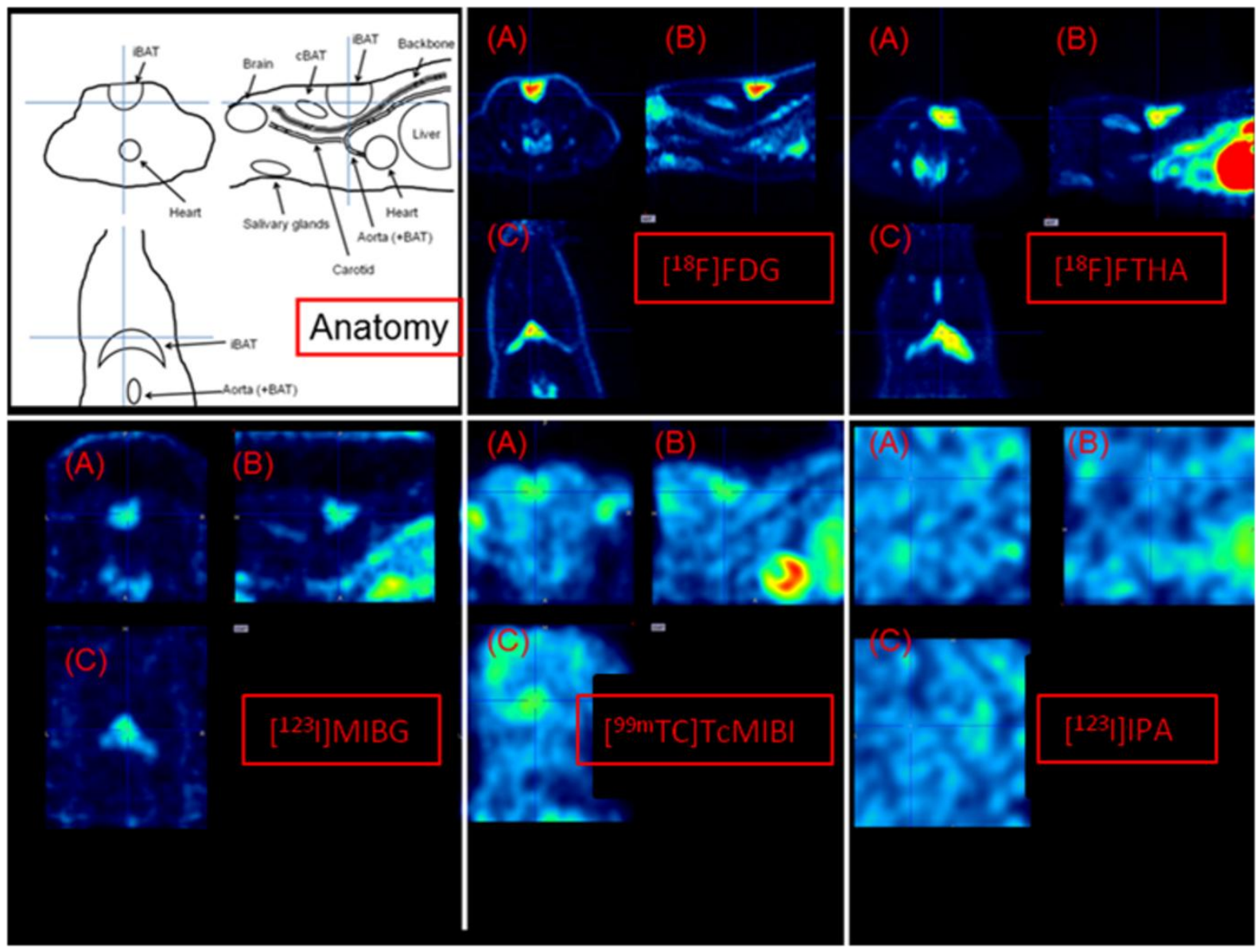

Fig 4: Transverse (A), sagittal (B) and coronal (C) slices of images from a cold-acclimated rat, centered on iBAT, depicting the anatomy, $\left[{ }^{18} \mathrm{~F}\right]-\mathrm{FDG}$ distribution, $\left[{ }^{18} \mathrm{~F}\right]-\mathrm{FTHA}$ distribution, $\left[{ }^{123} \mathrm{I}\right]-\mathrm{MIBG}$ distribution, $\left[{ }^{99 \mathrm{~m}} \mathrm{TC}\right]-\mathrm{MIBI}$ and $\left[{ }^{123} \mathrm{I}\right]-$ IPA distribution. iBAT, and to some extent cBAT show a high uptake for all tracers except $\left[{ }^{123} \mathrm{I}\right]-$ IPA.

Figure 5 shows the SUV mean values for each tracer in iBAT in different conditions. It can be seen that acute cold exposure results in an increased $S U V_{\text {mean }}$ value for $\left[{ }^{18} \mathrm{~F}\right] \mathrm{FDG}$, $\left[{ }^{18} \mathrm{~F}\right] \mathrm{FTHA},\left[{ }^{123} \mathrm{I}\right] \mathrm{MIBG}$ and $\left[{ }^{99 \mathrm{~m}} \mathrm{Tc}\right] \mathrm{TcM} \mathrm{BBI}$ in iBAT when compared to baseline conditions ( $\mathrm{p}$ values are respectively $0.11 ; 0.03 ; 0.001$ and 0.02 ) (also see Table 1 ). Cold acclimation results in similar increases when compared to room temperature values. As shown in figure 2 , the metabolically active tissue volume in iBAT is increased after cold acclimation when investigated with $\left[{ }^{18} \mathrm{~F}\right] \mathrm{FDG},\left[{ }^{18} \mathrm{~F}\right] \mathrm{FTHA},\left[{ }^{123} \mathrm{I}\right] \mathrm{MIBG}$ and $\left[{ }^{99 \mathrm{~m}} \mathrm{Tc}\right] \mathrm{TcMIBI}$. Surprisingly, this increase in labeled tissue is already present after single acute cold exposure for $\left[{ }^{18} \mathrm{~F}\right] \mathrm{FTHA}$ and to some extent also $\left[{ }^{123}\right.$ I]MIBG. $\left[{ }^{123}\right.$ I]IPA shows poor uptake in iBAT, preventing accurate VOI drawing. As a result, it is only possible to estimate SUV ${ }_{\text {mean }}\left[{ }^{123}\right.$ I]IPA values in iBAT, but 
not the metabolic volume or total metabolic activity. The $S_{U} V_{\text {mean }}$ values show no change over the course over the experiment.

Table 1: SUV, metabolic volume and total metabolic activity of $\left[{ }^{18} \mathrm{~F}\right] \mathrm{FDG},\left[{ }^{18} \mathrm{~F}\right] \mathrm{FTHA},\left[{ }^{123}\right] \mathrm{MIBG},\left[{ }^{99 \mathrm{~m}} \mathrm{Tc}\right] \mathrm{TCMIBI}$ and $\left[{ }^{123} \mid\right]$ IPA in iBAT in baseline conditions, after acute cold exposure, after cold acclimation and after uptake in the cold. $\uparrow$ indicates a $p$-value $<0,10$ when compared to baseline conditions, while $\dagger$ indicates a $p$-value $<0,10$ when compared to the value after acute cold exposure. NQ indicates "not quantifiable", while NA means these data are not available.

\begin{tabular}{|c|c|c|c|c|}
\hline iBAT & Baseline & $\begin{array}{l}\text { Acute cold } \\
\text { exposure }\end{array}$ & Acclimated to cold & Uptake in cold \\
\hline Tracer & \multicolumn{4}{|c|}{$\operatorname{SUV}\left(\mathrm{g} / \mathrm{cm}^{3}\right)$} \\
\hline$\left[{ }^{18} \mathrm{~F}\right] \mathrm{FDG}$ & $1.54 \pm 0.26$ & $3.24 \pm 0.88$ & $3.10 \pm 1.39$ & $3.23 \pm 1.51$ \\
\hline$\left[{ }^{18} \mathrm{~F}\right] \mathrm{FTHA}$ & $0.92 \pm 0.07$ & $2.14 \pm 0.20 \uparrow$ & $1.78 \pm 0.22 \uparrow$ & $2.36 \pm 0.24 \uparrow$ \\
\hline$\left[{ }^{123} \mathrm{I}\right] \mathrm{MIBG}$ & $0.86 \pm 0.24$ & $3.15 \pm 0.20 \uparrow$ & $2.06 \pm 0.42 \uparrow$ & $1.82 \pm 0.12 \uparrow$ \\
\hline$\left[{ }^{99 m}\right.$ Tc]TcMIBI & $1.99 \pm 0.31$ & $2.69 \pm 0.34 \uparrow$ & $2.20 \pm 0.40$ & $2.83 \pm 0.56$ \\
\hline \multirow[t]{2}{*}[{}^{123}|]{$\mid P A$} & $1.27 \pm 0.04$ & $1.21 \pm 0.09$ & $1.22 \pm 0.01$ & NA \\
\hline & \multicolumn{4}{|c|}{ Metabolic volume $\left(\mathrm{cm}^{3}\right)$} \\
\hline$\left[{ }^{18} \mathrm{~F}\right] \mathrm{FDG}$ & $0.32 \pm 0.07$ & $0.35 \pm 0.12$ & $0.59 \pm 0.06 \uparrow$ & $0.54 \pm 0.03 \uparrow$ \\
\hline$\left[{ }^{18} \mathrm{~F}\right] \mathrm{FTHA}$ & $0.20 \pm 0.01$ & $0.62 \pm 0.04 \uparrow$ & $0.80 \pm 0.06 \uparrow, \dagger$ & $0.64 \pm 0.12 \uparrow$ \\
\hline$\left[{ }^{123} \mathrm{I}\right] \mathrm{MIBG}$ & $0.08 \pm 0.02$ & $0.15 \pm 0.02 \uparrow$ & $0.41 \pm 0.05 \uparrow, \dagger$ & $0.30 \pm 0.03 \uparrow, \dagger$ \\
\hline$\left[{ }^{99 m} \mathrm{Tc}\right] \mathrm{TcMIBI}$ & $0.23 \pm 0.03$ & $0.23 \pm 0.05$ & $0.36 \pm 0.05 \uparrow, \uparrow$ & $0.42 \pm 0.05 \uparrow, \dagger$ \\
\hline \multirow[t]{2}{*}[{}^{123}|]{$\mid P A$} & $\mathrm{NQ}$ & $\mathrm{NQ}$ & $\mathrm{NQ}$ & NA \\
\hline & \multicolumn{4}{|c|}{ Total metabolic activity (SUV $\times$ Volume) $\left(\mathrm{cm}^{3}\right)$} \\
\hline$\left[{ }^{18} \mathrm{~F}\right] \mathrm{FDG}$ & $0.48 \pm 0.09$ & $0.89 \pm 0.11 \uparrow$ & $1.71 \pm 0.52 \uparrow$ & $1.78 \pm 0.66 \uparrow$ \\
\hline$\left[{ }^{18} \mathrm{~F}\right] \mathrm{FTHA}$ & $0.18 \pm 0.01$ & $1.41 \pm 0.16 \uparrow$ & $1.41 \pm 0.17 \uparrow$ & $1.54 \pm 0.38 \uparrow$ \\
\hline$\left[^{123} \mathrm{I}\right] \mathrm{MIBG}$ & $0.07 \pm 0.04$ & $0.46 \pm 0.06 \uparrow$ & $0.79 \pm 0.12 \uparrow, \dagger$ & $0.54 \pm 0.02 \uparrow, \dagger$ \\
\hline$\left[{ }^{99 m} \mathrm{Tc}\right] \mathrm{TcMIBI}$ & $0.43 \pm 0.06$ & $0.59 \pm 0.08$ & $0.74 \pm 0.06 \uparrow$ & $1.25 \pm 0.34 \uparrow, \dagger$ \\
\hline$\left[{ }^{123} \mid\right] \mid P A$ & $\mathrm{NQ}$ & $\mathrm{NQ}$ & $\mathrm{NQ}$ & NA \\
\hline
\end{tabular}




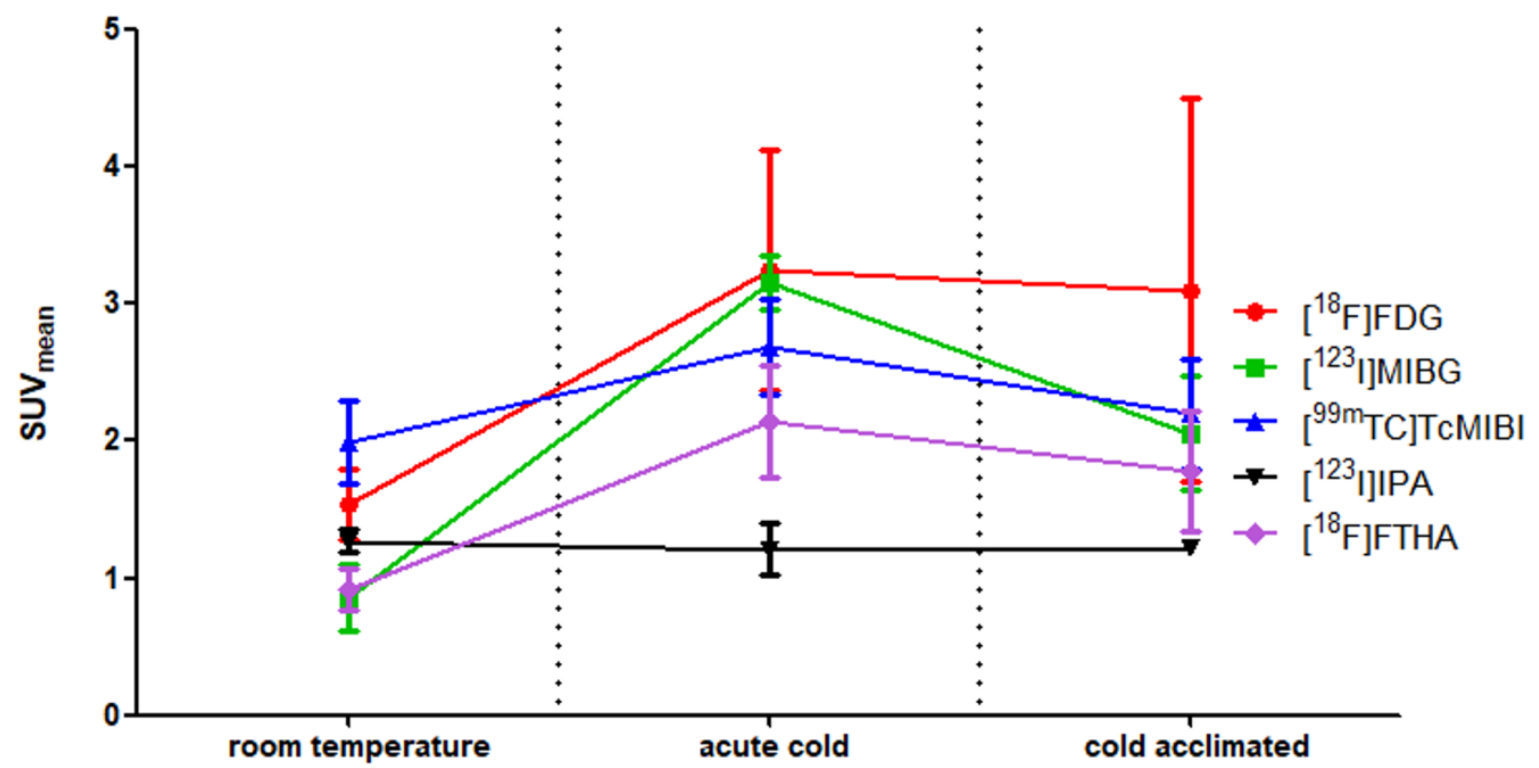

Fig 5: iBAT SUV ${ }_{\text {mean }}$ values of $\left[{ }^{18} \mathrm{~F}\right]-\mathrm{FDG},\left[{ }^{18} \mathrm{~F}\right]-\mathrm{FTHA},\left[{ }^{123} \mathrm{I}\right]-\mathrm{MIBG},\left[{ }^{99 \mathrm{~m}} \mathrm{Tc}\right]-\mathrm{MIBI}$ and $\left[{ }^{123} \mathrm{l}\right]-\mathrm{IPA}$ in different temperature conditions.

In comparison, the myocardium and the liver showed no significant changes in $\mathrm{SUV}_{\text {mean }}$ values throughout the study for any of the tracers, nor did their (metabolic) volume change. In addition, there was no difference in data obtained from images that were acquired by injecting the tracer in cold-acclimated animals under the camera, in a room where the animal was no longer exposed to cold during tracer distribution, and images that were acquired after the tracer had been given the chance to distribute in the cold-acclimated animal for 30 minutes in a cold environment (also see Table 1).

Analysis of biodistribution data obtained from dissected tissue (Table 2) confirms the data obtained from images. Dissection data did allow quantification of a number of aspects that were impossible to derive from imaging data, such as the discrimination between iWAT and iBAT, thereby clearly showing that only iBAT has tracer uptake. Perivascular BAT, often visible but never quantifiable on images due to its small size and structure, showed a similar uptake to that in BBAT when corrected for weight. 
Table 2: Biodistribution (determined by dissection) of $\left[{ }^{18} \mathrm{~F}\right] \mathrm{FDG},\left[{ }^{18} \mathrm{~F}\right] \mathrm{FTHA},\left[{ }^{123}\right] \mathrm{MIBG},\left[{ }^{99 \mathrm{~m}} \mathrm{TC}\right] \mathrm{TCMIBI}$ and $\left.\left[{ }^{123}\right]\right] \mathrm{IPA}$ in selected organs $1 \mathrm{~h}$ after tracer uptake in the cold.

\begin{tabular}{|l|l|l|l|l|l|}
\hline \%ID/g & {$\left[{ }^{18} \mathrm{~F}\right] \mathrm{FDG}$} & $\left.{ }^{18} \mathrm{~F}\right] \mathrm{FTHA}$ & $\left.{ }^{123} \mathrm{I}\right] \mathrm{MIBG}$ & {$\left[{ }^{99 \mathrm{~T}} \mathrm{Tc}\right] \mathrm{TCMIBI}$} & {$\left[{ }^{123} \mathrm{I}\right] \mathrm{IPA}$} \\
\hline iBAT & $2.89 \pm 0.66$ & $1.36 \pm 0.39$ & $0.93 \pm 0.23$ & $0.90 \pm 0.10$ & $0.37 \pm 0.04$ \\
\hline iWAT & $0.41 \pm 0.12$ & $0.16 \pm 0.06$ & $0.18 \pm 0.03$ & $0.16 \pm 0.02$ & $0.26 \pm 0.03$ \\
\hline Perivascular & $3.65 \pm 1.55$ & $1.08 \pm 0.30$ & $2.02 \pm 0.54$ & $1.49 \pm 0.37$ & $0.52 \pm 0.05$ \\
\hline Intestinal WAT & $0.19 \pm 0.01$ & $0.14 \pm 0.05$ & $0.12 \pm 0.03$ & $0.05 \pm 0.01$ & $0.22 \pm 0.10$ \\
\hline $\begin{array}{l}\text { Subcutaneous } \\
\text { WAT }\end{array}$ & $0.18 \pm 0.02$ & $0.08 \pm 0.01$ & $0.17 \pm 0.05$ & $0.10 \pm 0.03$ & $0.04 \pm 0.07$ \\
\hline Liver & & & & & \\
\hline Lung & $0.37 \pm 0.04$ & $3.16 \pm 0.38$ & $1.64 \pm 0.14$ & $1.25 \pm 0.26$ & $0.68 \pm 0.04$ \\
\hline Heart & $0.36 \pm 0.05$ & $0.53 \pm 0.11$ & $3.45 \pm 0.39$ & $0.55 \pm 0.02$ & $0.57 \pm 0.02$ \\
\hline Muscle & $2.34 \pm 0.25$ & $1.01 \pm 0.08$ & $4.35 \pm 0.34$ & $3.00 \pm 0.23$ & $0.58 \pm 0.01$ \\
\hline Salivary glands & $0.10 \pm 0.01$ & $0.07 \pm 0.01$ & $0.11 \pm 0.01$ & $0.12 \pm 0.02$ & $0.40 \pm 0.04$ \\
\hline Blood & $0.34 \pm 0.06$ & $0.12 \pm 0.01$ & $0.16 \pm 0.01$ & $0.02 \pm 0.01$ & $0.93 \pm 0.02$ \\
\hline
\end{tabular}

\section{MR Spectroscopy}

The use of the gradient-echo sequence with a fat suppression pulse made it possible to visualize the position of BAT in rat (Fig 6). The FLASH sequence combined with a fat suppression pulse, makes the WAT darker in comparison to the BAT. Temperature was determined in BAT, and as a reference, also in muscle tissue by MRS and furthermore, rectal temperature was determined. The one-hour cooling protocol resulted in a decreased temperature of $1.9 \pm 0.9{ }^{\circ} \mathrm{C}$ in non-acclimated animals and a decrease of $1.8 \pm 0.9{ }^{\circ} \mathrm{C}$ in cold-acclimated animals (also see Table 3). During this period of cooling, MRS-derived temperature in BAT decreased by $1.2 \pm 0.9^{\circ} \mathrm{C}$ in non-acclimated animals but increased by $0.3 \pm 1.5{ }^{\circ} \mathrm{C}$ in cold-acclimated animals $(\mathrm{p}=0.22)$. MRS-derived temperature in muscular tissue (including a minor amount of subcutaneous adipose tissue) decreased by $2.4 \pm 1.5^{\circ} \mathrm{C}$ in non-acclimated animals and by $1.4 \pm 1.8^{\circ} \mathrm{C}$ in cold-acclimated animals $(p=0.18)$. In coldacclimated animals the decrease in BAT temperature is less pronounced than that in 
subcutaneous muscular tissue $(p=0.08)$ or in the rectum $(p=0.004)$, while temperature in non-acclimated animals showed a similar time course in BAT vs. muscle and rectal temperature $(p>0.15$ and $>0.17$ respectively).

Table 3: MRS-derived temperature differences in BAT and Muscle and rectal temperature difference in control and cold-acclimated animals. There is no statistically significant difference between cold-acclimated and control animals.

\begin{tabular}{|l|l|l|}
\hline $\begin{array}{l}\text { Temperature change upon } 1 \text { hour } \\
\text { of cooling }\end{array}$ & Control & Cold-acclimated \\
\hline Rectal & $-1.9 \pm 0.9^{\circ} \mathrm{C}$ & $-1.8 \pm 0.9^{\circ} \mathrm{C}$ \\
\hline MRS-derived muscle & $-2.4 \pm 1.5^{\circ} \mathrm{C}$ & $-1.4 \pm 1.8^{\circ} \mathrm{C}$ \\
\hline MRS-derived BAT & $-1.2 \pm 0.9^{\circ} \mathrm{C}$ & $+0.3 \pm 1.5^{\circ} \mathrm{C}$ \\
\hline
\end{tabular}
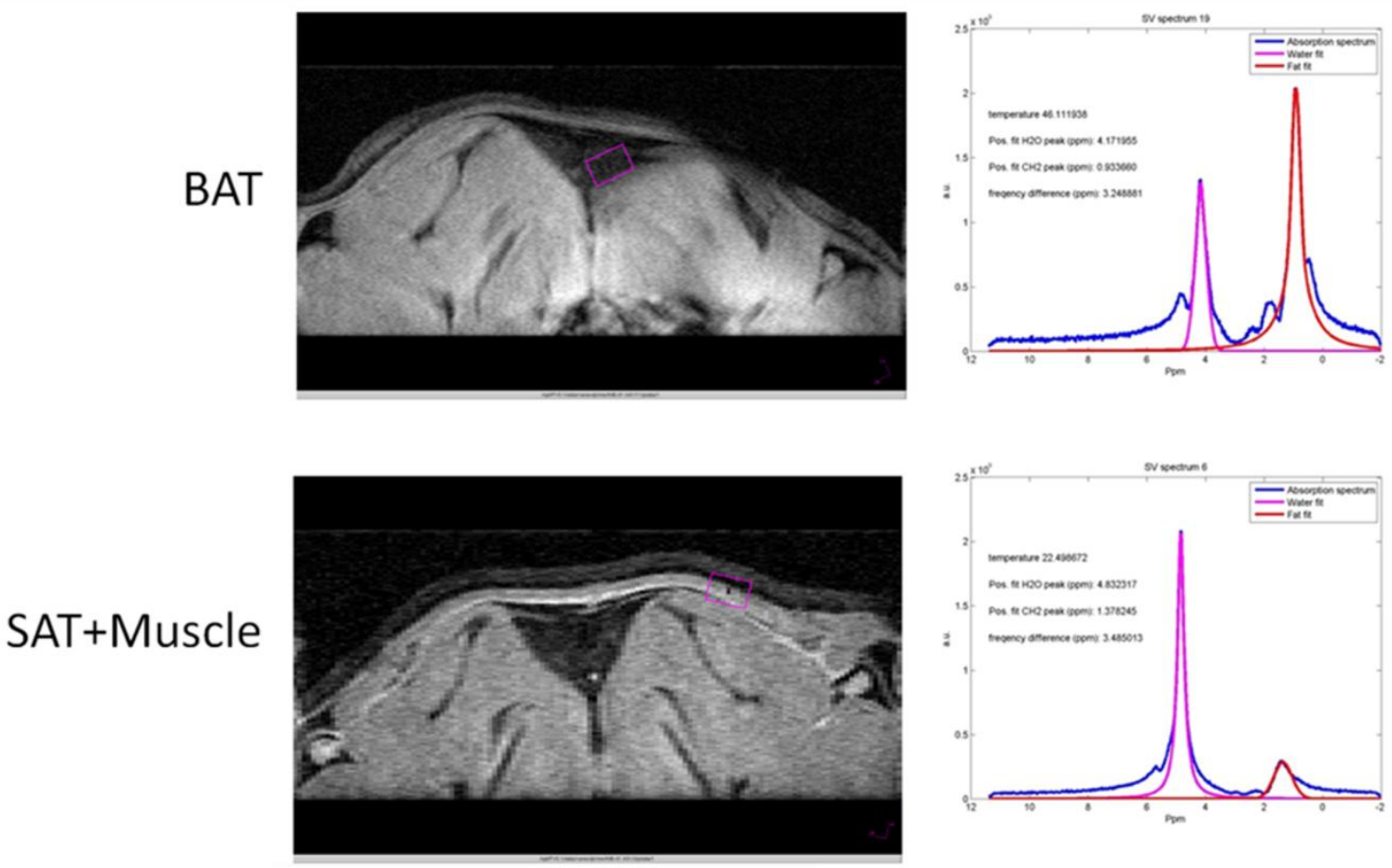

FLASH image

MRS spectrum of water and lipid signal

Fig 6: Images and their corresponding spectra from different positions in the body. BAT = Brown Adipose tissue, SAT = Subcutaneous Adipose Tissue. 


\section{mRNA expression and protein expression}

mRNA expression of genes related to BAT metabolism (PPARY2, C/EBPa, UCP1, ADRB3, DIO2, ATGL, PRDM16) were higher in iBAT compared to iWAT. Similar results were observed for GLUT4 mRNA expression when comparing iBAT to iWAT although the results did not reach statistical significance (data not shown). When examining protein expression, control animals showed higher levels of UCP1 and GLUT4 protein expression in iBAT compared to WAT, however CD36 protein expression was similar between BBAT and WAT $(p=0.43)$.

Cold acclimation did not alter mRNA expression of the selected genes in BAT. PRDM16 mRNA expression decreased following cold acclimation in BAT $(p=0.013)$. No changes in protein levels of UCP1, GLUT4 or CD36 in BAT were detected following cold acclimation using western blot (data not shown). 


\section{Discussion}

In this study, we used a rat model to assess BAT molecular imaging with $\left[{ }^{18} \mathrm{~F}\right] \mathrm{FDG}$, $\left.\left[{ }^{18} \mathrm{~F}\right] \mathrm{FTHA},\left[{ }^{123}\right]\right] \mathrm{MIBG},\left[{ }^{99 \mathrm{~T}} \mathrm{Tc}\right] \mathrm{TCMIBI}$ and $\left[{ }^{123} \mathrm{I}\right] \mathrm{IPA}$ in baseline and different cold-stimulated conditions. Additionally we investigated temperature of BAT and muscle as a negative control in cold stimulated conditions by MRS and analyzed mRNA and protein expression of a number of relevant genes.

In our model, cold acclimation caused a clear growth of iBAT volume, while white interscapular adipose tissue decreased in volume. mRNA and protein levels easily allowed to distinguish brown from white adipose tissue in our study, but did not show any significant differences between control and cold-acclimated animals. Unlike reported in literature ${ }^{26,35-37}$ we cannot report an up regulation of BAT specific genes (e.g. UCP1, PPARy, LPL). This can be caused by several reasons e.g. the biological half-life of certain mRNAs is in the order of hours and therefore dependent on diurnal variations. Timing of sampling might therefore of high importance ${ }^{38,39}$. Furthermore, the choice of housekeeping genes is a topic of discussion. In our experiment, a broadly used housekeeping gene, GAPDH was variable throughout the experiment and therefore not suitable as reference. As we expose the animals to cold over a long period, cell type alterations in the whole fat depot are possible which can be caused e.g. by cell differentiation. In such experiments, the choice of housekeeping gene is especially difficult, as these alterations might affect the transcriptional apparatus and by that the absolute expression of the housekeeping gene might be changed 26.

Protein expression levels of relevant genes did allow, just like mRNA expression levels, to distinguish BAT from WAT. However, just like mRNA expression levels, cold-acclimation did not lead to a significant change in protein expression levels.

Although we were not able to report any differences in mRNA/protein levels of BAT in cold acclimated vs. control animals as reported in literature (e.g. UCP1 ${ }^{26}$, PPARy ${ }^{35}, \mathrm{CD} 36{ }^{36,37}$ ) 
we were able to distinguish between BAT and WAT by these techniques, which was important for ex vivo analysis of tissue samples.

MRS showed that the temperature drop in BAT was less pronounced after cold acclimation, which can be interpreted as an increase in BAT activity. In cold acclimated animals BAT temperature differed significantly in comparison to rectal and muscle temperature. A comparison between BAT temperatures of non cold acclimated vs. cold acclimated animals showed a clear trend towards higher temperatures in cold acclimated animals but did not reach significant differences. This is also in accordance with the results obtained from the biodistribution where cold acclimation significantly increased iBAT volume. A larger BAT depot, which results from cold acclimation, would be better suited to maintain or even increase its temperature during cold due to more active BAT.

$\left[{ }^{18} \mathrm{~F}\right] \mathrm{FDG}$ allowed iBAT visualization in warm conditions as well as in animals exposed to acute cold and cold-acclimated animals. If animals were exposed to cold, cBAT was visible as well. $\left[{ }^{18} \mathrm{~F}\right] \mathrm{FTHA},\left[{ }^{123} \mathrm{I}\right] \mathrm{MIBG}$ and $\left[{ }^{99 \mathrm{~m}} \mathrm{Tc}\right] \mathrm{TcMIBI}$ poorly visualized iBAT in warm conditions, but clearly showed iBAT and to some extent also cBAT in animals exposed to acute cold and when animals were acclimated to cold. $\left[{ }^{123}\right.$ I]IPA did not visualize iBAT in any setting and is therefore not suited as a BAT imaging tracer.

The analysis of tracer SUV $_{\text {mean }}$ values in iBAT showed that, when compared to warm conditions, the focal uptake of $\left[{ }^{18} \mathrm{~F}\right] \mathrm{FDG},\left[{ }^{18} \mathrm{~F}\right] \mathrm{FTHA}$ and $\left[{ }^{123} \mathrm{I} \mathrm{MIBG}\right.$ in animals exposed to acute cold was about double, while for $\left.{ }^{99 \mathrm{~m}} \mathrm{Tc}\right] \mathrm{TcMIBI}$ the increase was by a factor of 1.3 . Considering the time window of 4 hours cold exposure, the factor of 1.3 is probably due to an increase in perfusion / blood flow and not to an increase in mitochondrial density. This confirms earlier findings of increased blood flow due to cold exposure with other tracers such as $\left[{ }^{201}\right.$ TI]thallium chloride ${ }^{11}$.

Cold-acclimation did not further increase focal uptake of any of the tracers, indicating that one single $4 \mathrm{~h}$ cold exposure is sufficient to reach a maximum tracer uptake in (the metabolically active part of) iBAT in our rodent model. This is in contrast to what has been reported in humans, where the SUV mean of active BAT continued to increase upon chronic 
cold acclimation ${ }^{27,40}$. We hypothesized that this effect is induced by the fact that room temperature $\left(22^{\circ} \mathrm{C}\right)$ is already below the thermoneutral zone of rats $\left(\sim 30^{\circ} \mathrm{C}\right){ }^{41}$ so that a slight cold acclimation already takes place under control conditions.

The volume of tissue with a high tracer uptake shows a different pattern, as the volume after cold exposure is similar to that in warm conditions and is only increased upon coldacclimation for $\left[{ }^{18} \mathrm{~F}\right] \mathrm{FDG}$ and $\left[{ }^{99 \mathrm{~m}} \mathrm{Tc}\right] \mathrm{MIBI}$. For $\left[{ }^{18} \mathrm{~F}\right] \mathrm{FTHA}$ and $\left[{ }^{123}\right] \mathrm{MIBG}$ the increase in volume already starts after acute cold exposure, and then increases further upon coldacclimation. These findings are to some extent not congruent with those found in literature from clinical studies, in which $\left[{ }^{18} \mathrm{~F}\right] \mathrm{FTHA}$ showed a lack of uptake under acute cold exposure and less uptake compared to FDG upon cold stimulation ${ }^{14}$. This difference in $\left[{ }^{18} \mathrm{~F}\right] \mathrm{FTHA}$ may be due to a metabolic difference in animal species (rat vs. human), but may also be due to the higher difficulty of delineating brown adipose tissue in humans compared to rats. The volume increase of active BAT is in accordance with the results obtained from MRS and the biodistribution where increased BAT temperature or volume could only be found after cold acclimation.

The total BAT activity is increased firstly by an acute cold exposure which induced an increase in metabolic activity in a small volume of iBAT (i.e. activation of existing brown adipocytes), and secondly by a cold-acclimation induced increased in metabolically active volume (i.e. increased number of activated brown adipocytes). This is different from humans, where cold acclimation leads to both an increased volume and increased SUV $\mathrm{V}_{\text {mean }}$ value ${ }^{27}$. It is possible that, compared to the necessary presence of frequently activated BAT in rodents, human BAT may be more facultative and therefore can be stimulated to a greater extent when compared to baseline room temperature conditions.

All tracer except for $\left[{ }^{123}\right.$ I]IPA were able to visualize BAT under acute and acclimated cold conditions. With the support of the different tracer we were able to investigate different aspects of BAT metabolism and features during cold exposure and compare these results to other measurement techniques. Invasive measurements of BAT volume were coherent with results obtained by MRS and dissection of iBAT. 
The current imaging procedures in humans, with different cooling protocols and different tracers in different centers, is known to confer significantly different results in terms of total BAT activity, especially when comparing different tracers ${ }^{1,42-46}$. Our data may offer an explanation for this phenomenon, as tracer uptake can be dependent on the amount of cold exposure, and the nature of this dependence seems different for each tracer. 


\section{Conclusion}

$\left[{ }^{18} \mathrm{~F}\right] \mathrm{FDG},\left[{ }^{18} \mathrm{~F}\right] \mathrm{FTHA},\left[{ }^{123} \mathrm{IMIBG}\right.$ and $\left[{ }^{99 m} \mathrm{Tc}\right] \mathrm{TcMIBI}$, but not $\left[{ }^{123} \mathrm{I}\right] \mathrm{IPA}$, are suitable for imaging aspects of BAT activity using non-invasive molecular imaging, while MRS is able to quantify heat production in BAT, even in an animal model where classical ex vivo techniques fail to show significant trends. The uptake in BAT of each tracer responds differently to acute cold exposure, and cold-acclimation does not increase BAT tracer uptake as strongly in our animal model as it does in humans. Those differences in tracer uptake characteristics should be considered during study planning as well as it should be translated to clinical applications. 


\section{References}

1 Cannon, B. \& Nedergaard, J. Brown adipose tissue: function and physiological significance. Physiol Rev 84, 277-359, doi:10.1152/physrev.00015.2003 84/1/277 [pii] (2004).

2 Nedergaard, J., Bengtsson, T. \& Cannon, B. New powers of brown fat: fighting the metabolic syndrome. Cell Metab 13, 238-240, doi:S1550-4131(11)00053-2 [pii] 10.1016/j.cmet.2011.02.009 (2011).

Cypess, A. M. \& Kahn, C. R. The role and importance of brown adipose tissue in energy homeostasis. Curr Opin Pediatr 22, 478-484, doi:10.1097/MOP.0b013e32833a8d6e [doi] (2010).

Lee, P., Greenfield, J. R., Ho, K. K. \& Fulham, M. J. A critical appraisal of the prevalence and metabolic significance of brown adipose tissue in adult humans. Am J Physiol Endocrinol Metab 299, E601-606, doi:ajpendo.00298.2010 [pii] 10.1152/ajpendo.00298.2010 (2010).

5 Saito, M. et al. High incidence of metabolically active brown adipose tissue in healthy adult humans: effects of cold exposure and adiposity. Diabetes 58, 1526-1531, doi:db09-0530 [pii] 10.2337/db09-0530 (2009).

6 Bauwens, M. et al. Molecular imaging of brown adipose tissue in health and disease. Eur J Nucl Med Mol Imaging 41, 776-791, doi:10.1007/s00259-013-2611-8 [doi] (2014).

7 Machann, J., Horstmann, A., Born, M., Hesse, S. \& Hirsch, F. W. Diagnostic imaging in obesity. Best Pract Res Clin Endocrinol Metab 27, 261-277, doi:S1521690X(13)00021-3 [pii] 10.1016/j.beem.2013.02.003 [doi] (2013).

Lee, P., Swarbrick, M. M. \& Ho, K. K. Brown Adipose Tissue in Adult Humans: A Metabolic Renaissance. Endocr Rev, doi:er.2012-1081 [pii] 10.1210/er.2012-1081 [doi] (2013).

9 Symonds, M. E. et al. Thermal imaging to assess age-related changes of skin temperature within the supraclavicular region co-locating with brown adipose tissue in healthy children. $J$ Pediatr 161, 892-898, doi:S0022-3476(12)00492-1 [pii] 10.1016/j.jpeds.2012.04.056 [doi] (2012).

10 Boon, M. R. et al. Supraclavicular skin temperature as a measure of 18F-FDG uptake by BAT in human subjects. PLoS One 9, e98822, doi:10.1371/journal.pone.0098822 [doi] PONE-D-14-06900 [pii] (2014).

11 Baba, S., Engles, J. M., Huso, D. L., Ishimori, T. \& Wahl, R. L. Comparison of uptake of multiple clinical radiotracers into brown adipose tissue under cold-stimulated and nonstimulated conditions. J Nucl Med 48, 1715-1723, doi:jnumed.107.041715 [pii] 10.2967/jnumed.107.041715 [doi] (2007).

12 Kyparos, D. et al. Assessment of brown adipose tissue activity in rats by $99 \mathrm{mTc}$ sestamibi uptake. Physiol Res 55, 653-659, doi:890 [pii] (2006).

13 Goetze, S., Lavely, W. C., Ziessman, H. A. \& Wahl, R. L. Visualization of brown adipose tissue with 99mTc-methoxyisobutylisonitrile on SPECT/CT. J Nucl Med 49, 752-756, doi:jnumed.107.048074 [pii] 10.2967/jnumed.107.048074 [doi] (2008).

14 Ouellet, V. et al. Brown adipose tissue oxidative metabolism contributes to energy expenditure during acute cold exposure in humans. The Journal of clinical investigation 122, 545-552, doi:10.1172/JCI60433 (2012).

15 Admiraal, W. M. et al. Combining 123I-metaiodobenzylguanidine SPECT/CT and 18F-FDG PET/CT for the assessment of brown adipose tissue activity in humans during cold exposure. J Nucl Med 54, 208-212, doi:jnumed.112.111849 [pii] 10.2967/jnumed.112.111849 [doi] (2013).

16 Huang, Y. C., Wang, P. W., Tang, S. W., Hung, P. L. \& Hsu, C. C. Identifying Ga-67 uptake in brown adipose tissue with SPECT/CT. Clin Nucl Med 34, 964-966, doi:10.1097/RLU.0b013e3181bed182 [doi] 00003072-200912000-00040 [pii] (2009). 
17 Yu, X. X., Lewin, D. A., Forrest, W. \& Adams, S. H. Cold elicits the simultaneous induction of fatty acid synthesis and beta-oxidation in murine brown adipose tissue: prediction from differential gene expression and confirmation in vivo. FASEB J 16, 155-168, doi:10.1096/fj.01-0568com (2002).

18 Townsend, K. L. \& Tseng, Y.-H. Brown fat fuel utilization and thermogenesis. Trends Endocrinol Metab 25, 168-177, doi:10.1016/j.tem.2013.12.004 (2014).

19 Blondin, D. P. et al. Selective Impairment of Glucose but Not Fatty Acid or Oxidative Metabolism in Brown Adipose Tissue of Subjects With Type 2 Diabetes. Diabetes 64, 2388-2397, doi:10.2337/db14-1651 (2015).

20 Putri, M. et al. CD36 is indispensable for thermogenesis under conditions of fasting and cold stress. Biochem Biophys Res Commun 457, 520-525, doi:S0006291X(15)00031-5 [pii] 10.1016/j.bbrc.2014.12.124 [doi] (2015).

21 Bachman, E. S. et al. betaAR signaling required for diet-induced thermogenesis and obesity resistance. Science 297, 843-845, doi:10.1126/science.1073160 (2002).

22 Cypess, A. M. et al. Activation of human brown adipose tissue by a $\beta 3$-adrenergic receptor agonist. Cell Metab 21, 33-38, doi:10.1016/j.cmet.2014.12.009 (2015).

23 Sun, L., Yan, J., Sun, L., Velan, S. S. \& Leow, M. K. S. A synopsis of brown adipose tissue imaging modalities for clinical research. Diabetes Metab, doi:10.1016/j.diabet.2017.03.008 (2017).

24 Lee, P. et al. High prevalence of brown adipose tissue in adult humans. $J$ Clin Endocrinol Metab 96, 2450-2455, doi:jc.2011-0487 [pii] 10.1210/jc.2011-0487 (2011).

25 Nascimento, E. B. M. et al. Genetic Markers of Brown Adipose Tissue Identity and In Vitro Brown Adipose Tissue Activity in Humans. Obesity (Silver Spring) 26, 135-140, doi:10.1002/oby.22062 (2018).

26 Nedergaard, J. \& Cannon, B. UCP1 mRNA does not produce heat. Biochim Biophys Acta 1831, 943-949, doi:S1388-1981(13)00027-9 [pii] 10.1016/j.bbalip.2013.01.009 [doi] (2013).

27 van der Lans, A. A. et al. Cold acclimation recruits human brown fat and increases nonshivering thermogenesis. The Journal of clinical investigation, doi:68993 [pii] 10.1172/JCl68993 [doi] (2013).

28 Broeders, E., Bouvy, N. D. \& van Marken Lichtenbelt, W. D. Endogenous ways to stimulate brown adipose tissue in humans. Ann Med, doi:10.3109/07853890.2013.874663 [doi] (2014).

29 Barrett, J. A. et al. Comparison of high-specific-activity ultratrace 123/131I-MIBG and carrier-added 123/131I-MIBG on efficacy, pharmacokinetics, and tissue distribution. Cancer Biother Radiopharm 25, 299-308, doi:10.1089/cbr.2009.0695 [doi] (2010).

30 Samnick, S. et al. Investigation of iodine-123-labelled amino acid derivatives for imaging cerebral gliomas: uptake in human glioma cells and evaluation in stereotactically implanted C6 glioma rats. Eur J Nucl Med 27, 1543-1551 (2000).

31 Mertens, J. et al. Synthesis, radiosynthesis, and in vitro characterization of [125I]-2iodo-L-phenylalanine in a R1M rhabdomyosarcoma cell model as a new potential tumor tracer for SPECT. Nucl Med Biol 31, 739-746, doi:10.1016/j.nucmedbio.2004.03.003 [doi] S0969805104000496 [pii] (2004).

32 DeGrado, T. R., Coenen, H. H. \& Stocklin, G. 14(R,S)-[18F]fluoro-6-thiaheptadecanoic acid (FTHA): evaluation in mouse of a new probe of myocardial utilization of long chain fatty acids. J Nucl Med 32, 1888-1896 (1991).

33 Fueger, B. J. et al. Impact of animal handling on the results of 18F-FDG PET studies in mice. J Nucl Med 47, 999-1006, doi:47/6/999 [pii] (2006).

34 Fischer, A. W. et al. UCP1 inhibition in Cidea-overexpressing mice is physiologically counteracted by brown adipose tissue hyperrecruitment. Am J Physiol Endocrinol Metab 312, E72-e87, doi:10.1152/ajpendo.00284.2016 (2017).

35 Festuccia, W. T. et al. PPARgamma activation attenuates cold-induced upregulation of thyroid status and brown adipose tissue PGC-1alpha and D2. American journal of physiology. Regulatory, integrative and comparative physiology 303, R1277-1285, doi:10.1152/ajpregu.00299.2012 (2012). 
36 Bartelt, A. et al. Brown adipose tissue activity controls triglyceride clearance. Nature medicine 17, 200-205, doi:10.1038/nm.2297 (2011).

37 Bartelt, A., Merkel, M. \& Heeren, J. A new, powerful player in lipoprotein metabolism: brown adipose tissue. Journal of molecular medicine (Berlin, Germany) 90, 887-893, doi:10.1007/s00109-012-0858-3 (2012).

38 Patel, H. V., Freeman, K. B. \& Desautels, M. Selective loss of uncoupling protein mRNA in brown adipose tissue on deacclimation of cold-acclimated mice. Biochemistry and cell biology = Biochimie et biologie cellulaire 65, 955-959 (1987).

39 Pico, C. et al. Stabilization of the mRNA for the uncoupling protein thermogenin by transcriptional/translational blockade and by noradrenaline in brown adipocytes differentiated in culture: a degradation factor induced by cessation of stimulation? The Biochemical journal 302 ( Pt 1), 81-86 (1994).

40 Yoneshiro, T. et al. Recruited brown adipose tissue as an antiobesity agent in humans. The Journal of clinical investigation, doi:67803 [pii] 10.1172/JCl67803 [doi] (2013).

41 Romanovsky, A. A., Ivanov, A. I. \& Shimansky, Y. P. Selected contribution: ambient temperature for experiments in rats: a new method for determining the zone of thermal neutrality. Journal of applied physiology (Bethesda, Md. : 1985) 92, 26672679, doi:10.1152/japplphysiol.01173.2001 (2002).

42 Muzik, O. et al. 150 PET measurement of blood flow and oxygen consumption in cold-activated human brown fat. J Nucl Med 54, 523-531, doi:jnumed.112.111336 [pii] 10.2967/jnumed.112.111336 [doi] (2013).

43 Stock, M. J. Thermogenesis and brown fat: relevance to human obesity. Infusionstherapie 16, 282-284 (1989).

44 Rothwell, N. J. \& Stock, M. J. A role for brown adipose tissue in diet-induced thermogenesis. Nature 281, 31-35 (1979).

45 Rothwell, N. J. \& Stock, M. J. Luxuskonsumption, diet-induced thermogenesis and brown fat: the case in favour. Clin Sci (Lond) 64, 19-23 (1983).

46 Yoneshiro, T. et al. Brown adipose tissue, whole-body energy expenditure, and thermogenesis in healthy adult men. Obesity (Silver Spring) 19, 13-16, doi:oby2010105 [pii] 10.1038/oby.2010.105 (2011). 


\section{Supplementary Information}

\section{mRNA quantification}

Selected tissues were harvested from 16-week old Wistar rats that were housed continuously at room temperature $(\mathrm{n}=3)$ and frozen in RNA-later (Qiagen) at $-80{ }^{\circ} \mathrm{C}$ for later RNA isolation and gene expression analyses. The selected tissues were brown interscapular adipose tissue (iBAT), white interscapular adipose tissue (iWAT) and intraperitoneal WAT (ipWAT). Rat mRNA primer sets were PPARy, C/EBPa,, Sirtuin1, UCP1, UCP2, ADRB3, DIO2, GLUT4, ATGL, LPL and PRDM16.

Tissues were lysed, disrupted and homogenized using the Mini-BeadBeater by violently agitating $2 \mathrm{ml}$ screw-cap microvials containing small glass beads and RLT buffer (Qiagen) supplemented with 1\% 2-mercaptoethanol (Sigma). Total cellular RNA was isolated from lysed cells using RNeasy Mini kit (Qiagen) according to manufacturer's instructions. Genomic DNA was removed by DNAse I (Invitrogen) treatment followed by reverse transcription using random hexamer primers (Invitrogen) and Superscript III Reverse Transcriptase (Invitrogen) according to standard procedures. Primers for quantitative PCR analysis were generated using primer-BLAST software (NCBI). All primers were selected to span exon-exon boundaries with a maximal amplification length of $300 \mathrm{bp}$. Primer specificity was confirmed by melting curve analyses and product size confirmation by gel-based PCR analyses. Realtime PCR was performed with Sybr green detection (SensiMix SYBR \& Fluorescein Kit, Bioline) using an iCycler iQ (Biorad) and primers (10pmol) specific for the different genes. The PCR program consisted of $10 \mathrm{~min}$. initial heating at $95^{\circ} \mathrm{C}$ (hot start polymerase), followed by 35 cycles amplification $\left(30 \mathrm{sec}\right.$. at $95^{\circ} \mathrm{C}, 20 \mathrm{sec}$. at the optimized annealing temperature and $20 \mathrm{sec}$. at $72^{\circ} \mathrm{C}$ ) and a final heating up to $90^{\circ} \mathrm{C}$ (increasing $0.5^{\circ} \mathrm{C} / 30 \mathrm{sec}$.) for the generation of a melting curve. Quantification of a gene of interest was done by generating a standard curve using serial dilutions of a reference sample (mixed cDNA of BAT of 3 different rats). Relative expression levels were obtained by normalizing to the expression of $\beta$-actin in the corresponding sample. Each data point of the graphs was generated by 
determining expression of the gene of interest on the different rats in duplicate and normalizing these data to the corresponding expression of $\beta$-actin used as housekeeping gene in our assay ( $\beta$-actin was chosen as it was the most stable housekeeping gene in our experiment).

S1 Table: Relative mRNA expression levels (shown as a percentage of beta-actin expression) of different genes in iBAT, iWAT and ipWAT. Cold-acclimation = animals exposed to cold for $6 \mathrm{~h}$ per day for 4 weeks. - indicates a value below $1 \% .\left(^{*}\right)$ iicates a statistically significant difference between animals housed at RT or in coldacclimated conditions, while $(\dagger)$ indicates a statistically significant difference between brown adipose tissue and white adipose tissue.

\begin{tabular}{|c|c|c|c|c|c|c|}
\hline & Room tempe & housing & & Cold acclimat & & \\
\hline mRNA gene & iBAT & iWAT & ipWAT & iBAT & iWAT & ipWAT \\
\hline PPARy2 (†) & $139 \pm 25$ & $35 \pm 12$ & $50 \pm 7$ & $111 \pm 11$ & $32 \pm 12$ & $39 \pm 6$ \\
\hline $\mathrm{C} / \mathrm{EBP} \alpha(\dagger)$ & $237 \pm 43$ & $77 \pm 24$ & $93 \pm 20$ & $110 \pm 28\left(^{*}\right)$ & $55 \pm 19$ & $80 \pm 22$ \\
\hline FOXo1 & $139 \pm 38$ & $123 \pm 7$ & $71 \pm 19$ & $144 \pm 20$ & $84 \pm 21$ & $85 \pm 10$ \\
\hline Sirtuin1 & $198 \pm 31$ & $145 \pm 15$ & $125 \pm 24$ & $139 \pm 27$ & $96 \pm 2$ & $84 \pm 8$ \\
\hline UCP1 (†) & $238 \pm 43$ & $77 \pm 24$ & $93 \pm 20$ & $110 \pm 28\left(^{*}\right)$ & $55 \pm 19$ & $80 \pm 22$ \\
\hline UCP2 & $4 \pm 3$ & $13 \pm 8$ & $10 \pm 2$ & $6 \pm 1$ & $14 \pm 4$ & $20 \pm 9$ \\
\hline ADRB3 (†) & $517 \pm 175$ & $124 \pm 77$ & $157 \pm 63$ & $193 \pm 64\left(^{*}\right)$ & $50 \pm 30$ & $25 \pm 18\left(^{*}\right)$ \\
\hline DIO2 (†) & $5 \pm 3$ & - & - & $6 \pm 1$ & - & - \\
\hline GLUT4 (†) & $29 \pm 5$ & $3 \pm 1$ & $2 \pm 1$ & $24 \pm 5$ & $4 \pm 1$ & $6 \pm 1$ \\
\hline ATGL (†) & $295 \pm 78$ & $66 \pm 55$ & $51 \pm 21$ & $183 \pm 48$ & $20 \pm 11$ & $17 \pm 5$ \\
\hline LPL & $120 \pm 46$ & $83 \pm 38$ & $136 \pm 20$ & $129 \pm 18$ & $86 \pm 41$ & $130 \pm 30$ \\
\hline PRDM16 (†) & $125 \pm 15$ & $11 \pm 4$ & $7 \pm 1$ & $55 \pm 3\left(^{*}\right)$ & $4 \pm 1$ & $8 \pm 5$ \\
\hline
\end{tabular}


S2 Table: Primer sequences for RT-PCR. For each gene, a minimum of 20 bases was chosen for the primer length, which was increased where necessary to ensure specificity.

\begin{tabular}{|c|c|c|}
\hline mRNA gene & Forward & Reverse \\
\hline PPARY2 & GCCTGCGGAAGCCCTTTGGT & CAGCAAGCCTGGGCGGTCTC \\
\hline C/EBPa & GGTACGGCGGGAACGCAACA & GAAGATGCCCCGCAGCGTGT \\
\hline FOXo1 & GGACAGCCGCGCAAGACCAG & GACGGCTGGAACTGTCCGGG \\
\hline Sirtuin1 & GCTCGCCTTGCGGTGGACTT & GCCAGGGTGGTGATGGTCCC \\
\hline UCP1 & ACCTTCCCGCTGGACACTGC & CGGTGCGCACTAGCCCTTGA \\
\hline UCP2 & GCTGGGACAGCTGCCTGCAT & CAGCAGGTTGCCTCCCACCG \\
\hline ADRB3 & ACGAGATGGCTCCGTGGCCT & CGGCCCCATCAGCGGTCTTC \\
\hline DIO2 & GGGCTGCGCTGTGTCTGGAA & TAGGCTGGCTGTCCCACCCC \\
\hline GLUT4 & ACCCACCGGCAGCCTCTGAT & TGTGCTGCAGACATTGGCCTGG \\
\hline ATGL & TGGACGCCTGGGCATCTCCC & CACCCTGGGTTAGCCACCGTTTA \\
\hline LPL & AGTCTGGCTGACACTGGACAAACA & GCACCAACAGTTCCTCTCCAGGC \\
\hline PRDM16 & CCAATCAGGCGGGGTCTGGC & \\
\hline Beta-actin & CGACAACGGCTCCGGCATGT & \\
\hline
\end{tabular}




\section{Chapter 4: \\ Synthesis, radiosynthesis and in vitro evaluation of $\left[{ }^{18} \mathrm{~F}\right]$ Bodipy- $\mathrm{C}_{16} /$ triglyceride as a dual modal imaging agent for brown adipose tissue}

Andreas Paulus,

Marco Maenen,

Natascha Drude,

Emmani BM Nascimento,

Wouter D. van Marken Lichtenbelt,

Felix M. Mottaghy,

Matthias Bauwens

published as:

Synthesis, radiosynthesis and in vitro evaluation of $18 \mathrm{~F}$-Bodipy-C16/triglyceride as a dual modal imaging agent for brown adipose tissue. PLoS One 12, (2017) 


\section{Abstract}

Background: Brown adipose tissue research is in the focus in the field of endocrinology. We designed a dual-modal fluorescent/PET fatty acid based tracer on commercially available Bodipy- $\mathrm{C}_{16}$, which can be synthesized to its corresponding triglyceride and which combines the benefits of fluorescent and PET imaging.

Methods: Bodipy- $\mathrm{C}_{16}$ was coupled to 1,3-diolein resulting in Bodipy-triglyceride. Bodipy- $\mathrm{C}_{16}$ and Bodipy-triglyceride compounds were radiolabeled with fluorine-18 using an ${ }^{18} \mathrm{~F} /{ }^{19} \mathrm{~F}$ exchange reaction to yield a dual-modal imaging molecule. Uptake of radiolabeled and nonlabeled Bodipy- $\mathrm{C}_{16}$ and Bodipy-triglyceride was analyzed by fluorescence imaging and radioactive uptake in cultured adipocytes derived from human brown adipose tissue and white adipose tissue.

Results: Bodipy- $\mathrm{C}_{16}$ and Bodipy-triglyceride were successfully radiolabeled and Bodipy- $\mathrm{C}_{16}$ showed high shelf life and blood plasma stability (99\% from 0-4 h). The uptake of Bodipy- $\mathrm{C}_{16}$ increased over time in cultured adipocytes, which was further enhanced after betaadrenergic stimulation with norepinephrine. The uptake of Bodipy- $\mathrm{C}_{16}$ was inhibited by oleic acid and CD36 inhibitor sulfosuccinimidyl-oleate. The poor solubility of Bodipy-triglyceride did not allow stability or in vitro experiments.

Conclusion: The new developed dual modal fatty acid based tracers Bodipy- $\mathrm{C}_{16}$ and Bodipy-triglyceride showed promising results to stimulate further in vivo evaluation and will help to understand brown adipose tissues role in whole body energy expenditure. 


\section{Introduction}

Positron emission tomography (PET) allows non-invasive whole body imaging for different purposes by detecting pairs of annihilation rays. The positron emitter fluorine- 18 is frequently used due to its short half-life (109 min), which makes it suitable for imaging purposes, and its broad domain in chemical reactions. Nevertheless PET is limited, already by physical laws (pathway of the positron), in spatial resolution and therefore cannot detect microscopic or subcellular structures. On the other hand optical fluorescence imaging has a high spatial resolution, making it an interesting topic for intraoperative imaging as well as in vitro evaluation of tracers ${ }^{1,2}$. However, fluorescence imaging is lacking of high penetration depths. By combining PET and fluorescence imaging it is possible to overcome the disadvantages of both techniques and to create a new powerful tool to image from the whole-body down to sub-cellular level with the same imaging agent. The increased complexity and the effect of the fluorescent dye on the biodistribution are the major challenges when it comes to the development of a dual-modal imaging agent.

Brown adipose tissue (BAT) research has evolved vastly within endocrine research. For a long time it was thought that BAT was only present in infants but retrospective PET/CT studies with $\left[{ }^{18} \mathrm{~F}\right]$ Fluoro-2-deoxy-2-D-glucose $\left(\left[{ }^{18} \mathrm{~F}\right] \mathrm{FDG}\right)$ identified active BAT in adult humans ${ }^{3-5}$. These findings could be confirmed later by dedicated cold exposure studies where a direct correlation between cold exposure and BAT metabolic activity, measured through $\left[{ }^{18} \mathrm{~F}\right] \mathrm{FDG}$ uptake, was reported ${ }^{6-8}$. The potential of BAT to combat obesity and obesity-associated diseases makes BAT an interesting target ${ }^{9}$.

The variety of quantification approaches of BAT volume and metabolic activity reaches from in vitro experiments ${ }^{10}$ over invasive imaging with fluorescence probes ${ }^{11}$ or tritiated compounds ${ }^{12}$ to non-invasive experiments with PET ${ }^{3-5,13,14}$, SPECT ${ }^{15,16}$ and MRI ${ }^{17-19}$. Even though fatty acids (FAs) are the main fuel source for adipocytes, $\left[{ }^{18} \mathrm{~F}\right] \mathrm{FDG}$ is mostly used in studies to quantify BAT activity ${ }^{4,20,21}$. FA uptake is more difficult to quantify because there is a large variety of different FAs and triglycerides (TGs) present in the human body which 
makes the uptake dependent on the affinity of the single FA and not on the substance class itself. Nevertheless FAs are the major metabolized substances in BAT and therefore it is possible that BAT activity and lipid uptake is largely underestimated by FDG scans (which only show glucose-related uptake) ${ }^{13}$. Therefore the need exists to use a FA-based BAT tracer to quantify BAT activity and FA uptake, to study uptake dynamics and to exclude the chance of underestimating BATs metabolic activity with FDG scans.

Radiolabeled FAs in general have been developed in several variations for imaging purposes (e.g. FTHA (14(R,S)- $\left[{ }^{18}\right.$ F]fluoro-6-thia-heptadecanoic acid), BMIPP (beta-methyl-p-[1 $\left.{ }^{123}\right]$ iodophenylpentadecanoic acid), $\left[{ }^{11} \mathrm{C}\right]$ palmitate $\left.{ }^{22-26}\right)$. We here report the development of a FA-based tracer which is suitable for both, PET and fluorescence imaging from the fluorescent FA Bodipy- $C_{16}$ (BDP-FA) with which it is possible to image from whole body to sub-cellular level. Bodipy dyes have been already used to image brown adipose tissue ${ }^{11}$ and it has been proven that fatty acid transport proteins (FATP) have a preference for Bodipy-FL coupled to a long carbon chain $(C \geq 8)^{27}$. Furthermore, downstream metabolic reactions in white adipocytes were already visualized ${ }^{28}$. Since we did not want to decrease the good binding properties of BDP-FA by introduction of another chelator molecule, we got interested in ${ }^{18} \mathrm{~F} /{ }^{19} \mathrm{~F}$ exchange reactions used to transform fluorescent dyes into dual-modality PET/fluorescent imaging dyes ${ }^{29-33}$. Because the FA is only modified at the end of the carbon chain, neither an increased steric demand, nor lowering of the targeting efficiency is expected. In comparison to previous reports, we want to go a step further and synthesize also the, in vivo predominant, triglyceride form of the $\left[{ }^{18} \mathrm{~F}\right] \mathrm{BDP}-\mathrm{FA}$. Here we describe a synthetic approach resulting in a dual-modal molecule to visualize BAT in vivo and in vitro with the same tracer which should help to understand this not completely evaluated tissue, its functions and metabolism. 


\section{Materials and Methods}

Commercially available compounds were used without further purification unless otherwise stated. BODIPY-FL-C ${ }_{16}$ was purchased from Thermo Fischer Scientific (99\%) (Netherlands). 1,3-diolein was purchased from Sigma Aldrich ( $\geq 99 \%$ ). DMEM/F-12 was purchased from ThermoFischer (Waltham, MA).

All HPLC purifications $\left(1.0 \mathrm{~mL} / \mathrm{min}\right.$, solvent $\mathrm{A} ; 0.1 \%$ TFA in water, solvent $\left.\mathrm{B} ; \mathrm{CH}_{3} \mathrm{CN}, 50^{\circ} \mathrm{C}\right)$ were performed on a Shimadzu UFLC HPLC system equipped with a DGU-20A $\mathrm{A}_{5}$ degasser, a SPD-M20A UV detector, a LC-20AT pump system, a CBM-20A communication BUS module, a CTO-20AC column oven, and a Scan-RAM radio-TLC/HPLC-detector from LabLogic using an Aeris ${ }^{\mathrm{TM}}$ Widepore column (XB-C18, $3.6 \mu \mathrm{m}, 4.6 \mathrm{~mm} \times 250 \mathrm{~mm}$ ) for the BDP-FA or an Aeris ${ }^{\mathrm{TM}}$ Widepore column $(\mathrm{C} 4,3.6 \mu \mathrm{m}, 4.6 \mathrm{~mm} \times 250 \mathrm{~mm}$ ) for the Bodipy-triglyceride (BDPTG). ESI-MS was performed on a Applied Biosystems SCIEX API 150 EX electrospray ionization quadrupole (ESI-Q) mass spectrometer with the method of McAnoy et al. ${ }^{34}$. Briefly, $0.1 \mathrm{M}$ aqueous ammonium acetate solution was added to the probe to observe the ammonium salt in the MS.

${ }^{1} \mathrm{H}$-NMR spectra were carried out on a Bruker Ultrashield TH 400 plus at $400 \mathrm{MHz}$. Tol- $\mathrm{d}_{8}$ was used as solvent with TMS as internal standard. Chemical shifts are reported in parts per million (ppm) relative to the internal standard.

\section{Synthesis of BDP-TG 2}

BDP-FA $1(300 \mu \mathrm{g}, 0.6 \mu \mathrm{mol})$ in acetonitrile was evaporated to complete dryness before the reactant was reconstituted in toluene $(100 \mu \mathrm{L})$. To the resulting solution $\mathrm{SOCl}_{2}$ in toluene (100 $\mu \mathrm{L}, 4$ vol.-\%) was added, incubated for $5 \mathrm{~min}$ at $70^{\circ} \mathrm{C}$ in a closed vial and evaporated. The product was reconstituted in toluene $(50 \mu \mathrm{L})$ containing 1,3-diolein $(2 \mu \mathrm{L}, 2.8 \mu \mathrm{mol})$ and heated to $100^{\circ} \mathrm{C}$ for $30 \mathrm{~min}$. After the reaction time, purification by HPLC $(1 \mathrm{~mL} / \mathrm{min}, 30 \%$ to $15 \% \mathrm{~A}$ in $5 \mathrm{~min}, 15 \%$ to $0 \% \mathrm{~A}$ from 5 to $6 \mathrm{~min}, 0 \% \mathrm{~A}$ to $20 \mathrm{~min}$ ) yielded $2(225 \mu \mathrm{g}, 75 \%)$ as a red solid; $t_{R}=12.3$ min. ESI-MS(+): $\mathrm{m} / \mathrm{z}(\%)=1058(100)[\mathrm{M}-\mathrm{F}]^{+}, 1095(82)\left[\mathrm{M}+\mathrm{NH}_{4}\right]^{+} .{ }^{1} \mathrm{H}$ 
NMR (400 MHz, Tol- $\left.\mathrm{d}_{8}\right) ; \delta(p p m)=5.46(\mathrm{~m}, 4 \mathrm{H}), 4.26(\mathrm{~m}, 2 \mathrm{H}), 4.06(\mathrm{~m}, 2 \mathrm{H}), 3.13(\mathrm{~m}, 1 \mathrm{H})$, $1.75(\mathrm{~s}, 3 \mathrm{H})$.

Additional experiments were performed using BMIPP (beta-methyl-piodophenylpentadecanoic acid) as starting FA. Different ways of synthesis were evaluated, where reaction time, temperature and chlorinating agent were changed (see results section).

\section{Radiolabeling of Bodipy- $\mathrm{C}_{16} 3$}

Aqueous fluorine-18 solution was loaded on a QMA-cartridge which was preconditioned with $15 \mathrm{~mL} \mathrm{~K} \mathrm{~K}_{2} \mathrm{CO}_{3}$ in water and $20 \mathrm{~mL}$ water. Fluorine-18 (42 MBq) was eluted with a mixture of $600 \mu \mathrm{L}$ acetonitrile, $300 \mu \mathrm{L} \mathrm{H}_{2} \mathrm{O}$ and $100 \mu \mathrm{L} \mathrm{K}_{2} \mathrm{CO}_{3}$ solution $(5 \mathrm{mg} / \mathrm{mL})$. Fluorine-18 solution was transferred into a drying vessel containing tetra-n-butylammonium bromide $(80 \mu \mathrm{L})$ as a phase transfer agent. Acetonitrile $(3 \times 1.0 \mathrm{~mL})$ was added and the solution of fluorine-18 was dried by heating to $100{ }^{\circ} \mathrm{C}$ with a continuous flow of argon. After reconstitution of fluorine-18 in anhydrous acetonitrile $(100 \mu \mathrm{L})$, a solution of $1(50 \mu \mathrm{g}, 0.1 \mu \mathrm{mol})$ and $\mathrm{SnCl}_{4}(0.2 \mathrm{M}$ in acetonitrile, $100 \mu \mathrm{L}$ ) was added to the activity solution and the reaction was stirred at r.t. for 30 min. After addition of water $(200 \mu \mathrm{L})$ and filtration (Millex, hydrophile PVDF $0.22 \mu \mathrm{m})$ a quality control was performed by HPLC ( $1 \mathrm{~mL} / \mathrm{min}, 30 \%$ to $15 \% \mathrm{~A}$ in $5 \mathrm{~min}, 15 \%$ to $0 \% \mathrm{~A}$ from 5 to $6 \mathrm{~min}, 0 \% \mathrm{~A}$ to $20 \mathrm{~min}$ ) and afforded 3 (decay corrected radiochemical yield (RCY): $76 \%, 22 \mathrm{MBq}$ ) with a decay corrected specific activity of $220 \mathrm{MBq} / \mu \mathrm{mol}$ and a radiochemical purity of $\geq 99 \%$; $t_{R}=13.3$ min. In addition a TLC with Toluene, $\mathrm{CHCl}_{3}$ and $\mathrm{MeOH}(80.9 \%$, $14.3 \%, 4.8 \%)$ was performed.

\section{Radiolabeling of Bodipy-TG 4}

Drying process was performed as mentioned in previous section. After reconstitution of fluorine-18 (83 MBq) in anhydrous acetonitrile $(100 \mu \mathrm{L})$, a solution of 2 in toluene $(107 \mu \mathrm{g}$, $0.1 \mu \mathrm{mol}$ in $50 \mu \mathrm{L})$ and $\mathrm{SnCl}_{4}(0.2 \mathrm{M}$ in acetonitrile, $100 \mu \mathrm{L})$ was added to the solution with the activity and the reaction solution was stirred at room temperature (r.t.) for $30 \mathrm{~min}$. After addition of water $(200 \mu \mathrm{L})$, filtration and washing with water $(2 \times 200 \mu \mathrm{L})$ a quality control was 92 
performed by HPLC ( $1 \mathrm{~mL} / \mathrm{min}, 30 \%$ to $15 \% \mathrm{~A}$ in $5 \mathrm{~min}, 15 \%$ to $0 \% \mathrm{~A}$ from 5 to $6 \mathrm{~min}, 0 \% \mathrm{~A}$ to $20 \mathrm{~min}$ ) and afforded 4 (decay corrected $\mathrm{RCY}: 44 \%, 25 \mathrm{MBq}$ ) with a decay corrected specific activity of $250 \mathrm{MBq} / \mu \mathrm{mol}$ and a radiochemical purity of $>95 \% ; t_{R}=12.5 \mathrm{~min}$. In addition TLC with toluene, $\mathrm{CHCl}_{3}$ and $\mathrm{MeOH}(80.9 \%, 14.3 \%, 4.8 \%)$ was performed.

\section{Human primary adipocyte cultures derived from BAT and white adipocytes (WAT)}

The isolation and differentiation of human adipocytes has been described before ${ }^{35}$. The study was reviewed and approved by the ethics committee of Maastricht University Medical Center (METC 10-3-012, NL31367.068.10). Informed was obtained prior to surgery. The precursor cells were obtained from a stromal vascular fraction of BAT and WAT tissue. The sample was taken from a 34 year old male with a benign formation in the left thyroid gland. The cells have been metabolically characterized ${ }^{35}$. In short, the stromal vascular fraction was obtained from BAT and subcutaneous WAT biopsies from the same individual undergoing deep neck surgery. Collected cells were grown to confluence prior to start of differentiation in DMEM/Ham's F-12 (Gibco) supplemented with 10\% Fetal Bovine Serum (Bodinco BV). Differentiation medium composed of biotin (33 $\mu \mathrm{M})$, D-pantothenate $(17 \mu \mathrm{M})$, h-insulin (100 nM), dexamethasone (100 nM), IBMX (250 $\mu \mathrm{M})$, rosiglitazone $(5 \mu \mathrm{M})$, T3 (2 $\mathrm{nM})$, transferrin $(10 \mu \mathrm{g} / \mathrm{ml})$. After 7 days of differentiation, the medium was exchanged for maintenance medium composed of biotin $(33 \mu \mathrm{M})$, pantothenate $(17 \mu \mathrm{M})$, insulin $(100 \mathrm{nM})$, dexamethasone (10 nM), T3 (2 nM), and transferrin $(10 \mu \mathrm{g} / \mathrm{ml})$.

\section{In vitro uptake of 3 and 4 in cultured adipocytes derived from human BAT and WAT}

Adipocytes derived from human BAT and WAT were incubated with 3 and $4(1 \mathrm{nM}, 100 \mu \mathrm{L})$ for $1 \mathrm{~h} .3$ was added in $0.5 \%$ fatty acid free bovine albumin in DMEM/F-12. 4 was dissolved in $50 \%$ PEG in DMEM/F-12. Adipocytes were exposed to the tracer or preincubated with sulfosuccinimidyl oleate $(500 \mu \mathrm{M}, 100 \mu \mathrm{L}, 30 \mathrm{~min})$ or norepinephrine $(1 \mu \mathrm{M}, 100 \mu \mathrm{L}, 30 \mathrm{~min})$. Radioactivity was quantified by measuring washed, detached cells with a WIZARD ${ }^{2}$ automatic $y$-counter from Perkin Elmer. Number of cells was determined by three extra wells 
which underwent a standard cell count protocol using a LUNA II (Logosbio) automated cell counter.

\section{In vitro imaging of cultured adipocytes derived from human BAT and WAT}

Adipocytes derived from human BAT and WAT were incubated with 1 and $2(0-4 \mu \mathrm{M}, 500 \mu \mathrm{L})$ for different time points (1-24 h) in experimental medium. 1 was added in 0,5\% fatty acid free bovine albumin in DMEM/F-12. 2 was dissolved in 50\% PEG in DMEM/F-12. Adipocytes were exposed to the tracer or coincubated with oleic acid $(400 \mu \mathrm{M}, 500 \mu \mathrm{L})$ or preincubated with sulfosuccinimidyl-oleate $(500 \mu \mathrm{M}, 500 \mu \mathrm{L}, 30 \mathrm{~min})$. After incubation adipocytes were fixed in $3.7 \%$ formaldehyde $\left(4^{\circ} \mathrm{C}, 30 \mathrm{~min}\right)$ and stained with DAPI (4',6-diamidino-2phenylindole) (RT, 5 min). The adipocytes were imaged with a Sony Eclipse e800 fluorescence camera. The signal was measured in the FITC channel (460-490 nm excitation, 510-550 nm emission) and in the DAPI channel (385-415 nm excitation, 450-470 nm emission). Quantification of signal was performed with Fiji ${ }^{36}$ as well as correction for exposure time, background and cell auto-fluorescence. For every data point at least three cells were analyzed. Graphs and statistical analysis was performed using GraphPad Prism 6.

\section{Fluorescence measurements (microplate reader)}

Adipocytes derived from human BAT cultured on 96 well chamber slides were incubated with 1 and $2(2 \mu \mathrm{M}, 100 \mu \mathrm{L})$ for different time points (1-4 h). 1 was added in 0,5\% fatty acid free bovine albumin in DMEM/F-12. 2 was dissolved in 50\% PEG in DMEM/F-12. Adipocytes were exposed to the tracer or preincubated with norepinephrine $(1 \mu \mathrm{M}, 500 \mu \mathrm{L}, 30 \mathrm{~min})$. After incubation adipocytes were washed 3 times (30 seconds each) with cold PBS and suspended in PBS. The signal was measured using a SpectraMax M2 plate reader (molecular devices) (excitation $485 \mathrm{~nm}$, emission $520 \mathrm{~nm}$ ). Graphs and statistical analysis was performed using GraphPad Prism 6. 


\section{Ex vivo stability}

Shelf life of 3 was investigated under following conditions: $24 \mathrm{MBq}(60 \mu \mathrm{L})$ were added to $\mathrm{H}_{2} \mathrm{O}(1 \mathrm{~mL})$ and integrity was examined by HPLC (1-4 h). Areas under the peak of free fluorine-18 and metabolites were compared to the area under the peak of $\mathbf{3}$.

Plasma stability was examined by adding $28 \mathrm{MBq}(60 \mu \mathrm{L})$ of 3 to $1 \mathrm{~mL}$ of human plasma $\left(37^{\circ} \mathrm{C}\right)$. After certain time points $(20,40,60 \mathrm{~min}$ and $2-4 \mathrm{~h})$ integrity of the compound was analyzed by HPLC.

Determining the aqueous or plasma stability of the radiolabeled TG 4 failed due to the insolubility of the compound in aqueous medium. 


\section{Results}

Different conditions for the esterification of the BDP- $\mathrm{C}_{16}$ to BDP-TG were tested (Table 1). The best yield, analyzed by HPLC injection of the crude reaction mixture, was achieved with BDP- ${ }_{16}$ in Toluene $(50 \mu \mathrm{L})$ and the strong chlorinating agent thionylchloride at $70^{\circ} \mathrm{C}$ in 30 min. More hydrophilic solvents, larger reaction volumes, lower temperatures or milder chlorination conditions resulted in lower yields and/or byproducts. In optimal conditions, after reaction and purification 2 was obtained in a yield of $75 \%$. After purification of 2 further analysis of quenching effects was performed by HPLC. Both, FA and TG, showed similar absorption when the same molar amount was injected. NMR of $\mathbf{2}$ confirmed the identity of the TG (Fig 1a and S1 Fig 4). The disappearance of the alcohol function (3.75 ppm) with the simultaneous formation of a third ester bond ( $3.15 \mathrm{ppm})$ plus the additional BDP peaks (1.75 ppm and $2.47 \mathrm{ppm}$ ) proved the successful synthesis of $\mathbf{2}$. Additionally ESI-MS of $\mathbf{2}$ supports these findings as peaks found in the spectrum correspond with the calculated molecular masses (Fig 1b).

Table 1: Different esterification conditions for BMIPP or BDP-C16. Yields tested by injection of the crude reaction mixture into HPLC and comparison of the esterified vs. the non-esterified FA signal plus byproducts

\begin{tabular}{|c|c|c|c|c|c|c|c|c|}
\hline Fatty acid & $\begin{array}{l}\text { Coupling } \\
\text { agent }\end{array}$ & Solvent & $\begin{array}{l}\text { Rec. } \\
\text { volume }[\mu \mathrm{L}]\end{array}$ & Activator & $\begin{array}{l}\text { Temperature } \\
{\left[{ }^{\circ} \mathrm{C}\right]}\end{array}$ & $\begin{array}{l}\text { Reaction time } \\
\text { [min] }\end{array}$ & $\begin{array}{l}\text { Yield } \\
\text { [\%] }\end{array}$ & $\mathbf{n}$ \\
\hline BMIPP & 1,3-Diolein & Toluene & 50 & $\mathrm{SOCl}_{2}$ & 70 & 30 & 72 & 4 \\
\hline BMIPP & 1,3-Diolein & Acetonitrile & 50 & $\mathrm{SOCl}_{2}$ & 70 & 30 & 0.6 & 1 \\
\hline BMIPP & 1,3-Diolein & Diethylether & 50 & $\mathrm{SOCl}_{2}$ & 70 & 30 & 67 & 1 \\
\hline BMIPP & 1,3-Diolein & Tetrachlormethane & 50 & $\mathrm{SOCl}_{2}$ & 70 & 30 & 8 & 1 \\
\hline BMIPP & 1,3-Diolein & Benzene & 50 & $\mathrm{SOCl}_{2}$ & 70 & 30 & 38 & 1 \\
\hline BMIPP & 1,3-Diolein & Toluene & 50 & Oxalyl Chloride & 70 & 30 & 43 & 1 \\
\hline BMIPP & 1,3-Diolein & Toluene & 50 & Oxalyl Chloride & 70 & 60 & 44 & 1 \\
\hline BMIPP & 1,3-Diolein & Toluene & 50 & $\mathrm{SOCl}_{2}$ & 70 & 90 & 54 & 2 \\
\hline BMIPP & 1,3-Diolein & Toluene & 50 & $\mathrm{SOCl}_{2}$ & 70 & 120 & 67 & 2 \\
\hline BMIPP & 1,3-Diolein & Toluene & 50 & $\mathrm{SOCl}_{2}$ & 70 & 150 & 86 & 2 \\
\hline BMIPP & $\mathrm{EtOH}$ & $\mathrm{MeCN}$ & 100 & $\mathrm{SOCl}_{2}$ & 0 & 30 & 1 & 1 \\
\hline BMIPP & $\mathrm{EtOH}$ & $\mathrm{MeCN}$ & 100 & $\mathrm{SOCl}_{2}$ & 22 & 30 & 64 & 1 \\
\hline BMIPP & $\mathrm{EtOH}$ & $\mathrm{MeCN}$ & 100 & $\mathrm{SOCl}_{2}$ & 70 & 30 & 88 & 1 \\
\hline Bodipy $\mathrm{C}_{16}$ & 1,3-Diolein & Toluene & 200 & $\mathrm{SOCl}_{2}$ & 70 & 30 & 59 & 1 \\
\hline Bodipy $\mathrm{C}_{16}$ & 1,3-Diolein & Toluene & 50 & $\mathrm{SOCl}_{2}$ & 70 & 30 & 95 & 8 \\
\hline
\end{tabular}


a)

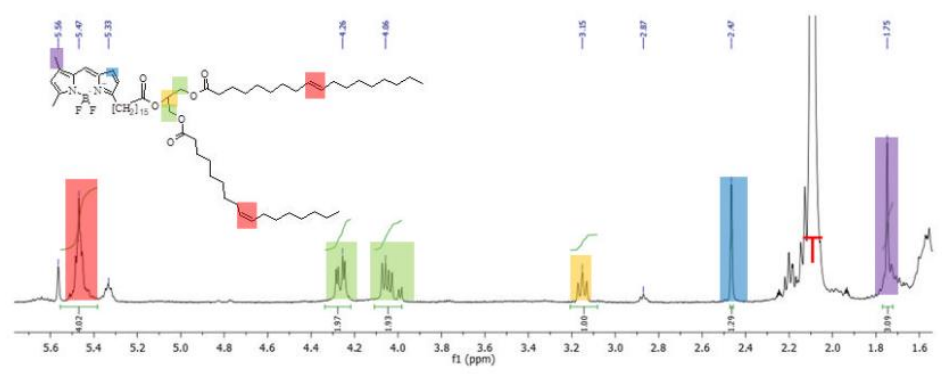

b)

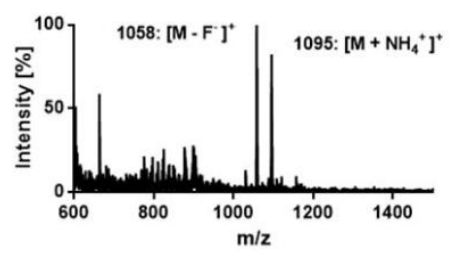

Fig 1: BDP-TG analysis. a) ${ }^{1} \mathrm{H}-\mathrm{NMR}$ of BD-TG in toluene-d5, red T corresponds to the toluene peek b) ESI-MS of BDP-TG with $\mathrm{NH}_{4} \mathrm{OAC}$ in Chloroform/MeOH 50:50

The radiolabeled dual-modality imaging agent $\left[{ }^{18} \mathrm{~F}\right] \mathrm{BDP}-\mathrm{TG}$ was synthesized in a two-step procedure. First the Bodipy-FA 1 was esterified to BDP-TG 2 and then radiolabeled with fluorine-18 using the strong Lewis acid $\mathrm{SnCl}_{4}$ in dry acetonitrile/toluene. After $30 \mathrm{~min}$ of incubation, $\left[{ }^{18} \mathrm{~F}\right] \mathrm{BODIPY}-\mathrm{TG} 4$ was isolated by washing 3 times with water allowing $44 \%$ radiochemical yield, a specific activity of $250 \mathrm{MBq} / \mu \mathrm{mol}$ and a radiochemical purity of $>95 \%$ (Fig 2b). First approaches to radiolabel the BDP-FA and perform the esterification afterwards resulted in higher labeling yields (76\%) (Fig 2a) in the first step but the following esterification afforded only small amounts of radiolabeled BDP-TG. The radiolabeling was performed in acetonitrile but in previous cold esterification attempts it was shown that only small yields can be reached in this solvent (Table 1). A complete exchange of acetonitrile to toluene is time consuming as well as the problem of $\left[{ }^{18} \mathrm{~F}\right] \mathrm{BDP}-\mathrm{FA}$ getting attached to the glass vial arises. Different reaction conditions for the radiolabeling can be found in Table 2 . 
Table 2: radiolabeling of BDP-FA 3 and BDP-TG 4. Different conditions tested for both compounds. Radiochemical yields calculated after purification

\begin{tabular}{|c|c|c|c|c|c|c|}
\hline Agent & $\mathrm{V}\left(\mathrm{SnCl}_{4}\right)[\mu \mathrm{L}]$ & Solvent & Volume $[\mu \mathrm{L}]$ & Reaction time [min] & RCY [\%] & $\mathbf{n}$ \\
\hline Bodipy $\mathrm{C}_{16}$ & $100(0.1 \mathrm{M})$ & $\mathrm{MeCN}+\mathrm{K}_{222}+\mathrm{K}_{2} \mathrm{CO}_{3}$ & 250 & 30 & 7.3 & 4 \\
\hline Bodipy $\mathrm{C}_{16}$ & $30(0.1 \mathrm{M})$ & $\mathrm{MeCN}+\mathrm{K}_{222}+\mathrm{K}_{2} \mathrm{CO}_{3}$ & 180 & 30 & 13.8 & 2 \\
\hline Bodipy $\mathrm{C}_{16}$ & $100(0.2 \mathrm{M})$ & $\mathrm{MeCN}+\mathrm{K}_{222}+\mathrm{K}_{2} \mathrm{CO}_{3}$ & 250 & 30 & 28 & 4 \\
\hline Bodipy $\mathrm{C}_{16}$ & $100(0.3 \mathrm{M})$ & $\mathrm{MeCN}+\mathrm{K}_{222}+\mathrm{K}_{2} \mathrm{CO}_{3}$ & 250 & 30 & 0 & 1 \\
\hline Bodipy $\mathrm{C}_{16}$ & $100(0.2 \mathrm{M})$ & $\mathrm{MeCN}+\mathrm{K}_{2} \mathrm{CO}_{3}$ & 250 & 30 & 76 & 9 \\
\hline Bodipy-Tg & $100(0.2 \mathrm{M})$ & $\mathrm{MeCN}+\mathrm{K}_{2} \mathrm{CO}_{3} / \mathrm{DMA}$ & 250 & 30 & 0 & 1 \\
\hline Bodipy-Tg & $100(0.2 M)$ & $\mathrm{MeCN}+\mathrm{K}_{2} \mathrm{CO}_{3} /$ Toluene & 250 & 30 & 44 & 7 \\
\hline
\end{tabular}

a)

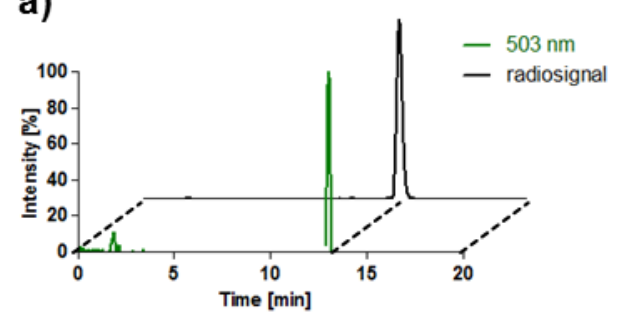

b)

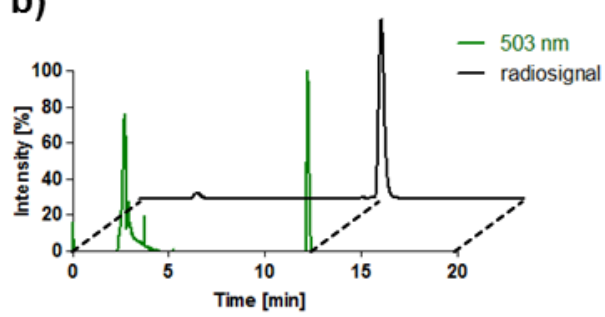

Fig 2: chromatograms for BDP-FA/TG a) HPLC chromatograms (radio trace and absorbance at $503 \mathrm{~nm}$ ) of ${ }^{18} \mathrm{~F}$ BDP-FA 3 on a C18 column. b) HPLC chromatograms (radio trace and absorbance at $503 \mathrm{~nm}$ ) of $\left[{ }^{18} \mathrm{~F}\right]$ BDP-TG 4 (peak at 3 min corresponds to toluene which was used to solubilize the probe) on a C4 column.

Shelf life and plasma stability showed 99\% intact radiolabeled compound 3 after 4 h (S1 Fig 5). Fluorescent uptake of $\mathbf{1}$ was evaluated in vitro with cultured adipocytes derived from human BAT. Adipocytes were incubated with BDP-FA $(2 \mu \mathrm{M})$ for 1 to $4 \mathrm{~h}$ and fluorescence was measured with a microplate reader (SpectraMax M2) (Fig 3a). An increase over time was observed where BAT took up 274\%, 362\% and $697 \%$ more after $2 \mathrm{~h}, 3 \mathrm{~h}$ and $4 \mathrm{~h}$ compared to the $1 \mathrm{~h}$ time point. Activation with norepinephrine $(1 \mu \mathrm{M}, 30 \mathrm{~min}$ before incubation with BDP-FA) increased BAT uptake of 1 by $134 \%, 199 \%$ and $143 \%$ after 2,3 and $4 \mathrm{~h}$ compared to their basal uptake values at these time points. Only after $1 \mathrm{~h}$ no significant increase was observed. Single cell uptake was analyzed and quantified with a fluorescence microscope (Sony Eclipse e800) under different conditions (S1 Fig 1). Concentration dependent uptake was examined within a $2 \mathrm{~h}$ time period (Fig 3b). A clear Michaelis - 
Menten like kinetic was observed in uptake-positive BAT cells (with $k_{m}=1.15 \mu M, R^{2}=0.93$ ). Coincubation with $400 \mu \mathrm{M}$ oleic acid reduced uptake of BDP-FA by $46 \%$.

a)

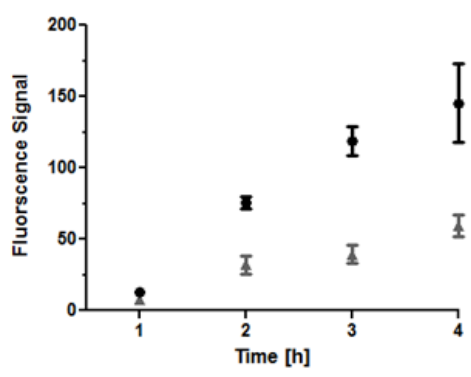

c)

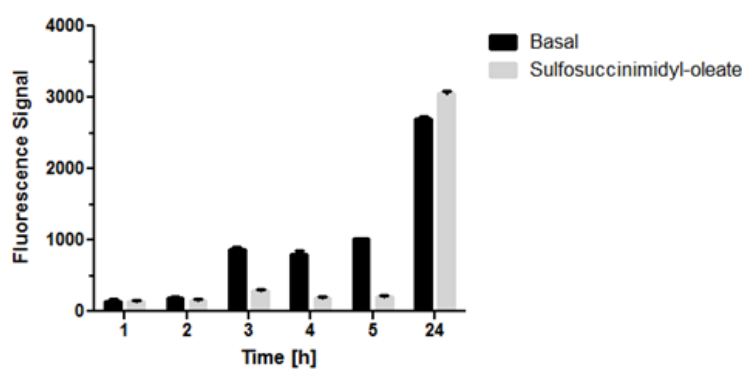

b)

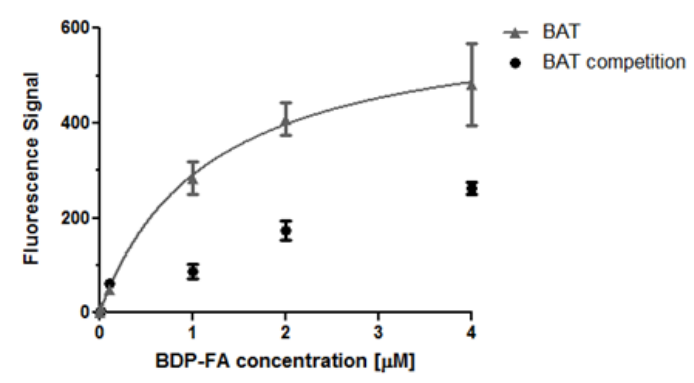

d)

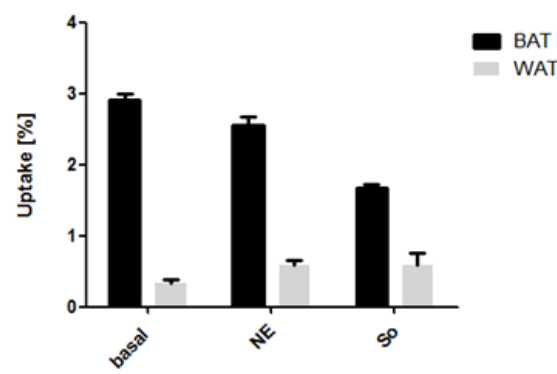

Fig 3: in vitro cell uptake a) uptake time dependence measured with $2 \mu \mathrm{M} 1$ in BAT with and without activation with norepinephrine (microplate) b) uptake concentration dependence measured in BAT over $2 \mathrm{~h}$ with and without coincubation with oleic acid (fluorescence microscope) c) BAT blocking study over time with sulfosuccinimidyloleat (fluorescence microscope) d) uptake of 3 in BAT and WAT cells under basal conditions, activation with Norepinephrine (NE) and blocking with sulfosuccinimidyl-oleat (So) after $1 \mathrm{~h}$ incubation time

Time dependence with simultaneous inhibition of the cluster of differentiation 36 (CD36), which is a scavenger protein for long chain fatty acids ${ }^{37}$ and was shown to be essential for thermogenesis in animals during fasting conditions ${ }^{16}$, was additionally quantified on a cellular level (Fig 3c) (S1 Fig 1). By preincubation with sulfosuccinimidyl-oleate a blocking of $73 \% \pm 6 \%$ was reached after $3-5 \mathrm{~h}$. After $24 \mathrm{~h}$ the uptake recovered to basal conditions. No uptake was observed by incubation with 2 (2 $\mu \mathrm{M}, 24$ h) (S1 Fig 3). 
Cell uptake experiments were also performed in WAT cells to further analyze the suitability of the BDP-FA as a tracer for adipocytes and to compare BAT and WAT cells. The WAT cells were obtained from the same human sample as the BAT cells.

In first microplate activation experiments it was shown that, similar to BAT, the uptake of 1 increased over time. After 2 h, $3 \mathrm{~h}$ and $4 \mathrm{~h}$ the uptake increased by $221 \%, 294 \%$ and $357 \%$. Activation of the cells by norepinephrine resulted in an increase in uptake between $10 \%$ and $48 \%$ and was significant lower compared to BAT cells.

In WAT cells incubated with $1(0-4 \mu \mathrm{M})$ for different concentrations, a Michaelis - Menten like kinetic was observed in uptake-positive cells (with $k_{m}=1.58 \mu \mathrm{M}$ and $R^{2}=0.97$ ). The uptake was also reduced with an excess of oleic acid $(400 \mu \mathrm{M})$ by $53 \%$.

CD36 dependency on uptake kinetics was also investigated in WAT cells (S1 Fig 2). Sulfosuccinimidyl-oleat only had a significant negative effect on the uptake of the $2 \mathrm{~h}$ and $3 \mathrm{~h}$ group $(51 \% \pm 16 \%)$ but in general the uptake kinetics of the preincubated cells with sulfosuccinimidyl-oleat followed more the kinetics of the cells under basal conditions.

BAT and WAT uptake of $\mathbf{3}$ and $\mathbf{4}$ was investigated to prove the functionality of the radiolabeled compounds and to quantify the total uptake of both tracers. Interestingly, in this experimental setup, BAT took up in all cases more FAs than WAT (Fig 3d). After $1 \mathrm{~h}$ WAT took up $0.3 \% \pm 0.05 \%$ and BAT $2.9 \% \pm 0.09 \%$. Activation of WAT with norepinephrine showed a small increase in uptake $(0.6 \% \pm 0.07 \%$ vs. $0.3 \% \pm 0.05 \%)$ whereas the uptake in BAT was slightly decreased $(2.6 \% \pm 0.11 \%$ vs. $2.9 \% \pm 0.09 \%)$. An effect could be observed for preincubation with sulfosuccinimidyl-oleat in BAT after $1 \mathrm{~h}(1.7 \% \pm 0.04 \%$ vs. $2.9 \% \pm$ $0.09 \%)$. WAT showed no significant decrease $(0.58 \% \pm 0.18 \%$ vs. $0.3 \% \pm 0.05 \%)$.

Incubation experiments with the radiolabeled TG 2 were conducted additionally but showed no consistent and reproducible results (data not shown). 


\section{Discussion}

Imaging of BAT has evolved to an interesting and fast developing topic in endocrine research. Several imaging approaches have been used in the past to visualize and quantify BAT and its metabolic activity reaching from in vitro experiments ${ }^{10}$ over invasive imaging with fluorescence probes ${ }^{11}$ or tritiated compounds ${ }^{12}$ to non-invasive experiments with PET ${ }^{3-}$ ${ }^{5,13,14}$, SPECT ${ }^{15,16}$ and MRI ${ }^{17-19}$. Most often $\left[{ }^{18} \mathrm{~F}\right] \mathrm{FDG}$ scans are used for BAT imaging. This has the big disadvantage that it only shows glucose-related uptake and has the chance to underestimate BAT activity because the major metabolized substance class in BAT is FAs. There is therefore a need for a FA BAT tracer to quantify metabolic activity in a more precise way. In studies with $\left[{ }^{18} \mathrm{~F}\right] \mathrm{FTHA}$ it was observed that radiolabeled FAs showed an increased uptake in BAT under cold stimulation in humans ${ }^{13}$. With our developed tracer it is possible to examine uptake characteristics with both PET and fluorescence imaging. Therefore scans from subcellular level, to determine the localization of the probe within the cell, to whole body scans are possible.

In vivo FAs are transported as TGs in lipoproteins towards adipocytes ${ }^{38,39}$. We were able to produce BDP-TG in a very reasonable yield (77\%). Both, the FA and the TG analog, were successfully radiolabeled (RCY: $76 \%$ for $\left[{ }^{18} \mathrm{~F}\right] \mathrm{BDP}-\mathrm{FA}$ and $44 \%$ for $\left[{ }^{18} \mathrm{~F}\right] \mathrm{BDP}-\mathrm{TG}$ ), comparable to previously achieved yields with other modified Bodipy-dyes by other groups ${ }^{31,40}$. Activation of fluorine-18 by $\mathrm{K}_{2} \mathrm{CO}_{3}$ and $\mathrm{K}_{222} \quad(4,7,13,16,21,24-$ Hexaoxa-1,10diazabicyclo[8.8.8]hexacosane) resulted in side products and decomposition of the Bodipydye. Reactions without addition of a base, such as $\mathrm{K}_{2} \mathrm{CO}_{3}$, gave lower labeling yields. Shelf life and plasma stability of $\left[{ }^{18} \mathrm{~F}\right] \mathrm{BDP}-\mathrm{FA}$ indicated its suitability as an in vivo imaging agent, although these values could not be determined for $\left[{ }^{18} \mathrm{~F}\right] \mathrm{BDP}-\mathrm{TG}$ due to its insolubility in aqueous medium. Nevertheless no large stability deviations are expected for $\left[{ }^{18} \mathrm{~F}\right] \mathrm{BDP}-\mathrm{FA}$ and $\left[{ }^{18} \mathrm{~F}\right] \mathrm{BDP}-\mathrm{TG}$, as the lipid backbone should not affect the boron-fluoride bond in a large extend. Next to our synthesis work we put effort in first in vitro application of our cold tracer. Uptake experiments proved that the BDP-FA is taken up with the characteristics of a regular 
FA $\left(k_{m}=1.15 \mu \mathrm{M}\right.$ compared to $k_{m}=0.2 \mu \mathrm{M}$ of oleate ${ }^{41}$ and cis-parinaric acid: $k_{m}=1.5 \mu \mathrm{M}$ in 3T3 fibroblasts ${ }^{42}$ ) and uptake could be decreased by coincubation with oleic acid in excess. BAT cells were sensitive to norepinephrine and uptake was increased by a preincubation with this hormone. Sulfosuccinimidyl-oleat as an antagonist blocked CD36 and overall uptake of BDP-FA was decreased to a minimum. This shows that CD36 is essential for the lipid uptake in BAT cells and is in accordance to already published in vivo results ${ }^{43,44}$. Only after $24 \mathrm{~h}$ the cells were able to overcome this blocking procedure and showed comparable uptake to basal conditions. Stahl et al. found over $90 \%$ of CD36 in serum starved adipocytes on the cell membrane ${ }^{42}$. Therefore it can be speculated that the increase in uptake resulted in a displacement of sulfosuccinimidyl-oleat at this time point.

The uptake in WAT cells of BDP-FA was also analyzed. Comparable to BAT cells fluorescence signal increased over time and uptake was partially blocked by coincubation with an excess of oleic acid. Neither the positive uptake effect in cells preincubated with norepinephrine nor the negative uptake effect in cells preincubated with sulfosuccinimidyloleat was observed in such an extent in WAT compared to BAT. Therefore a smaller amount of $\beta 3$-adrenoreceptors on the cell surface ${ }^{45}$ and a CD36 independent uptake mechanism ${ }^{46}$ is proposed for WAT cells.

In former experiments (data not shown) it was observed that the FA and the TG signal are significantly quenched in an aqueous medium. This is in accordance with other published results for the BDP-FA ${ }^{47}$. A self-quenching effect for different Bodipy-dyes depending on their solvent solubility has also been reported before ${ }^{48}$. This makes fluorescent imaging with this tracer susceptible for misinterpretation because one can underestimate the total uptake. Nevertheless we could easily and without any dose characterize, but not quantify, in vitro uptake kinetics of this fluorescent FA.

Even though first indications on uptake mechanism in brown and white adipocytes were obtained by fluorescent experiments, radiolabeled compounds were necessary to quantify cell uptake and to exclude the chance of a quenched fluorescent signal. Cell uptake experiments with the radiolabeled FA showed that after correction for different cell numbers, 
BAT took up significantly more $\left[{ }^{18} \mathrm{~F}\right] \mathrm{BDP}-\mathrm{FA}$ than WAT. Sulfosuccinimidyl-oleat decreased the uptake significantly after $1 \mathrm{~h}$ in the BAT group. By preincubation with norepinephrine the uptake in BAT was not affected (as seen in the fluorescent experiments, increased uptake could only be observed $2 \mathrm{~h}$ after stimulation). In WAT no significant effect was observed for the preincubation with sulfosuccinimidyl-oleat. Preincubation with norepinphrine resulted in the same uptake value as preincubation with sulfosuccinimidyl-oleat, which denotes to a norepinephrine insensitive and CD36 independent uptake mechanism. Overall, the results obtained with the radiolabeled BDP-FA are in accordance with the results obtained in the fluorescent experiments. By this method it was possible to quantify uptake values in percent uptake and a comparison between both cell types could be performed.

For the TG no uptake was observed with the presented methods. This might be due to the insolubility of TG in aqueous solutions and it is therefore not available for uptake by adipocytes. Alternatively, another reason could be that lipoprotein lipase, which is responsible for TG hydrolysis, is only activated by lipoproteins, which was not present in our in vitro experiments.

A possible solution for the inaccessibility of the BDP-TG tracer, non-radiolabeled and radiolabeled, for our in vitro cell model would be the incorporation of this tracer into lipoproteins. As TG are transported in vivo in these water soluble particles an incorporation of our tracer would 1) simulate the physiologic state how TG are transported and 2) overcome the limited solubility of the compound, which also limits the in vivo application. With other FAtracers (mainly tritiated) this has already been achieved and in vivo experiments have been performed ${ }^{11,12}$. In comparison to tritiated compounds, the here presented tracer has the advantage that it can be visualized and quantified by PET in vivo and its uptake mechanism and kinetics can be followed by fluorescence microscopy in vitro.

To conclude, we present the successful development of a multimodal FA/TG BAT tracer. We were able to conjugate $\mathrm{BDP}_{-} \mathrm{C}_{16}$ to 1,3 -diolein and radiolabel this triglyceride. We then investigated its uptake characteristics in vitro with fluorescence imaging in a human BAT and WAT sample, and observed CD36 mediated uptake which was sensitive to norepinephrine in 
BAT cells. Additionally, we showed that BAT takes up significantly more FAs than WAT in our in vitro radioactive uptake experiments.

Future in vitro/vivo experiments are required with $\left[{ }^{18} \mathrm{~F}\right]$ Bodipy-TG, incorporated into a chylomicron, where these first insights in brown adipose tissue metabolism will help to specify the role of this interesting tissue for whole body energy metabolism. 


\section{References}

1 van Dam, G. M. et al. Intraoperative tumor-specific fluorescence imaging in ovarian cancer by folate receptor- $\alpha$ targeting: first in-human results. Nat Med 17, 1315-1319, doi:10.1038/nm.2472 (2011).

2 Bradbury, M. S. et al. Clinically-translated silica nanoparticles as dual-modality cancertargeted probes for image-guided surgery and interventions. Integr Biol (Camb) 5, 74-86, doi:10.1039/c2ib20174g (2013).

Lee, P., Greenfield, J. R., Ho, K. K. Y. \& Fulham, M. J. A critical appraisal of the prevalence and metabolic significance of brown adipose tissue in adult humans. Am J Physiol Endocrinol Metab 299, E601-606, doi:10.1152/ajpendo.00298.2010 (2010).

Cohade, C., Mourtzikos, K. A. \& Wahl, R. L. "USA-Fat": prevalence is related to ambient outdoor temperature-evaluation with 18F-FDG PET/CT. J Nucl Med 44, 1267-1270 (2003).

Hany, T. F. et al. Brown adipose tissue: a factor to consider in symmetrical tracer uptake in the neck and upper chest region. Eur J Nucl Med Mol Imaging 29, 1393-1398, doi:10.1007/s00259-002-0902-6 (2002).

van Marken Lichtenbelt, W. D. et al. Cold-activated brown adipose tissue in healthy men. $N$ Engl J Med 360, 1500-1508, doi:10.1056/NEJMoa0808718 (2009).

7 Virtanen, K. A. et al. Functional brown adipose tissue in healthy adults. N Engl J Med 360, 1518-1525, doi:10.1056/NEJMoa0808949 (2009).

8 Saito, M. et al. High incidence of metabolically active brown adipose tissue in healthy adult humans: effects of cold exposure and adiposity. Diabetes 58, 1526-1531, doi:10.2337/db090530 (2009).

9 Rippe, J. M., Crossley, S. \& Ringer, R. Obesity as a chronic disease: modern medical and lifestyle management. J Am Diet Assoc 98, S9-15 (1998).

10 Henkin, A. H. et al. Real-time noninvasive imaging of fatty acid uptake in vivo. ACS Chem Biol 7, 1884-1891, doi:10.1021/cb300194b (2012).

11 Bartelt, A. et al. Brown adipose tissue activity controls triglyceride clearance. Nat Med 17, 200-205, doi:10.1038/nm.2297 (2011).

12 Khedoe, P. P. S. J. et al. Brown adipose tissue takes up plasma triglycerides mostly after lipolysis. J Lipid Res 56, 51-59, doi:10.1194/jlr.M052746 (2015).

13 Ouellet, V. et al. Brown adipose tissue oxidative metabolism contributes to energy expenditure during acute cold exposure in humans. J Clin Invest 122, 545-552, doi:10.1172/jci60433 (2012).

14 Bucci, M. et al. Enhanced fatty acid uptake in visceral adipose tissue is not reversed by weight loss in obese individuals with the metabolic syndrome. Diabetologia 58, 158-164, doi:10.1007/s00125-014-3402-x (2015).

15 Syamsunarno, M. R. A. A. et al. Fatty acid binding protein 4 and 5 play a crucial role in thermogenesis under the conditions of fasting and cold stress. PLoS One 9, e90825, doi:10.1371/journal.pone.0090825 (2014).

16 Putri, M. et al. CD36 is indispensable for thermogenesis under conditions of fasting and cold stress. Biochem Biophys Res Commun 457, 520-525, doi:10.1016/j.bbrc.2014.12.124 (2015).

17 Grimpo, K. et al. Brown adipose tissue dynamics in wild-type and UCP1-knockout mice: in vivo insights with magnetic resonance. J Lipid Res 55, 398-409, doi:10.1194/jlr.M042895 (2014).

18 Holstila, M. et al. Measurement of brown adipose tissue mass using a novel dual-echo magnetic resonance imaging approach: a validation study. Metabolism 62, 1189-1198, doi:10.1016/j.metabol.2013.03.002 (2013).

19 van Rooijen, B. D. et al. Imaging cold-activated brown adipose tissue using dynamic T2*weighted magnetic resonance imaging and 2-deoxy-2-[18F]fluoro-D-glucose positron emission tomography. Invest Radiol 48, 708-714, doi:10.1097/RLI.0b013e31829363b8 (2013). 
Cypess, A. M. et al. Identification and importance of brown adipose tissue in adult humans. $N$ Engl J Med 360, 1509-1517, doi:10.1056/NEJMoa0810780 (2009).

21 Cypess, A. M. et al. Activation of human brown adipose tissue by a $\beta 3$-adrenergic receptor agonist. Cell Metab 21, 33-38, doi:10.1016/j.cmet.2014.12.009 (2015).

22 DeGrado TR, C. H., Stocklin G. 14(R,S)-[18F]fluoro-6-thia-heptadecanoic acid (FTHA): evaluation in mouse of a new probe of myocardial utilization of long chain fatty acids. $J$ Nucl Med 32, 1888-1896 (1991).

23 Goodmen M.M., K. F. F., Elmaleh D.R., Strauss H.W. New myocardial imaging agents: Synthesis of 15-(p-[123I]iodophenyl)-3(R,S)-methylpentadecanoic acid by decomposition of a 3,3-(1,5-pentanedyl)triazene precursor. J. Org. Chem 49, 2322-2325 (1984).

24 Tamaki, N. et al. Assessment of myocardial fatty acid metabolism with positron emission tomography at rest and during dobutamine infusion in patients with coronary artery disease. Am Heart J 125, 702-710 (1993).

25 Schelbert, H. R. Myocardial ischemia and clinical applications of positron emission tomography. Am J Cardiol 64, 46E-53E (1989).

26 Schelbert, H. R. et al. Effects of substrate availability on myocardial C-11 palmitate kinetics by positron emission tomography in normal subjects and patients with ventricular dysfunction. Am Heart J 111, 1055-1064 (1986).

27 Dubikovskaya, E., Chudnovskiy, R., Karateev, G., Park, H. M. \& Stahl, A. Measurement of longchain fatty acid uptake into adipocytes. Methods Enzymo/ 538, 107-134, doi:10.1016/b978-012-800280-3.00007-4 (2014).

28 Kasurinen, J. A novel fluorescent fatty acid, 5-methyl-BDY-3-dodecanoic acid, is a potential probe in lipid transport studies by incorporating selectively to lipid classes of BHK cells. Biochem Biophys Res Commun 187, 1594-1601 (1992).

29 Liu, S. et al. Lewis acid-assisted isotopic 18F-19F exchange in BODIPY dyes: facile generation of positron emission tomography/fluorescence dual modality agents for tumor imaging. Theranostics 3, 181-189, doi:10.7150/thno.5984 (2013).

30 Hendricks, J. A. et al. Synthesis of [18F]BODIPY: bifunctional reporter for hybrid optical/positron emission tomography imaging. Angew Chem Int Ed Engl 51, 4603-4606, doi:10.1002/anie.201107957 (2012).

31 Keliher, E. J., Klubnick, J. A., Reiner, T., Mazitschek, R. \& Weissleder, R. Efficient acidcatalyzed (18) F/(19) F fluoride exchange of BODIPY dyes. ChemMedChem 9, 1368-1373, doi:10.1002/cmdc.201300506 (2014).

$32 \mathrm{Li}, \mathrm{Z}$. et al. Rapid aqueous [18F]-labeling of a bodipy dye for positron emission tomography/fluorescence dual modality imaging. Chem Commun (Camb) 47, 9324-9326, doi:10.1039/c1cc13089g (2011).

33 Paulus, A. et al. Development of a clickable bimodal fluorescent/PET probe for in vivo imaging. EJNMMI Res 5, 120, doi:10.1186/s13550-015-0120-4 (2015).

34 McAnoy, A. M., Wu, C. C. \& Murphy, R. C. Direct qualitative analysis of triacylglycerols by electrospray mass spectrometry using a linear ion trap. J Am Soc Mass Spectrom 16, 14981509, doi:10.1016/j.jasms.2005.04.017 (2005).

Broeders, E. P. et al. The Bile Acid Chenodeoxycholic Acid Increases Human Brown Adipose Tissue Activity. Cell metabolism 22, 418-426, doi:10.1016/j.cmet.2015.07.002 (2015). methods 9, 676-682, doi:10.1038/nmeth.2019 (2012).

Kuda, O. et al. Sulfo-N-succinimidyl oleate (SSO) inhibits fatty acid uptake and signaling for intracellular calcium via binding CD36 lysine 164: SSO also inhibits oxidized low density lipoprotein uptake by macrophages. The Journal of biological chemistry 288, 15547-15555, doi:10.1074/jbc.M113.473298 (2013).

38 Weinstock, P. H. et al. Lipoprotein lipase controls fatty acid entry into adipose tissue, but fat mass is preserved by endogenous synthesis in mice deficient in adipose tissue lipoprotein lipase. Proc Natl Acad Sci U S A 94, 10261-10266 (1997). 
39 Mead, J. R., Irvine, S. A. \& Ramji, D. P. Lipoprotein lipase: structure, function, regulation, and role in disease. J Mol Med (Berl) 80, 753-769, doi:10.1007/s00109-002-0384-9 (2002).

40 Liu, S. et al. Efficient synthesis of fluorescent-PET probes based on $\left[{ }^{18} \mathrm{~F}\right] \mathrm{BODIPY}$ dye. Chem Commun (Camb) 50, 7371-7373, doi:10.1039/c4cc01411a (2014).

41 Hui, T. Y. \& Bernlohr, D. A. Fatty acid transporters in animal cells. Frontiers in bioscience : $a$ journal and virtual library 2, d222-231 (1997).

42 Stahl, A., Evans, J. G., Pattel, S., Hirsch, D. \& Lodish, H. F. Insulin causes fatty acid transport protein translocation and enhanced fatty acid uptake in adipocytes. Developmental cell $\mathbf{2}$, 477-488 (2002).

43 Anderson, C. M. et al. Dependence of brown adipose tissue function on CD36-mediated coenzyme Q uptake. Cell Rep 10, 505-515, doi:10.1016/j.celrep.2014.12.048 (2015).

44 Coburn, C. T., Hajri, T., Ibrahimi, A. \& Abumrad, N. A. Role of CD36 in membrane transport and utilization of long-chain fatty acids by different tissues. J Mol Neurosci 16, 117-121; discussion 151-117, doi:10.1385/jmn:16:2-3:117 (2001).

45 Lowell, B. B. \& Flier, J. S. Brown adipose tissue, beta 3-adrenergic receptors, and obesity. Annual review of medicine 48, 307-316, doi:10.1146/annurev.med.48.1.307 (1997).

46 Kampf, J. P., Parmley, D. \& Kleinfeld, A. M. Free fatty acid transport across adipocytes is mediated by an unknown membrane protein pump. Am J Physiol Endocrinol Metab 293, E1207-1214, doi:10.1152/ajpendo.00259.2007 (2007).

47 Thumser, A. E. \& Storch, J. Characterization of a BODIPY-labeled fluorescent fatty acid analogue. Binding to fatty acid-binding proteins, intracellular localization, and metabolism. Mol Cell Biochem 299, 67-73, doi:10.1007/s11010-005-9041-2 (2007).

48 Zhu, S. L. et al. Highly Water-Soluble Neutral BODIPY Dyes with Controllable Fluorescence Quantum Yields. Org Lett 13, 438-441, doi:10.1021/ol102758z (2011). 


\section{Supplementary Information}

\section{BAT}

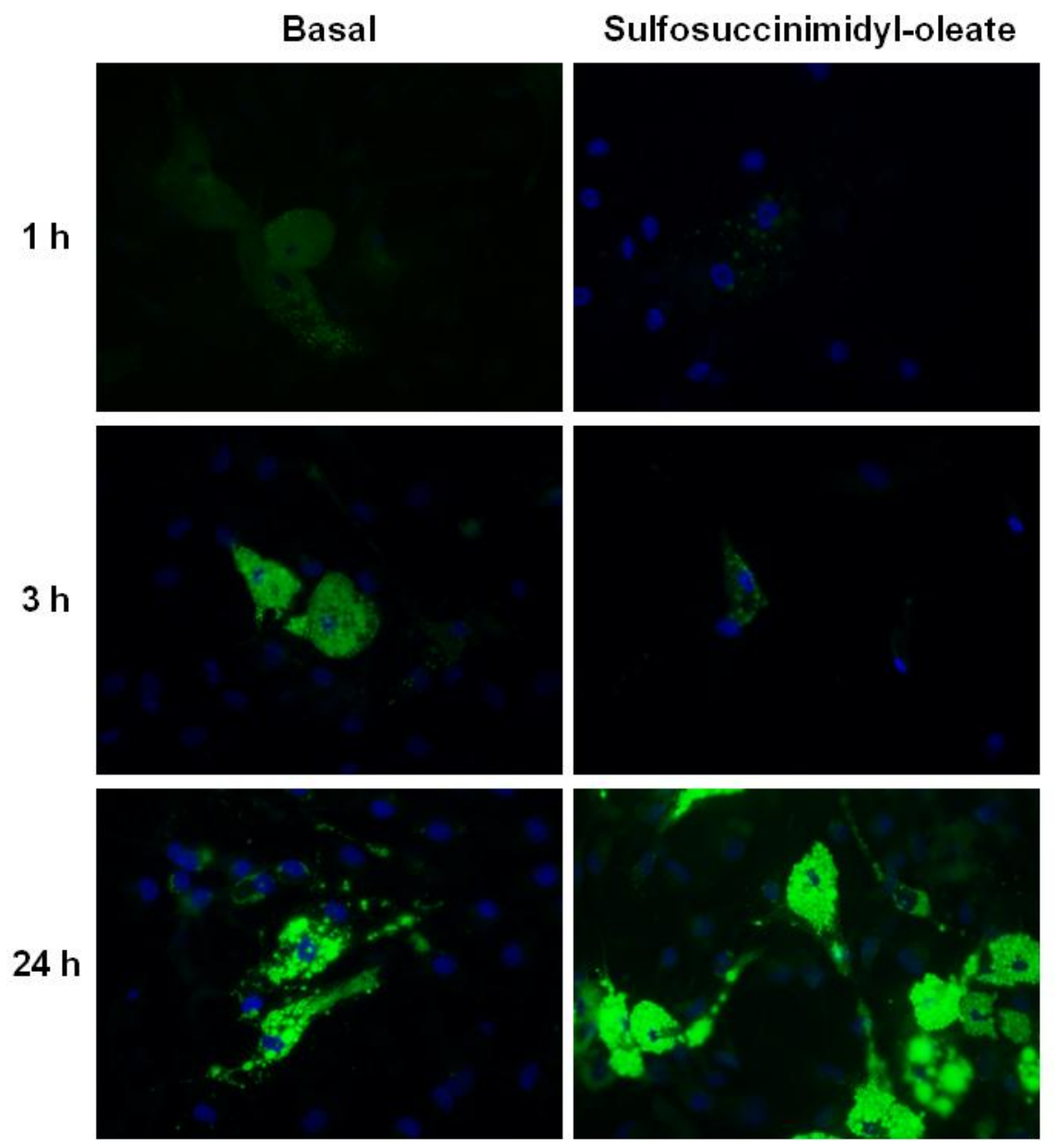

S1 Fig 1: uptake of 1 in BAT images obtained from fluorescence microscope by incubation with BDP-FA under basal conditions, and sulfosuccinimidyl - oleat incubation. Green (Bodipy-signal): 460-490 excitation, 510-550 emission, Blue (Dapi-signal): 385-415 excitation, 450-470 emmision. 


\section{WAT}

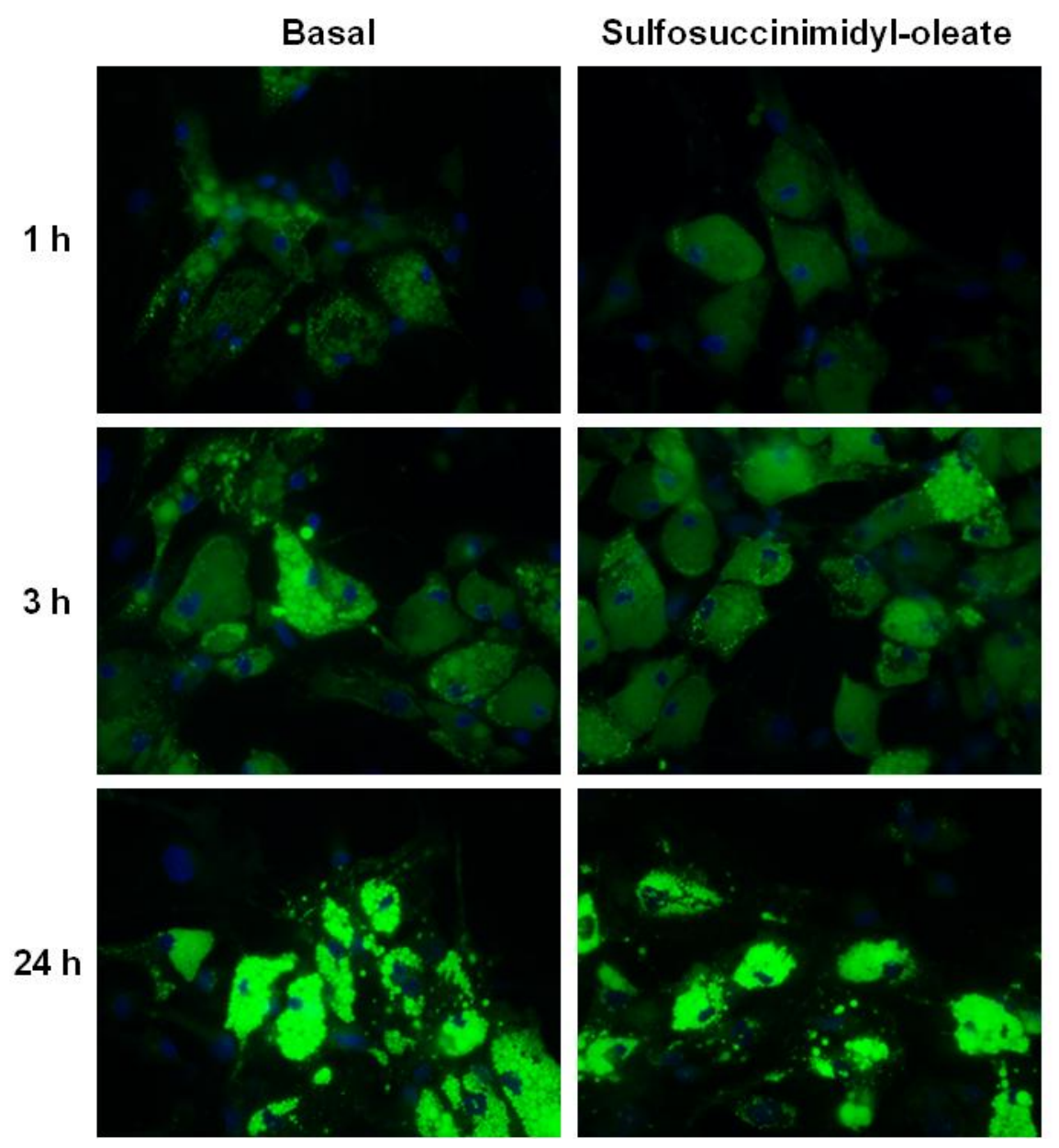

S1 Fig 2: uptake of 1 in WAT images obtained from fluorescence microscope by incubation with BDP-FA under basal conditions and sulfosuccinimidyl - oleat incubation. Green (Bodipy-signal): 460-490 excitation, 510-550 emission, Blue (Dapi-signal): 385-415 excitation, 450-470 emmision. 


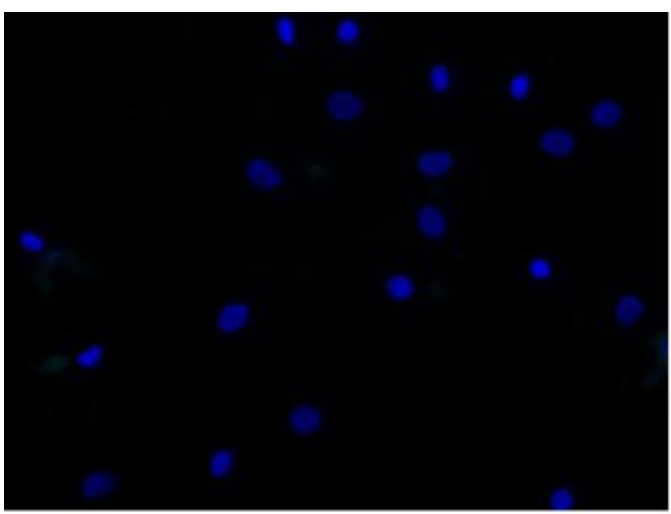

WAT

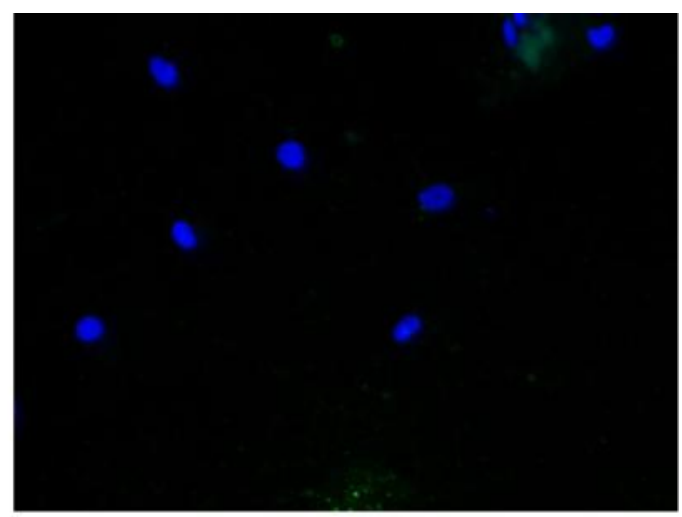

BAT

S1 Fig 3: uptake of 2 in WAT and BAT images obtained from fluorescence microscope by incubation with BDPTG $(2 \mu \mathrm{M}, 24 \mathrm{~h})$ under basal conditions. Green (Bodipy-signal): 460-490 excitation, 510-550 emission, Blue (Dapisignal): 385-415 excitation, 450-470 emmision.

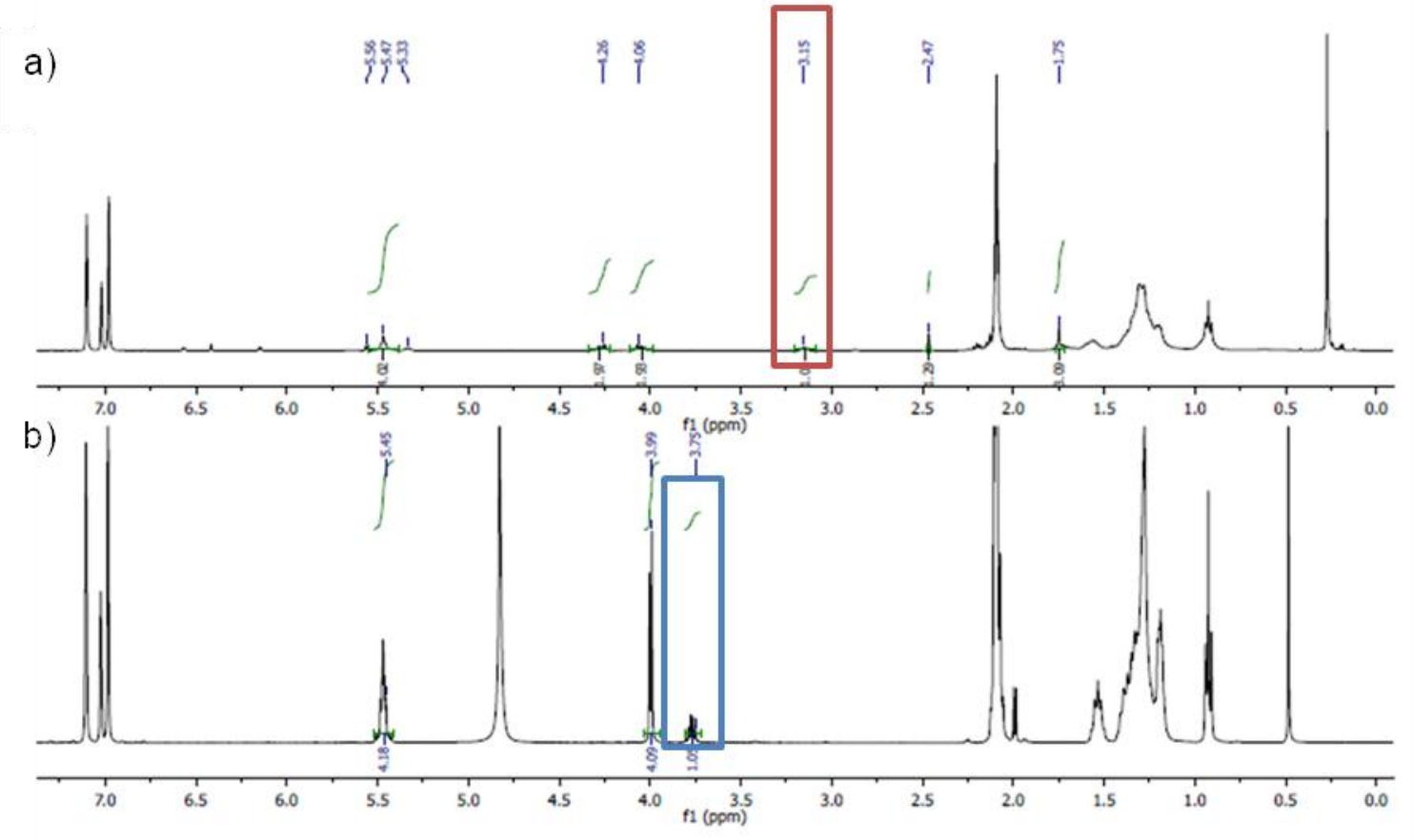

S1 Fig 4: NMR analysis NMR spectra of BDP-TG 1(a) and 1,3-Diolein (b), alcohol function of the Diolein is shown in red square, formed triple ester bond is shown in blue square. No significant impurities were noted. 


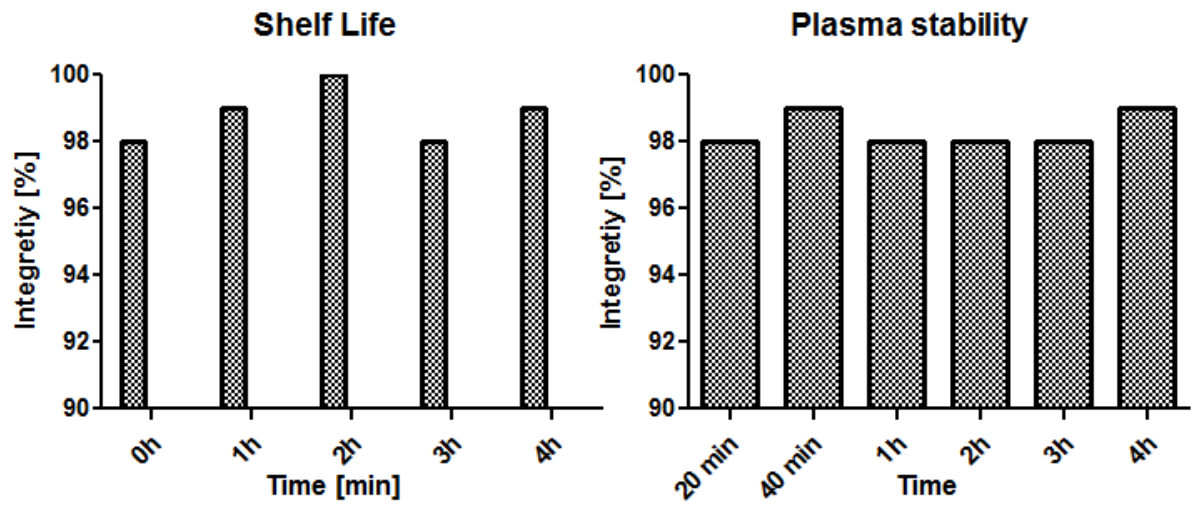

S1 Fig 5: Shelf Life and Plasma Stability of 3 


\section{Chapter 5: \\ $\left[{ }^{18} \mathrm{~F}\right] \mathrm{BODIPY}$-triglyceride-containing chylomicron-like particles as an imaging agent for brown adipose tissue in vivo}

Andreas Paulus,

Natascha Drude,

Emmani B.M. Nascimento,

Eva M. Buhl,

Jimmy F.P. Berbée,

Patrick C.N. Rensen,

Wouter van Marken Lichtenbelt,

Felix M. Mottaghy,

Matthias Bauwens

published as:

$\left[{ }^{18} \mathrm{~F}\right] \mathrm{BODIPY}$-triglyceride-containing chylomicron-like particles as an imaging agent for brown adipose tissue in vivo. Scientific Reports 9, (2019) 


\section{Abstract}

Background: Brown adipose tissue (BAT) is present in human adults and the current gold standard to visualize and quantify BAT is $\left[{ }^{18} \mathrm{~F}\right] \mathrm{FDG}$ PET-CT. However, this method fails to detect BAT under insulin-resistant conditions associated with ageing and weight gain, such as type 2 diabetes. The aim of this study was to develop a novel triglyceride-based tracer for BAT. For this purpose we designed a dual-modal fluorescent/PET fatty acid tracer based on commercially available BODIPY-FL-C ${ }_{16}$, which can be esterified to its correspondent triglyceride, radiolabeled and incorporated into pre-synthesized chylomicron-like particles.

Methods: BODIPY-FL- $\mathrm{C}_{16}$ was coupled to 1,2-diolein with a subsequent radiolabeling step resulting in $\left[{ }^{18} \mathrm{~F}\right] \mathrm{BODIPY}-\mathrm{C}_{16}$-triglyceride that was incorporated into chylomicron-like particles. Various quality control steps using fluorescent and radioactive methods were conducted before BAT visualization was tested in mice.

Results: Triglyceride synthesis, radiolabeling and subsequent incorporation into chylomicron-like particles was carried out in decent yields. This radiotracer appeared able to visualize BAT in vivo, and the uptake of the radiotracer was stimulated by cold exposure.

Conclusion: The here reported method can be used to incorporate radiolabeled triglycerides into pre-synthesized chylomicron-like particles. Our approach is feasible to visualize and quantify the uptake of triglyceride-derived fatty acids by BAT. 


\section{Introduction}

Brown adipose tissue (BAT) research has evolved from an underestimated to a fast developing field in endocrine research and non-invasive imaging is an important technique to visualize and quantify BATs metabolic activity. Brown adipocytes have the ability to combust energy to heat by nonshivering thermogenesis in their mitochondria by virtue of the presence of uncoupling protein 1 (UCP1) ${ }^{1}$. It has been shown that BAT activation can be triggered by cold exposure, which induces a release of noradrenalin from nerve endings ${ }^{2}$. This neurotransmitter binds to adrenergic receptors on the BAT membrane and promotes an induction of intracellular lipolysis which leads to a release of fatty acids (FAs) from triglyceride

(TG)-filled lipid droplets

3

(Fig

1).

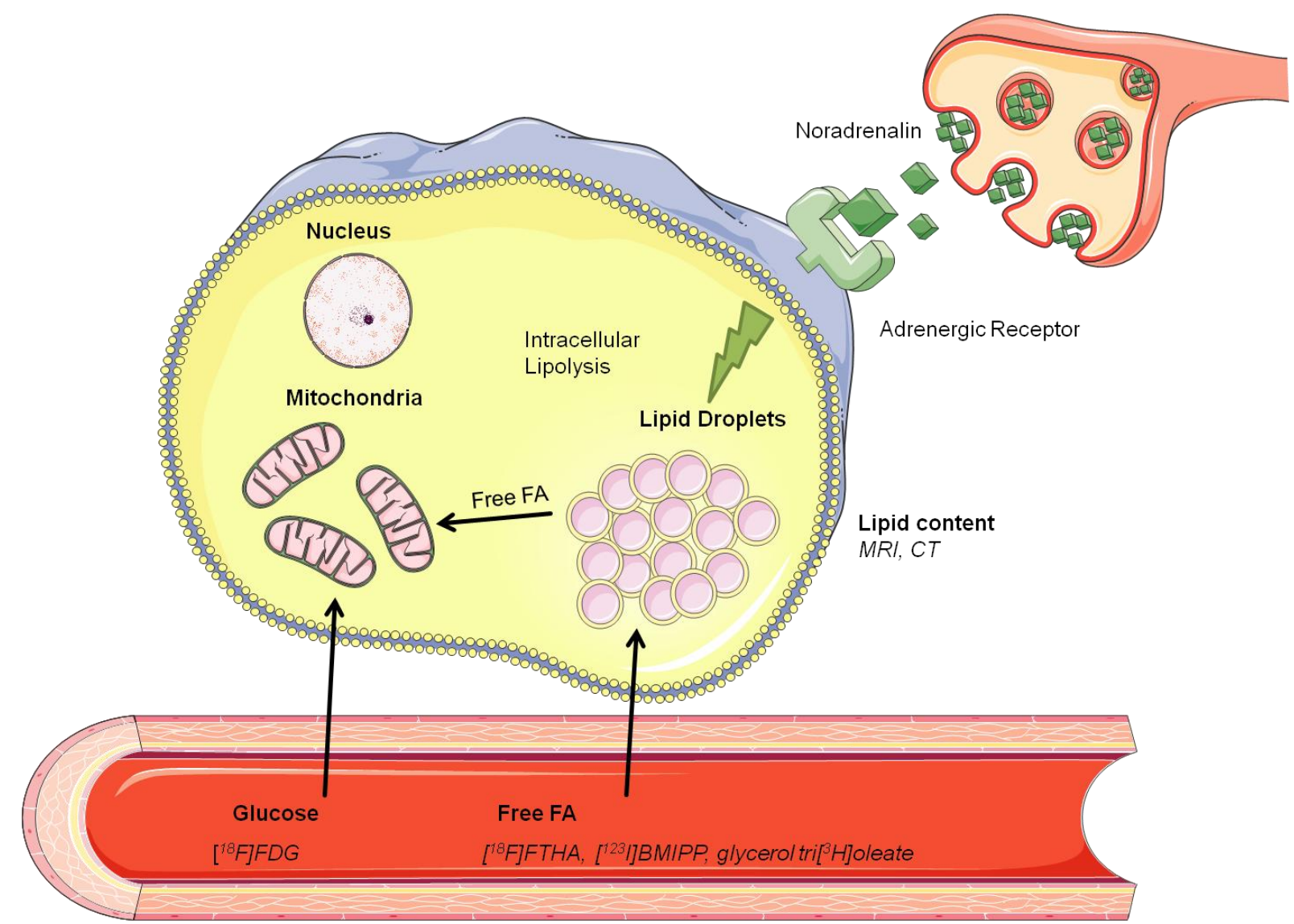

Fig 1: BAT activation by noradrenergic stimulation and possible quantification approaches by $\left[{ }^{18} \mathrm{~F}\right] \mathrm{FDG}$ (glucose consumption), $\left[{ }^{18} \mathrm{~F}\right] \mathrm{FTHA},\left[{ }^{123} \mathrm{I}\right.$ BMIPP, glycerol trii $\left[{ }^{3} \mathrm{H}\right]$ oleate-derived $\left[{ }^{3} \mathrm{H}\right]$ oleate (lipid uptake) and MRI, CT (lipid content). 
Those FAs activate UCP1 within the inner mitochondrial membrane ${ }^{2}$ whereby the proton gradient across the membrane is dispersed and heat is produced.

In activated BAT, internal lipid droplets are replenished by nutrient uptake from plasma in three different ways: uptake of TG-rich lipoprotein (TRL)-derived FAs, glucose uptake followed by de novo lipogenesis, and uptake of circulating albumin-bound FAs ${ }^{2-5}$. Although direct TRL particle uptake with adjacent FA release has been suggested ${ }^{4}$, more recent findings using glycerol tri $\left[{ }^{3} \mathrm{H}\right]$ oleate and $\left[{ }^{14} \mathrm{C}\right]$ cholesteryl oleate double-labeled TRL-like particles showed an approx. 10-fold higher uptake of FAs compared to cholesteryl esters by BAT ${ }^{5,6}$, indicating that the majority of TG-derived FAs is internalized after liberation by lipoprotein lipase (LPL). In fact, TRL-derived FAs were identified as the main supply of TGs in BAT ${ }^{3,7}$ and TG-derived FA internalization was shown to be dependent on the presence of lipoprotein lipase (LPL) ${ }^{7,8}$, cluster of differentiation 36 (CD36) ${ }^{9}$ and fatty acid transport

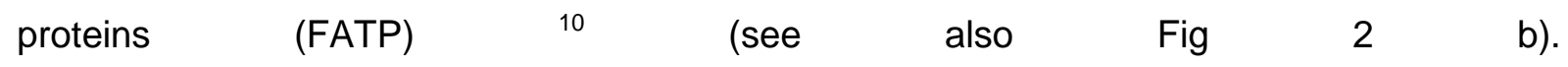
a)

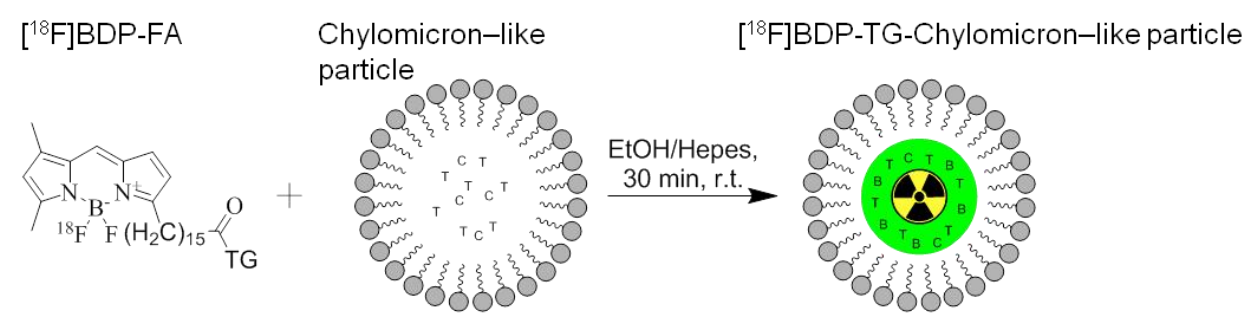

b)
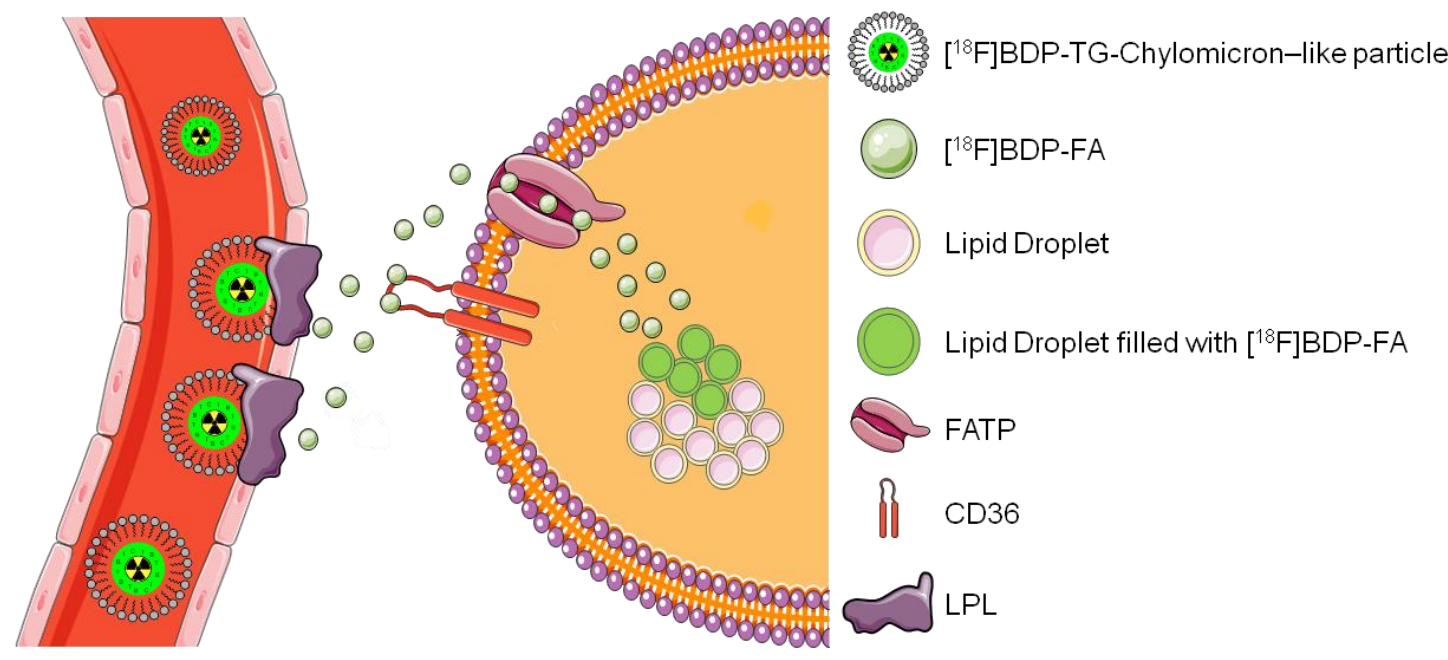

Fig 2: a) Incorporation of radiolabeled $\left[{ }^{18} \mathrm{~F}\right] \mathrm{BDP}-\mathrm{TG}$ into pre-synthesized chylomicron-like particles. b) uptake of TG-rich lipoprotein (TRL)-derived FAs from the plasma facilitated by LPL, CD36 and FATP. 
The variety of quantification approaches of BAT volume and metabolic activity reaches from invasive imaging with fluorescence probes ${ }^{4}$ or ${ }^{3} \mathrm{H}$-labeled $\mathrm{TG}^{5}$ to non-invasive experiments with PET ${ }^{11-15}$, SPECT ${ }^{16,17}$ and MRI ${ }^{18-20}$ and was reviewed recently by us ${ }^{21} \cdot\left[{ }^{18} \mathrm{~F}\right] \mathrm{FDG}$ (as a measure for glucose uptake) is frequently used in studies to quantify BAT activity and is currently the gold standard ${ }^{12,22-24}$ (Fig 1). Nevertheless FAs are the main metabolized substance class in BAT, which is not simply mirrored by $\left[{ }^{18} \mathrm{~F}\right] \mathrm{FDG}$ scans ${ }^{14}$. In addition, insulin resistance such as type 2 diabetes of BAT occurring with ageing and weight gain will underestimate BAT activity as assessed with $\left[{ }^{18} \mathrm{~F}\right] \mathrm{FDG}$ scans, whereas FA and oxidative metabolism is not dependent on insulin sensitivity ${ }^{25}$. It should be mentioned that LPL activity was decreased during insulin resistance in mice ${ }^{26}$ and insulin was found to be essential for the lipolytic processing of TRLs by BAT ${ }^{27}$. Therefore BAT visualization with TRLs could become difficult during diabetic conditions, but it might be the most precise way to gain information about BATs lipid turnover and metabolic activity. Taken together, we reasoned a TG-derived FA tracer is needed to visualize and quantify lipid uptake by BAT to better reflect the thermogenic potential of BAT compared to $\left[{ }^{18} \mathrm{~F}\right] \mathrm{FDG}$.

Radiolabeled FAs in general have been developed in several variations for imaging purposes (e.g. $\left[{ }^{18} \mathrm{~F}\right] \mathrm{FTHA}$ and $\left[{ }^{125}\right] \mathrm{BMIPP}{ }^{28,29}$ ). We here report the development of a FA-tracer based on fluorescent FA BODIPY-FL-C ${ }_{16}$ (BDP-FA), which is suitable for both PET and fluorescence imaging, and present a method to esterify the FA into a TG and subsequently incorporate it into a chylomicron-like particle. We hypothesized that by this approach the physiological situation is mimicked where TRL-derived TGs get lipolyzed locally before they are taken up by brown adipocytes. Additionally it will be possible to image from whole body to sub-cellular level and in vitro experiments can be carried out with the same molecule without any radiation dose. BODIPY dyes have been already used to image BAT ${ }^{4}$ and it is known that FA transport proteins (FATP) have a preference for BODIPY-FL coupled to a long carbon chain $(C \geq 8)^{30}$. Furthermore, downstream metabolic reactions in white and brown adipocytes have already been visualized in vitro ${ }^{31,32}$. 
To avoid decreasing the FA characteristic properties of BDP-FA by introduction of another chelator molecule, we performed ${ }^{18} \mathrm{~F} /{ }^{19} \mathrm{~F}$ exchange reactions used to transform fluorescent dyes into dual-modality PET/fluorescent imaging dyes ${ }^{4,33-36}$. Neither an increased steric demand, nor lowering of the targeting efficiency of the FA towards proteins responsible for FA uptake is expected as BDP-FA is only modified at the end of the carbon chain and therefore keeps its FA characteristics. We recently described the synthesis and radiolabeling of $\left[{ }^{18} \mathrm{~F}\right] \mathrm{BDP}-\mathrm{TG}$ and conducted first in vitro experiments with primary human adipocytes where $\left[{ }^{18} \mathrm{~F}\right] \mathrm{BDP}-\mathrm{FA}$ uptake could be modified by different BAT activating and blocking agents ${ }^{32}$. The aim of the presented study was to incorporate the $\left[{ }^{18} \mathrm{~F}\right] \mathrm{BDP}-\mathrm{TG}$ into chylomicron-like particles to obtain one of the first TG-based PET imaging agents and to test the new developed tracer in mice. Different to other used FA-based imaging tracers, the here presented TG will be first lipolyzed on-site before it can be internalized by BAT. This reflects the physiological situation in a better way than other FA-based tracers do and will help to quantify BATs consumption of lipids and its contribution to whole body energy expenditure. 


\section{Methods}

Commercially available compounds were used without further purification unless otherwise stated. BDP-FA was purchased from Thermo Fischer Scientific (99\%) (Netherlands). 1,3diolein was purchased from Sigma Aldrich ( $\geq 99 \%$ ). 1,2-diolein was purchased from Cayman Chemicals (USA) ( $\geq 95 \%$ ). DMEM/F-12 was purchased from ThermoFischer (Waltham, MA). All HPLC purifications $\left(1.0 \mathrm{~mL} / \mathrm{min}\right.$, solvent $\mathrm{A} ; 0.1 \%$ TFA in $\mathrm{H}_{2} \mathrm{O}$, solvent $\mathrm{B} ; \mathrm{CH}_{3} \mathrm{CN}, 50^{\circ} \mathrm{C}$ ) were performed on a Shimadzu UFLC HPLC system equipped with a DGU-20A ${ }_{5}$ degasser, a SPD-M20A UV detector, a LC-20AT pump system, a CBM-20A communication BUS module, a CTO-20AC column oven, and a Scan-RAM radio-TLC/HPLC-detector from LabLogic using an Aeris ${ }^{\mathrm{TM}}$ Widepore column $(\mathrm{C} 4,3.6 \mu \mathrm{m}, 4.6 \mathrm{~mm} \times 250 \mathrm{~mm})$ for the BDP-TG. ESI-MS was performed on an Applied Biosystems SCIEX API 150 EX electrospray ionization quadrupole (ESI-Q) mass spectrometer with the method of McAnoy et al. ${ }^{53}$. Briefly, $0.1 \mathrm{M}$ aqueous ammonium acetate solution was added to the sample to observe the ammonium salt of the synthesized TG in the MS.

${ }^{1} \mathrm{H}$-NMR spectra were carried out on a Bruker Ultrashield TH 400 plus at $400 \mathrm{MHz}$. Tol- $\mathrm{d}_{8}$ was used as solvent with TMS as internal standard. Chemical shifts are reported in parts per million (ppm) relative to the internal standard.

Gel electrophoresis was used to determine the amount of free fluorine-18 and $\left[{ }^{18}\right.$ F]BDP-TG in the solution containing $\left[{ }^{18} \mathrm{~F}\right] \mathrm{BDP}-\mathrm{TG}$ incorporated in chylomicron-like particles. Gel electrophoresis was carried out under native running conditions where the sample was mixed (1:2) with native sample buffer and loaded into an any kD TGX gel (20 kBq per lane). For visualization phosphor screens were exposed for $10 \mathrm{~h}$ to the gel and analyzed by a Typhoon FLA 7000 phosphor imager (GE Healthcare).

\section{Synthesis of chylomicron-like particles}

Synthesis of chylomicron-like particles was performed as reported before ${ }^{37,54}$. Briefly, emulsion particles were prepared from triolein $(70 \mathrm{mg})$, egg yolk phosphatidylcholine (Lipoid) 
(22.7 mg), lysophosphatidylcholine $(2.3 \mathrm{mg})$, cholesteryl oleate $(3.0 \mathrm{mg})$, and cholesterol $(2.0$ mg). Sonification was performed using a Soniprep 150 (MSE Scientific Instruments, UK) that was equipped with a water bath for temperature $\left(54{ }^{\circ} \mathrm{C}\right)$ maintenance, at $10 \mu \mathrm{m}$ output. The emulsion was fractionated by density gradient ultracentrifugation steps in a Beckman SW 40 $\mathrm{Ti}$ rotor. After centrifugation for $30 \mathrm{~min}$ at $17,850 \mathrm{rpm}$ at $20{ }^{\circ} \mathrm{C}$, an emulsion fraction containing chylomicron-like particles was removed from the top of the tube by aspiration. Characterization of chylomicron-like particles was done by DLS and transmission electron microscopy. Chylomicron-like particles were stored at $4{ }^{\circ} \mathrm{C}$ and were used within 5 days following preparation.

\section{Dynamic Light Scattering}

The particle sizes were measured by photon correlation spectroscopy performed at an angle of $90^{\circ}$; with a setup consisting of an ALV-SP8 goniometer, an ALV-SIPC photomultiplier, a multiple T digital real-time ALV-7004 correlator, and a solid state laser (Koheras) with a red laser $(\lambda=633 \mathrm{~nm})$ as light source. The time resolved signal of two Single Photon Counting Modules was cross-correlated. To prevent multiple scattering highly diluted chylomicron-like particle solutions of $0.1 \mathrm{mg} / \mathrm{mL}$ in bi-distilled and filtered $\mathrm{H}_{2} \mathrm{O} \quad(1.2 \mu \mathrm{m}$ poly(tetrafluoroethylene) membrane filters) were prepared. Sample cuvettes were immersed in a toluene bath and tempered within an error of $\pm 0.1^{\circ} \mathrm{C}$. Autocorrelation functions of intensity fluctuations $g_{2}(q, t)$ are converted by the Siegert relation and give the field autocorrelation function $\mathrm{f}(\mathrm{q}, \mathrm{t})$ :

$f(q, t)=\int_{0}^{\infty} G\left(D_{0}\right) \exp \left\{-D_{0} q^{2} \tau\right\} d D_{0}$

Where $\mathrm{T}$ is the decay time, $\mathrm{G}\left(\mathrm{D}_{0}\right)$ is the distribution function of $\mathrm{D}_{0}$, the diffusion coefficient and $\mathrm{q}$ as the scattering vector defined as

$q=\frac{4 \pi n}{\lambda_{0}} \sin \left(\frac{\theta}{2}\right)$

with $\theta$ being the scattering angle and $\lambda_{0}$ being the wavelength of the laser light in vacuum. 
The intensity-weighted decay-time $\mathrm{x}$ distributions obtained from the field autocorrelation function by cumulant analysis were analyzed in respect to multimodality. For each diffusive mode the decay rate $\Gamma=1 / \mathrm{T}$ was plotted against the squared length of the scattering vector $q^{2}$. The slope gave the Z-average translational diffusion coefficient $D_{0}$ and results in the hydrodynamic radius $R_{h}$ after use of the Stokes Einstein equation:

$D_{0}=\frac{k_{B} T}{6 \pi \eta R_{h}}$

with $q, k_{B}, T$ and $\eta$ being the scattering vector, the Boltzmann constant, absolute temperature, and solvent viscosity, respectively. A hydrodynamic radius distribution was calculated from the regularized Laplace inversion of correlation functions with CONTIN algorithm.

\section{Transmission electron microscopy}

Samples were allowed to adsorb on glow discharged formvar-carbon-coated nickel grids (Maxtaform, 200 mesh, Plano, Wetzlar, Germany) for $3 \mathrm{~min}$. Adhesive drops were removed by filter paper. Negative staining was performed with uranyl acetate $\left(0.5 \%\right.$ in $\mathrm{H}_{2} \mathrm{O}$, Science Services $\mathrm{GmbH}$, Munich, Germany) for 1-3 seconds. Excess liquid was removed, samples were air dried and examined using a LEO 906 E transmission electron microscope (Zeiss, Oberkochen, Germany), operated at an acceleration voltage of $60 \mathrm{kV}$.

\section{Synthesis of BDP-TG}

Synthesis was performed as reported before ${ }^{32}$. Briefly, BDP-FL- ${ }_{16}(300 \mu \mathrm{g}, 0.6 \mu \mathrm{mol})$ in acetonitrile was evaporated to complete dryness before the reactant was reconstituted in toluene $(100 \mu \mathrm{L})$. To the resulting solution $\mathrm{SOCl}_{2}$ in toluene $(100 \mu \mathrm{L}, 4$ vol.-\%) was added, incubated for $5 \mathrm{~min}$ at $70^{\circ} \mathrm{C}$ in a closed vial and evaporated. The product was reconstituted in toluene $(50 \mu \mathrm{L})$ containing 1,2-diolein $(2 \mu \mathrm{L}, 2.8 \mu \mathrm{mol})$ and heated to $100{ }^{\circ} \mathrm{C}$ for $30 \mathrm{~min}$. After the reaction time, purification by HPLC $(1 \mathrm{~mL} / \mathrm{min}, 30 \%$ to $15 \% \mathrm{~A}$ in $5 \mathrm{~min}, 15 \%$ to $0 \% \mathrm{~A}$ from 5 to $6 \mathrm{~min}, 0 \% \mathrm{~A}$ to $20 \mathrm{~min})$ yielded $2(225 \mu \mathrm{g}, 75 \%)$ as a red solid; $\mathrm{t}_{\mathrm{R}}=12.3 \mathrm{~min}$. ESI- 
MS (+) m/z (\%) = $1058(100)\left[M-F^{-}\right]^{+}, 1095(82)\left[\mathrm{M}+\mathrm{NH}_{4}\right]^{+} .{ }^{1} \mathrm{H}$ NMR (400 MHz, Tol-d $)$; $\delta(\mathrm{ppm})=5.46(\mathrm{~m}, 4 \mathrm{H}), 4.26(\mathrm{~m}, 2 \mathrm{H}), 4.06(\mathrm{~m}, 2 \mathrm{H}), 3.13(\mathrm{~m}, 1 \mathrm{H}), 1.75(\mathrm{~s}, 3 \mathrm{H})$.

\section{Radiolabeling of BDP-TG}

Radiolabeling was performed as reported before ${ }^{32}$. Briefly, aqueous fluorine-18 solution was loaded on a QMA-cartridge which was preconditioned with $15 \mathrm{~mL} \mathrm{~K}_{2} \mathrm{CO}_{3}$ in $\mathrm{H}_{2} \mathrm{O}$ and $20 \mathrm{~mL}$ $\mathrm{H}_{2} \mathrm{O}$. Fluoride (42 MBq) was eluted with a mixture of $600 \mu \mathrm{L}$ acetonitrile, $400 \mu \mathrm{L} \mathrm{H}_{2} \mathrm{O}$ and 6 mg Sodium p-toluenesulfonate (Sigma-Aldrich). Fluorine-18 solution was transferred into a drying vessel containing tetra-n-butylammonium bromide $(80 \mu \mathrm{L})$ as a phase transfer agent. Acetonitrile $(3 \times 1.0 \mathrm{~mL})$ was added and the solution of fluorine-18 was dried by heating to $100^{\circ} \mathrm{C}$ with a continuous flow of argon. After reconstitution of Fluorine-18 in anhydrous acetonitrile $(100 \mu \mathrm{L})$, a solution of BDP-TG in toluene $(107 \mu \mathrm{g}, 0.1 \mu \mathrm{mol}$ in $50 \mu \mathrm{L})$ and $\mathrm{SnCl}_{4}$ $(0.2 \mathrm{M}$ in acetonitrile, $100 \mu \mathrm{L})$ was added to the solution with the activity and the reaction solution was stirred at room temperature (r.t.) for $30 \mathrm{~min} .\left[{ }^{18} \mathrm{~F}\right] \mathrm{BDP}-\mathrm{TG}$ was obtained (decay corrected RCY: 44\%, $25 \mathrm{MBq}$ ) with a decay corrected specific activity of $250 \mathrm{MBq} / \mu \mathrm{mol}$ and a radiochemical purity of $45 \%$ determined by a radio-TLC with toluene, $\mathrm{CHCl}_{3}$ and $\mathrm{MeOH}$ $(80.9 \%, 14.3 \%, 4.8 \%)$ of the reaction solution.

\section{Ex vivo incorporation of $\left[{ }^{18} \mathrm{~F}\right] \mathrm{BDP}-\mathrm{TG}$ into chylomicron-like particles}

To $\left[{ }^{18} \mathrm{~F}\right] \mathrm{BDP}-\mathrm{TG}(233 \mathrm{MBq})$ in the reaction solution $500 \mu \mathrm{L} \mathrm{H}_{2} \mathrm{O}$ were added and centrifuged for $5 \mathrm{~min}$. The aqueous phase was aspirated and another $500 \mu \mathrm{L} \mathrm{H}_{2} \mathrm{O}$ were added to precipitate the remaining $\mathrm{SnCl}_{4}$. The mixture was heated to $100{ }^{\circ} \mathrm{C}$, the organic phase was evaporated and the aqueous phase was taken off. $\left[{ }^{18} \mathrm{~F}\right] \mathrm{BDP}-\mathrm{TG}$ was reconditioned in $20 \mu \mathrm{L}$ $\mathrm{EtOH}$ and another radio - TLC was performed. [ $\left.{ }^{18} \mathrm{~F}\right] \mathrm{BDP}-\mathrm{TG}$ could be obtained with a radiochemical purity of $>96 \%$ and an overall decay corrected radiochemical yield of $21 \%$. $400 \mu \mathrm{L}$ chylomicron-like particles in HEPES were added (1.5 mg TG content) and incubated for $1 \mathrm{~h}$ at r.t.. $\left[{ }^{18} \mathrm{~F}\right] \mathrm{BDP}-\mathrm{TG}$-chylomicron-like particles were obtained (overall decay corrected $\mathrm{RCY}: 18 \%, 19 \mathrm{MBq}$ ) with a radiochemical purity of $>99 \%$ analyzed by gel electrophoresis 
and radio-TLC (Fig 3 e and f). Shorter incubation time points and different temperatures were tested by radio-TLC (Fig $3 \mathrm{~b}$ and $\mathrm{c}$ )

\section{Fluorescence measurements of BDP-TG-chylomicron-like particles}

BDP-TG-chylomicron-like particles $(80 \mu \mathrm{L})(0.1 \mu \mathrm{mol}$ BDP-TG dissolved in $20 \mu \mathrm{L}$ EtOH + chylomicron-like particles $(750 \mu \mathrm{g}$ TG content in $200 \mu \mathrm{L}$ HEPES), BDP-TG (80 $\mu \mathrm{L})(0.1 \mu \mathrm{mol}$ dissolved in $20 \mu \mathrm{L} \mathrm{EtOH}+200 \mu \mathrm{L}$ HEPES) and chylomicron-like particles (750 $\mu \mathrm{g} \mathrm{TG}$ content in $200 \mu \mathrm{L}$ HEPES) are measured using a SpectraMax M2 plate reader (molecular devices) (excitation $485 \mathrm{~nm}$, emission $520 \mathrm{~nm}$ ).

\section{Animal experiments}

Experimental protocols were approved by the "Centrale Commissie Dierproeven" and all animal experiments and procedures were performed in accordance with the guidelines set of this institution. From 13:00 p.m. on,female C57BI/6 mice (fasted for $4 \mathrm{~h}$ at r.t. or fasted and cold exposed at $4{ }^{\circ} \mathrm{C}$ for $4 \mathrm{~h}$ ) were anesthetized (Isoflurane, 1.5-2.0\% at $2 \mathrm{~mL} / \mathrm{min}$ in oxygen), mice kept at r.t. were put on a heating pad and both groups were injected with $\left[{ }^{18} \mathrm{~F}\right] \mathrm{BDP}-\mathrm{TG}$-chylomicron-like particles $(1-5 \mathrm{MBq})$ in HEPES $(100 \mu \mathrm{L})$ via the tail vein. Mice were scanned dynamically for $1 \mathrm{~h}$ on a microPET (Focus 120, Siemens). Images were analyzed using Pmod V3.707. After the scanning time animals were killed and organs harvested, weighed wet and counted using a WIZARD ${ }^{2}$ automatic $y$-counter from Perkin Elmer.

\section{Statistical analyses}

Data are presented as mean $\pm S D$, unless indicated otherwise. Differences at a probability level (p) of 0.05 were considered statistically significant. GraphPad Prism 5.01 (La Jolla, CA, USA) for Windows was used for statistical analyses. 


\section{Availability of materials and data}

All data generated or analysed during this study are included in this published article (and its Supplementary Information files). 


\section{Results}

\section{Synthesis of BDP-TG}

Synthesis of BDP-TG was conducted as described before ${ }^{32}$. The resulting TG was obtained with a yield of $45 \pm 8 \% \mathrm{SD}$ after HPLC purification. BDP-TG has a $t_{r}$ of 12.3 min and NMR and ESI-MS confirmed the identity of BDP-TG.

\section{Radiolabeling of BDP-TG}

The radiolabeled dual-modality imaging agent $\left[{ }^{18} \mathrm{~F}\right] \mathrm{BDP}-\mathrm{TG}$ was synthesized in a two-step procedure and was obtained with a decay corrected specific activity of $250 \mathrm{MBq} / \mathrm{\mu mol}$ and a decay corrected radiochemical yield of $44 \%$. After washing with $\mathrm{H}_{2} \mathrm{O}\left[{ }^{18} \mathrm{~F}\right] \mathrm{BDP}-\mathrm{TG}$ was obtained with an overall decay corrected radiochemical yield of $21 \%$ and a radiochemical purity $>96 \%$. Shelf life and plasma stability showed $99 \%$ intact $\left[{ }^{18} \mathrm{~F}\right]$ BDP-FA after $4 \mathrm{~h}^{32}$. Because of the insolubility of $\left[{ }^{18} \mathrm{~F}\right] \mathrm{BDP}-\mathrm{TG}$ in aqueous medium shelf life and plasma stability experiments needed to be performed with $\left[{ }^{18} \mathrm{~F}\right] \mathrm{BDP}-\mathrm{FA}$, however no difference in stability is expected.

\section{Synthesis of chylomicron-like particles and characterization}

Chylomicron-like particles were synthesized essentially as reported before ${ }^{5,6,37}$. After synthesis size of the particles was determined by DLS, showing a mean diameter of $164 \pm 20$ $\mathrm{nm}$ and a polydispersity index of $0.181(\mathrm{n}=4)$. Additionally, particles were analyzed by transmission electron microscopy. Polydisperse particles could be visualized, all of which showed an encapsulated lipid core and a distinct surface shell with a mean particle diameter of $156 \pm 55 \mathrm{~nm}(\mathrm{n}=25)$ (Fig S1). 


\section{Ex vivo incorporation of $\left[{ }^{18} \mathrm{~F}\right] \mathrm{BDP}-\mathrm{TG}$ into chylomicron-like particles and}

characterization

After synthesis the chylomicron-like particles were loaded with BDP-TG or $\left[{ }^{18} \mathrm{~F}\right] \mathrm{BDP}-\mathrm{TG}$. Interestingly, once the BDP-TG is encapsulated, particles show a dark band within their lipid core (compare Fig 3 a with Fig S1). Incorporation of $\left[{ }^{18} \mathrm{~F}\right] \mathrm{BDP}-\mathrm{TG}$ into chylomicron-like particles in time was analyzed by TLC. After 25 min more than $99 \%$ of the TG was incorporated (Fig 3 b). Different temperatures did not affect the incorporation speed, where r.t. showed the best result after $60 \mathrm{~min}(99.5 \%)$ compared to $0{ }^{\circ} \mathrm{C}(98.9 \%)$ and $38{ }^{\circ} \mathrm{C}(99.1 \%)$ (Fig $3 \mathrm{c}$ ). To test whether the $\left[{ }^{18} \mathrm{~F}\right] \mathrm{BDP}-\mathrm{TG}$ was truly incorporated, chylomicron-like particles loaded with BDP-TG were measured on a fluorescence microplate reader. Excitation was compared to chylomicron-like particles or BDP-TG alone. A significant increase in intensity (>1,400 fold) was observed for the chylomicron-like particles loaded with BDP-TG in comparison to the particles or the BDP-TG alone (Fig $3 \mathrm{~d}$ ). Additionally, chylomicron-like particles incubated with $\left[{ }^{18} \mathrm{~F}\right] \mathrm{BDP}-\mathrm{TG}$ did not show any impurities of free fluorine-18 or free $\left[{ }^{18} \mathrm{~F}\right] \mathrm{BDP}-\mathrm{TG}$ after $60 \mathrm{~min}$ of incubation, analyzed by gel electrophoresis and radio-TLC (Fig 3 e and f). 
a)

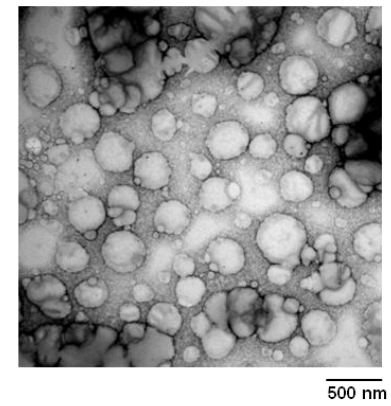

d)

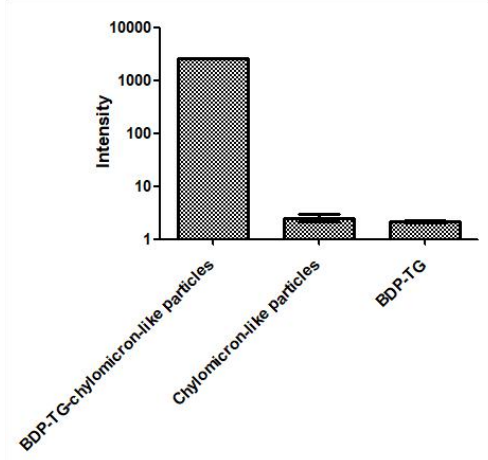

b)

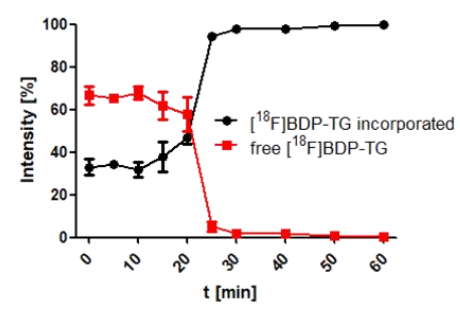

e)

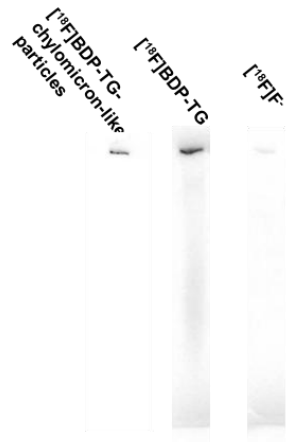

c)

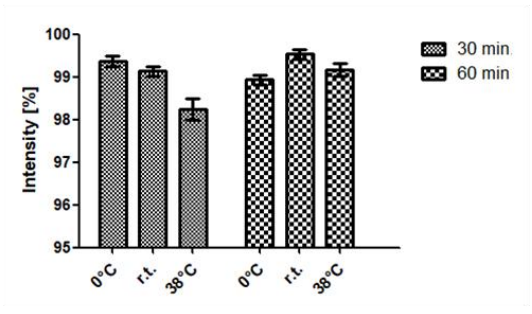

f)

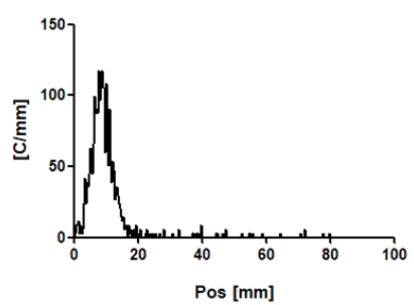

Fig 3: a) Transmission electron microscopy of chylomicron-like particles incubated with $\left[{ }^{18}\right.$ F]BDP-TG. b) Incorporation of $\left[{ }^{18} \mathrm{~F}\right] \mathrm{BDP}-\mathrm{TG}$ into chylomicron-like particles. c) Temperature dependence of the incorporation of $\left[{ }^{18}\right.$ F]BDP-TG into chylomicron-like particles. d) Fluorescence measurement by a microplate reader of BDP-TGchylomicron-like particles, chylomicron-like particles and BDP-TG. e) Phosphorimaging after gel electrophoresis of chylomicron-like particles labeled with $\left[{ }^{18} \mathrm{~F}\right] \mathrm{BDP}-\mathrm{TG}$ (starting position), $\left[{ }^{18} \mathrm{~F}\right] \mathrm{BDP}-\mathrm{TG}$ (mainly at starting position) and free fluorine-18 (end position). f) TLC of $\left[{ }^{18} \mathrm{~F}\right] \mathrm{BDP}-\mathrm{TG}$-chylomicron-like particles (Pos=10 mm); possible impurities: free fluorine-18 (Pos=10 mm), free $\left[{ }^{18} \mathrm{~F}\right] \mathrm{BDP}-\mathrm{TG}(\mathrm{Pos}=70 \mathrm{~mm})$.

\section{Animal experiments}

$\left[{ }^{18} \mathrm{~F}\right] \mathrm{BDP}-\mathrm{TG}$-chylomicron-like particles (1-5 MBq) were injected into female C57BI/6 mice, which were fasted for $4 \mathrm{~h}$ either at r.t. or at $4^{\circ} \mathrm{C}$. After scanning for $1 \mathrm{~h}$ the animals were euthanized and the organs were harvested. Analysis of the PET images showed highest uptake in liver and heart at r.t. and at $4{ }^{\circ} \mathrm{C}$ (Fig 4 a and b). A rapid increase with a slow washout in both organs could be visualized (Fig S2 a and b). In bone a constant increase in signal was observed (Fig S2 c and d), which probably indicates a defluorination process of the tracer in vivo, as reported in literature ${ }^{36}$. Lung showed a fast increase with a fast washout and stayed constant at later time points under both temperature conditions. Brain as 
a negative control showed negligible uptake. BAT uptake increased significantly when comparing cold exposed animals vs. control animals at 50-60 min p.i. (Mann-Whitney U, $\mathrm{n}=10$, two tailed $\mathrm{p}<0.0001)$ (Fig S2 $\mathrm{c}$ and $\mathrm{d})$.

PET images are supported by the results of the biodistribution. Highest uptake values in animals kept at r.t. were found in heart $(17.9 \pm 3.3 \% \mathrm{ID} / \mathrm{g})$, liver $(16.8 \pm 2.6 \% \mathrm{ID} / \mathrm{g})$, bone $(9.0$ $\pm 3.0 \% \mathrm{ID} / \mathrm{g})$ and spleen $(8.5 \pm 2.2 \% \mathrm{ID} / \mathrm{g})$. After $1 \mathrm{~h}$ only $4.5 \pm 1.1 \% \mathrm{ID} / \mathrm{g}$ were found in the blood, indicating a fast blood clearance during the scanning time. In total $6.9 \pm 1.3 \%$ ID was found in the blood calculated by an assumed total blood volume of $5.85 \mathrm{~mL} / 100 \mathrm{~g}{ }^{38}$. Uptake by BAT $(3.5 \pm 0.7 \% \mathrm{ID} / \mathrm{g})$ was approximately 3 -fold higher than uptake by WAT $(1.1 \pm 0.6 \%$ ID/g; Mann-Whitney U, $n=5$, two tailed $p<0.001$ ).

In fasted animals exposed to $4{ }^{\circ} \mathrm{C}$ highest uptake was reached in heart $(33.7 \pm 9.5 \% \mathrm{ID} / \mathrm{g})$, liver $(32.0 \pm 5.5 \% \mathrm{ID} / \mathrm{g})$ and spleen $(14.7 \pm 7.9 \% \mathrm{ID} / \mathrm{g})$. Uptake in BAT was found to be $6.9 \pm$ $1.1 \% \mathrm{ID} / \mathrm{g}$ and was significantly higher (Mann-Whitney $\mathrm{U}, \mathrm{n}=5$, two tailed, $\mathrm{p}<0.001$ ) compared to WAT $(1.5 \pm 0.2 \% \mathrm{ID} / \mathrm{g})$. Total activity remaining in blood was calculated to be $4.9 \pm 0.8 \%$ ID and was therefore significantly lower (Mann-Whitney $U, n=10$, two tailed, $\mathrm{p}<0.01)$ compared to animals fasted at $\mathrm{r}$.t. Organs which showed a significant difference between r.t. and cold exposed fasting were heart (Mann-Whitney $U, n=10$, two tailed, $p<0.001$ ), liver (Mann-Whitney $U, n=10$, two tailed, $p<0.001$ ), spleen (Mann-Whitney $U, n=10$, two tailed, $p<0.01$ ), BAT (Mann-Whitney $U, n=10$, two tailed, $p<0.001$ ) and perivascular adipose tissue (PVAT) (Mann-Whitney $U, n=10$, two tailed, $p<0.001$ ). No difference could be found in WAT, bone, muscle and all other analysed organs (Fig $4 \mathrm{c}$ and d). 
a)

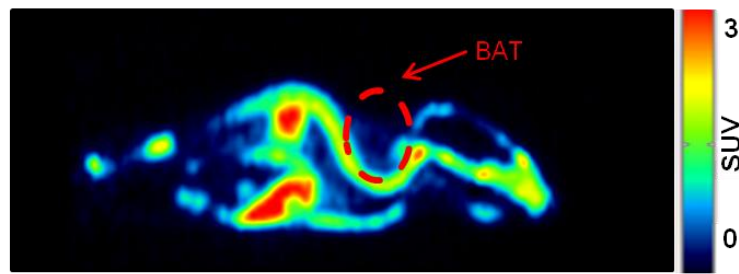

b)

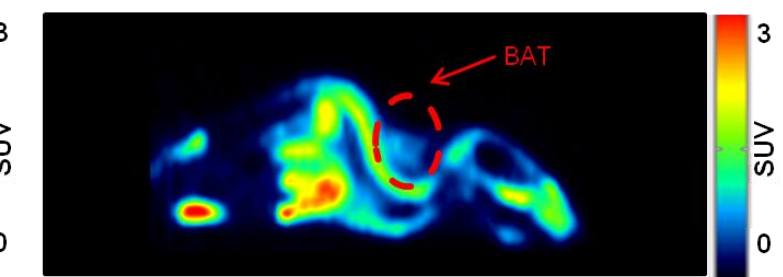

c)

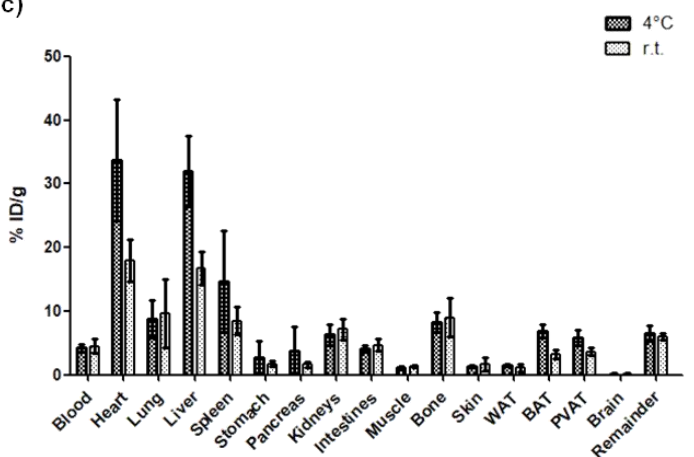

d)

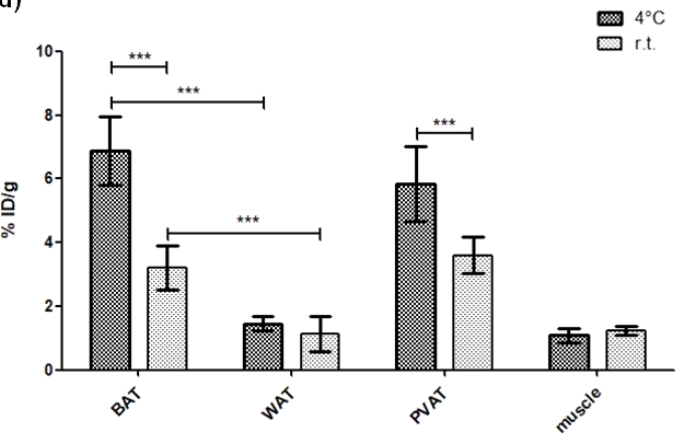

Fig 4: a) PET image (40-60 min) of $\left[{ }^{18}\right.$ F]BDP-TG- chylomicron-like particles in a r.t. fasted animal. b) PET image (40-60 min) of $\left[{ }^{18} \mathrm{~F}\right] \mathrm{BDP}-\mathrm{TG}$-chylomicron-like particles in a $4{ }^{\circ} \mathrm{C}$ fasted animal. c) Biodistribution of $\left[{ }^{18} \mathrm{~F}\right] \mathrm{BDP}-\mathrm{TG}-$ chylomicron-like particles $1 \mathrm{~h}$ after injection. d) BAT uptake in comparison to WAT, Aorta + PVAT and muscle. 


\section{Discussion}

Exploring BAT and its metabolism has become an interesting and fast developing topic in endocrine research. A variety of different imaging approaches have been used in the past reaching from in vitro experiments ${ }^{39}$ over invasive imaging with fluorescence probes ${ }^{4}$ or ${ }^{3} \mathrm{H}$ compounds ${ }^{5}$ to non-invasive experiments with PET ${ }^{11-15}$, SPECT ${ }^{16,17}$ and MRI ${ }^{18-20}$. In a clinical environment most often $\left[{ }^{18} \mathrm{~F}\right] \mathrm{FDG}$ scans are used for BAT imaging but it only shows glucose-related uptake and has therefore the chance to misinterpret BAT activity by underestimating lipid uptake and metabolism. Additionally, $\left[{ }^{18} \mathrm{~F}\right] \mathrm{FDG}$ uptake is dependent on insulin sensitivity and therefore might not reflect the real activation state of BAT. In studies with [ ${ }^{18}$ F]FTHA it was observed that radiolabeled FAs showed an increased uptake in BAT under cold stimulation in humans ${ }^{14}$. However, these results with a free FA-based tracer might be less relevant because the majority of FAs is TRL derived ${ }^{3,7}$ where FAs are transported as TGs. With our developed tracer $\left[{ }^{18} \mathrm{~F}\right] \mathrm{BDP}-\mathrm{TG}$ which is incorporated into chylomicron-like particles we can overcome these limitations and gain new insights in BATs lipid metabolism.

BDP-TG was produced in a decent yield (45\%) like previously published ${ }^{32}$ and radiolabeling was carried out with a decay corrected radiochemical yield of $44 \%$ which is in accordance to radiolabeling yields reported in literature ${ }^{35,40}$.

Chylomicron-like particles have been synthesized with a mean diameter of $164 \mathrm{~nm}$ (DLS) and $156 \mathrm{~nm}$ (TEM). Those sizes are in accordance with previously described particles 5,6,37. After synthesis of the particles, loading with either BDP-TG or $\left[{ }^{18} \mathrm{~F}\right] \mathrm{BDP}-\mathrm{TG}$ was performed. A pre-purification of $\left[{ }^{18} \mathrm{~F}\right] \mathrm{BDP}-\mathrm{TG}$ from free fluorine-18 and $\mathrm{SnCl}_{4}$ before incubation with chylomicron-like particles is of immense importance. In a previous approach $\left[{ }^{18} \mathrm{~F}\right] \mathrm{BDP}-\mathrm{TG}$ received a single wash with $\mathrm{H}_{2} \mathrm{O}(500 \mu \mathrm{L})$ before it was incubated with the particles. After 60 min the sample was purified by centrifugal filtration with an Amicon Ultra centrifugal filter (10 $\mathrm{KDa}$ ). This caused two problems: 1) remaining $\mathrm{SnCl}_{4}$ caused a co-precipitation of the particles 2) filtration destroyed the particles yielding large lipid emulsions. This could be 
overcome by an intensified washing procedure where all the $\mathrm{SnCl}_{4}$ as well as free fluorine-18 was washed out before $\left[{ }^{18} \mathrm{~F}\right] \mathrm{BDP}-\mathrm{TG}$ was added to the chylomicron-like particles.

An incorporation of the TG during the formation of the chylomicron-like particles in the sonicator has been tested but resulted in a breakdown of the boron-fluoride bond. Incorporation speed of $\left[{ }^{18} \mathrm{~F}\right] \mathrm{BDP}-\mathrm{TG}$ into chylomicron-like particles was found to be fast (>99\% after 60 min (Fig 3 b)) and temperature seemed to have no effect on the incorporation yield and speed (Fig $3 \mathrm{c}$ ). Purity of radiolabeled chylomicron-like particles was found to be $>96 \%$ and therefore suitable for in vivo applications. (Fig 3 e and f).

Additionally, we evaluated the incorporation of the BDP-TG into chylomicron-like particles by fluorescence. We previously found that the fluorescence intensity is strongly related to the environment of the compound, meaning that only if the BDP-TG is dissolved it will give a fluorescence signal ${ }^{32}$. BDP-TG incorporated into chylomicron-like particles in HEPES solution showed a huge increase in signal (1413 fold) compared to BDP-TG or chylomicronlike particles alone. This indicates that once the BDP-TG is incorporated into a chylomicronlike particle it regains its fluorescence because it is in a lipophilic environment.

In vivo preferential uptake of $\left[{ }^{18} \mathrm{~F}\right] \mathrm{BDP}-\mathrm{TG}$ in BAT compared to WAT was observed. Exposure to cold during fasting, thereby activating BAT ${ }^{2,24}$, pronounced the difference, indicating the ability of our tracer to visualize BATs metabolic activity and FA consumption. Although not visible on the microPET images, biodistribution data showed that PVAT followed a similar trend. Muscle tissue, which may become activated in the cold due to shivering ${ }^{41}$ showed only low uptake of $\left[{ }^{18} \mathrm{~F}\right] \mathrm{BDP}-\mathrm{TG}$ and no increased uptake due to coldexposure. This does not exclude a higher metabolic activity of muscle, as muscle may preferentially use glucose under conditions of cold exposure ${ }^{42}$.

BAT was however not the only tissue with a high uptake of $\left[{ }^{18} \mathrm{~F}\right] \mathrm{BDP}-\mathrm{TG}$. Uptake of the tracer was in fact highest in liver, heart, spleen and bone, and a significant increase by cold exposure is also demonstrated in liver, heart and spleen. Hepatocytes have a low LPL expression ${ }^{6}$. High uptake values can be explained by increased uptake of remnants of the chylomicron-like particles, which still contain TGs ${ }^{43}$, or by spill over of FAs generated during 
lipolysis ${ }^{44}$. This might also explain the elevated uptake due to cold activation because more remnants and FA are produced in this situation. Since the heart has high LPL expression ${ }^{45,46}$ a high tracer accumulation was expected. Increased LPL activity due to cold stimulation was already reported in cardiomyocytes ${ }^{47,48}$ which explains the increased heart uptake. The spleen, as an organ of the mononuclear phagocytic system, contains high numbers of macrophages. Those macrophages are able to engulf large particles which might explain the marked uptake observed in the spleen ${ }^{49}$. Lung uptake might be the result of a polydisperse particle distribution, as large particles are prone to get entrapped in lungs capillaries ${ }^{50}$. Indeed, in previous experiments with filtrated particles, where particle coagulation was frequent and sizes $>1000 \mathrm{~nm}$ diameter could easily be reached, we experienced very high uptake values of $>200 \% \mathrm{ID} / \mathrm{g}$ in the lung.

We also noted a high uptake of radioactivity in the bone. Although ex vivo plasma stability tests with $\left[{ }^{18} \mathrm{~F}\right] \mathrm{BDP}-\mathrm{FA}$ showed $>99 \%$ intact compound after $4 \mathrm{~h}^{32}$, this may not be valid in vivo. We were unable to demonstrate free fluorine-18 in vivo in the plasma, due to the rapid blood clearance and the difficulty to perform analyses on radiochemical purity of ${ }^{18} \mathrm{~F}$-labeled chylomicrons from within a blood sample. Still, in recent literature it was shown that in vivo the stability is not ensured for radiolabeled BODIPY-compounds, making it likely that our compound is defluorinated as well ${ }^{36}$. In a former publication 1,3-diolein was coupled to BDP$F^{32}$. We speculated that FAs on position 1 or 3 on the glycerol backbone might have a higher chance to get released during lipolysis. No significant differences in chemical and radiochemical yields during synthesis nor changes in the biodistribution can be reported for 1,3-diolein-BDP-FA vs. 1,2-diolein-BDP-FA (data not shown).

In comparison to our data, similar particles loaded with glycerol tri[ $\left.{ }^{3} \mathrm{H}\right]$ oleate previously showed higher uptake of $\left[{ }^{3} \mathrm{H}\right]$ oleate by BAT (approx. 5 fold ${ }^{6}, 6$ fold ${ }^{5}$ and 10 fold $^{51}$ ) and lower $\left[{ }^{3} \mathrm{H}\right]$ oleate uptake by liver (approx. 0.6 fold ${ }^{6}, 0.6$ fold ${ }^{5}$ and 0.5 fold ${ }^{51}$ ) and heart (approx. 0.3 fold ${ }^{6}, 0.3$ fold ${ }^{5}$ and 0.5 fold $^{51}$ ). Also no other organs showed an increased uptake when BAT was stimulated. Different experimental conditions (e.g. use of anesthetized vs. nonanesthetized mice) could be a reason for this difference in the biodistributions as gaseous 
anesthetics such as isoflurane are known to suppress adrenergic signaling ${ }^{52}$. In general these results may point to a reduced BAT LPL-activity due to anesthesia which results in increased uptake by liver and heart. 


\section{Conclusion}

In the current manuscript, we presented a dual-modal fluorescent and PET active TG which was successfully incorporated into chylomicron-like particles. With different quality control methods we showed incorporation of the radiolabeled TG into chylomicron-like particles. In vivo animal studies showed that the resulting tracer was able to reach BAT but was also taken up by other tissues which employ LPL-mediated FA uptake. BAT uptake of the tracer was increased in cold exposed animals. The here presented technique is able to visualize TRL-derived FA BAT uptake after TG-lipolysis which is advantageous in comparison to conventional FA-based tracers which do not reflect the physiological situation and are mainly taken up by the liver. We anticipate that $\left[{ }^{18} \mathrm{~F}\right] \mathrm{BDP}-\mathrm{TG}$-chylomicron-like particles are a promising step forward to visualize and quantify BATs lipid metabolism and gain more information about BATs contribution to whole body energy expenditure in the future. 


\section{References}

1 van Marken Lichtenbelt, W. D. \& Schrauwen, P. Implications of nonshivering thermogenesis for energy balance regulation in humans. American journal of physiology. Regulatory, integrative and comparative physiology 301, R285-296, doi:10.1152/ajpregu.00652.2010 (2011).

2 Cannon, B. \& Nedergaard, J. Brown adipose tissue: function and physiological significance. Physiol Rev 84, 277-359, doi:10.1152/physrev.00015.2003 (2004).

3 Festuccia, W. T., Blanchard, P.-G. \& Deshaies, Y. Control of Brown Adipose Tissue Glucose and Lipid Metabolism by PPARy. Front Endocrinol (Lausanne) 2, 84, doi:10.3389/fendo.2011.00084 (2011).

4 Bartelt, A. et al. Brown adipose tissue activity controls triglyceride clearance. Nat Med 17, 200-205, doi:10.1038/nm.2297 (2011).

$5 \quad$ Khedoe, P. P. S. J. et al. Brown adipose tissue takes up plasma triglycerides mostly after lipolysis. J Lipid Res 56, 51-59, doi:10.1194/jlr.M052746 (2015).

6 Berbee, J. F. et al. Brown fat activation reduces hypercholesterolaemia and protects from atherosclerosis development. Nature communications 6, 6356, doi:10.1038/ncomms7356 (2015).

7 Hoeke, G., Kooijman, S., Boon, M. R., Rensen, P. C. \& Berbee, J. F. Role of Brown Fat in Lipoprotein Metabolism and Atherosclerosis. Circulation research 118, 173-182, doi:10.1161/circresaha.115.306647 (2016).

8 Labbé, S. M. et al. In vivo measurement of energy substrate contribution to cold-induced brown adipose tissue thermogenesis. FASEB J 29, 2046-2058, doi:10.1096/fj.14-266247 (2015).

9 Coburn, C. T., Hajri, T., Ibrahimi, A. \& Abumrad, N. A. Role of CD36 in membrane transport and utilization of long-chain fatty acids by different tissues. J Mol Neurosci 16, 117-121; discussion 151-117, doi:10.1385/jmn:16:2-3:117 (2001).

10 Stahl, A. A current review of fatty acid transport proteins (SLC27). Pflugers Arch 447, 722727, doi:10.1007/s00424-003-1106-z (2004).

11 Lee, P., Greenfield, J. R., Ho, K. K. Y. \& Fulham, M. J. A critical appraisal of the prevalence and metabolic significance of brown adipose tissue in adult humans. Am J Physiol Endocrinol Metab 299, E601-606, doi:10.1152/ajpendo.00298.2010 (2010).

12 Cohade, C., Mourtzikos, K. A. \& Wahl, R. L. "USA-Fat": prevalence is related to ambient outdoor temperature-evaluation with 18F-FDG PET/CT. J Nucl Med 44, 1267-1270 (2003).

13 Hany, T. F. et al. Brown adipose tissue: a factor to consider in symmetrical tracer uptake in the neck and upper chest region. Eur J Nucl Med Mol Imaging 29, 1393-1398, doi:10.1007/s00259-002-0902-6 (2002).

14 Ouellet, V. et al. Brown adipose tissue oxidative metabolism contributes to energy expenditure during acute cold exposure in humans. J Clin Invest 122, 545-552, doi:10.1172/jci60433 (2012).

15 Bucci, M. et al. Enhanced fatty acid uptake in visceral adipose tissue is not reversed by weight loss in obese individuals with the metabolic syndrome. Diabetologia 58, 158-164, doi:10.1007/s00125-014-3402-x (2015).

16 Syamsunarno, M. R. A. A. et al. Fatty acid binding protein 4 and 5 play a crucial role in thermogenesis under the conditions of fasting and cold stress. PLoS One 9, e90825, doi:10.1371/journal.pone.0090825 (2014).

17 Putri, M. et al. CD36 is indispensable for thermogenesis under conditions of fasting and cold stress. Biochem Biophys Res Commun 457, 520-525, doi:10.1016/j.bbrc.2014.12.124 (2015).

18 Grimpo, K. et al. Brown adipose tissue dynamics in wild-type and UCP1-knockout mice: in vivo insights with magnetic resonance. J Lipid Res 55, 398-409, doi:10.1194/jlr.M042895 (2014). 
Holstila, M. et al. Measurement of brown adipose tissue mass using a novel dual-echo magnetic resonance imaging approach: a validation study. Metabolism 62, 1189-1198, doi:10.1016/j.metabol.2013.03.002 (2013). van Rooijen, B. D. et al. Imaging cold-activated brown adipose tissue using dynamic T2*weighted magnetic resonance imaging and 2-deoxy-2-[18F]fluoro-D-glucose positron emission tomography. Invest Radiol 48, 708-714, doi:10.1097/RLI.0b013e31829363b8 (2013). Paulus, A., van Marken Lichtenbelt, W., Mottaghy, F. M. \& Bauwens, M. Brown adipose tissue and lipid metabolism imaging. Methods (San Diego, Calif.) 130, 105-113, doi:10.1016/j.ymeth.2017.05.001 (2017).

22 Cypess, A. M. et al. Identification and importance of brown adipose tissue in adult humans. $N$ Engl J Med 360, 1509-1517, doi:10.1056/NEJMoa0810780 (2009).

23 Cypess, A. M. et al. Activation of human brown adipose tissue by a $\beta 3$-adrenergic receptor agonist. Cell Metab 21, 33-38, doi:10.1016/j.cmet.2014.12.009 (2015).

24 van Marken Lichtenbelt, W. D. et al. Cold-activated brown adipose tissue in healthy men. $N$ Engl J Med 360, 1500-1508, doi:10.1056/NEJMoa0808718 (2009).

25 Blondin, D. P. et al. Selective Impairment of Glucose but Not Fatty Acid or Oxidative Metabolism in Brown Adipose Tissue of Subjects With Type 2 Diabetes. Diabetes 64, 23882397, doi:10.2337/db14-1651 (2015).

Qu, S., Zhang, T. \& Dong, H. H. Effect of hepatic insulin expression on lipid metabolism in diabetic mice. Journal of diabetes 8, 314-323, doi:10.1111/1753-0407.12293 (2016).

Heine, M. et al. Lipolysis Triggers a Systemic Insulin Response Essential for Efficient Energy Replenishment of Activated Brown Adipose Tissue in Mice. Cell Metab 28, 644-655.e644, doi:10.1016/j.cmet.2018.06.020 (2018).

28 DeGrado TR, C. H., Stocklin G. 14(R,S)-[18F]fluoro-6-thia-heptadecanoic acid (FTHA): evaluation in mouse of a new probe of myocardial utilization of long chain fatty acids. $J$ Nucl Med 32, 1888-1896 (1991).

Goodmen M.M., K. F. F., Elmaleh D.R., Strauss H.W. New myocardial imaging agents: Synthesis of 15-(p-[123I] iodophenyl)-3(R,S)-methylpentadecanoic acid by decomposition of a 3,3-(1,5-pentanedyl)triazene precursor. J. Org. Chem 49, 2322-2325 (1984).

Dubikovskaya, E., Chudnovskiy, R., Karateev, G., Park, H. M. \& Stahl, A. Measurement of longchain fatty acid uptake into adipocytes. Methods Enzymol 538, 107-134, doi:10.1016/b978-012-800280-3.00007-4 (2014).

31 Kasurinen, J. A novel fluorescent fatty acid, 5-methyl-BDY-3-dodecanoic acid, is a potential probe in lipid transport studies by incorporating selectively to lipid classes of BHK cells. Biochem Biophys Res Commun 187, 1594-1601 (1992).

32 Paulus, A. et al. Synthesis, radiosynthesis and in vitro evaluation of 18F-BodipyC16/triglyceride as a dual modal imaging agent for brown adipose tissue. PLoS One 12, e0182297, doi:10.1371/journal.pone.0182297 (2017).

33 Liu, S. et al. Lewis acid-assisted isotopic 18F-19F exchange in BODIPY dyes: facile generation of positron emission tomography/fluorescence dual modality agents for tumor imaging. Theranostics 3, 181-189, doi:10.7150/thno.5984 (2013).

34 Hendricks, J. A. et al. Synthesis of [18F]BODIPY: bifunctional reporter for hybrid optical/positron emission tomography imaging. Angew Chem Int Ed Engl 51, 4603-4606, doi:10.1002/anie.201107957 (2012).

35 Keliher, E. J., Klubnick, J. A., Reiner, T., Mazitschek, R. \& Weissleder, R. Efficient acidcatalyzed (18) F/(19) F fluoride exchange of BODIPY dyes. ChemMedChem 9, 1368-1373, doi:10.1002/cmdc.201300506 (2014).

36 Paulus, A. et al. Development of a clickable bimodal fluorescent/PET probe for in vivo imaging. EJNMMI Res 5, 120, doi:10.1186/s13550-015-0120-4 (2015).

37 Rensen, P. C. N. et al. Selective Liver Targeting of Antivirals by Recombinant Chylomicrons - a New Therapeutic Approach to Hepatitis-B. Nature Medicine 1, 221-225 (1995). 
Bannerman, R. M. in The Mouse in Biomedical Research Vol. 3 Normative Biology, Immunology, and Husbandry (ed J. David Small Henry L. Foster, James G. Fox) 293 - 312 (Academic Press, 1983).

Henkin, A. H. et al. Real-time noninvasive imaging of fatty acid uptake in vivo. ACS Chem Biol 7, 1884-1891, doi:10.1021/cb300194b (2012).

Liu, S. et al. Efficient synthesis of fluorescent-PET probes based on $\left[{ }^{18} \mathrm{~F}\right] \mathrm{BODIPY}$ dye. Chemical communications (Cambridge, England) 50, 7371-7373, doi:10.1039/c4cc01411a (2014).

41 Gagnon, D. D. et al. The effects of cold exposure on leukocytes, hormones and cytokines during acute exercise in humans. PLoS One 9, e110774, doi:10.1371/journal.pone.0110774 (2014).

42 Blondin, D. P. et al. Contributions of white and brown adipose tissues and skeletal muscles to acute cold-induced metabolic responses in healthy men. The Journal of physiology 593, 701714, doi:10.1113/jphysiol.2014.283598 (2015).

43 Karpe, F. et al. Removal of triacylglycerols from chylomicrons and VLDL by capillary beds: the basis of lipoprotein remnant formation. Biochemical Society transactions 35, 472-476, doi:10.1042/bst0350472 (2007).

44 Lewis, G. F., Carpentier, A., Adeli, K. \& Giacca, A. Disordered fat storage and mobilization in the pathogenesis of insulin resistance and type 2 diabetes. Endocrine reviews 23, 201-229, doi:10.1210/edrv.23.2.0461 (2002).

45 Niu, Y. G., Hauton, D. \& Evans, R. D. Utilization of triacylglycerol-rich lipoproteins by the working rat heart: routes of uptake and metabolic fates. The Journal of physiology 558, 225237, doi:10.1113/jphysiol.2004.061473 (2004).

46 Bharadwaj, K. G. et al. Chylomicron- and VLDL-derived lipids enter the heart through different pathways: in vivo evidence for receptor- and non-receptor-mediated fatty acid uptake. J Biol Chem 285, 37976-37986, doi:10.1074/jbc.M110.174458 (2010).

47 Radomski, M. W. \& Orme, T. Response of lipoprotein lipase in various tissues to cold exposure. Am J Physiol 220, 1852-1856, doi:10.1152/ajplegacy.1971.220.6.1852 (1971).

Keig, P. \& Borensztajn, J. Regulation of rat heart lipoprotein lipase activity during cold exposure. Proceedings of the Society for Experimental Biology and Medicine. Society for Experimental Biology and Medicine (New York, N.Y.) 146, 890-893 (1974).

Anselmo, A. C. et al. Delivering nanoparticles to lungs while avoiding liver and spleen through adsorption on red blood cells. ACS nano 7, 11129-11137, doi:10.1021/nn404853z (2013).

Blanco, E., Shen, H. \& Ferrari, M. Principles of nanoparticle design for overcoming biological barriers to drug delivery. Nature biotechnology 33, 941-951, doi:10.1038/nbt.3330 (2015).

51 Kooijman, S. et al. Inhibition of the central melanocortin system decreases brown adipose tissue activity. J Lipid Res 55, 2022-2032, doi:10.1194/jlr.M045989 (2014).

52 Ohlson, K. B., Mohell, N., Cannon, B., Lindahl, S. G. \& Nedergaard, J. Thermogenesis in brown adipocytes is inhibited by volatile anesthetic agents. A factor contributing to hypothermia in infants? Anesthesiology 81, 176-183 (1994).

53 McAnoy, A. M., Wu, C. C. \& Murphy, R. C. Direct qualitative analysis of triacylglycerols by electrospray mass spectrometry using a linear ion trap. J Am Soc Mass Spectrom 16, 14981509, doi:10.1016/j.jasms.2005.04.017 (2005).

54 Redgrave, T. G. \& Maranhao, R. C. Metabolism of protein-free lipid emulsion models of chylomicrons in rats. Biochim Biophys Acta 835, 104-112 (1985). 


\section{Supplementary Information}

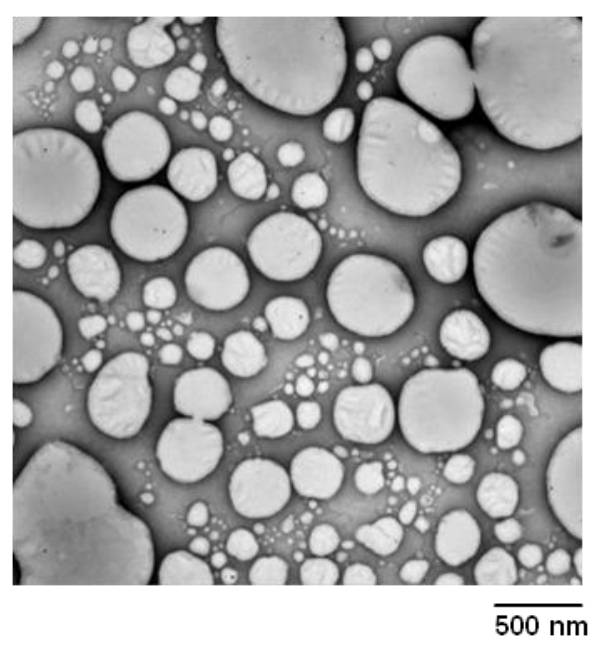

Fig S1: Representative picture of transmission electron microscopy of chylomicron-like particles without BDP-TG loading.

$4^{\circ} \mathrm{C}$

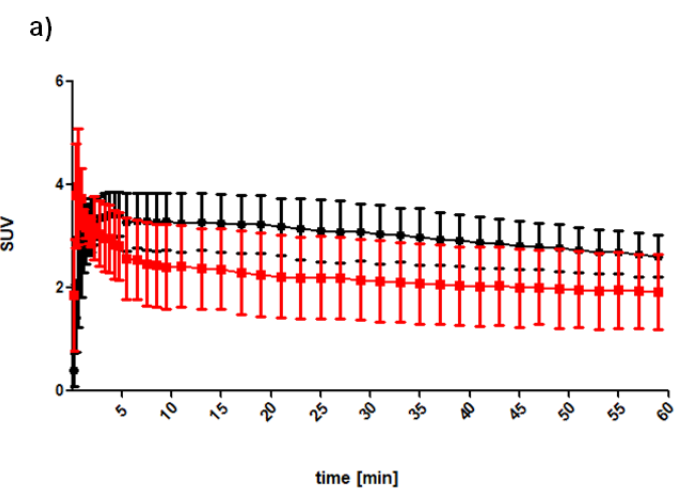

c)

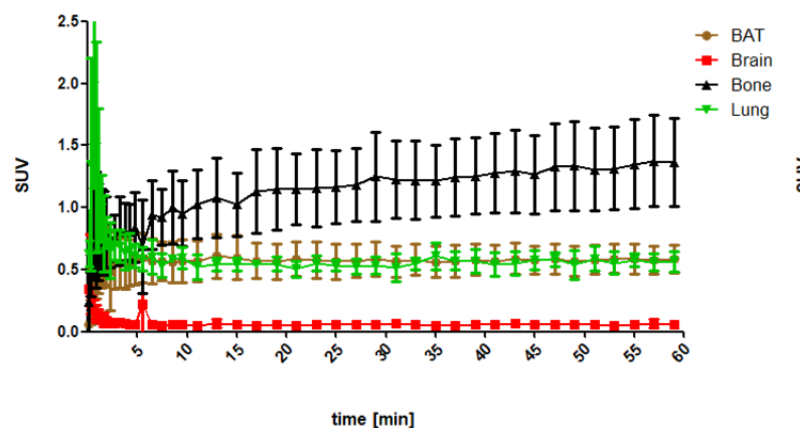

$22^{\circ} \mathrm{C}$

b)

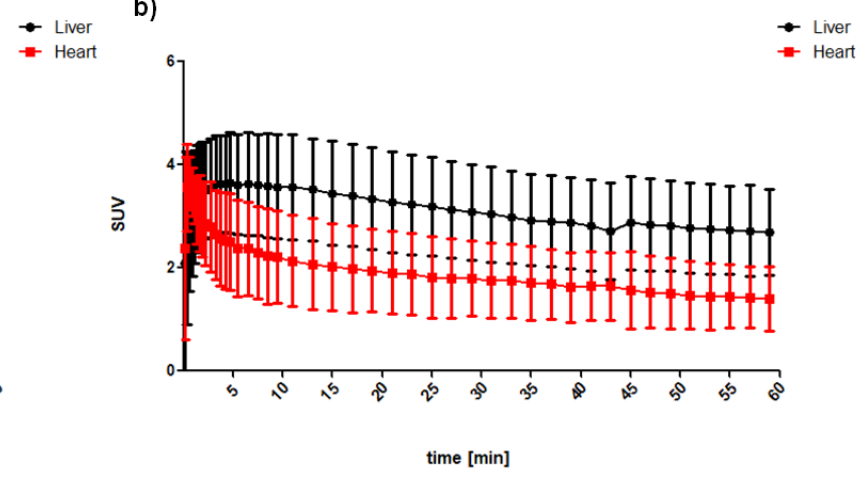

d)

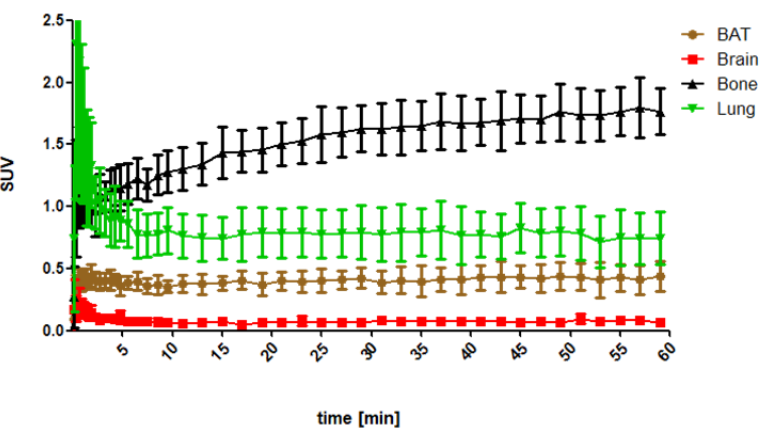

Fig S2: a) Time activity curves for specified organs in $4{ }^{\circ} \mathrm{C}$ fasted animals b) Time activity curves for specified organs in $22^{\circ} \mathrm{C}$ fasted animals 


\section{Chapter 6:}

Triglyceride-rich lipoprotein derived fatty acid uptake by brown adipose tissue in control and diabetic mice at room temperature, acute cold exposure and cold acclimation

Andreas Paulus,

Natascha Drude,

Emmani B.M. Nascimento, Jimmy F.P. Berbée,

Patrick C.N. Rensen,

Wouter van Marken Lichtenbelt,

Felix M. Mottaghy,

Matthias Bauwens

submitted as:

Brown adipose tissue uptake of triglyceride-rich lipoprotein derived fatty acids in diabetic or obese mice under different temperature conditions. Molecular Imaging \& Biology, (2019) 


\section{Abstract}

Background: Brown adipose tissue (BAT) is present in adult humans and contributes to their overall energy expenditure. The most often used tracer to visualize BAT and its metabolism is $\left[{ }^{18} \mathrm{~F}\right] \mathrm{FDG}$ which suffers from the problem that it is not able to visualize BATs complete metabolic activity. Under insulin resistant conditions associated with ageing and weight gain this method fails to detect BAT. We here used our novel developed triglyceridebased tracer to visualize BATs metabolic activity under different temperature conditions and in a mouse model with induced diabetes.

Methods: Control and streptozotocin-induced diabetic mice, housed at $21^{\circ} \mathrm{C}$, acutely exposed to cold or cold acclimated over 28 days, were injected with $\left[{ }^{18} \mathrm{~F}\right] \mathrm{BDP}-\mathrm{TG}$ chylomicron-like particles and scanned dynamically for $32.5 \mathrm{~min}$.

Results: $\left[{ }^{18} \mathrm{~F}\right] \mathrm{BDP}-\mathrm{TG}$-chylomicron-like particles were able to visualize BAT under all conditions. Increased uptake was found in control mice acutely exposed to cold but not in other conditions. Diabetes reduced BAT uptake to levels of control mice housed at $21^{\circ} \mathrm{C}$.

Conclusion: BAT was visualized under conditions were commonly used techniques (e.g. $\left.\left[{ }^{18} \mathrm{~F}\right] \mathrm{FDG}\right)$ fail. BAT activation by cold exposure under diabetic conditions could not be detected indicating an insulin dependent uptake mechanism. 


\section{Introduction}

Brown adipose tissue (BAT) research has evolved rapidly within the last 2 decades to an important field in endocrine research. To visualize BAT and its metabolism, non-invasive imaging is a central technique. BAT has the ability to uncouple its ATP production and to produce heat instead of ATP. During this process protons enter the mitochondrial matrix by uncoupling protein 1 (UCP1) ${ }^{1}$, a BAT specific protein, and release their energy as heat ${ }^{2,3}$. This process is considered as nonshivering thermogenesis ${ }^{2,4}$.

BAT activity is triggered by cold stimulation and the chance to visualize BAT in animals and lean humans raises ${ }^{5-7}$. During cld exposure, thermoreceptors in the skin are stimulated and activate neurons in the hypothalamus, resulting in a release of norepinephrine ${ }^{2,8}$. Norepinephrine binding to $\beta 3$-adrenoeceptors on BAT is activating a signalling cascade, which will lead to lipolysis of intracellular triglycerides (TG) and at the end result in UCP1 activation ${ }^{9,10}$. Therefore BAT might be an interesting target in the fight against obesity as it "burns" lipids instead of storing them.

Most BAT scans were performed with $\left[{ }^{18} \mathrm{~F}\right] \mathrm{FDG}$ because of BATs history. For long, symmetrical accumulations in the supraclavicular area during $\left[{ }^{18} \mathrm{~F}\right] \mathrm{FDG}$ positron emission tomography (PET) (e.g. during cancer scans) were attributed to cervical muscle until later scans using PET/computed tomography (CT) could show that Hounsfield units are similar to them of adipose tissue ${ }^{11-13}$. Therefore a high number of retrospective BAT studies have been published and until now $\left[{ }^{18} \mathrm{~F}\right] \mathrm{FDG}$ is used to visualize BAT. The prevalence to find active BAT depots during $\left[{ }^{18} \mathrm{~F}\right] \mathrm{FDG} / \mathrm{PET}$ scans is strongly dependent on different variables such as age, BMI, or outdoor temperature ${ }^{14,15}$.

BAT $\left[{ }^{18} \mathrm{~F}\right] \mathrm{FDG} / \mathrm{PET}$ scans suffer from two severe problems: 1) Fatty acids (FAs) have been identified as the main metabolized substance class ${ }^{16,17}$ and therefore $\left[{ }^{18} \mathrm{~F}\right] \mathrm{FDG} / \mathrm{PET}$ might largely underestimate BATs metabolic activity. 2) In clinical studies $\left[{ }^{18} \mathrm{~F}\right] \mathrm{FDG}$ BAT uptake was impaired in diabetic patients but uptake of $\left[{ }^{18} \mathrm{~F}\right] \mathrm{FTHA}$ (a radiolabeled FA) was not altered when compared to non-diabetic controls ${ }^{18}$. As a high number of obese patients suffer from 
diabetes type II ${ }^{19}$ their insulin resistance will additionally decrease $\left[{ }^{18} \mathrm{~F}\right] \mathrm{FDG}$ uptake in BAT and underestimate BATs metabolic activity.

Due to this facts BAT visualization with lipid tracers would be advantageous over $\left[{ }^{18} \mathrm{~F}\right] \mathrm{FDG}$. FA based tracers, such as $\left[{ }^{18} \mathrm{~F}\right] \mathrm{FTHA}{ }^{20}$ or $\left[{ }^{125}\right] \mathrm{BMIPP}{ }^{21}$ have been developed and can be found in clinical applications. But even FA tracer might not be the optimal choice.

During BAT activation internal lipid droplets are replenished by nutrient uptake from plasma in three different ways: uptake of FAs from triglyceride (TG)-rich lipoproteins (TRL) after external lipolysis, glucose uptake followed by de novo lipogenesis, and uptake of circulating albumin-bound FAs ${ }^{2,22-24}$. It was found that TRL-derived FAs are the main supply of TGs in BAT ${ }^{24,25}$. Due to this fact, free radiolabeled FAs applied in vivo rely on many different uncontrolled uptake and incorporation process before they are taken up by BAT, which we wanted to avoid. Therefore we have developed a radiolabeled TG ${ }^{26}$ which we were able to incorporate into a pre-synthesized chylomicron-like particle ${ }^{27}$. Additionally the tracer was tested in vivo and was able to visualize BAT at room temperature $\left(21^{\circ} \mathrm{C}\right)$ conditions as well as its uptake was increased by acute cold exposure.

In this manuscript we investigate the effect of induced diabetes as well as acute cold and cold-acclimation in a mouse model on BAT metabolism visualized by our recently developed lipid based tracer $\left[{ }^{18} \mathrm{~F}\right] \mathrm{BODIPY}\left(\left[{ }^{18} \mathrm{~F}\right] \mathrm{BDP}\right)-\mathrm{TG}$-chylomicron-like particle. 


\section{Methods}

Commercially available compounds were used without further purification unless otherwise stated. BDP-FA was purchased from Thermo Fischer Scientific (99\%) (Netherlands). 1,2diolein was purchased from Cayman Chemicals (USA) $(\geq 95 \%)$. All HPLC purifications (1.0 $\mathrm{mL} /$ min, solvent $\mathrm{A} ; 0.1 \%$ TFA in $\mathrm{H}_{2} \mathrm{O}$, solvent $\mathrm{B} ; \mathrm{CH}_{3} \mathrm{CN}, 50^{\circ} \mathrm{C}$ ) were performed on a Shimadzu UFLC HPLC system equipped with a DGU-20A $\mathrm{A}_{5}$ degasser, a SPD-M20A UV detector, a LC-20AT pump system, a CBM-20A communication BUS module, a CTO-20AC column oven, and a Scan-RAM radio-TLC/HPLC-detector from LabLogic using an

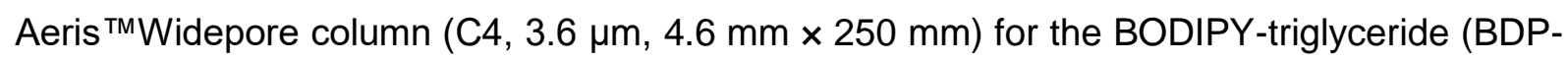
TG). ESI-MS was performed on an Applied Biosystems SCIEX API 150 EX electrospray ionization quadrupole (ESI-Q) mass spectrometer with the method of McAnoy et al. ${ }^{28}$. Briefly, $0.1 \mathrm{M}$ aqueous ammonium acetate solution was added to the sample to observe the ammonium salt of the synthesized TG in the MS.

${ }^{1} \mathrm{H}-\mathrm{NMR}$ spectra were carried out on a Bruker Ultrashield TH 400 plus at $400 \mathrm{MHz}$. Tol- $\mathrm{d}_{8}$ was used as solvent with TMS as internal standard. Chemical shifts are reported in parts per million (ppm) relative to the internal standard.

\section{Synthesis of chylomicron-like particles}

Synthesis of chylomicron-like particles was performed as reported before ${ }^{29,30}$. Briefly, emulsion particles were prepared from triolein $(70 \mathrm{mg})$, egg yolk phosphatidylcholine (Lipoid) (22.7 mg), lysophosphatidylcholine $(2.3 \mathrm{mg})$, cholesteryl oleate $(3.0 \mathrm{mg})$, and cholesterol (2.0 mg). Sonification was performed using a Soniprep 150 (MSE Scientific Instruments, UK) that was equipped with a water bath for temperature $\left(54^{\circ} \mathrm{C}\right)$ maintenance, at $10 \mu \mathrm{m}$ output. The emulsion was fractionated by density gradient ultracentrifugation steps in a Beckman SW 40 Ti rotor. After centrifugation for $30 \mathrm{~min}$ at $17,850 \mathrm{rpm}$ at $20{ }^{\circ} \mathrm{C}$, an emulsion fraction containing chylomicron-like particles was removed from the top of the tube by aspiration. Characterization of chylomicron-like particles was done by DLS and transmission electron 
microscopy. Chylomicron-like particles were stored at $4{ }^{\circ} \mathrm{C}$ and were used within 5 days following preparation.

\section{Synthesis of BDP-TG}

Synthesis was performed as reported before ${ }^{26}$. Briefly, BDP-FL-C ${ }_{16}(300 \mu \mathrm{g}, 0.6 \mu \mathrm{mol})$ in acetonitrile was evaporated to complete dryness before the reactant was reconstituted in toluene $(100 \mu \mathrm{L})$. To the resulting solution $\mathrm{SOCl}_{2}$ in toluene $(100 \mu \mathrm{L}, 4$ vol.-\%) was added, incubated for $5 \mathrm{~min}$ at $70^{\circ} \mathrm{C}$ in a closed vial and evaporated. The product was reconstituted in toluene $(50 \mu \mathrm{L})$ containing 1,2-diolein $(2 \mu \mathrm{L}, 2.8 \mu \mathrm{mol})$ and heated to $100{ }^{\circ} \mathrm{C}$ for $30 \mathrm{~min}$. After the reaction time, purification by HPLC ( $1 \mathrm{~mL} / \mathrm{min}, 30 \%$ to $15 \% \mathrm{~A}$ in $5 \mathrm{~min}, 15 \%$ to $0 \% \mathrm{~A}$ from 5 to $6 \mathrm{~min}, 0 \% \mathrm{~A}$ to $20 \mathrm{~min})$ yielded $2(225 \mu \mathrm{g}, 75 \%)$ as a red solid; $\mathrm{t}_{\mathrm{R}}=12.3 \mathrm{~min}$. ESIMS (+) m/z (\%) = $1058(100)\left[M-F^{-}\right]^{+}, 1095(82)\left[M+\mathrm{NH}_{4}\right]^{+} .{ }^{1} \mathrm{H}$ NMR (400 MHz, Tol-d 8 ; $\delta(\mathrm{ppm})=5.46(\mathrm{~m}, 4 \mathrm{H}), 4.26(\mathrm{~m}, 2 \mathrm{H}), 4.06(\mathrm{~m}, 2 \mathrm{H}), 3.13(\mathrm{~m}, 1 \mathrm{H}), 1.75(\mathrm{~s}, 3 \mathrm{H})$.

\section{Radiolabeling of BDP-TG}

Radiolabeling was performed as reported before ${ }^{26}$. Briefly, aqueous fluorine- 18 solution was loaded on a QMA-cartridge which was preconditioned with $15 \mathrm{~mL} \mathrm{~K}_{2} \mathrm{CO}_{3}$ in $\mathrm{H}_{2} \mathrm{O}$ and $20 \mathrm{~mL}$ $\mathrm{H}_{2} \mathrm{O}$. Fluoride (42 MBq) was eluted with a mixture of $600 \mu \mathrm{L}$ acetonitrile, $400 \mu \mathrm{L} \mathrm{H}_{2} \mathrm{O}$ and 6 mg Sodium p-toluenesulfonate (Sigma-Aldrich). Fluorine-18 solution was transferred into a drying vessel containing tetra-n-butylammonium bromide $(80 \mu \mathrm{L})$ as a phase transfer agent. Acetonitrile $(3 \times 1.0 \mathrm{~mL})$ was added and the solution of fluorine-18 was dried by heating to $100{ }^{\circ} \mathrm{C}$ with a continuous flow of argon. After reconstitution of Fluorine-18 in anhydrous acetonitrile $(100 \mu \mathrm{L})$, a solution of BDP-TG in toluene $(107 \mu \mathrm{g}, 0.1 \mu \mathrm{mol}$ in $50 \mu \mathrm{L})$ and $\mathrm{SnCl}_{4}$ (0.2 $\mathrm{M}$ in acetonitrile, $100 \mu \mathrm{L})$ was added to the solution with the activity and the reaction solution was stirred at room temperature (r.t.) for $30 \mathrm{~min}$. $\left[{ }^{18} \mathrm{~F}\right] \mathrm{BDP}-\mathrm{TG}$ was obtained (decay corrected RCY: 44\%, $25 \mathrm{MBq}$ ) with a decay corrected specific activity of $250 \mathrm{MBq} / \mu \mathrm{mol}$ and a radiochemical purity of $45 \%$ determined by a radio-TLC with toluene, $\mathrm{CHCl}_{3}$ and $\mathrm{MeOH}$ $(80.9 \%, 14.3 \%, 4.8 \%)$ of the reaction solution. 


\section{Ex vivo incorporation of $\left[{ }^{18} \mathrm{~F}\right] \mathrm{BDP}-\mathrm{TG}$ into chylomicron-like particles}

Incorportaion of radiolabeled $\left[{ }^{18} \mathrm{~F}\right] \mathrm{BDP}-\mathrm{TG}$ was performed as reported before ${ }^{27}$. Briefly, the $\left[{ }^{18} \mathrm{~F}\right] \mathrm{BDP}-\mathrm{TG}$ solution (233 MBq) was quenched with $500 \mu \mathrm{L} \mathrm{H}_{2} \mathrm{O}$ and centrifuged for 5 min. The organic phase was washed 3 times with $500 \mu \mathrm{L} \mathrm{H}_{2} \mathrm{O}$ before $\left[{ }^{18} \mathrm{~F}\right] \mathrm{BDP}-\mathrm{TG}$ was reconditioned in $20 \mu \mathrm{L} \mathrm{EtOH}$. $\left[{ }^{18} \mathrm{~F}\right] \mathrm{BDP}-\mathrm{TG}$ could be obtained with a radiochemical purity of $>$ $96 \%$ and an overall decay corrected radiochemical yield of $21 \% .400 \mu \mathrm{L}$ chylomicron-like particles in HEPES were added (1.5 mg TG content) and incubated for $1 \mathrm{~h}$ at r.t.. $\left[{ }^{18} \mathrm{~F}\right] \mathrm{BDP}$ TG-chylomicron-like particles were obtained (overall decay corrected RCY: 18\%, $19 \mathrm{MBq}$ ) with a radiochemical purity of $>99 \%$ analyzed by gel electrophoresis and radio-TLC.

\section{Animal experiments}

Experimental protocols were approved by the "Centrale Commissie Dierproeven" and all animal experiments and procedures were performed in accordance with the guidelines set of this institution. 23 female C57BI/6 mice were divided into 2 groups. Group 1 served as control group and group 2 was injected with Streptozocin 10 days before the experiment to destroy the $\beta$-cells in the pancreas ${ }^{31}$. Mice from group 1 were fed with a normal diet $(10 \%$ kcal fat content, Research Diets Inc.), while group 2 received a high fat diet ${ }^{32}$ (45\% kcal fat content, Research Diets Inc.) from the day of Streptozocin injection. An animal was considered as diabetic when the glucose level at the day of the experiment was $>10 \mathrm{mM}$.

Both groups were divided into 3 subgroups where subgroup 1 was fasted for $4 \mathrm{~h}$ at $21^{\circ} \mathrm{C}$ before the imaging experiment. Subgroup 2 was housed at $21{ }^{\circ} \mathrm{C}$ but was fasted for $4 \mathrm{~h}$ during exposure to $6{ }^{\circ} \mathrm{C}$ prior to tracer injection. Subgroup 3 was exposed to cold for $6 \mathrm{~h}$ per day for 28 days and was fasted for $4 \mathrm{~h}$ before tracer injection (Fig 1).

Mice were anesthetized (Pentobarbital, $60 \mathrm{mg} / \mathrm{kg}$ i.p.), and injected with $\left[{ }^{18} \mathrm{~F}\right] \mathrm{BDP}-\mathrm{TG}$ chylomicron-like particles (1-10 MBq) in HEPES $(100 \mu \mathrm{L})$ via the tail vein. Mice were scanned dynamically for $32.5 \mathrm{~min}$ on a microPET (Focus 120, Siemens). Images were analyzed using Pmod V3.707. After the scanning time animals were killed and organs 
harvested, weighed wet and counted using a WIZARD ${ }^{2}$ automatic $y$-counter from Perkin Elmer.

Additionally mice $(n=12)$ were divided into two groups. Group 1 was injected at day 0 either with $\left[{ }^{18} \mathrm{~F}\right] \mathrm{FDG}(\mathrm{n}=4)$ or with $\left[{ }^{18} \mathrm{~F}\right] \mathrm{FTHA}(\mathrm{n}=4)(10 \pm 2 \mathrm{MBq})$ and scanned dynamically for 20 min. After 14 days of cold acclimation $\left(4^{\circ} \mathrm{C}\right.$ for $6 \mathrm{~h} /$ day), group 2 was also injected with $\left[{ }^{18} \mathrm{~F}\right.$ FDG $(n=4)$ or with $\left[{ }^{18} \mathrm{~F}\right]$ FTHA $(n=4)(10 \pm 2 \mathrm{MBq})$ and scanned dynamically for 20 min. BAT uptake was analyzed by SUV values.

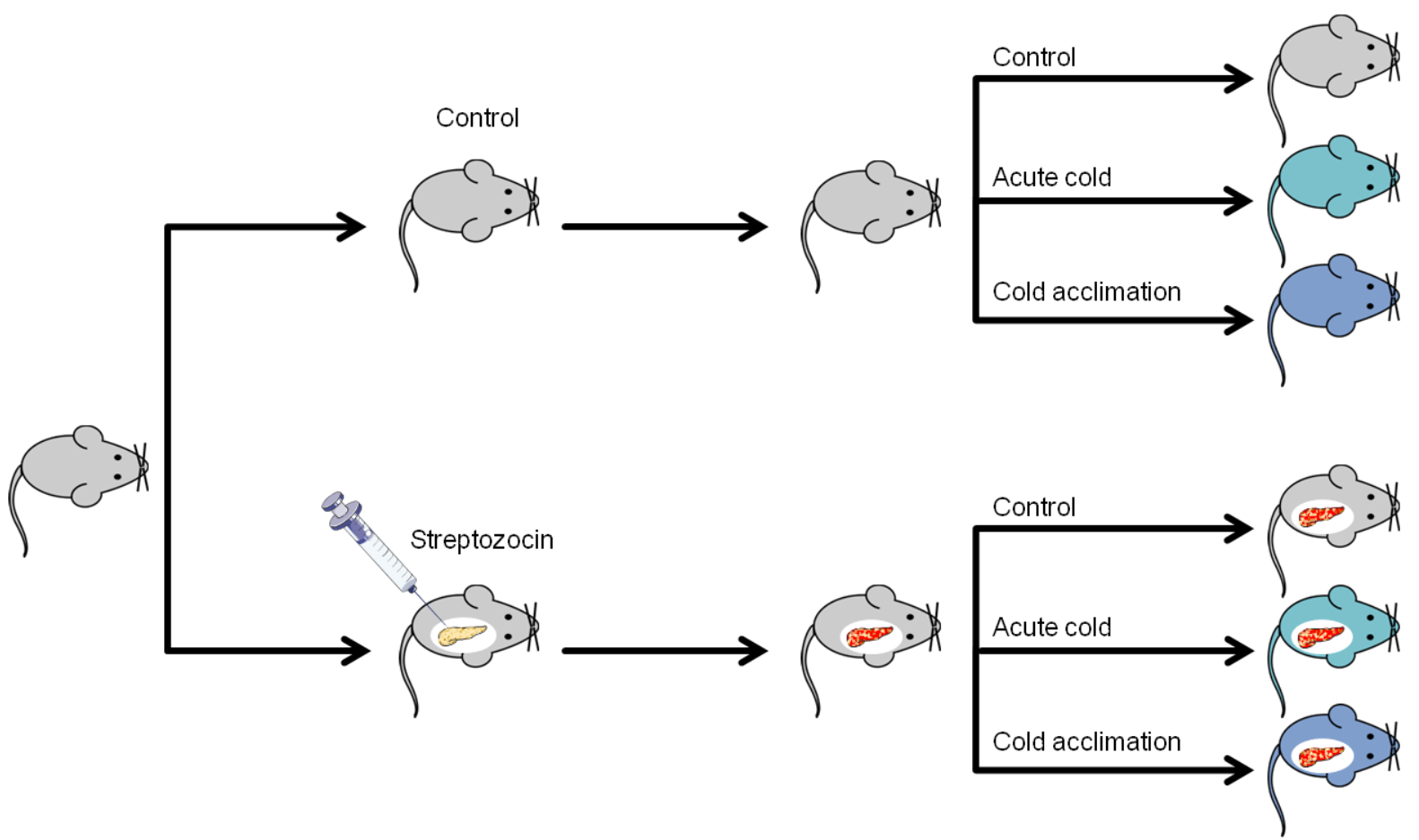

Fig 1: Mice were divided into 2 groups. Group 1 was used as a control group. Group 2 was injected with Streptozocin 10 days before the imaging experiment and afterwards fed with a high fat diet to induce diabetis. Both groups were divided into 3 subgroups where subgroup 1 was housed at $21^{\circ} \mathrm{C}$ before the experiment. Subgroup 2 was housed at $21^{\circ} \mathrm{C}$ but was exposed to $6{ }^{\circ} \mathrm{C}$ for $4 \mathrm{~h}$ prior to tracer injection. Subgroup 3 was exposed to cold for $6 \mathrm{~h}$ per day for 28 days before the imaging experiment. 


\section{Statistical analyses}

Data are presented as mean $\pm S D$, unless indicated otherwise. Differences at a probability level (p) of 0.05 were considered statistically significant. GraphPad Prism 5.01 (La Jolla, CA, USA) for Windows was used for statistical analyses.

\section{Availability of materials and data}

All data generated or analysed during this study are included in this published article (and its Supplementary Information files). 


\section{Results}

\section{Synthesis of BDP-TG, radiolabeling and incorportation into chylomicron-like particles}

Esterification of BDP- $\mathrm{C}_{16}$ yielded BDP-TG $(45 \pm 8 \%)$ after HPLC purification $\left(\mathrm{t}_{\mathrm{r}} 12.3 \mathrm{~min}\right)$ and its identity was confirmed by NMR and ESI-MS like reported before ${ }^{26}$. Radiolabeling of BDPTG was conducted as described before (44\% decay corrected rcy., $250 \mathrm{MBq} / \mathrm{\mu mol}$ corrected specific activity). After washing steps $\left[{ }^{18} \mathrm{~F}\right] \mathrm{BDP}-\mathrm{TG}$ could be obtained with an overall rcy. of $21 \%$ (rcp. $>96 \%$ ).

Chylomicron-like particles were synthesized with a mean diameter of $164 \pm 20 \mathrm{~nm}$ and a polydispersity index of $0.181(n=4)$. Electron microscopy confirmed the identity of the particles.

$\left[{ }^{18} \mathrm{~F}\right] \mathrm{BDP}-\mathrm{TG}$ was incorporated into chylomicron-like particles like reported before ${ }^{27}$. After 60 min at r.t. more than $99 \%$ of the $\left[{ }^{18} \mathrm{~F}\right] \mathrm{BDP}-\mathrm{TG}$ was incorporated in the particle and no free fluorine-18 was found in solution.

\section{Animal experiments}

$\left[{ }^{18} \mathrm{~F}\right] \mathrm{BDP}-\mathrm{TG}$-chylomicron-like particles $(1-10 \mathrm{MBq})$ were injected i.v. into female C57BI/6 mice, which were fasted for $4 \mathrm{~h}$ either at $21^{\circ} \mathrm{C}$ or at $4^{\circ} \mathrm{C}$. After scanning for $32.5 \mathrm{~min}$ the animals were euthanized and the organs were harvested. Analysis of the PET images showed highest uptake in liver, and heart of mice exposed at $21^{\circ} \mathrm{C}$, acute cold and cold acclimation (Fig 4 and Fig S1-6 a) in both control and diabetic animals. A rapid increase with a slow washout in both organs could be visualized (Fig S1-6 a). In bone a constant increase in signal was observed (Fig S1-6 b), which probably indicates a defluorination process of the tracer in vivo, as reported in literature ${ }^{33}$. Lung showed a fast increase with a fast washout and stayed constant at later time points under all temperature conditions. Brain as a negative control showed negligible uptake (Fig S1-6 b). 

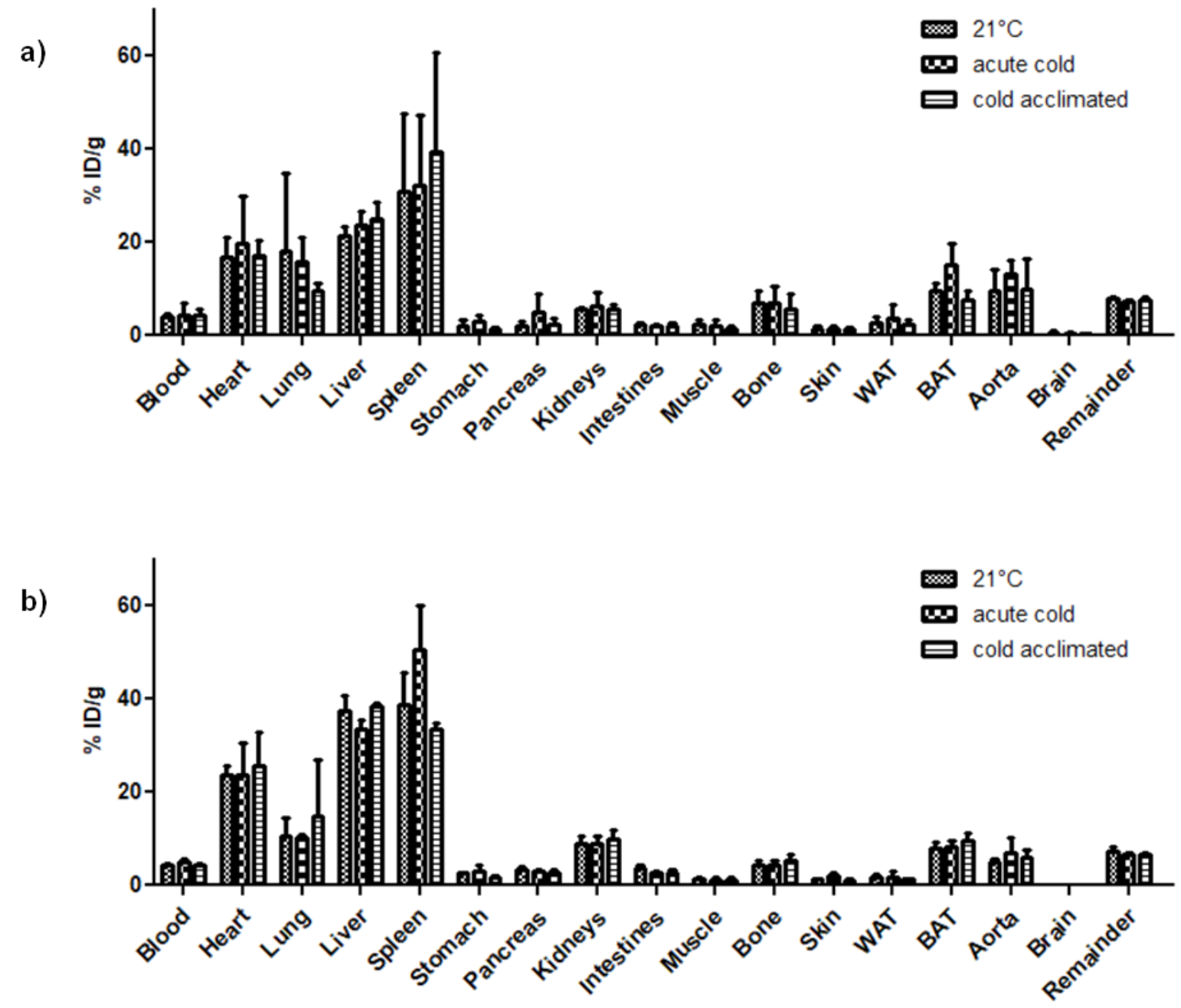

Fig 2: Biodistribution data of control (a) and diabetic (b) mice at $21^{\circ} \mathrm{C}$, under accute cold and cold acclimation 30 min after injection of [18F]BDP-TG-chylomicron-like particles.

BAT uptake was significant increased under control conditions by acute cold vs. $21{ }^{\circ} \mathrm{C}$ (Mann-Whitney $\mathrm{U}, \mathrm{n}=3$, two tailed, $\mathrm{p}<0.05$ ) as well as by acute cold vs. cold acclimation (Mann-Whitney $\mathrm{U}, \mathrm{n}=3$, two tailed, $\mathrm{p}<0.05$ ) (Fig $\mathrm{S1-3}$ b). No other effects due to cold exposure were observed in the control group and in the group with induced diabetes. Under acute cold exposure the control group showed significant increased BAT uptake vs. the diabetic group (Mann-Whitney $\mathrm{U}, \mathrm{n}=6$, two tailed, $\mathrm{p}<0.001$ ) (Fig $\mathrm{S} 2$ and $5 \mathrm{~b}$ ). No other significant group differences can be reported. 
PET images are supported by the results of the biodistribution. Highest uptake values in control animals housed at $21^{\circ} \mathrm{C}$ were found in spleen $(30.1 \pm 16.9 \% \mathrm{ID} / \mathrm{g})$, liver $(21.5 \pm 2.0 \%$ $\mathrm{ID} / \mathrm{g})$, lung $(18.0 \pm 2.0 \% \mathrm{ID} / \mathrm{g})$, and heart $(16.9 \pm 4.1 \% \mathrm{ID} / \mathrm{g})$ (Fig $3 \mathrm{a})$. After $30 \mathrm{~min}$ only $4.7 \pm$ $2.2 \% \mathrm{ID} / \mathrm{g}$ were found in the blood, indicating a fast blood clearance during the scanning time. Uptake by BAT $(9.6 \pm 1.7 \% \mathrm{ID} / \mathrm{g})$ was approximately 3.5 -fold higher than uptake by WAT $(2.8 \pm 1.4 \%$ ID/g; Mann-Whitney $U, n=4$, two tailed $p<0.001)$ (Fig 2 a).

In animals exposed to acute cold highest uptake was reached in spleen $(32.2 \pm 14.8 \% \mathrm{ID} / \mathrm{g})$, liver $(23.8 \pm 3.9 \% \mathrm{ID} / \mathrm{g})$ and heart $(19.9 \pm 9.8 \% \mathrm{ID} / \mathrm{g})$. Uptake in BAT was found to be $15.1 \pm$ 4.7\% ID/g and was significantly higher (Mann-Whitney $U, n=4$, two tailed, $p<0.05$ ) compared to WAT $(3.6 \pm 3.0 \% \mathrm{ID} / \mathrm{g})$ (Fig $2 \mathrm{a})$.

In cold acclimated animals highest uptake was reached in spleen (39.3 $\pm 21.3 \% \mathrm{ID} / \mathrm{g})$, liver $(24.9 \pm 3.6 \% \mathrm{ID} / \mathrm{g})$ and heart $(17.2 \pm 3.3 \% \mathrm{ID} / \mathrm{g})$. Uptake in BAT was found to be $7.6 \pm 1.9 \%$ $\mathrm{ID} / \mathrm{g}$ and was significantly higher (Mann-Whitney $\mathrm{U}, \mathrm{n}=3$, two tailed, $\mathrm{p}<0.05$ ) compared to WAT $(2.4 \pm 0.9 \% \mathrm{ID} / \mathrm{g})$ (Fig $2 \mathrm{a})$.

BAT uptake in animals exposed to acute cold showed a clear trend towards increased uptake compared to animals housed at $21^{\circ} \mathrm{C}$ but could not reach significance (MannWhitney $U, n=6$, two tailed, $p=0.07$ ). Acute cold vs. cold acclimation animals showed a significant increase in uptake in animals exposed to acute cold (Mann-Whitney $U, n=6$, two tailed, $\mathrm{p}<0.05)$ where housing at $21^{\circ} \mathrm{C}$ vs. cold acclimation did not show significant differences. Other organs did not show any response to acute cold or cold acclimation (2way Anova).

Highest uptake values in diabetic animals housed at $21^{\circ} \mathrm{C}$ were found in spleen $(38.7 \pm 6.9 \%$ $\mathrm{ID} / \mathrm{g})$, liver $(37.5 \pm 3.3 \% \mathrm{ID} / \mathrm{g})$ and heart $(23.7 \pm 1.9 \% \mathrm{ID} / \mathrm{g}) .4 .4 \pm 0.3 \% \mathrm{ID} / \mathrm{g}$ were found in the blood. Uptake by BAT $(8.0 \pm 1.3 \% \mathrm{ID} / \mathrm{g})$ was 4.2 -fold higher than uptake by WAT $(1.9 \pm 0.5 \%$ ID/g; Mann-Whitney U, n=4, two tailed $p<0.001$ ) (Fig 2 b).

In diabetic cold exposed animals highest uptake was reached in spleen $(50.3 \pm 9.7 \% \mathrm{ID} / \mathrm{g})$, liver $(33.4 \pm 2.1 \% \mathrm{ID} / \mathrm{g})$ and heart $(23.8 \pm 6.6 \% \mathrm{ID} / \mathrm{g})$. Uptake in BAT was found to be $8.2 \pm$ 
$1.4 \% \mathrm{ID} / \mathrm{g}$ and was significantly higher (Mann-Whitney $\mathrm{U}, \mathrm{n}=4$, two tailed, $\mathrm{p}<0.001$ ) compared to WAT $(1.8 \pm 1.2 \% \mathrm{ID} / \mathrm{g})$ (Fig 2 b).

In cold acclimated animals highest uptake was reached in liver (38.4 $\pm 0.6 \% \mathrm{ID} / \mathrm{g})$, spleen $(33.4 \pm 1.2 \% \mathrm{ID} / \mathrm{g})$ and heart $(25.5 \pm 7.2 \% \mathrm{ID} / \mathrm{g})$. Uptake in BAT was found to be $9.5 \pm 1.8 \%$ $\mathrm{ID} / \mathrm{g}$ and was significantly higher (Mann-Whitney $\mathrm{U}, \mathrm{n}=3$, two tailed, $\mathrm{p}<0.05$ ) compared to WAT $(1.4 \pm 0.1 \%$ ID/g) (Fig 2 b).

All three conditions $\left(22^{\circ} \mathrm{C}\right.$, acute cold exposure and cold acclimation) in diabetic animals were compared to each other but only showed significant differences in spleen in $22^{\circ} \mathrm{C}$ vs. acute cold $(p<0.001)$ and acute cold vs. cold acclimated $(p<0.001)$ (2way Anova).

When control and diabetic animals were compared at the same temperature significant difference was found at $22{ }^{\circ} \mathrm{C}$ in liver $(p<0.001)$, in acute cold animals in liver $(p<0.05)$, spleen $(p<0.001)$ and BAT $(p<0.05)$ and in cold acclimated animals in liver $(p<0.01)$.

BAT uptake of $\left[{ }^{18} \mathrm{~F}\right] \mathrm{BDP}-\mathrm{TG}$ was plotted against the glucose level and both groups differed significantly by their glucose levels (Mann-Whitney $U, n=23$, two tailed, $p<0.05$ ) but not by their BAT uptake values (Fig 3).

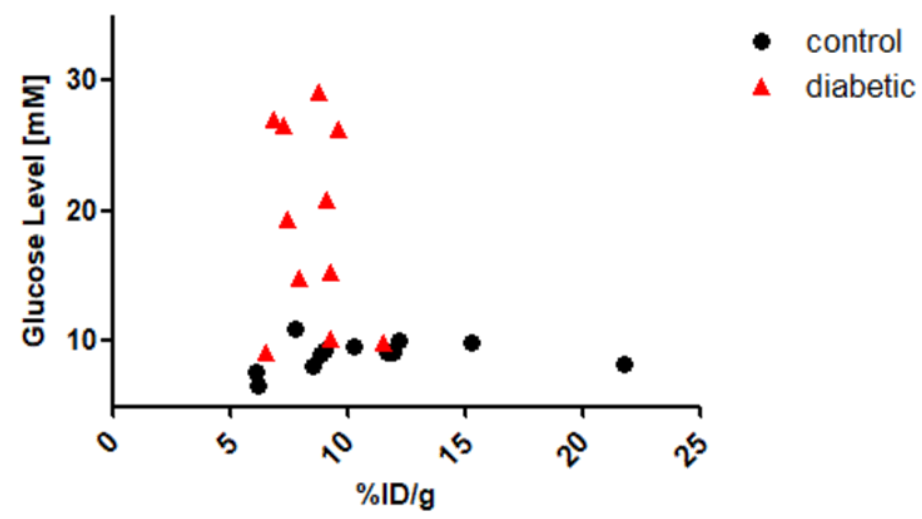

Fig 3: glucose level $[\mathrm{mM}]$ and \%ID/g BAT uptake of $\left[{ }^{18} \mathrm{~F}\right] \mathrm{BDP}-\mathrm{TG}$-chylomicron-like particles in control and diabetes induced mice. 


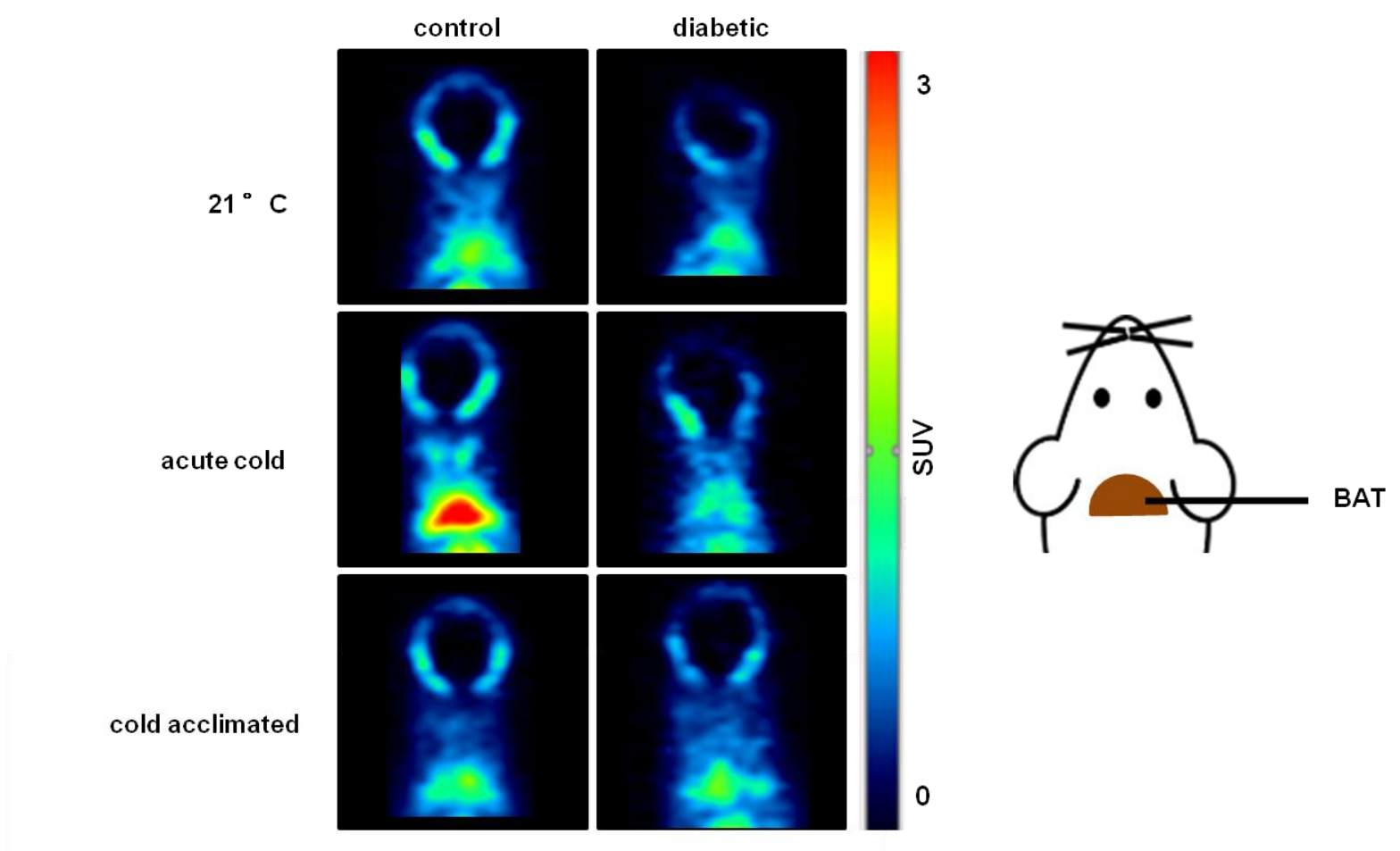

Fig 4: PET images (22-32.5 min) of $\left[{ }^{18} \mathrm{~F}\right] \mathrm{BDP}-\mathrm{TG}$ - chylomicron-like particles in control and diabetic mice under different temperature conditions.

BAT uptake of $\left[{ }^{18} \mathrm{~F}\right] \mathrm{FDG}$ was significant higher compared to $\left[{ }^{18} \mathrm{~F}\right] \mathrm{FTHA}$ in animals housed at $21{ }^{\circ} \mathrm{C}(2.5 \pm 1.1$ vs. $0.5 \pm 0.1)$ (Mann-Whitney $\mathrm{U}, \mathrm{n}=8$, two tailed, $\left.\mathrm{p}<0.05\right)$. The same difference in uptake can also be reported for animals acclimated to cold for 14 days (3.0 \pm 1.0 vs. $0.4 \pm 0.1$ ) (Mann-Whitney $U, n=8$, two tailed, $p<0.05$ ). Animals scanned with the same radiotracer did not show a significant response to 14 days of cold exposure for $\left[{ }^{18} \mathrm{~F}\right] \mathrm{FDG}$ (Mann-Whitney $U, n=8$, two tailed, $p>0.05$ ) and for $\left[{ }^{18} \mathrm{~F}\right] \mathrm{FTHA}$ (Mann-Whitney $\mathrm{U}, \mathrm{n}=8$, two tailed, $p>0.05)$. 


\section{Discussion}

BAT and its metabolism has become an interesting topic in the field of endocrine research within the last two decades. A high amount of imaging and quantification approaches, reaching from in vitro experiments ${ }^{34}$, over invasive ${ }^{23}$ or fluorescent probes ${ }^{22}$ to noninvasive imaging techniques with PET ${ }^{11-13,35,36}$, SPECT ${ }^{37,38}$ and MRI ${ }^{39-41}$, has been adapted or especially developed to explore BAT. Till now $\left[{ }^{18} \mathrm{~F}\right] \mathrm{FDG}$ is the most often used technique for BAT imaging but it is suffering from the problem that it is only able to show glucose related uptake. Therefore $\left[{ }^{18} \mathrm{~F}\right] \mathrm{FDG}$ might largely underestimate BATs metabolic activity as FAs are the main metabolized substance class ${ }^{16,17}$. Another disadvantage of BAT imaging with $\left[{ }^{18} \mathrm{~F}\right] \mathrm{FDG}$ is that it is strongly dependent on insulin sensitivity. In a clinical study it was shown that BATs glucose uptake was strongly impaired during insulin resistance where FA uptake was not affected under these conditions when compared to healthy controls ${ }^{18}$. These findings indicate that even during insulin resistance, BATs oxidative metabolism and FA uptake are not altered ${ }^{25}$. TRL-derived TGs were identified as BATs main source of FAs ${ }^{24,25}$ and lipoprotein lipase (LPL) was shown to be crucial for processing TRLs in vivo ${ }^{25,42}$. As LPL activity is decreased during insulin resistance ${ }^{43}$, and insulin was found to be essential for the lipolysis of TRLs ${ }^{44}$, uptake of TRL-derived FA is also altered under diabetic conditions which might complicate BAT detection. Nevertheless, to our opinion, radiolabeled TG encapsulated into TRLs might be the most accurate way to visualize BATs FA uptake and metabolism as it reflects the in vivo situation best.

In the presented study we put emphasis on different cold exposure protocols as well as on BAT lipid uptake during diabetes. The radiotracer was synthesized according to previous work ${ }^{26,27}$ but sedation of mice was performed with pentobarbital instead of isoflurane. Due to the different sedative used, tracer uptake in BAT was significantly increased at $21^{\circ} \mathrm{C}$ but other characteristics previously discussed were still present ${ }^{27}$. An increase in tracer uptake under control conditions due to acute cold exposure was observed but could not reach significance (Fig 2 a). Similar to experiments in humans, long term cold acclimation could not 
increase tracer uptake in BAT compared to exposure to $21^{\circ} \mathrm{C}{ }^{45}$. This effect was also observed in mice acclimated to cold and injected with $\left[{ }^{18} \mathrm{~F}\right] \mathrm{FDG}$ and $\left[{ }^{18} \mathrm{~F}\right] \mathrm{FTHA}$.

In diabetic mice no difference between housing at $21^{\circ} \mathrm{C}$, acute cold exposure or cold acclimation could be found. Even the pronounced uptake after acute cold exposure vs. $21^{\circ} \mathrm{C}$ (Fig 2 b) could not be observed anymore. In a recent publication Heine et al. described BATs dependence on insulin to maintain its lipolytic capacity to process TRLs ${ }^{44}$. The here presented results are in accordance to this work. Nevertheless, BAT could be visualized under conditions where $\left[{ }^{18} \mathrm{~F}\right] \mathrm{FDG}$ would have failed ${ }^{46}$. In general BAT uptake was comparable to uptake in control mice housed at $21^{\circ} \mathrm{C}$ which indicates BATs metabolic activity under diabetic conditions.

When control and diabetic animals were compared at different temperature conditions increased uptake in liver, spleen and BAT was found which also points to an insulin dependent uptake mechanism.

As a high number of patients which suffer from obesity also suffer from diabetes, additional experiments with obese mice are planned to decrypt BATs metabolism under these conditions.

In general it is to note that a combination of the here presented tracer and MRI or CT would be an optimal choice to quantify BATs lipid consumption. With $\left[{ }^{18} \mathrm{~F}\right] \mathrm{BDP}$-TG-chylomicron-like particles it is possible to measure lipid influx, where Magnet Resonance Imaging (MRI) and Computed Tomography (CT) are able to quantify intracellular lipid usage at the same time.

Possible drawbacks might be the influence of the diet on the pharmacokinetics of the tracer and the possibility to overestimate BATs activity because of blood pool activity. A high fat diet was necessary to induce diabetic conditions. Therefore higher amounts of TGs were expected in the blood which would reduce tracer uptake by competition. Blood perfusion in BAT was found to be increased due to cold by a factor of $2^{47}$. Therefore we cannot rule out the possibility of measuring only blood pool activity. Nevertheless, the relative low amount of activity found in the blood and the clearance of the tracer point more towards an active tracer uptake. 


\section{Conclusion}

We were able to visualize BAT uptake of TRL derived FAs under different metabolic and temperature conditions. Cold acclimation of control mice could not show increased FA uptake where acute cold exposure had an observable effect. Under diabetic conditions no difference between different temperatures was noted but uptake values were comparable to control mice housed at $21{ }^{\circ} \mathrm{C}$. $\left[{ }^{18} \mathrm{~F}\right] \mathrm{BDP}-\mathrm{TG}$-chylomicron-like particles showed BAT uptake under diabetic conditions. A combination between the here presented tracer and MRI or CT would be advantageous to fully quantify BATs lipid consumption. 


\section{References}

1

van Marken Lichtenbelt, W. D. \& Schrauwen, P. Implications of nonshivering thermogenesis for energy balance regulation in humans. American journal of physiology. Regulatory, integrative and comparative physiology 301, R285-296, doi:10.1152/ajpregu.00652.2010 (2011).

Cannon, B. \& Nedergaard, J. Brown adipose tissue: function and physiological significance. Physiol Rev 84, 277-359, doi:10.1152/physrev.00015.2003 (2004).

Nicholls, D. G. \& Locke, R. M. Thermogenic mechanisms in brown fat. Physiol Rev 64, 1-64 (1984).

Enerbäck, S. et al. Mice lacking mitochondrial uncoupling protein are cold-sensitive but not obese. Nature 387, 90-94, doi:10.1038/387090a0 (1997).

van Marken Lichtenbelt, W. D. et al. Cold-activated brown adipose tissue in healthy men. $N$ Engl J Med 360, 1500-1508, doi:10.1056/NEJMoa0808718 (2009).

Virtanen, K. A. et al. Functional brown adipose tissue in healthy adults. $N$ Engl J Med 360, 1518-1525, doi:10.1056/NEJMoa0808949 (2009).

Saito, M. et al. High incidence of metabolically active brown adipose tissue in healthy adult humans: effects of cold exposure and adiposity. Diabetes 58, 1526-1531, doi:10.2337/db090530 (2009).

Lowell, B. B. \& Spiegelman, B. M. Towards a molecular understanding of adaptive thermogenesis. Nature 404, 652-660, doi:10.1038/35007527 (2000).

Bachman, E. S. et al. betaAR signaling required for diet-induced thermogenesis and obesity resistance. Science 297, 843-845, doi:10.1126/science.1073160 (2002).

Cypess, A. M. et al. Activation of human brown adipose tissue by a $\beta 3$-adrenergic receptor agonist. Cell Metab 21, 33-38, doi:10.1016/j.cmet.2014.12.009 (2015).

Lee, P., Greenfield, J. R., Ho, K. K. \& Fulham, M. J. A critical appraisal of the prevalence and metabolic significance of brown adipose tissue in adult humans. Am J Physiol Endocrinol Metab 299, E601-606, doi:ajpendo.00298.2010 [pii]10.1152/ajpendo.00298.2010 (2010).

2 Cohade, C., Mourtzikos, K. A. \& Wahl, R. L. "USA-Fat": prevalence is related to ambient outdoor temperature-evaluation with 18F-FDG PET/CT. Journal of nuclear medicine : official publication, Society of Nuclear Medicine 44, 1267-1270 (2003).

Hany, T. F. et al. Brown adipose tissue: a factor to consider in symmetrical tracer uptake in the neck and upper chest region. Eur J Nucl Med Mol Imaging 29, 1393-1398, doi:10.1007/s00259-002-0902-6 (2002).

Pace, L. et al. Determinants of physiologic 18F-FDG uptake in brown adipose tissue in sequential PET/CT examinations. Molecular imaging and biology : MIB : the official publication of the Academy of Molecular Imaging 13, 1029-1035, doi:10.1007/s11307-0100431-9 (2011).

Hanssen, M. J. et al. Short-term cold acclimation recruits brown adipose tissue in obese humans. Diabetes, doi:10.2337/db15-1372 (2016).

Yu, X. X., Lewin, D. A., Forrest, W. \& Adams, S. H. Cold elicits the simultaneous induction of fatty acid synthesis and beta-oxidation in murine brown adipose tissue: prediction from differential gene expression and confirmation in vivo. FASEB J 16, 155-168, doi:10.1096/fj.010568com (2002).

Townsend, K. L. \& Tseng, Y.-H. Brown fat fuel utilization and thermogenesis. Trends Endocrinol Metab 25, 168-177, doi:10.1016/j.tem.2013.12.004 (2014).

Blondin, D. P. et al. Selective Impairment of Glucose but Not Fatty Acid or Oxidative Metabolism in Brown Adipose Tissue of Subjects With Type 2 Diabetes. Diabetes 64, 23882397, doi:10.2337/db14-1651 (2015). 
Al-Goblan, A. S., Al-Alfi, M. A. \& Khan, M. Z. Mechanism linking diabetes mellitus and obesity. Diabetes, metabolic syndrome and obesity : targets and therapy 7, 587-591, doi:10.2147/DMSO.S67400 (2014).

DeGrado TR, C. H., Stocklin G. 14(R,S)-[18F]fluoro-6-thia-heptadecanoic acid (FTHA): evaluation in mouse of a new probe of myocardial utilization of long chain fatty acids. J Nucl Med 32, 1888-1896 (1991).

21 Goodmen M.M., K. F. F., Elmaleh D.R., Strauss H.W. New myocardial imaging agents: Synthesis of 15-(p-[123I]iodophenyl)-3(R,S)-methylpentadecanoic acid by decomposition of a 3,3-(1,5-pentanedyl)triazene precursor. J. Org. Chem 49, 2322-2325 (1984).

22 Bartelt, A. et al. Brown adipose tissue activity controls triglyceride clearance. Nat Med 17, 200-205, doi:10.1038/nm.2297 (2011).

23 Khedoe, P. P. S. J. et al. Brown adipose tissue takes up plasma triglycerides mostly after lipolysis. J Lipid Res 56, 51-59, doi:10.1194/jlr.M052746 (2015).

24 Festuccia, W. T., Blanchard, P.-G. \& Deshaies, Y. Control of Brown Adipose Tissue Glucose and Lipid Metabolism by PPARY. Front Endocrinol (Lausanne) 2, 84, doi:10.3389/fendo.2011.00084 (2011).

25 Hoeke, G., Kooijman, S., Boon, M. R., Rensen, P. C. \& Berbee, J. F. Role of Brown Fat in Lipoprotein Metabolism and Atherosclerosis. Circulation research 118, 173-182, doi:10.1161/circresaha.115.306647 (2016).

26 Paulus, A. et al. Synthesis, radiosynthesis and in vitro evaluation of 18F-BodipyC16/triglyceride as a dual modal imaging agent for brown adipose tissue. PLoS One 12, e0182297, doi:10.1371/journal.pone.0182297 (2017).

27 Paulus, A. et al. [(18)F]BODIPY-triglyceride-containing chylomicron-like particles as an imaging agent for brown adipose tissue in vivo. Scientific reports 9, 2706, doi:10.1038/s41598-019-39561-z (2019).

28 McAnoy, A. M., Wu, C. C. \& Murphy, R. C. Direct qualitative analysis of triacylglycerols by electrospray mass spectrometry using a linear ion trap. J Am Soc Mass Spectrom 16, 14981509, doi:10.1016/j.jasms.2005.04.017 (2005).

29 Rensen, P. C. N. et al. Selective Liver Targeting of Antivirals by Recombinant Chylomicrons - a New Therapeutic Approach to Hepatitis-B. Nat Med 1, 221-225 (1995).

30 Redgrave, T. G. \& Maranhao, R. C. Metabolism of protein-free lipid emulsion models of chylomicrons in rats. Biochim Biophys Acta 835, 104-112 (1985).

31 Eleazu, C. O., Eleazu, K. C., Chukwuma, S. \& Essien, U. N. Review of the mechanism of cell death resulting from streptozotocin challenge in experimental animals, its practical use and potential risk to humans. Journal of diabetes and metabolic disorders 12, 60-60, doi:10.1186/2251-6581-12-60 (2013).

32 Gilbert, E. R., Fu, Z. \& Liu, D. Development of a nongenetic mouse model of type 2 diabetes. Experimental diabetes research 2011, 416254, doi:10.1155/2011/416254 (2011).

33 Paulus, A. et al. Development of a clickable bimodal fluorescent/PET probe for in vivo imaging. Ejnmmi Res 5, 120, doi:10.1186/s13550-015-0120-4 (2015).

34 Henkin, A. H. et al. Real-time noninvasive imaging of fatty acid uptake in vivo. ACS Chem Biol 7, 1884-1891, doi:10.1021/cb300194b (2012).

35 Ouellet, $V$. et al. Brown adipose tissue oxidative metabolism contributes to energy expenditure during acute cold exposure in humans. J Clin Invest 122, 545-552, doi:10.1172/jci60433 (2012).

36 Bucci, M. et al. Enhanced fatty acid uptake in visceral adipose tissue is not reversed by weight loss in obese individuals with the metabolic syndrome. Diabetologia 58, 158-164, doi:10.1007/s00125-014-3402-x (2015).

37 Syamsunarno, M. R. A. A. et al. Fatty acid binding protein 4 and 5 play a crucial role in thermogenesis under the conditions of fasting and cold stress. PloS one 9, e90825, doi:10.1371/journal.pone.0090825 (2014). 
38 Putri, M. et al. CD36 is indispensable for thermogenesis under conditions of fasting and cold stress. Biochem Biophys Res Commun 457, 520-525, doi:10.1016/j.bbrc.2014.12.124 (2015).

39 Grimpo, K. et al. Brown adipose tissue dynamics in wild-type and UCP1-knockout mice: in vivo insights with magnetic resonance. J Lipid Res 55, 398-409, doi:10.1194/jlr.M042895 (2014).

40 Holstila, M. et al. Measurement of brown adipose tissue mass using a novel dual-echo magnetic resonance imaging approach: a validation study. Metabolism 62, 1189-1198, doi:10.1016/j.metabol.2013.03.002 (2013).

41 van Rooijen, B. D. et al. Imaging cold-activated brown adipose tissue using dynamic T2*weighted magnetic resonance imaging and 2-deoxy-2-[18F]fluoro-D-glucose positron emission tomography. Invest Radiol 48, 708-714, doi:10.1097/RLI.0b013e31829363b8 (2013).

42 Labbé, S. M. et al. In vivo measurement of energy substrate contribution to cold-induced brown adipose tissue thermogenesis. FASEB J 29, 2046-2058, doi:10.1096/fj.14-266247 (2015).

43 Qu, S., Zhang, T. \& Dong, H. H. Effect of hepatic insulin expression on lipid metabolism in diabetic mice. Journal of diabetes 8, 314-323, doi:10.1111/1753-0407.12293 (2016).

44 Heine, M. et al. Lipolysis Triggers a Systemic Insulin Response Essential for Efficient Energy Replenishment of Activated Brown Adipose Tissue in Mice. Cell Metab 28, 644-655.e644, doi:10.1016/j.cmet.2018.06.020 (2018).

45 Blondin, D. P. et al. Dietary fatty acid metabolism of brown adipose tissue in cold-acclimated men. Nature communications 8, 14146, doi:10.1038/ncomms14146 (2017).

$46 \mathrm{Wu}, \mathrm{C}$. et al. Activating brown adipose tissue for weight loss and lowering of blood glucose levels: a microPET study using obese and diabetic model mice. PLoS One 9, e113742, doi:10.1371/journal.pone.0113742 (2014).

47 Orava, J. et al. Different metabolic responses of human brown adipose tissue to activation by cold and insulin. Cell Metab 14, 272-279, doi:10.1016/j.cmet.2011.06.012 (2011). 


\section{Supplementary Information}

a)

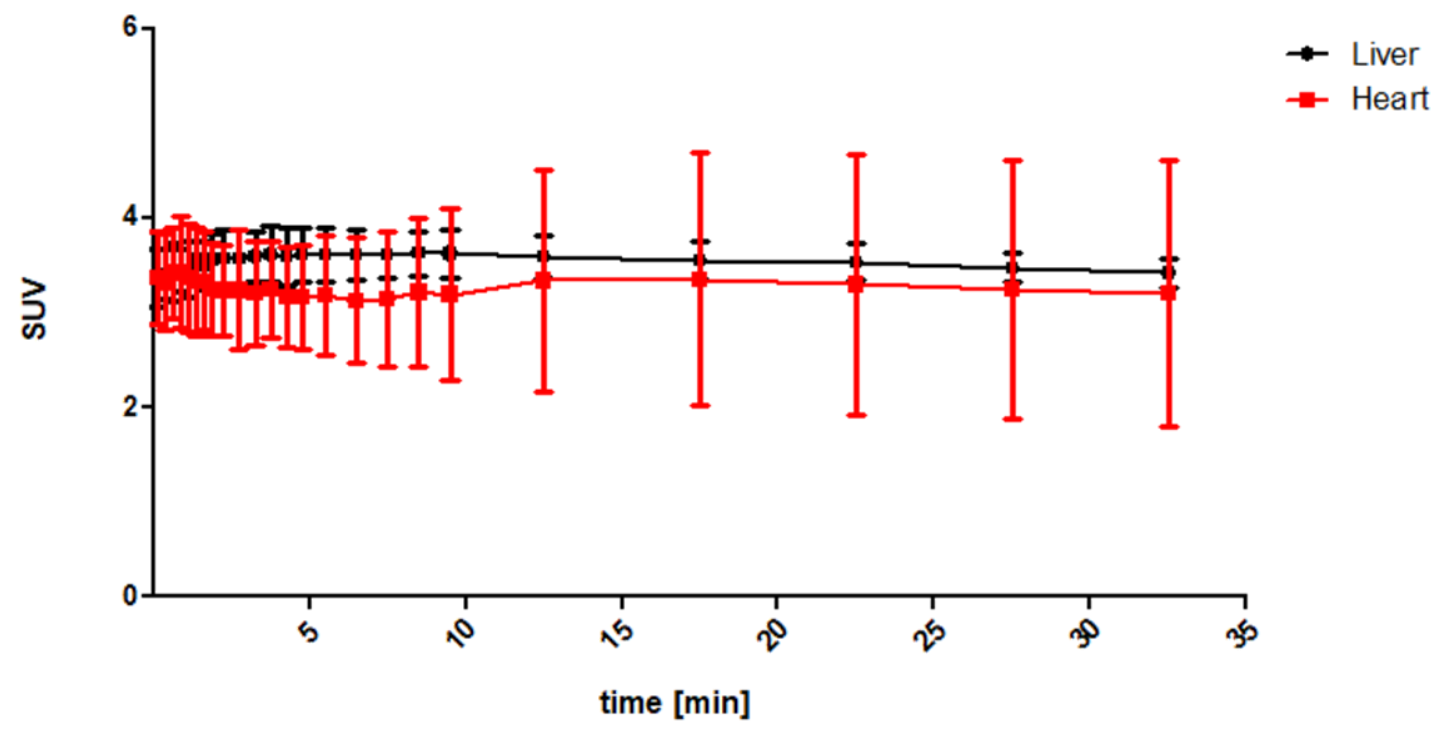

b)

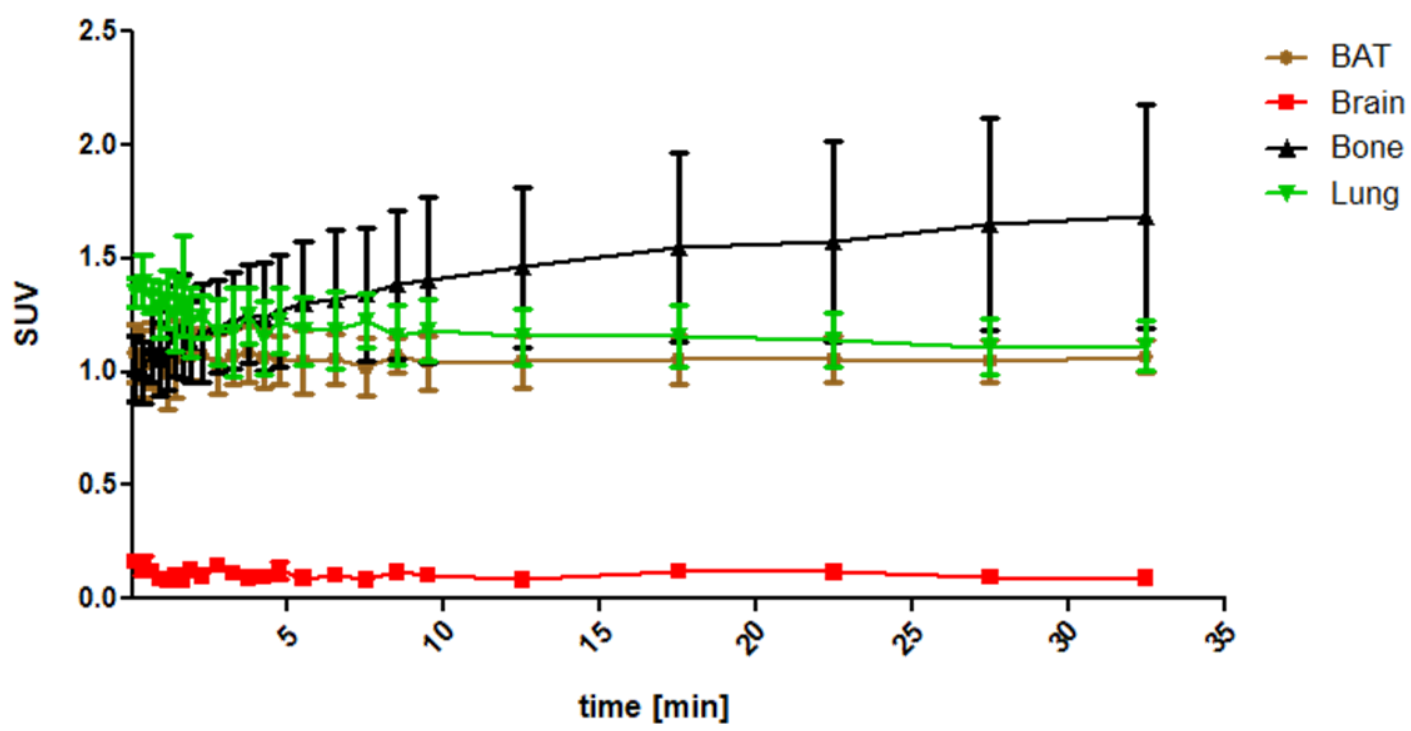

Fig S1: time activity curves in control mice housed $21^{\circ} \mathrm{C}$ in a) liver and heart b) BAT, brain, bone, lung. 
a)

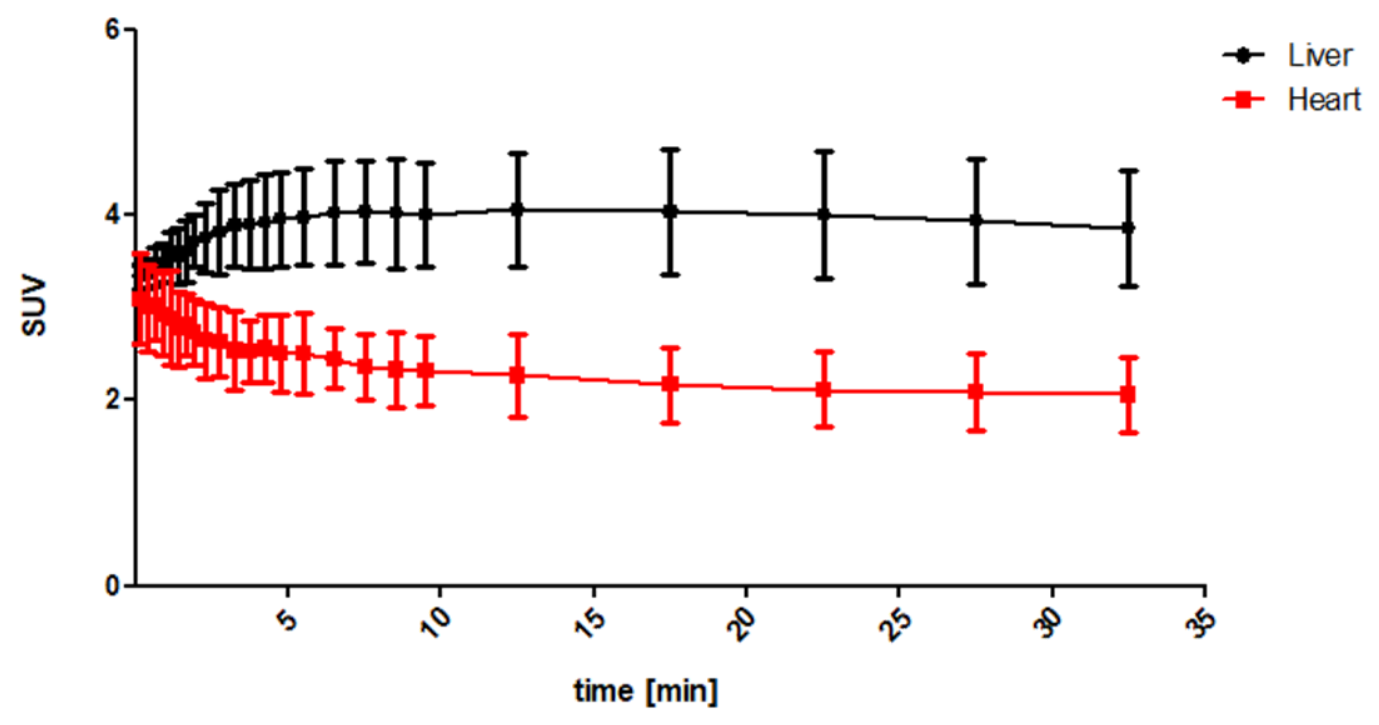

b)

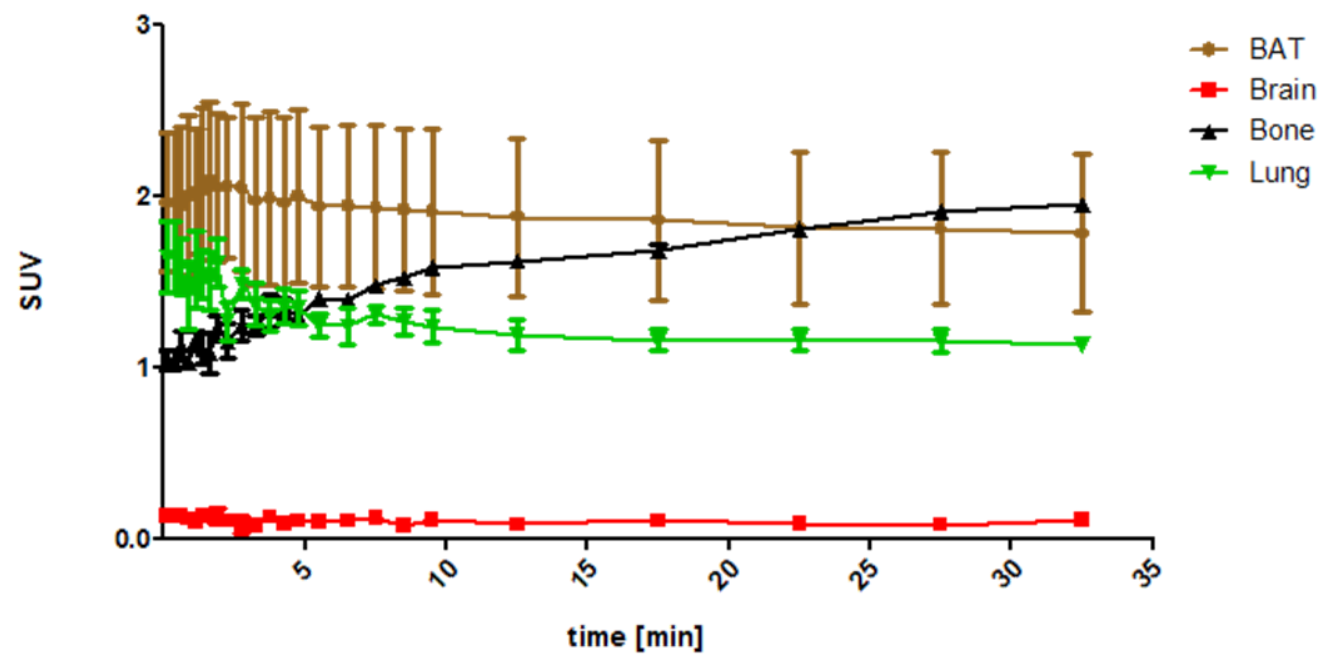

Fig S2: time activity curves in control acute cold exposed mice in a) liver and heart b) BAT, brain, bone, lung. 


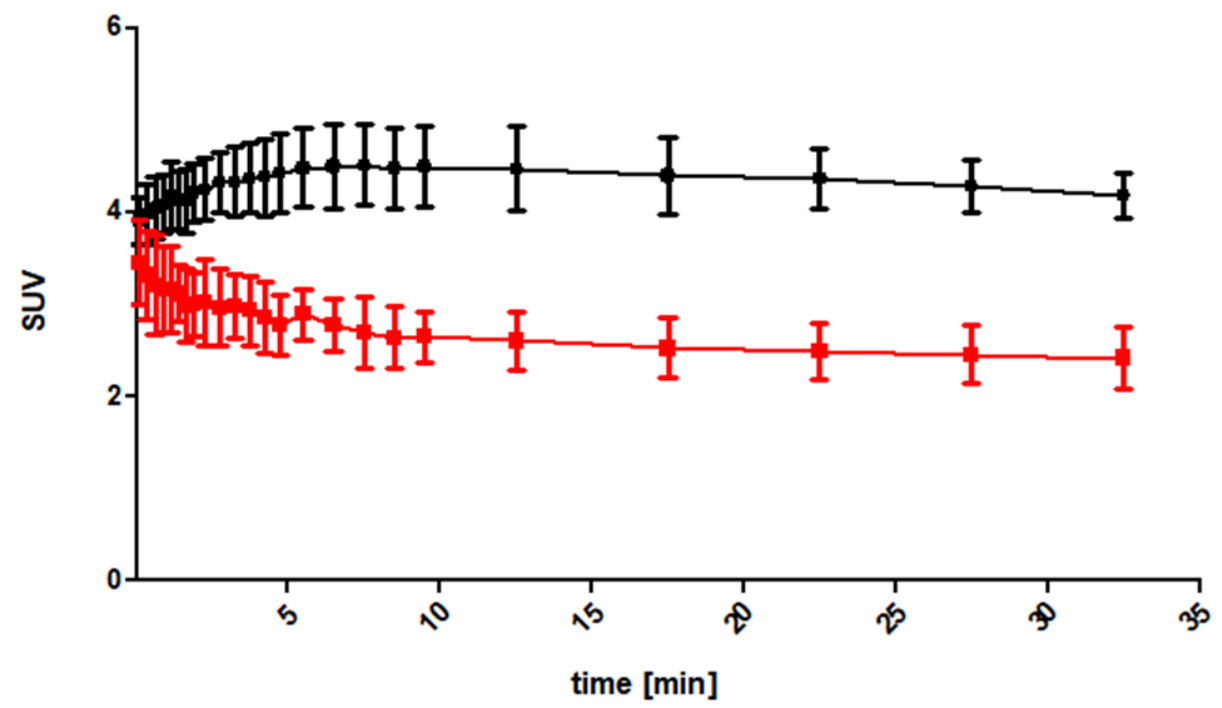

Liver

- Heart

time [min]

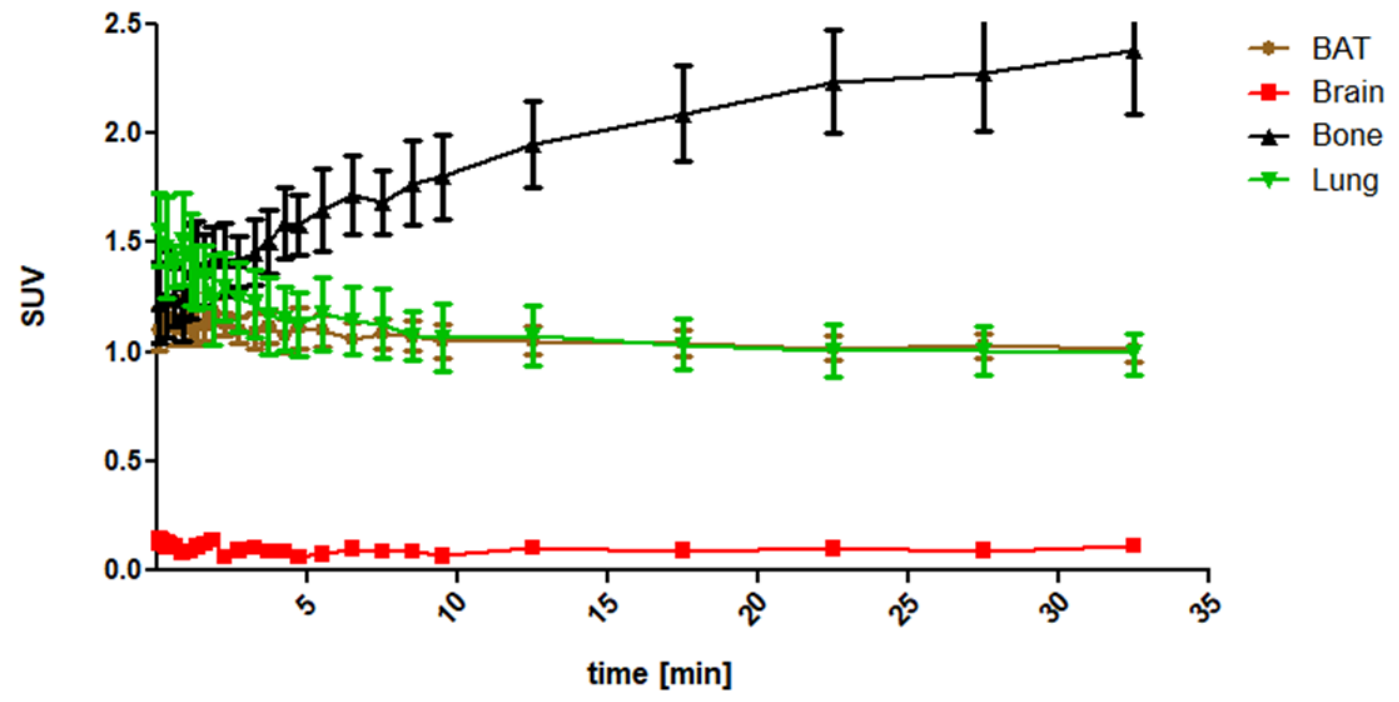

Fig S3: time activity curves in control cold acclimated mice in a) liver and heart b) BAT, brain, bone, lung. 

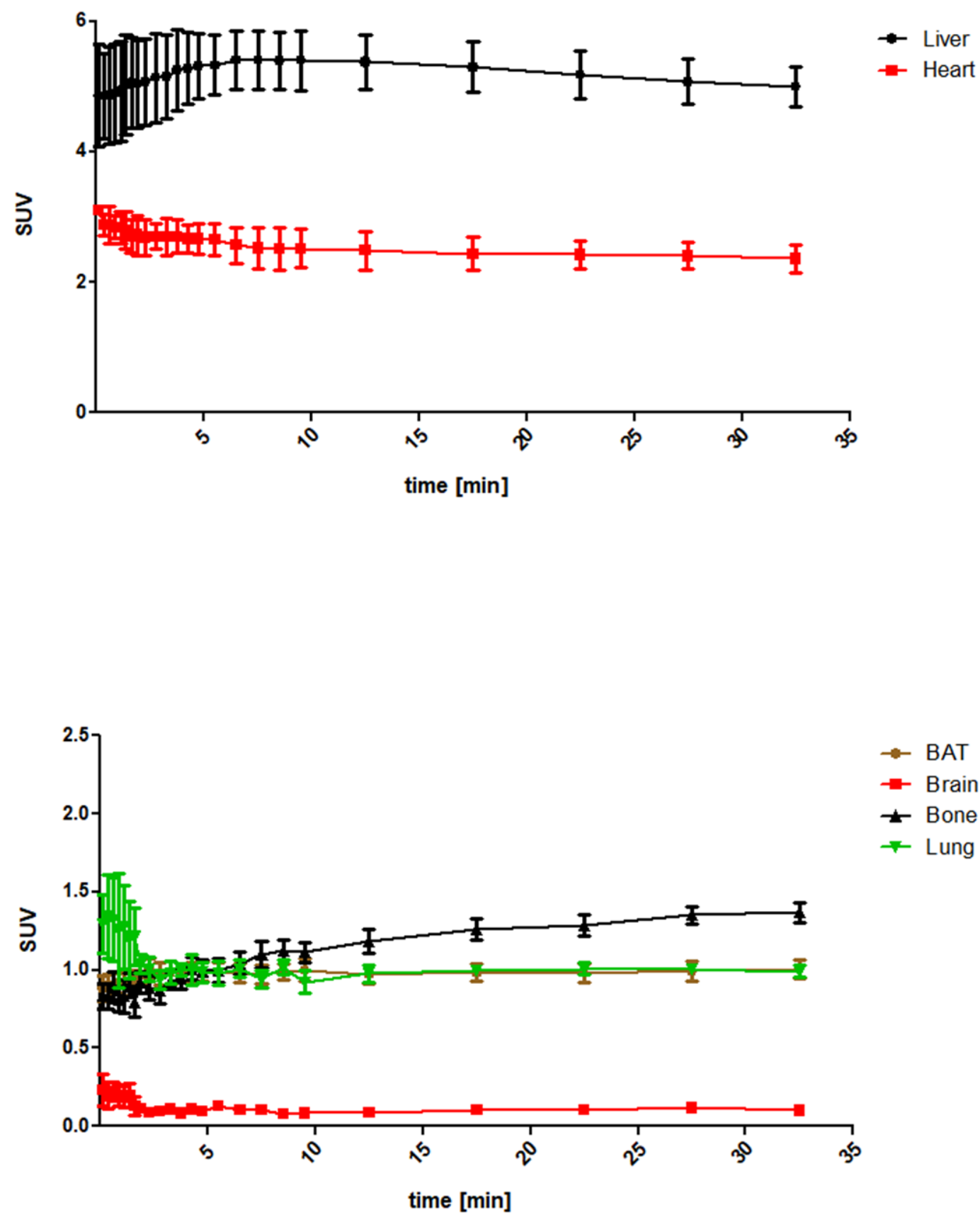

Fig S4: time activity curves in diabetic mice housed $21^{\circ} \mathrm{C}$ in a) liver and heart b) BAT, brain, bone, lung. 

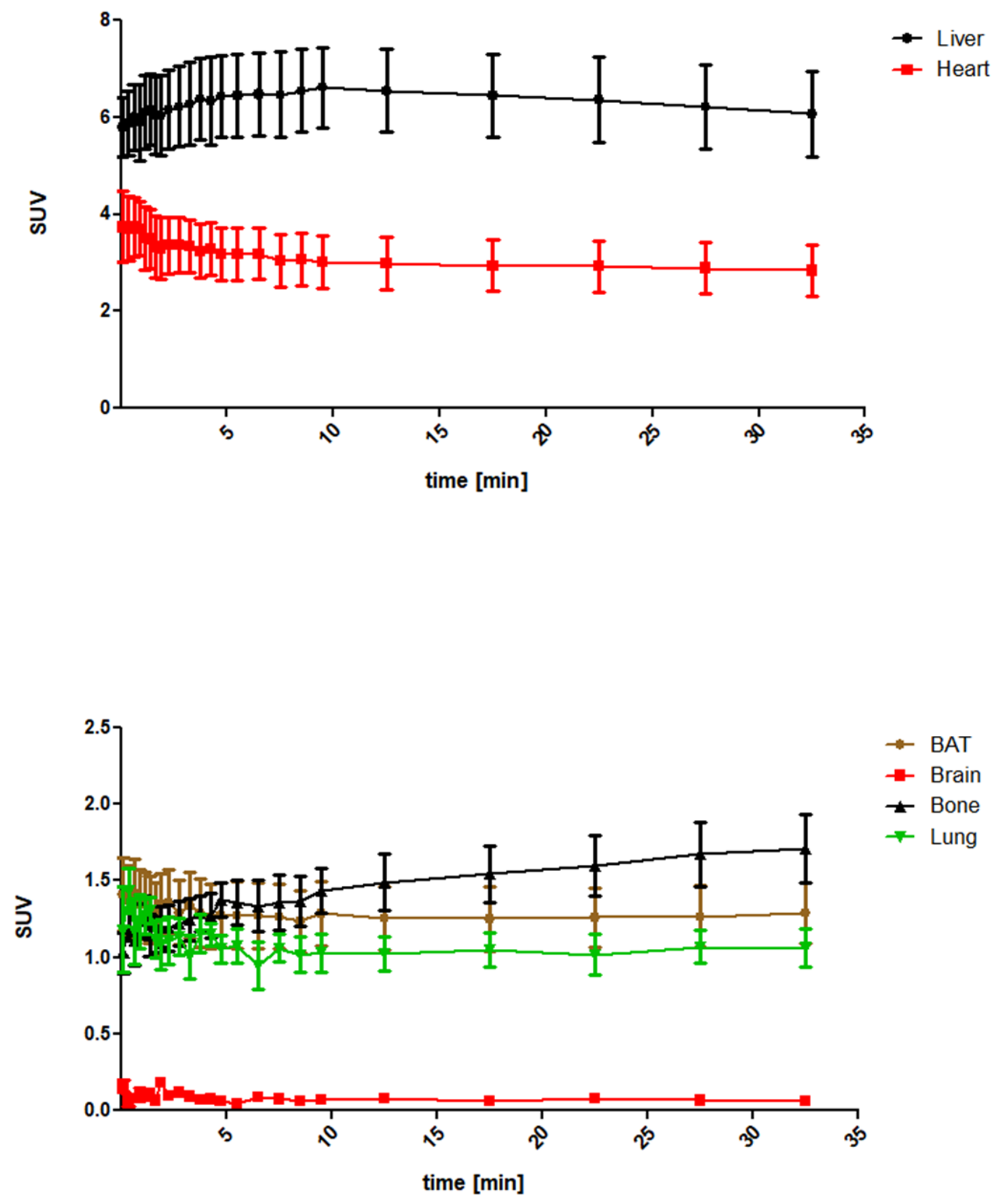

Fig S5: time activity curves in diabetic acute cold exposed mice in a) liver and heart b) BAT, brain, bone, lung. 


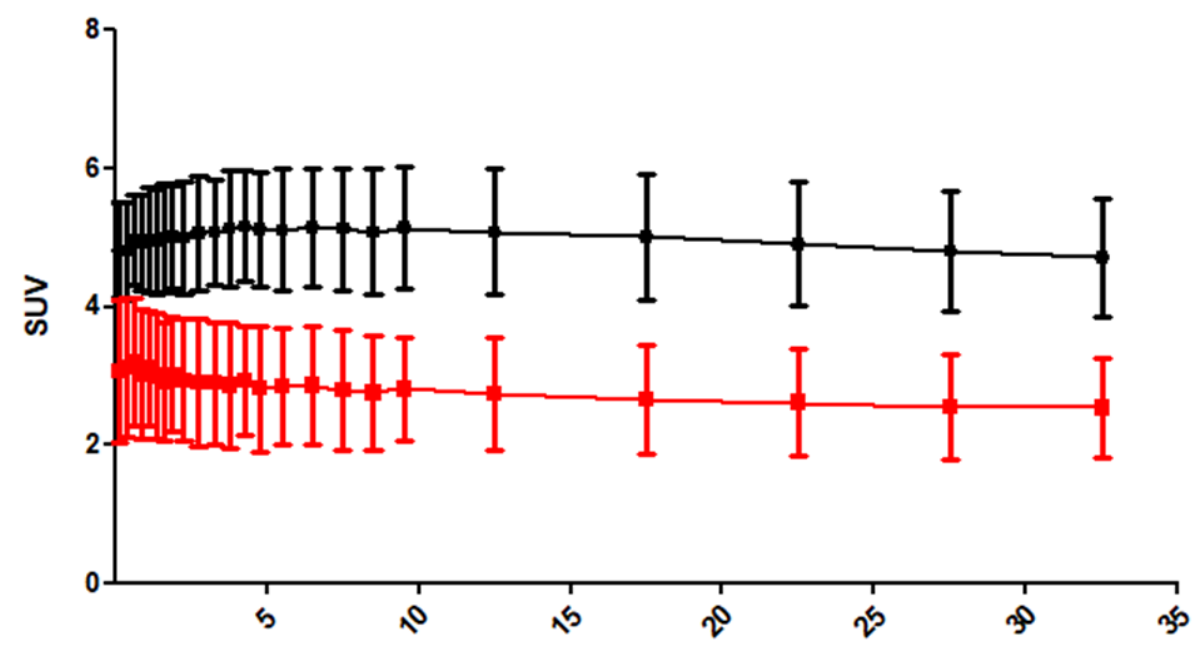

time [min]

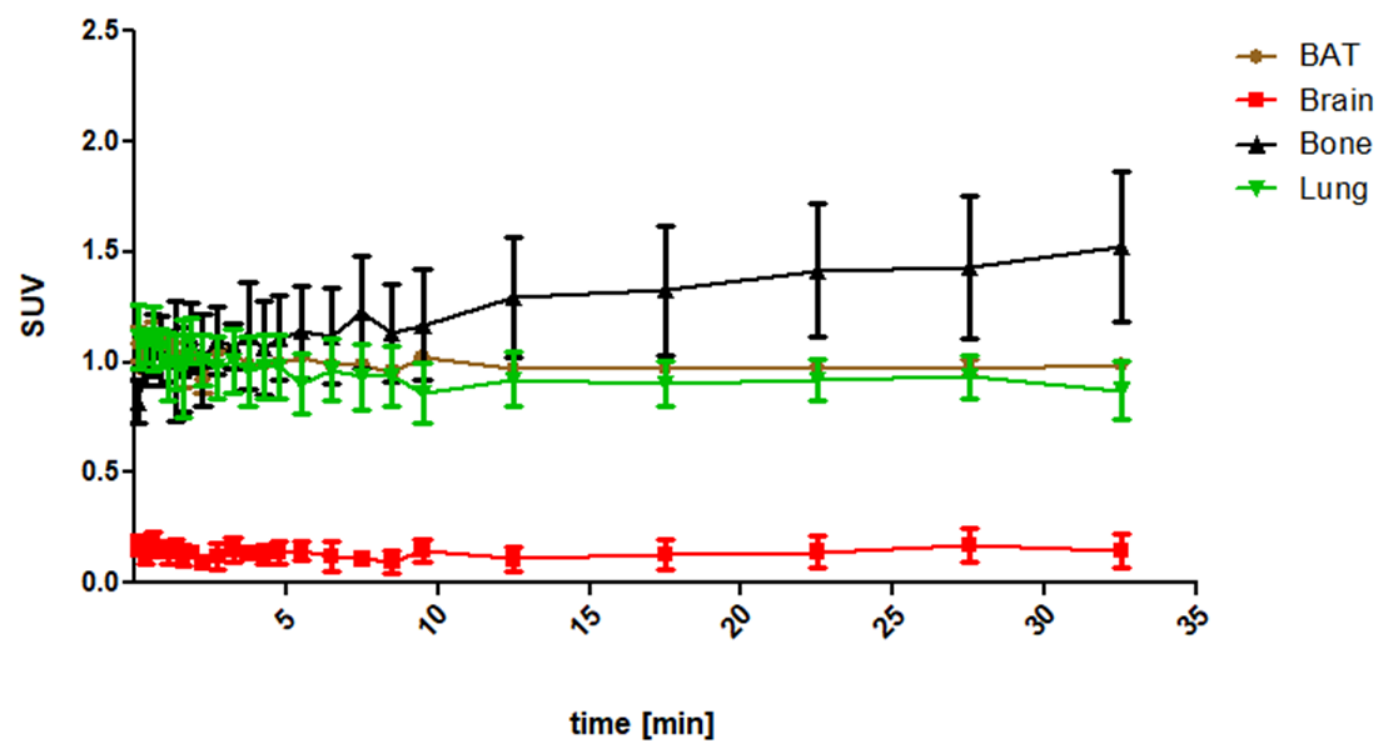

Fig S6: time activity curves in diabetic cold acclimated mice in a) liver and heart b) BAT, brain, bone, lung. 
Chapter 7:

Discussion

Andreas Paulus 
Brown adipose tissue (BAT) research started as an underestimated research field in the last century which was thought to have limited beneficial effect for adult humans. Already in the 20 's ${ }^{1}$ brown adipocytes in humans were described and following studies ${ }^{2-4}$ analyzed BATs function in newborns. Nevertheless, BATs size was found to decrease with aging and therefore it was thought to be irrelevant for adults ${ }^{5-7}$. In the 80 's of the last century significant amounts of BAT were found in outdoor workers ${ }^{8}$ and since the 00 's of this century active BAT was imaged and then verified in human adults based on $\left[{ }^{18} \mathrm{~F}\right]$ Fluoro-2-deoxy-2-Dglucose $\left(\left[{ }^{18} \mathrm{~F}\right] \mathrm{FDG}\right)$ Positron Emission Tomography/Computed Tomography (PET/CT) ${ }^{9-11}$ and consecutive biopsies. Subsequent dedicated cold exposure experiments showed an increased $\left[{ }^{18} \mathrm{~F}\right] \mathrm{FDG}$ uptake ${ }^{12-14}$ and short term cold exposure was able to recruit BAT even in obese subjects ${ }^{15}$. BAT research gained more and more interest over time and new techniques and tracers to image BATs volume and metabolic activity have been developed. Nevertheless, the predominant PET tracer for BAT imaging is $\left[{ }^{18} \mathrm{~F}\right] \mathrm{FDG}$. Its broad availability and relative long half-life offer the opportunity for non-in-house production and shipment to the place of usage. Anyways, the disadvantages of the use of a glucose tracer have been described earlier, i.e. this tracer offers only information about BAT volume and glucose consumption. As this reflects only a small portion of the energy metabolism, the overall metabolic BAT activity cannot be determined with $\left[{ }^{18} \mathrm{~F}\right] \mathrm{FDG}$. Therefore there is need for new methods and techniques to unravel BATs contribution to whole body expenditure.

Reviewing the use of lipid metabolism imaging and its application in the field of BAT we concluded (chapter 2) that many different techniques are available to image BAT and its metabolism from which are some already translated to the clinic, some have the potential to be translated and some will have only preclinical application. MRI, SPECT and PET are all suitable to non-invasively image BAT but also the right tracer should be chosen to visualize different aspects of BAT. We expected PET imaging with radiolabeled FAs to be the most promising technique for BAT metabolism imaging because it reflects its main metabolized substance class ${ }^{16}$ but also other imaging modalities such as fluorescence imaging and MRI 166 
will have an impact on the exploration of BAT and its contribution to whole body energy expenditure.

To demonstrate the many different opportunities to visualize BAT we looked broader (chapter 3) and compared different imaging techniques, available in our institute, with regard to their ability to monitor BAT activity. We included MR Spectroscopy (MRS) but also PET and SPECT which was conducted with tracers which were already applied in the clinic but where no inter-tracer comparison was available. Additionally we investigated the effect of acute cold exposure and cold acclimation on the biodistribution of the different tracers as no data was available on this information. Here, we concluded that different modalities, like PET, SPECT and MRS were able to visualize BAT in rats and that BAT could also be identified by its protein and mRNA levels. With MRS we were able to quantify heat production of BAT. $\left[{ }^{18} \mathrm{~F}\right] \mathrm{FDG},\left[{ }^{18} \mathrm{~F}\right] \mathrm{FTHA}$ and $\left[{ }^{123} \mathrm{I}\right] \mathrm{MIBG}$ showed pronounced uptake under acute cold conditions, like reported in literature ${ }^{17}$, but uptake was not further increased significantly by cold acclimation. In humans the situation is different. Here the SUV value increases up on chronic cold acclimation ${ }^{18,19}$ but we hypothesized that BAT in rats housed at $22{ }^{\circ} \mathrm{C}$ is already acclimated to a small extend as this temperature is below their thermoneutral zone $\left(\sim 30^{\circ} \mathrm{C}\right)$ ${ }^{20}$. The other tracers did not show significant increased uptake values up on cold stimulation or were not able to visualize BAT.

Based on the conclusions from chapter 2 and 3, we looked deeper into the use of radiolabelled FAs as a tool to assess BAT activity.

FA tracers like $\left[{ }^{18} \mathrm{~F}\right] \mathrm{FTHA}$ and $\left[{ }^{123}\right.$ I]BMIPP might already have advantages over $\left[{ }^{18} \mathrm{~F}\right] \mathrm{FDG}$ but nevertheless FAs should not be applied as such because usually BAT takes up FAs after lipolysis of TGs resulting from triglyceride-rich lipoproteins (TRLs) ${ }^{21}$. Therefore a conversion of the discussed FAs to their corresponding TGs following and incorporation into TRLs would be necessary to mimic the in vivo situation best. We focused on this tasks and experienced several problems during the synthesis of such TGs (chapter 4) and carrier systems (chapter 5). Esterification of FAs to TG is a straight forward technique. However, most protocols focus on large amounts of precursor which is in most cases not necessary and too 
expensive for the synthesis of radiotracers. Therefore, a downscaling of these reactions needed to be done. Also a radiolabeling of the TG might lead to several problems as most radiolabelings with halogens are performed in polar solvents where the TG-precursor molecule would not be soluble. An intermediate solvent system needed to be found as well as extensive purification steps to assure that, during the following incorporation of the TG into the lipoprotein-like particles, the particle itself is not altered. Quality controls had to be implemented before in vivo/vitro administration.

We developed a dual modal fluorescent/PET active TG (chapter 4) which was tested in vitro and compared to the crude FA. First we aimed to esterify FTHA but within this step all we observed was a major side-product. We hypothesised that due to the strong chlorinating agent thionyl chloride, which is used during the esterification, the thioether bond is not stable. Also by variations of the reaction conditions the product was not successfully synthesized. The next FA we choose was the commercially available BODIPY- $\mathrm{C}_{16}$ (BDP-FA). This FA offers the opportunity to radiolabel it with fluorine-18 by $a{ }^{19} \mathrm{~F} /{ }^{18} \mathrm{~F}$ exchange reaction on its boron core but is also fluorescent which facilitates first in vitro testing. Esterification with 1,3diolein was successfully performed and radiolabeling of the BDP-FA and the BDP-TG was carried out in decent yields which were in accordance to literature ${ }^{22,23}$. The following in vitro uptake experiments with primary human BAT and WAT cells revealed that BDP-FA is taken up with the characteristics of other FAs $\left(k_{m}=1.15 \mu M\right){ }^{24,25}$ but not the BDP-TG. As BDP-TG is highly lipophilic it will not dissolve in the aqueous cell medium and will therefore not be available for any cells. We analyzed uptake characteristics by fluorescence and found a CD36 dependent uptake in BAT which could be stimulated by norepinephrine. WAT cells seemed to be resistant to the same interactions, which was also reported in literature ${ }^{26,27}$ and therefore a different uptake mechanism was assumed. From literature ${ }^{28,29}$ but also by our own experience we observed that BDP-dyes have a high potential for quenching effects as soon as they are not perfectly solubilised. Therefore, similar experiments with the $\left[{ }^{18} \mathrm{~F}\right] \mathrm{BDP}-\mathrm{FA}$ were conducted and comparable results were found. 
In chapter 4 a study describing the possibility of BDP-FA employed as a FA based tracer is presented. It is taken up with the characteristics of a FA and can be characterized by its fluorescence. It can be radiolabeled by a straight forward technique offering the opportunity for real, unquenched, uptake quantification. BDP-FA was esterified to its corresponding TG, which did not show any uptake in in vitro experiments due to its highly lipophilic character. Nevertheless BDP-TG could also be radiolabeled in a decent yield.

As already mentioned the main lipid source of BAT is lipolysed FAs from TRLs ${ }^{30}$. Therefore, we focused (chapter 5 ) in a next step on the incorporation of the BDP-TG/[ $\left.{ }^{18} \mathrm{~F}\right] \mathrm{BDP}-\mathrm{TG}$ into a chylomicron-like particle which we synthesized ex vivo. For this purpose we adapted a method from our collaborator Prof. Rensen who labelled particles with $\left[{ }^{3} \mathrm{H}\right]$ triolein ${ }^{31-36}$. Different to his approach we intended to label the particles after formation, and reduce the total labelling time from 1 day to $<2$ hours. A direct labeling during formation of the particles was tested but resulted only in free fluorine-18. We hypothesized that the high energies emitted from the sonicator, which is necessary for particle formation, is sufficient to break the boron-fluoride bond. Additionally long synthesis times and extensive workup would not be beneficial due to the relative short half-life of fluorine-18. We tested a variety of loading procedures (e.g. extruder, gentle sonication, heating) and incubation for $1 \mathrm{~h}$ at room temperature turned out to bring the highest incorporation yields. To our knowledge this is the first time chylomicron-like particles were loaded in such a way and this method might be beneficial for other attempts to label lipoproteins after their formation. Different quality control measures were taken to assure that the BDP-TG/ $\left[{ }^{18} \mathrm{~F}\right] \mathrm{BDP}-\mathrm{TG}$ is truly located in the lipid core of the particle. It was found that extensive washing of the $\left[{ }^{18} \mathrm{~F}\right] \mathrm{BDP}-\mathrm{TG}$ is of immense importance as the $\mathrm{SnCl}_{4}$ which is used during the radiolabeling step precipitates in aqueous medium and causes a co-precipitation of the chylomicron-like particles. Also a purification of $\left[{ }^{18} \mathrm{~F}\right] \mathrm{BDP}-\mathrm{TG}$ from free fluorine-18 is ensured by multiple washing steps because a later purification of the $\left[{ }^{18} \mathrm{~F}\right] \mathrm{BDP}-\mathrm{TG}$-chylomicron-like particles by centrifugal filters caused an irreversible aggregation of the particles. In vivo data proved the uptake of $\left[{ }^{18} \mathrm{~F}\right] \mathrm{BDP}-\mathrm{TG}$ chylomicron-like particles by BAT but also high uptake values were observed in heart, liver 
and spleen. Heart, as an organ with a known lipoprotein lipase expression, ${ }^{37,38}$ is able to bind high numbers of lipoproteins and therefore this high uptake values are not remarkable. High uptake values for liver were explained by remnant particles which still contained $\left[{ }^{18} \mathrm{~F}\right] \mathrm{BDP}-\mathrm{TG}{ }^{39}$. The spleen contains high numbers of macrophages which are able to engulf large particles. This might explain the marked uptake observed in the spleen ${ }^{40}$. BAT uptake was in any case significantly increased in comparison to WAT and uptake in BAT could be significantly increased by cold exposure for $4 \mathrm{~h}$ before the experiment.

In chapter 5 we describe the synthesis from $\left[{ }^{18} \mathrm{~F}\right] \mathrm{BDP}-\mathrm{TG}$ to the radiolabeled chylomicron-like particle. Rigorous washing steps are of importance and determine the quality of the final product. In vivo we were able to show $\left[{ }^{18} \mathrm{~F}\right] \mathrm{BDP}-\mathrm{TG}$-chylomicron-like particles suitability as a BAT imaging agent.

As we proved the suitability of $\left[{ }^{18} \mathrm{~F}\right] \mathrm{BDP}$-TG-chylomicron-like particles to visualize BAT and its metabolism we went a step further (chapter 6) and investigated its behaviour under different cooling protocols and under diabetic conditions. Interestingly we could only observe an increase in $\left[{ }^{18} \mathrm{~F}\right] \mathrm{BDP}-\mathrm{TG}$ uptake under acute cold stimulation in BAT where this effect was not visible after long term cold acclimation. Also no significant difference was detected in diabetic animals and both groups BAT uptake differed only under acute cold conditions. As already discussed, most BAT scans in patients are performed with $\left[{ }^{18} \mathrm{~F}\right] \mathrm{FDG}$. Here the same phenomenon was observed where $\left[{ }^{18} \mathrm{~F}\right] \mathrm{FDG}$ BAT uptake was impaired in diabetic patients but uptake of $\left[{ }^{18} \mathrm{~F}\right] \mathrm{FTHA}$ was not altered when compared to non-diabetic controls ${ }^{41}$. This may lead to the assumption that glucose uptake is not an indicator for thermogenesis in $\mathrm{BAT}^{42}$.

We compared the obtained results with data of $\left[{ }^{18} \mathrm{~F}\right] \mathrm{FDG}$ and $\left[{ }^{18} \mathrm{~F}\right] \mathrm{FTHA}$ under the same cooling protocol, but not in diabetic mice. Similar results were observed for $\left[{ }^{18} \mathrm{~F}\right] \mathrm{FDG}$ and $\left[{ }^{18} \mathrm{~F}\right] \mathrm{FTHA}$ where cold acclimation could not show an effect. These results are in accordance with the results we obtained in chapter 3 in a rat model where cold acclimation could not further increase any of the applied tracers, including $\left[{ }^{18} \mathrm{~F}\right] \mathrm{FDG}$ and $\left[{ }^{18} \mathrm{~F}\right] \mathrm{FTHA}$ in comparison to acute cold exposure, and where no elevated mRNA genes and protein levels related to 
BAT metabolism could be found. Cold acclimation leads to browning ${ }^{43}$ and therefore to a total increase of brown and beige BAT cells. We speculated that under long term cold exposure the single BAT depots might not be stimulated to such an extent anymore as under acute cold exposure because the total BAT mass has grown. An additional explanation would be that under acute cold the FA influx into BAT is up-regulated whereas by cold acclimation an equilibrium is reached where the influx is regulated to a constant level.

In the presented thesis we produced a radiolabeled TG which can be incorporated into lipoprotein-like particles for non-invasive in vivo imaging of lipid metabolism. This is to our knowledge the first time that PET active TGs were incorporated into chylomicron-like particles. Additionally those particles and also the BDP-FA can be used to quantify BAT uptake in vitro providing the opportunity for first testings without the use of radioactive material. We put emphasis on imaging the lipid uptake of BAT but this method can easily be adapted for other applications such as e.g. imaging of lipid uptake into the liver or heart. This methodology has the potential for in vivo imaging in humans but more work needs to be done, namely: 1) Exchange of the BDP-FA to a FA which can be used in humans. 2) Quality control of radiolabeled lipoproteins needs to be optimized.

Nevertheless, we have the opinion that imaging with radiolabeled TGs incorporated into lipoproteins mimics the in vivo situation, how lipids are transported in the body, better than other applied techniques so far and is therefore a huge step forward in the field of lipid metabolism imaging. 


\section{Conclusion}

In our experiments we found that $\left[{ }^{18} \mathrm{~F}\right] \mathrm{BDP}-\mathrm{TG}$-chylomicron-like particles are able to reach BAT and its uptake is up-regulated by acute cold stimulation. We also found that BAT did not show high lipid influx by cold acclimation. This may implicate that the contribution of BAT may not be as high as in optimistic studies a decade ago ${ }^{44}$.

However, we have developed a new lipid based imaging agent for BAT, which will help to uncover BATs contribution to whole body energy expenditure but which also can easily be adapted for other applications. The developed dual-modal tracer combines several advantages and has therefore a broad field of applications ranging from first in vitro testings without any radiation dose to non-invasive PET imaging. 


\section{References}

1 Cramer, W. On Glandular Adipose Tissue, and its Relation to other Endocrine Organs and to the Vitamine Problem. British journal of experimental pathology 1, 184-196 (1920).

2 Aherne, W. \& Hull, D. Brown adipose tissue and heat production in the newborn infant. The Journal of Pathology and Bacteriology 91, 223-234, doi:doi:10.1002/path.1700910126 (1966).

3 Ito, S. \& Kuroshima, A. [Distribution of brown adipose tissue in Japanese new-born infants]. Nihon seirigaku zasshi. Journal of the Physiological Society of Japan 29, 660-661 (1967).

4 Heim, T., Kellermayer, M. \& Dani, M. Thermal conditions and the mobilization of lipids from brown and white adipose tissue in the human neonate. Acta paediatrica Academiae Scientiarum Hungaricae 9, 109-120 (1968).

5 Heaton, J. M. The distribution of brown adipose tissue in the human. Journal of Anatomy 112, 35-39 (1972).

6 Tanuma, Y., Tamamoto, M., Ito, T. \& Yokochi, C. The occurrence of brown adipose tissue in perirenal fat in Japanese. Archivum histologicum Japonicum = Nihon soshikigaku kiroku 38, 43-70 (1975).

7 Astrup, A., Bulow, J., Madsen, J. \& Christensen, N. J. Contribution of BAT and skeletal muscle to thermogenesis induced by ephedrine in man. The American journal of physiology 248, E507-515, doi:10.1152/ajpendo.1985.248.5.E507 (1985).

8 Huttunen, P., Hirvonen, J. \& Kinnula, V. The occurrence of brown adipose tissue in outdoor workers. European journal of applied physiology and occupational physiology 46, 339-345 (1981).

9 Hany, T. F. et al. Brown adipose tissue: a factor to consider in symmetrical tracer uptake in the neck and upper chest region. Eur J Nucl Med Mol Imaging 29, 1393-1398, doi:10.1007/s00259-002-0902-6 (2002).

10 Cohade, C., Mourtzikos, K. A. \& Wahl, R. L. "USA-Fat": prevalence is related to ambient outdoor temperature-evaluation with 18F-FDG PET/CT. Journal of nuclear medicine : official publication, Society of Nuclear Medicine 44, 1267-1270 (2003).

11 Lee, P., Greenfield, J. R., Ho, K. K. Y. \& Fulham, M. J. A critical appraisal of the prevalence and metabolic significance of brown adipose tissue in adult humans. Am J Physiol Endocrinol Metab 299, E601-606, doi:10.1152/ajpendo.00298.2010 (2010).

12 van Marken Lichtenbelt, W. D. et al. Cold-activated brown adipose tissue in healthy men. $N$ Engl J Med 360, 1500-1508, doi:10.1056/NEJMoa0808718 (2009).

13 Virtanen, K. A. et al. Functional brown adipose tissue in healthy adults. N Engl J Med 360, 1518-1525, doi:10.1056/NEJMoa0808949 (2009).

14 Saito, M. et al. High incidence of metabolically active brown adipose tissue in healthy adult humans: effects of cold exposure and adiposity. Diabetes 58, 1526-1531, doi:10.2337/db090530 (2009).

15 Hanssen, M. J. et al. Short-term cold acclimation recruits brown adipose tissue in obese humans. Diabetes, doi:10.2337/db15-1372 (2016).

16 Ouellet, V. et al. Brown adipose tissue oxidative metabolism contributes to energy expenditure during acute cold exposure in humans. The Journal of clinical investigation 122, 545-552, doi:10.1172/JCl60433 (2012).

17 Baba, S., Engles, J. M., Huso, D. L., Ishimori, T. \& Wahl, R. L. Comparison of uptake of multiple clinical radiotracers into brown adipose tissue under cold-stimulated and nonstimulated conditions. J Nucl Med 48, 1715-1723, doi:jnumed.107.041715 [pii] 10.2967/jnumed.107.041715 [doi] (2007). 
van der Lans, A. A. et al. Cold acclimation recruits human brown fat and increases nonshivering thermogenesis. The Journal of clinical investigation, doi:68993 [pii] 10.1172/JCl68993 [doi] (2013).

Yoneshiro, T. et al. Recruited brown adipose tissue as an antiobesity agent in humans. The Journal of clinical investigation, doi:67803 [pii] 10.1172/JCl67803 [doi] (2013).

Romanovsky, A. A., Ivanov, A. I. \& Shimansky, Y. P. Selected contribution: ambient temperature for experiments in rats: a new method for determining the zone of thermal neutrality. Journal of applied physiology (Bethesda, Md. : 1985) 92, 2667-2679, doi:10.1152/japplphysiol.01173.2001 (2002).

21 Festuccia, W. T., Blanchard, P. G. \& Deshaies, Y. Control of Brown Adipose Tissue Glucose and Lipid Metabolism by PPARgamma. Frontiers in endocrinology 2, 84, doi:10.3389/fendo.2011.00084 (2011).

22 Keliher, E. J., Klubnick, J. A., Reiner, T., Mazitschek, R. \& Weissleder, R. Efficient acidcatalyzed (18) F/(19) F fluoride exchange of BODIPY dyes. ChemMedChem 9, 1368-1373, doi:10.1002/cmdc.201300506 (2014).

23 Paulus, A. et al. Development of a clickable bimodal fluorescent/PET probe for in vivo imaging. Ejnmmi Res 5, 120, doi:10.1186/s13550-015-0120-4 (2015).

24 Hui, T. Y. \& Bernlohr, D. A. Fatty acid transporters in animal cells. Frontiers in bioscience : $a$ journal and virtual library 2, d222-231 (1997).

25 Stahl, A., Evans, J. G., Pattel, S., Hirsch, D. \& Lodish, H. F. Insulin causes fatty acid transport protein translocation and enhanced fatty acid uptake in adipocytes. Developmental cell 2, 477-488 (2002).

26 Lowell, B. B. \& Flier, J. S. Brown adipose tissue, beta 3-adrenergic receptors, and obesity. Annual review of medicine 48, 307-316, doi:10.1146/annurev.med.48.1.307 (1997).

27 Kampf, J. P., Parmley, D. \& Kleinfeld, A. M. Free fatty acid transport across adipocytes is mediated by an unknown membrane protein pump. Am J Physiol Endocrinol Metab 293, E1207-1214, doi:10.1152/ajpendo.00259.2007 (2007).

Thumser, A. E. \& Storch, J. Characterization of a BODIPY-labeled fluorescent fatty acid analogue. Binding to fatty acid-binding proteins, intracellular localization, and metabolism. Mol Cell Biochem 299, 67-73, doi:10.1007/s11010-005-9041-2 (2007).

Zhu, S. L. et al. Highly Water-Soluble Neutral BODIPY Dyes with Controllable Fluorescence Quantum Yields. Org Lett 13, 438-441, doi:10.1021/ol102758z (2011).

Festuccia, W. T., Blanchard, P.-G. \& Deshaies, Y. Control of Brown Adipose Tissue Glucose and Lipid Metabolism by PPARY. Front Endocrinol (Lausanne) 2, 84, doi:10.3389/fendo.2011.00084 (2011).

31 Berbee, J. F. et al. Brown fat activation reduces hypercholesterolaemia and protects from atherosclerosis development. Nature communications 6, 6356, doi:10.1038/ncomms 7356 (2015).

32 Hoeke, G., Kooijman, S., Boon, M. R., Rensen, P. C. \& Berbee, J. F. Role of Brown Fat in Lipoprotein Metabolism and Atherosclerosis. Circ Res 118, 173-182, doi:10.1161/circresaha.115.306647 (2016).

33 Khedoe, P. P. S. J. et al. Brown adipose tissue takes up plasma triglycerides mostly after lipolysis. J Lipid Res 56, 51-59 (2015).

34 Kooijman, S. et al. Inhibition of the central melanocortin system decreases brown adipose tissue activity. J Lipid Res 55, 2022-2032 (2014).

35 Rensen, P. C. N. et al. Particle size determines both the receptor specificity of apoEcontaining emulsions in vivo and the alpha-helical content of apoE. Atherosclerosis 134, 361361 (1997).

36 Rensen, P. C. N. et al. Selective Liver Targeting of Antivirals by Recombinant Chylomicrons - a New Therapeutic Approach to Hepatitis-B. Nat Med 1, 221-225 (1995). 
37 Niu, Y. G., Hauton, D. \& Evans, R. D. Utilization of triacylglycerol-rich lipoproteins by the working rat heart: routes of uptake and metabolic fates. The Journal of physiology 558, 225237, doi:10.1113/jphysiol.2004.061473 (2004).

38 Bharadwaj, K. G. et al. Chylomicron- and VLDL-derived lipids enter the heart through different pathways: in vivo evidence for receptor- and non-receptor-mediated fatty acid uptake. J Biol Chem 285, 37976-37986, doi:10.1074/jbc.M110.174458 (2010).

39 Karpe, F. et al. Removal of triacylglycerols from chylomicrons and VLDL by capillary beds: the basis of lipoprotein remnant formation. Biochemical Society transactions 35, 472-476, doi:10.1042/bst0350472 (2007).

40 Anselmo, A. C. et al. Delivering nanoparticles to lungs while avoiding liver and spleen through adsorption on red blood cells. ACS nano 7, 11129-11137, doi:10.1021/nn404853z (2013).

41 Blondin, D. P. et al. Selective Impairment of Glucose but Not Fatty Acid or Oxidative Metabolism in Brown Adipose Tissue of Subjects With Type 2 Diabetes. Diabetes 64, 23882397, doi:10.2337/db14-1651 (2015).

42 Cypess, A. M., Haft, C. R., Laughlin, M. R. \& Hu, H. H. Brown fat in humans: consensus points and experimental guidelines. Cell metabolism 20, 408-415, doi:10.1016/j.cmet.2014.07.025 (2014).

$43 \mathrm{Wu}$, J., Cohen, P. \& Spiegelman, B. M. Adaptive thermogenesis in adipocytes: is beige the new brown? Genes Dev 27, 234-250, doi:10.1101/gad.211649.112 (2013).

44 Cannon, B. \& Nedergaard, J. Brown adipose tissue: function and physiological significance. Physiol Rev 84, 277-359, doi:10.1152/physrev.00015.2003 (2004). 


\section{Valorization}




\section{Social relevance}

Obesity has long been a severe issue but newest reports from the WHO show alarming numbers on the development of obesity. In 2016 worldwide more than 1.9 billion adults were overweight from which 650 million where obese. Frighteningly also 41 million children under the age of 5 and over 340 million children between the age of 5 and 19 were overweight or obese. According to the Robert Koch Institute $66 \%$ men and $50 \%$ women were overweight in Germany in 2011. In total 25\% were obese while this number has tripled between 1975 and 2014. Obesity is related to a number of other diseases such as diabetes type II, cardiovascular diseases and cancer. In 2015 worldwide deaths of 4 million people could be directly related to obesity but also people suffering from overweight have a decreased life expectancy. In the future the prevalence to develop obesity is predicted to rise to $33 \%$ (United States) within the next two decades. Therefore action needs to be taken to counteract this epidemic.

Obesity is the result of a positive energy balance. This can be overcome by a reduction of energy intake or an increase in energy expenditure. Reduction of energy intake is most often addressed by diets but in studies it could be shown that only a small number of patients could maintain their weight after a diet. The easiest way to increase energy expenditure might be physical activity. Similar like diets it was shown that people had problems following exercise plans on a regular level. Additionally, physical exercise might not be performed by extremely obese patients which attenuates its role on weight loss.

An alternative strategy to increase energy expenditure is the activation of brown adipose tissue (BAT). BATs contribution to overall energy expenditure is estimated to be $2-30 \%$ in humans but its role in lipid metabolism is not completely understood yet. Therefore this thesis is focused on BAT imaging to gain more information about its metabolism which should help to level out the impaired energy balance of obese people in the future. 


\section{Target group}

As reported in the last section, obesity is a worldwide epidemic. Finding new strategies to prevent people from becoming obese and reducing body weight of already obese people will have a huge impact on our worldwide society. An enormous number of overweight and obese people (1.9 billion) will be affected where obese people will benefit most. Nevertheless, overweight people will also gain quality of life after weight reduction. BAT might be an interesting target to solve this problem. Even in the past, studies already showed that BAT can be activated by mild cold exposure which should have an impact on how we are tempering our houses and offices. Anyhow, more research has to be done to obtain coherent results of such interventions but on the other hand it is important to inform the general public to call attention to this subject. Even though this study is more related to basic research, it might help to understand BATs metabolism and will therefore have on a long term an effect on the general society.

\section{Activities}

The here presented work was carried out as a collaboration between the Department of Radiology and Nuclear Medicine, Department of Nutrition and Movement Sciences, Nuclear Medicine of Maastricht University Medical Center+ and Department of Nuclear Medicine of University Hospital RWTH Aachen. Additionally, the Institute for Experimental Molecular Imaging of the University Hospital RWTH Aachen and the Department of Medicine of Leiden University Medical Center were involved in parts of the project. Specialists in the field of chemistry, biology, radiochemistry, animal handling, positron emission tomography, electron microscopy and BAT metabolism were involved. This extensive collaboration between different institutions and different fields of science shows the amount of knowledge that is necessary to carry out such studies.

The work performed in this thesis was presented in original articles that were published in scientific journals with a background in radiochemistry, imaging and BAT metabolism. The articles are not only published in those journals but are also available online and some are 
even open access. Therefore the obtained results are available to the broad scientific community. Results were also presented on national and international conferences. A new method to load lipoproteins with radiolabeled TGs was described and may improve BAT imaging in the near future.

\section{Innovation}

Active BAT in adult humans has first been described in the 00's of this century. A combination of positron emission tomography and computed tomography (PET/CT) helped to identify what has long thought to be artefacts as BAT depots. Till now most human scans were performed with 2-2-deoxy-2- $\left[{ }^{18} \mathrm{~F}\right]$ fluoroglucose $\left(\left[{ }^{18} \mathrm{~F}\right] \mathrm{FDG}\right)$ and a lot of retrospective studies with the same tracer were conducted. Even though $\left[{ }^{18} \mathrm{~F}\right] \mathrm{FDG}$ is able to visualize BAT and uptake was observed to be increased after cold exposure, it only reflects BATs glucose metabolism. In BAT mainly fatty acids (FA) are metabolised were de novo lipogenesis from glucose plays a minor role. Therefore $\left[{ }^{18} \mathrm{~F}\right] \mathrm{FDG}$ might largely underestimate BATs metabolic activity and a FA based tracer is needed to quantify BATs metabolic activity and potential. Some FA tracers are already in use for clinical test but even they do not completely reflect the situation in vivo. It was shown that BAT predominantly takes up lipids from triglyceride (TG)-rich lipoprotein (TRL)-derived FAs over circulating albumin-bound FA. Therefore application of radiolabeled free FA might not represent BATs metabolism completely.

The aim of this study was to develop a radiolabeld TG and to incorporate it into a lipoprotein particle which has been synthesized ex vivo. This method has the advantage that uptake of BAT does not rely on additional uptake mechanism of free FAs in vivo which would complicate data interpretation. To our knowledge ex vivo synthesized particles were only loaded with TGs radiolabeled with tritium which cannot be used for in vivo imaging. Therefore our approach is a step forward in the field of BAT visualization and quantification. In addition, the FA used in this work also offers the ability for fluorescence imaging. In vitro experiments could be carried out without any radiation and the behaviour could be characterized on a sub-cellular level. 


\section{Schedule \& Implementation}

In this thesis we developed a new lipid based radiotracer to image BAT and its metabolism. We could demonstrate that the radiotracer is taken up by BAT under control conditions and that the uptake could be increased significantly after cold exposure. To our knowledge this is the first time that radiolabeled TGs were incorporated into lipoprotein-like particles for in vivo imaging. We successfully gained information about BATs lipid metabolism under control and cold exposed conditions but also under diabetes, obesity and long term cold acclimation. The here presented methods can be applied to incorporate other radiolabeled FAs into lipoproteins and by that the current generation of FA tracer which are used in the clinic might be lifted up to another level because the in vivo situation is mimicked better than with only radiolabeled $\mathrm{FA}$.

More animal experiments have to be performed in the future to gain more information about BAT and its metabolic activity. As large scale human experiments are restricted by ethical and radiation protection laws we need animals to understand BATs function and translate those results to humans. 
Acknowledgement 
I cannot belief that these are my last words I am writing on my way to become a PhD. I am still thinking back at the time when I was in secondary school where I had large discussions with my parents and my grandmother about my school performance which was probably not the best ;). However, I always told them that the time I invested for learning was sufficient and that $\mathrm{I}$ do not need most of the subjects anyways. Probably nobody, including me, expected me to become a PhD but somehow I made it to this point. At the beginning, in 2015, I started here in Maastricht and thought that 4 years is a really long period but time was flying so quickly and I got to know so many great colleagues that I am thinking about the end of my PhD with a laughing but also with a crying eye. Thanks to all of you that I could learn so many techniques from you but also for working together as one big team. Without you this dissertation would not be possible.

Prof. Mottaghy thanks for offering me this super interesting PhD position in Maastricht and in Aachen. I still remember the day of my job interview in Aachen and you started with the sentence:" We do not have an open position here". I was confused but then you gave me the chance to work abroad in Maastricht. At first I was a bit sceptical but then it turned out to be a great decision as I could take advantage of both labs. Thank you for giving me the chance to visit that many interesting courses and conferences which also helped to develop myself as an independent researcher. In our meetings you always had good advices to bring the project a step further. Even though you are also working part time in Aachen and Maastricht I had the feeling that in case I experienced a problem I could always come to you to ask for help. I think that I had a great promotor in you.

Wouter, I also have to say a big "Thank you" for being my promotor. I really enjoyed our discussions about my project and your valuable comments on brown fat and its metabolism. I also have to thank you for integrating me into your department and into the CVON group which helped to get in touch with specialists in the field of brown adipose tissue. With your help I was able to expand my network and meet interesting people in the field. Thanks for always having an open ear and for your interest in my project. 
Matthias, I cannot say how much I need to thank you for your support and guidance during my $\mathrm{PhD}$. With your help I developed from a student to an independent research. You gave me the freedom to accomplish my own ideas during the project but pushed me to a direction if necessary. Thanks for your trust in my work. I really enjoyed our meetings because you always had an idea for my problems and gave important feedback. Next to all the scientific topics we discussed you always had time for personal conversations and always had a joke on your lips. Thanks for being my supervisor.

Thank you, Ivo and Roel, for all that funny and entertaining conversations during lunch breaks. It was a pleasure. I also have to say "Thank you" for all that useful advices I got from you.

I have to thank the whole department of nuclear medicine for having me. You guys always helped me out when I needed to pick up my radioactivity and the room was locked but also in any other situation I could ask for your help.

Thanks to the department of Nutrition and Movement Sciences for working together. A special thanks goes to Emmani for teaching me how to cell culture my adipocytes and for analyzation and interpretation of the data. I also want to thank Evelyn and Gert for taking over my cell culture when I was in Aachen.

Thank you Ingrid for helping me with the ESI-MS.

Other collaborators I would like to thank are Patrick and Jimmy. Thanks for your input on the chylomicron-like particles and our discussions to improve quality and purity. From your work I have learned a lot and without your support we would not have been able to successfully apply our tracer.

The department of nuclear medicine in Aachen also deserves a great "thank you". Thanks for letting me use your labs, even though there were "sometimes" contaminations ;). Especially I would like to thank Natascha Drude and Lena Tienken. You gave me the possibility to make so many contacts and use additional labs and equipment outside of the nuclear chemistry lab that I never ever would have been able to by myself. I would also like to thank Andreas Vogg, 
Katerina Eigner-Henke and Natascha Dümont for teaching me how to work in a GMPsurrounding.

I alslo need to thank Martine and Sandra from the RNL. Thanks for always helping out when I had problems in the lab and for trying to find a fast solution.

I would also like to thank Eva Buhl and Hiltrud Königs-Werner for measuring my samples with the TEM.

Defense and reading committee: thank you for reviewing my thesis and for being present at my dissertation.

I need to thank my mom, my dad, Silke, Gerd and Elisabeth for their support during the time of my studies and my PhD. You were always available for a chat in times where I needed some distraction from work but were also interested in the topics of my research.

Last but not least I need to thank Katharina for her support. You always had to bear me when I got stressed out from work but you always cheered me up. Thanks for always being there for me, also in hard times. I hope that we will experience numerous adventures in the close but also far future. 
Curriculum Vitae 
Andreas Paulus was born on the $27^{\text {th }}$ of October 1988 in Düren, Germany. He finished his secondary school at Burgau Gymnasium in Düren in 2008. After receiving his Bachelor degree in Applied Chemistry in 2012 he continued with his Master in Nuclear Application at the Fachhochschule Aachen. During this time he spend 6 months as an undergraduate researcher at the Memorial Sloan Kettering Cancer Center in New York City working on the development of new clickable radiotracer for prostate cancer imaging. In 2015 he obtained his master degree and started as a $\mathrm{PhD}$ student under the supervision of Prof. Dr. F. M. Mottaghy and Prof. Dr. W.D van Marken Lichtenbelt at the Department of Radiology and Nuclear Medicine at Maastricht University. He focused on the development of new lipid based imaging agents for brown adipose tissue as demonstrated in this dissertation as well as in numerous publications in scientific journals. 


\section{List of publications}




\section{Published}

Paulus, A., van Marken Lichtenbelt, W., Mottaghy, F. M. \& Bauwens, M. Brown adipose tissue and lipid metabolism imaging. Methods 130, 105-113, doi:10.1016/j.ymeth.2017.05.001 (2017).

2 Paulus, A., Maenen, M., Drude, N., Nascimento, E. B. M., van Marken Lichtenbelt, W. D., Mottaghy, F. M. \& Bauwens, M. Synthesis, radiosynthesis and in vitro evaluation of 18FBodipy-C16/triglyceride as a dual modal imaging agent for brown adipose tissue. PLoS One 12, e0182297, doi:10.1371/journal.pone.0182297 (2017).

3 Paulus, A., Drude, N., Nascimento, E. B. M., Buhl, E. M., Berbée, J. F. P., Rensen, P. C. N., van Marken Lichtenbelt, W. D., Mottaghy, F. M. \& Bauwens, M. [18F]BODIPY-triglyceridecontaining chylomicron-like particles as an imaging agent for brown adipose tissue in vivo. Scientific Reports 9, 2706, doi:10.1038/s41598-019-39561-z (2019).

4 Crivelli, S. M., Paulus, A., Markus, J., Bauwens, M., Berkes, D., De Vries, H. E., Mulder, M. T., Walter, J., Mottaghy, F. M., Losen, M. \& Martinez-Martinez, P. Synthesis, Radiosynthesis, and Preliminary in vitro and in vivo Evaluation of the Fluorinated Ceramide Trafficking Inhibitor (HPA-12) for Brain Applications. Journal of Alzheimer's disease : JAD 60, 783-794, doi:10.3233/JAD-161231 (2017).

\section{Submitted}

Paulus, A., van Ewijk, P., Nascimento, E., De Saint-Hubert, M., Hendrikx, G., Vogg, A., Pooters, I., M., S., Vanderlocht, J., Bos, G., Brans, B., Schrauwen-Hinderling, V., Mottaghy, F. \& Bauwens, M. Characterization of BAT activity in rats using invasive and non-invasive techniques. PLoS One (2019).

2 Paulus, A., Drude, N., van Marken Lichtenbelt, W. D., Mottaghy, F. M. \& Bauwens, M. Brown adipose tissue uptake of triglyceride-rich lipoprotein derived fatty acids in diabetic or obese mice under different temperature conditions. Molecular Imaging \& Biology (2019) 